\title{
Three Essays in Applied Econometrics: Understanding Population Changes
}

\author{
Samuel P. Taylor \\ West Virginia University, samuel.taylor@mail.wvu.edu
}

Follow this and additional works at: https://researchrepository.wvu.edu/etd

Part of the Agricultural and Resource Economics Commons, and the Regional Economics Commons

\section{Recommended Citation}

Taylor, Samuel P., "Three Essays in Applied Econometrics: Understanding Population Changes" (2020). Graduate Theses, Dissertations, and Problem Reports. 7568.

https://researchrepository.wvu.edu/etd/7568

This Dissertation is protected by copyright and/or related rights. It has been brought to you by the The Research Repository @ WVU with permission from the rights-holder(s). You are free to use this Dissertation in any way that is permitted by the copyright and related rights legislation that applies to your use. For other uses you must obtain permission from the rights-holder(s) directly, unless additional rights are indicated by a Creative Commons license in the record and/ or on the work itself. This Dissertation has been accepted for inclusion in WVU Graduate Theses, Dissertations, and Problem Reports collection by an authorized administrator of The Research Repository @ WVU.

For more information, please contact researchrepository@mail.wvu.edu. 
Three Essays in Applied Econometrics: Understanding Population Changes

\title{
Samuel P Taylor
}

Dissertation submitted to the Davis College of Agriculture, Natural Resources and Design at West Virginia University

in partial fulfillment of the requirements for the degree of Doctor of Philosophy in the Division of Resource Economics and Management

\author{
Heather Stephens, Ph.D., Chair \\ John Deskins, Ph.D. \\ Daniel Grossman, Ph.D. \\ Randall Jackson, Ph.D. \\ Peter Schaeffer, Ph.D.
}

Department of Resource Economics and Management

\author{
Morgantown, West Virginia
}

2020

Keywords: health economics, environmental economics, disaster, population change, opioids, synthetic control, water contamination, $\mathrm{C} 8, \mathrm{PFOA}, \mathrm{MCHM}$ 


\section{Abstract \\ Three Essays in Applied Econometrics}

\section{Samuel P Taylor}

This body of work consists of three research projects developed around a central theme - what might cause a person to leave the place where they live? As a native and resident of West Virginia, this question is not a purely academic one. My region has long struggled with how to retain our "best and brightest" in the face of challenging socio-economic conditions. Looking at the question differently, understanding what negative influences may exist to cause a person that might otherwise have remained in a place to leave, could provide large influences on policy and strategy for retention of residents in the area - and help to answer the "who" in the questions of economic and social redevelopment. My research utilizes econometric techniques to analyze questions related to demographic, natural resource, environmental, health, and regional economics. In this work, I have examined three different topics that may be related to the loss of regional populations, with a principal focus on rural and exurban counties in the United States (US), Appalachia, and the state of West Virginia (WV).

My first essay focuses on examining whether there are population losses, specifically of working-aged adults who may be out-migrating, caused or influenced by drug overdose deaths, including opioid deaths, and the concurrent economic impacts. Specifically, does a higher overdose death rate lead to increased population loss via out-migration from a place, particularly in rural areas? The opioid epidemic has been extensively studied, and is known to be more prevalent in rural and lower income places, with particular concentrations in Appalachia. For example, West Virginia, Ohio, Pennsylvania, and Kentucky were the top 4 states in the 2017 Centers for Disease Control (CDC) rankings for overdose death. If these higher death rates are causing outmigration, then the implied costs to those regions are higher than have been previously discussed, due to possible lost productivity and workforce losses. My results suggest that there is a strong, negative relationship between higher overdose death rates and future population change across the US.

My final two essays examine what, if any, long term population change effects result from two separate industrial "disasters" that impacted water supplies. The second essay focuses on the Elk River Spill (also known as the Freedom Industries spill) that occurred on January 9, 2014. A storage tank, owned by Freedom Industries, ruptured, spilling a toxic chemical, 4- 
methylcyclohexanemethanol (MCHM), into the Elk River. This spill contaminated the potable water of 300,000 residents in nine counties in the Charleston, WV, area, and rendered the water unusable for any purpose to residents for several weeks. Analysis using a synthetic control approach (SCM) suggests that this spill did have long term negative population effects on the most heavily impacted counties of the spill, notably in Kanawha County, where Charleston, WV, is located.

My final essay focuses on the impact on population change from the contamination of water by another chemical known as PFOA, which affected 10 counties in WV and Ohio along the Ohio River. While this analysis also utilizes a synthetic control approach, it also makes a contribution to the literature by helping advance the application of the SCM method to events that have an unclear "treatment" time. In this case, the timing is unclear due to the slow release of information. Its potential impact ranges from late 2004, when DuPont (the polluter) agreed to a \$107.6 million legal settlement, to 2012 when an independent panel - the "C8 Science Panel" release its findings, establishing a probable link to six disease categories, including cancer and thyroid disease. The extended time period over which information was released presented the largest challenge to our research, as there is a seven-year period of imperfect information about the impact of PFOA on residents of these counties. After isolating the timing, my results suggest that this spill also has had long term negative population effects in the impacted counties, with the cost of the loss of population greatly exceeding the cost of punitive fines and settlements in the aftermath of the incident. 


\section{Acknowledgments}

I am grateful to so many people who have guided, mentored, encouraged, and supported me through this process, one that many (including me) thought I was foolhardy to attempt.

First and foremost, thank you to the members of my committee - Heather Stephens, John Deskins, Daniel Grossman, Randall Jackson, and Peter Schaeffer - for research feedback, assistance, and mentorship through this process. I am a non-traditional student, and appreciate you all agreeing to help and guide me through this process. To Heather - thank you for helping me to crystallize an idea that both excited me academically and helped me to expand my horizons - and for sticking with me all the way through. To John, thanks for the guitar talk and reminding me that these aren't purely academic things we are working on here. To Dan, your assistance with the CDC data sets was crucial to my work - thank you for helping me navigate a strange land, and getting my work started. To Randy, your guidance from our first meeting has shaped how this came together, and I think the whole result is better for it. To Peter, I thank you for the kind words and guidance, ever since I first came to the Davis College.

I would like to thank Jerry Fletcher, who told me he thought I could do this a long time ago, and I wouldn't have made it here without his support. I miss your friendship and ideas, Jerry.

To friends and mentors who have talked ideas, and helped me make them a reality - notably Jim and Brian and Matt and Nick, thank you for bringing an outside perspective - and some cool tools - to this project.

To my parents, thank you so much for your love and encouragement my entire life. You never put boundaries on what I could or should do, and you never second-guessed me. I am fortunate to have you as my parents, and hope I can come anywhere close to the same for Jet.

Lastly, I would like to thank my wife, Carmen, and all of my family for their long-suffering support in getting this done. I've spent over the last seven years too many weekends, summer vacations, and evenings after work studying, doing homework, and performing this research. They have worked around my crazy schedules, let me test run my talks and helped carry the load in everything else while I got this done. For all the dinner conversations that revolved around my work, for all the cookouts where you let me nerd out on topics that no one else cared about, for all the late nights and early mornings, thank you. 


\section{Contents}

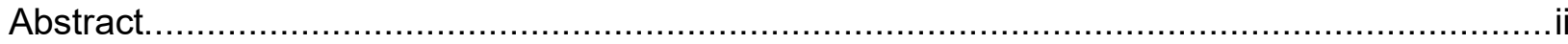

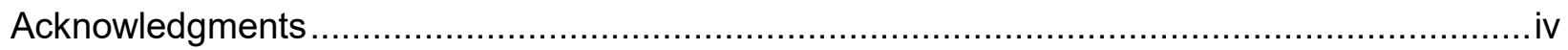

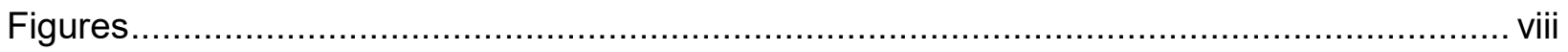

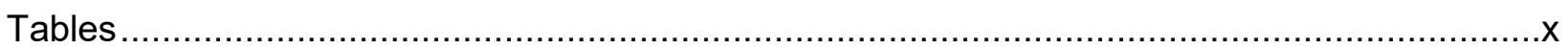

1 The Opioid Crisis and Economic Distress: The Consequences for Population Change....... 1

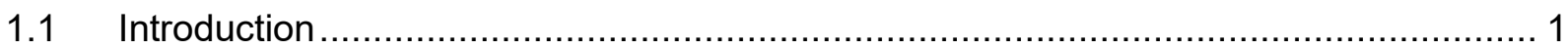

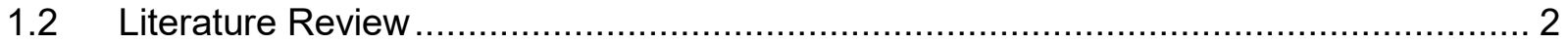

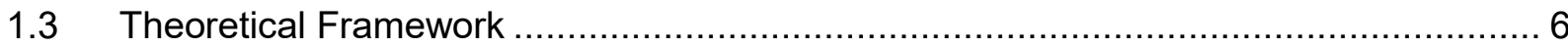

1.4 Data

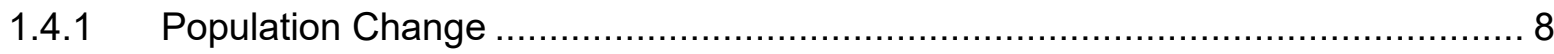

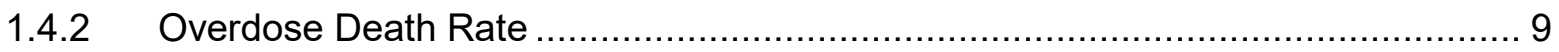

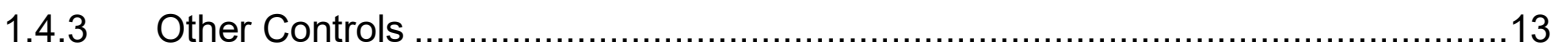

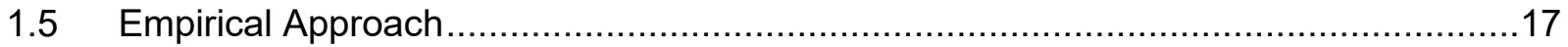

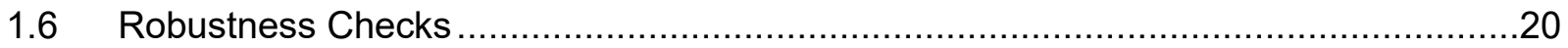

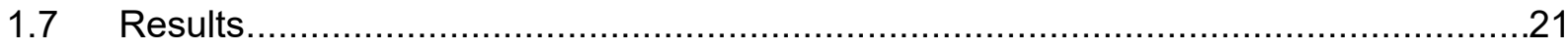

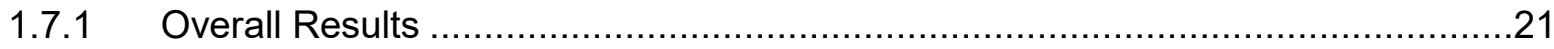

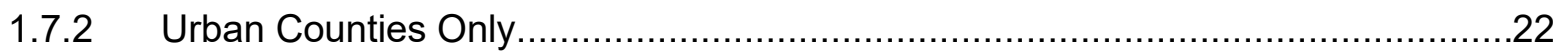

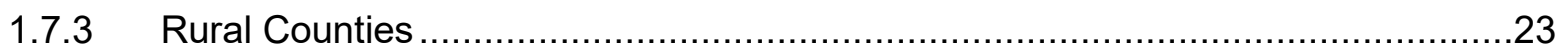

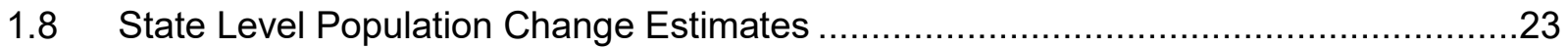

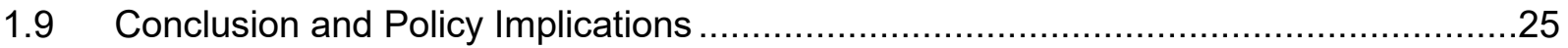

2 Water Contamination and Population Change: A Tipping Point in Distressed Communities? 27

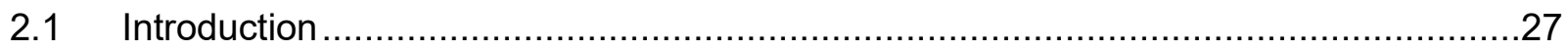

2.2 Background

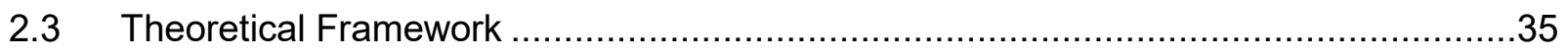

2.4 Data 


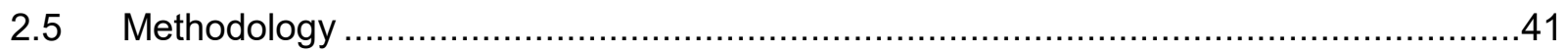

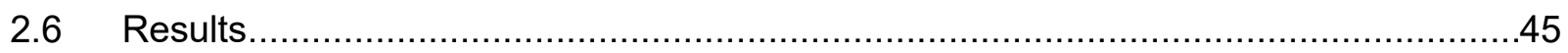

2.6.1 Impacted Counties - Kanawha County ………..................................................

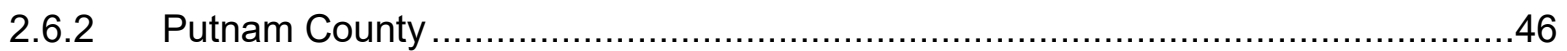

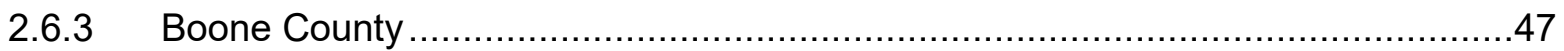

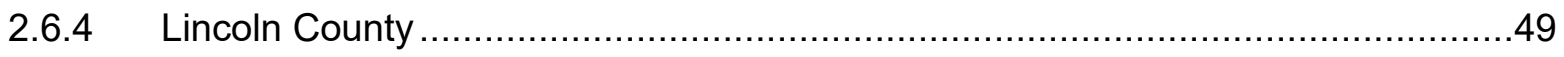

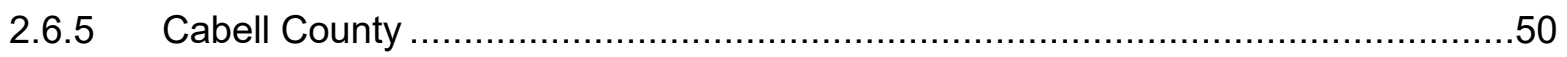

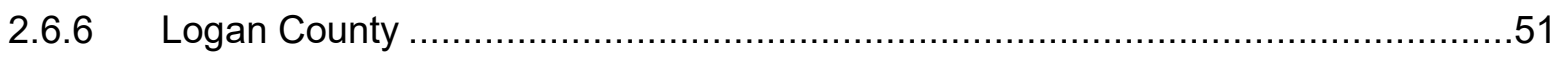

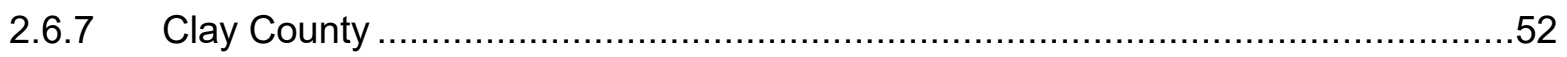

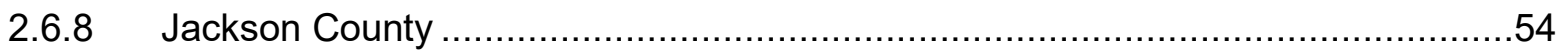

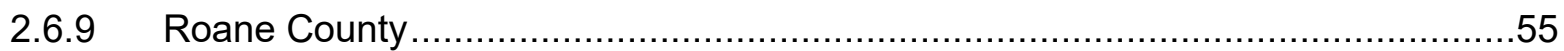

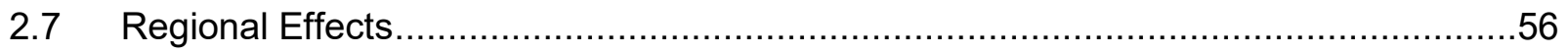

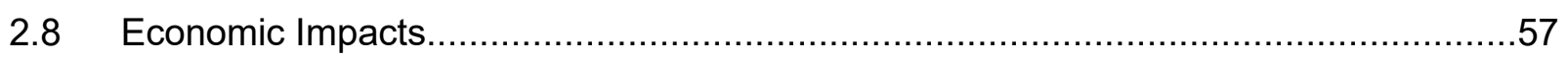

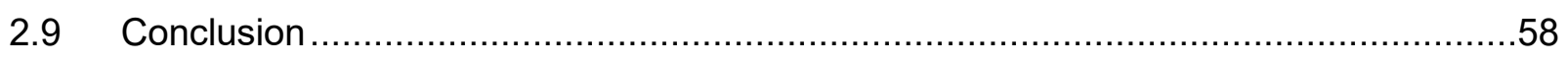

3 A Case Study on Fear: The impact of PFOA water contamination and environmental risk

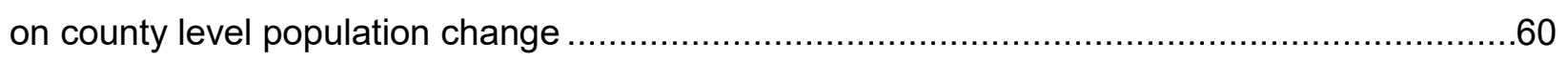

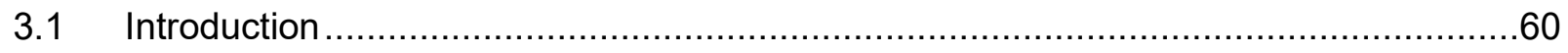

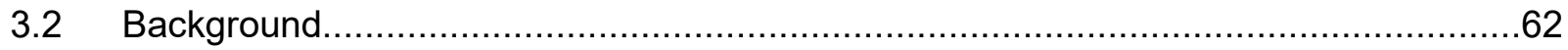

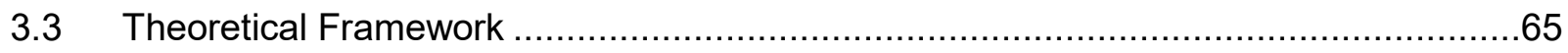

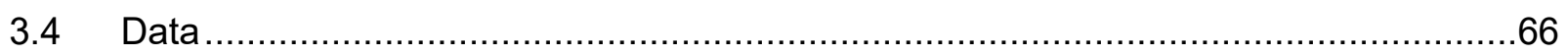

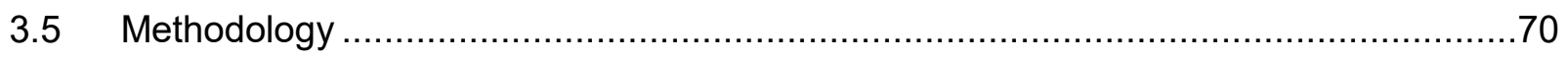

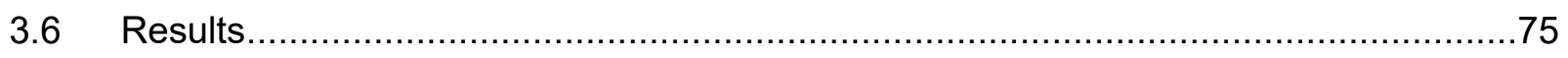

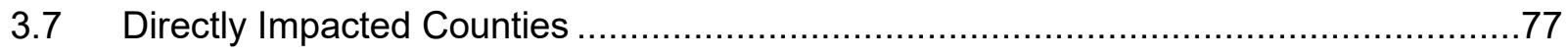

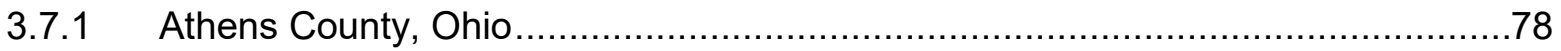

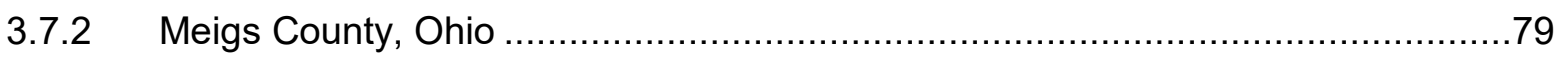

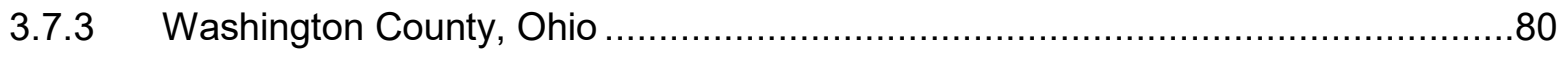

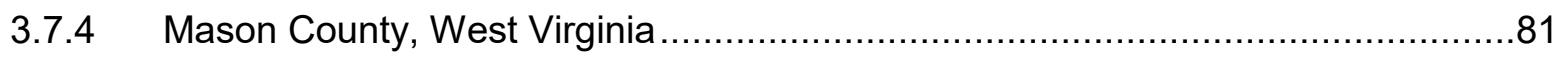




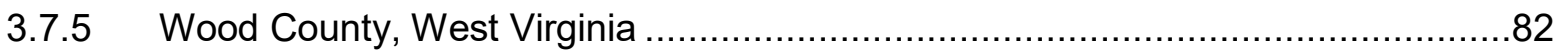

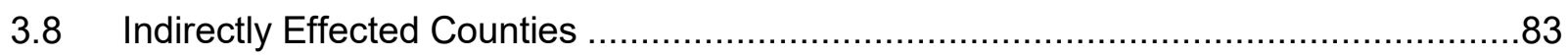

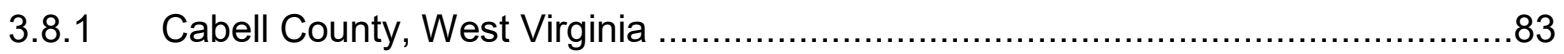

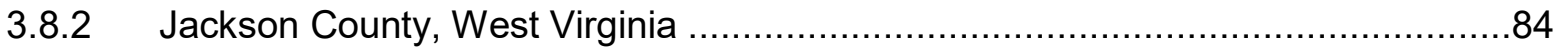

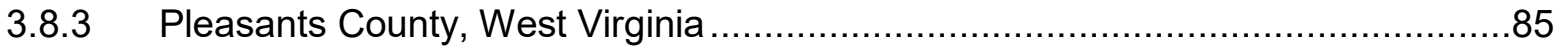

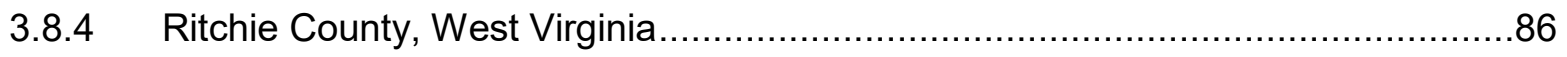

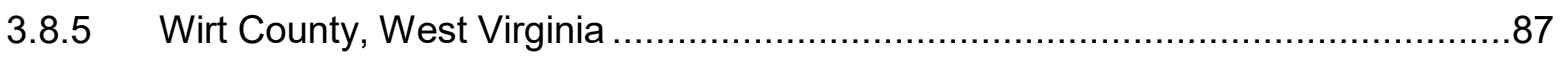

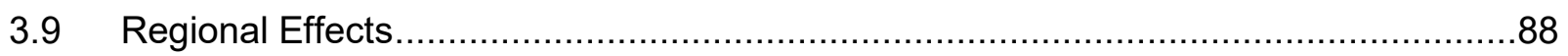

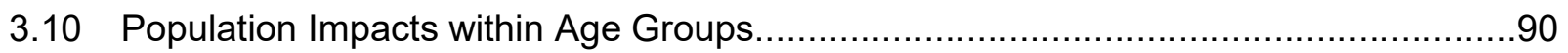

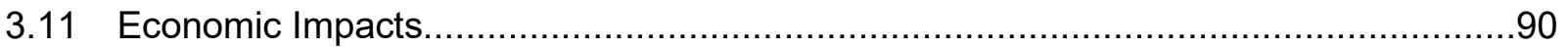

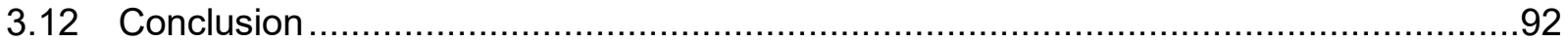

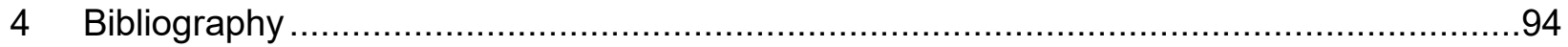

5 Appendix A - Topic 1 - The Opioid Crisis and Economic Distress: The Consequences for

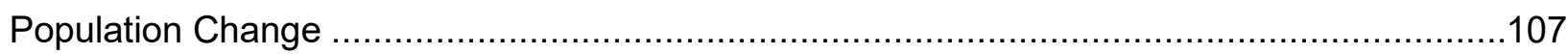

6 Appendix B - Topic 2 - Water Contamination and Population Change: A Tipping Point in Distressed Communities?

7 Appendix C - Topic 3 - A Case Study on Fear: The impact of PFOA water contamination and environmental risk on county level population change. 


\section{Figures}

Figure 1-1. Panel A. 3-Year Average Population Change and Panel B. Average Annual Opioid Overdose Death Rate, US Counties. Source, Author's Calculations Based on US Census Data and US Centers for Disease Control Data

Figure 1-2. Opioid Overdose Death Rate Occurrence Frequency, CDC WISQARS Data.

Source, Author's Calculations Based on CDC Data . 12

Figure 1-3. Labor force participation and Unemployment rates, 2008-2018. Source BLS Data

Figure 1-4. Appalachian Regional Commission Region. Source Appalachian Regional Commission .

Figure 1-5. Median Age Specific Net Migration Rates Across the Rural-Urban Continuum, 2000-2010. From Johnson and Winkler, 2015, used under Creative Commons License. .18

Figure 1-6. Opioid Death Rate Percentages by Age Group. Source, Author's Calculations Based On US Centers for Disease Control Data.

Figure 1-7. Overall Death Rate Percentages by Age Group. Source, Author's Calculations Based On US Centers for Disease Control Data.....

Figure 2-1. Affected Area of Elk River/Freedom Industries Spill Shown in Red. Star indicates source of the spill. Source wvwaterclaims.com 30

Figure 2-2. US and WV Coal Production by Year. Dotted Line for 2014.

Figure 2-3. Coal Production and Employment for West Virginia (left) and spill impacted area (right), 2001-2014.

Figure 2-4. Example of Changed Sample Pools and Model Specification on Synthetic County

Output.

Figure 2-5. Kanawha County Location and Synthetic Control vs. Actual Population Ratio .......46

Figure 2-6. Putnam County Location and Synthetic Control vs. Actual Population Ratio ..... .47

Figure 2-7. Boone County Location and Synthetic Control vs. Actual Population Ratio. Coal Mining Jobshares shown for comparison on the right axis. 48

Figure 2-8. Lincoln County Location and Synthetic Control vs. Actual Population Ratio ...........50

Figure 2-9. Cabell County and Synthetic Control vs. Actual Population Ratio .51

Figure 2-10. Logan County Location and Synthetic Control vs. Actual Population Ratio. Coal Mining Jobshares shown for comparison on the right axis .52

Figure 2-11. Clay County and Synthetic Control vs. Actual Population Ratio .53

Figure 2-12. Jackson County Location and Synthetic Control vs. Actual Population Ratio .54

Figure 2-13. Roane County Location and Synthetic Control vs. Actual Population Ratio .55 
Figure 2-14. Total Population Actual and Synthetic For Three Counties With $\Delta T R>0$, Significant

Placebo Tests Only .56

Figure 3-1. Counties in Ohio (dark grey) and West Virginia (light grey) included in C8 Science

Panel Analysis. Star indicates location of Washington Works Facility. 67

Figure 3-2. Example of Changed Sample Pools and Model Specification on Synthetic County

Output.

Figure 3-3. Athens County Location and Synthetic Control vs. Actual Population Ratio .78

Figure 3-4. Meigs County and Synthetic Control vs. Actual Population Ratio .79

Figure 3-5. Washington County and Synthetic Control vs. Actual Population Ratio..... 80

Figure 3-6. Mason County Location and Synthetic Control vs. Actual Population Ratio. .81

Figure 3-7. Wood County Location and Synthetic Control vs. Actual Population Ratio 82

Figure 3-8. Cabell County Location and Synthetic Control vs. Actual Population Ratio .... .84

Figure 3-9. Jackson County Location and Synthetic Control vs. Actual Population Ratio .85

Figure 3-10. Pleasants County Location and Synthetic Control vs. Actual Population Ratio.....86

Figure 3-11. Ritchie County Location and Synthetic Control vs. Actual Population Ratio .87

Figure 3-12. Wirt County Location and Synthetic Control vs. Actual Population Ratio .88

Figure 3-13. Total Population Actual and Synthetic for Counties With $\Delta T R>0$ Only .89

Figure 3-14. Total Population Actual and Synthetic for Counties Directly Impacted by C8 Spill 89 


\section{Tables}

Table 1-1. Description of Variables Used in this Analysis ................................................ 7

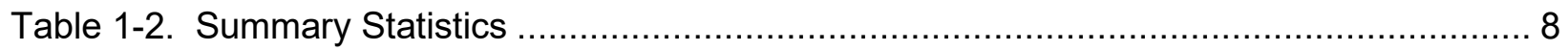

Table 1-3. Definitions of Opioid Overdose Death Rate Categories ...................................10

Table 1-4. Summary Statistics for Opioid Overdose Death Rate Categories ............................12

Table 1-5. Falsification Test. 3-Year Population Changes Do Not Appear to Have Any

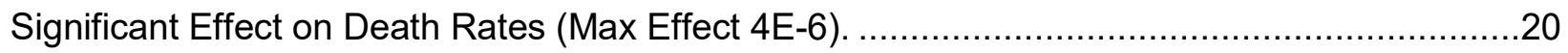

Table 1-6. Overall Results. 3-Year Population Change vs. 3-Year Moving Average Overdose

Rates. Other Results Suppressed (Tables Available in Appendix A, Tables 1-3). ...................22

Table 1-7. State Level Population Change - Highest Estimated Relative Population Losses,

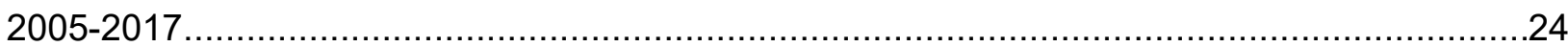

Table 1-8. State Level Population Change - Highest Estimated Income Losses, 2005-2017 ...25

Table 1-9. State Level Population Change - Highest Estimated 25-34 Year-old Population

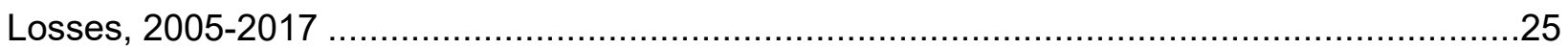

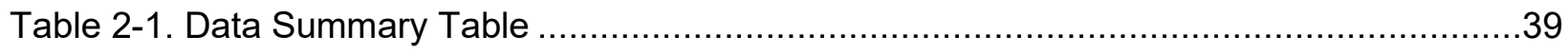

Table 2-2. Summary Statistics of Nine-County Study Region in WV ..................................40

Table 2-3. Estimated Population Loss Income Effect from Impacted Counties .........................58

Table 3-1. Impacted Counties, 2005 Populations, Directly Impacted Water Districts ................66

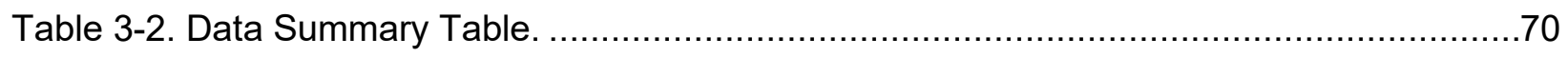

Table 3-3. Occurrence of highest score (Score= $\Delta T R / \mathrm{MSPE}$ ) by year.................................

Table 3-4. Summary Statistics of Study Counties............................................................

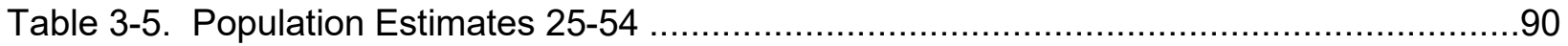

Table 3-6. Forecasted Population Direct Income Effect from Impacted Counties ......................91 


\section{The Opioid Crisis and Economic Distress: The Consequences for Population Change}

\subsection{Introduction}

In recent years, economic opportunity and quality of life factors have declined in many United States (US) rural areas. These rural places are geographically diverse, yet they share many characteristics, especially their historic reliance on declining industries, such as manufacturing (i.e. in the upper Midwest) and extraction (i.e. in the Appalachian region of the eastern US, especially from coal). Many of these places also have long-standing issues with poverty and low levels of labor force participation (Partridge et al., 2018; Stephens and Deskins, 2018; Krueger 2017; Dorsey, 1991).

While a significant body of research focuses on examining what factors may attract people to a region or location, less information exists about what factors may lead people to leave a place. Although migration in the US is at historic lows, this overall measure hides substantial heterogeneity across groups; highly-skilled individuals (college and high school graduates) are substantially more likely to migrate, and a majority of migration flows from rural to urban areas (Johnson et al., 2015). Perhaps due to out-migration of the highly-skilled, many rural regions have lower shares of college graduates and fewer economic opportunities. They also suffer from higher rates of drug addiction and death, primarily due to opioid abuse, which could further contribute to economic decline due to population loss and out-migration.

In this study, we empirically test whether the intensity of overdose death rates in a county is correlated with future population loss. This research fills a gap in the literature by examining county-level population changes, especially in key prime working age groups, to identify the specific impact of drug addiction and overdose-related deaths. In other words, is the opioid crisis leading to further losses of population through out-migration, especially of young adults? We also control for a host of other factors that have been shown to affect population changes and migration. Multiple researchers have discussed that this drug-death epidemic has multiple, long term causes, and no easy solutions in the hardest hit regions (Austin et al., 2018; Betz and Jones, 2018; Case and Deaton, 2017 and 2018; Goetz et al., 2017; Krueger, 2017; Monnat and Rigg, 2018; Partridge and Tsvetkova, 2017; Ruhm, 2018). For residents of the most impacted areas, this may lead to a despair that there is no chance of a place improving, that the disadvantages are too strong, and thus, the only remaining choices are to leave or die. 
We consider three-year population changes using a panel of county-level data for the 48 contiguous US States. Since the publicly-available data on opioid deaths from the Centers for Disease Control (CDC) suppresses counts for small population counties to protect confidentiality, we use a special tabulation that provides additional detail about death rates. This is especially important in the areas hardest hit by overdose deaths in order to understand fully the impact of these deaths. We find that higher overdose death rates appear to have an outsized impact on out-migration across the US, as evidenced by the large population declines especially among those in the 25-34 year-old age group. This age group is not affected by births and has low death rates, thus population changes are an indicator of structural outmigration. Importantly, they are also the group that distressed regions need to retain in order to pave a better future.

In the next section, we review the previous research. Then we present our data, our estimation approach, and our results. We conclude with a discussion of the implications of these findings for future policy.

\subsection{Literature Review}

Why people might move from a place where they live is a topic of enormous importance to economists and policy-makers. It is useful to think about migration as being divided into two distinct types. Type one is driven by changes internal to that person, also known as "natural migration". These migrations are typically tied to normal, or "natural" changes in a person's life, such as graduation from high school and choosing to attend college. In contrast to these natural migrations, "structural migrations" are caused by changes external to a person, such as the decline of a dominant industry or a natural disaster. In the discussion of what factors influence a migration decision, these natural and structural changes will often be at odds with each other, leading to a complicated decision framework, with results that can be difficult to attribute (Jackson and Schaeffer, 2017).

In investigating the migration patterns, there is a large body of literature investigating both what attracts people to a place and what factors lead to higher levels of economic growth. The confounding factor in applying previous research to our research question is that a great deal of this literature is focused on cities or non-rural areas. Rappaport (2002) finds that relatively small frictions to labor or capital mobility, combined with small changes to productivity or quality of life are sufficient to affect long-term and persistent population flows. Many of the most heavily 
impacted areas in the overdose crisis are experiencing significant changes to productivity and quality of life, which provides some context for examining population changes.

For example, a strain of previous research shows that there is a strong link between the number of college graduates in a region and positive economic development (Glaeser et al., 1995; Partridge et al., 2006; Shapiro, 2005; Simon et al., 2002). At the same time, the initial share of highly-educated people, along with employment stability, are the largest predictors to attracting those same types of people (Betz et al., 2015; Frey, 1995).

Related to this, a large literature has considered "brain drain" or the loss of talent from regions (Beine et al., 2001; Domina, 2006; Gibson and McKenzie, 2012; Hansen et al., 2003; Hawley and Rork, 2013; Hunter and Sutton, 2004; Kelchen and Webber, 2018; Petrin et al., 2014; Sherman and Sage, 2011; Stephens et al., 2013; Weber et al., 2007). This literature finds that minimizing the loss of talent may be more important than policies that attempt to attract talent. Some of the findings of these studies also tend to run counter to the prevailing language used by economic development and business attractor organizations. Hansen et al. (2003) find that the most significant components in retaining skilled workers are competitive salaries and benefits - which generally runs counter to local economic development agencies stressing that region's advantages from low wages. As noted by Hansen (Hansen et al., 2003, pp. 145), "this might appeal to businesses, but is hardly conducive to attracting well-trained young professionals." Work by Petrin et al., (2014) finds that high-achieving rural students may have stronger community attachments - and that their perceptions of local economic conditions are strongly influential in their decisions to stay. However, other research (Sherman and Sage, 2011) finds that communities may pressure their highest achieving students to leave for "better" places. In fact, in an attempt to increase local human capital, some places have set up programs that tie financial aid for college to a commitment to staying in that state after graduation, but the effectiveness of these policies isn't entirely clear (Kelchen and Webber, 2018). There is even evidence that these programs may only serve to delay out-migration until after the commitment period (Hawley and Rork, 2013). In general, people-based policies that improve human capital for individuals simply make them more mobile. As noted by Beine et al., (2001), scholarships and other similar types of "subsidies" could increase outmigration if the wage differential for graduates in other places, i.e. in urban areas, is high. 
Other research finds strong relationships between natural amenities and both migration and economic growth (Deller et al., 2001; McGranahan, 2008; Partridge, 2010; Partridge et al., 2017; Wasson et al., 2013). In fact, Deller et al. (2001) specifically focuses on the benefits for rural areas. This provides a measure of hope for policy-makers in rural areas - there are innate "amenities" in many rural places that could be used to recruit or retain workers, including public lands and opportunities for outdoor recreation. At the same time, natural amenities cannot be created or built, so this causes a quandary for places which lack these assets. Conversely, there is also a negative effect from places with a damaged environmental legacy. Brasington and Hite (2005) find that housing values decrease with proximity to polluted sites, and that people with higher incomes and higher education levels demand higher environmental quality. A related literature compares the impact of "quality of place" on the choice of locations, as compared with career opportunities, and finds that high-skilled workers are attracted to places with a higher quality of life, as defined by access to leisure and cultural activities, particularly once they have established their careers (Darchen and Tremblay, 2010; Florida, 2000; Gyourko et al., 1997; Shapiro 2005). Similarly, Frenkel et al., (2013) and Lawton (2013) find that proximity to work and to daily amenities (shopping, etc.), and housing affordability are strong predictors for where high-skilled workers will choose to reside, but if those requirements are met, the decision is then guided by "culture-oriented leisure patterns." However, these studies focus on already developed cities and places with high-concentrations of skilled workers and cultural and other amenities, and thus, their applicability to rural areas is unclear.

While, as noted above, there is some evidence that high-skilled workers may move for higher quality of life, people also relocate to areas with greater opportunity (Burns and Hotchkiss, 2019; Chetty and Hendren I and II, 2016; Davis and Haltiwanger, 2014; Knapp and White, 2016; Rodgers and Rodgers, 1997; Weber et al., 2007; Wilson, 2017; Wozniak, 2010; Yankow, 2003). It also appears that the sooner they make the decision to relocate for opportunity, the greater the positive impacts to both them and their children. For example, Chetty and Hendren II find that moving to better neighborhoods has significant impacts for the children that have relocated, simply growing up in a "better" county could lead to an increase in income by $10 \%$ over a lifetime. For places with historically poor economic and social outcomes this would suggest that a "get out as soon as you can" mentality is the most rational one for many residents of those places. This is, however, tempered by other direct and indirect factors - "better" counties and cities are more expensive and have tighter housing and employment markets, for example. 
By most measures, internal migration in the US is at historically low levels (Frey, 2017) and has been lower than expected for decades, across all demographic, socioeconomic groups, and geographic areas (Molloy et al., 2011, 2017; Partridge, 2010; Partridge et al., 2012; Rupasingha et al., 2015). Molloy et al. (2017) find that migration and job changing are related - and that both have declined since the 1980s. While other recent research suggests that migration in the US in general is becoming less responsive to employment growth. In layman's terms, people are generally not moving from places with low employment growth or low opportunity to places with higher growth or higher opportunity - and this is especially true in the Appalachian ${ }^{1}$ region of the US (Betz and Partridge, 2012). There is a large body of work that has examined the impacts of poverty on migration in the US and globally, finding that while the motivations for migration in the face of poverty are relatively straightforward - moving from a place of lower (or perceived lower) opportunity to higher opportunity - the effects are much more complicated. For example, Winters (2004) notes that, in general, the poorest, most desperate people are not the ones migrating, as they lack the resources. Frey et al. (1996) find that the effects of labor market competition may provide the strongest incentive for a poor resident population to move if the competition for jobs is high, a person is more likely to choose to relocate. However, the impact of poverty on migration from rural areas is somewhat conflicted, reflecting tradeoffs between moving from places with lower-costs of living, versus moving to places with higher opportunity (Weber et al., 2005).

The opioid epidemic in the US is an issue of titanic importance in its own right and has disproportionately impacted rural counties compared to larger cities (Keyes et al., 2014; Monnat and Rigg, 2018). Recent research finds strong relationships between lower incomes, higher unemployment and lower population density (rurality) on increasing opioid death rates and overdose death rates more generally (Boardman et al., 2001; Cerda et al., 2017; Goetz and Davlasheridze, 2018; Rossen et al., 2009; Song, 2017), and a concentration among those with a high school diploma or less, with particular increases in mid-life death rates for people aged 45-54 (Case and Deaton, 2017). Higher opioid death rates are also concentrated in populations that have seen declines in economic opportunity and physical health in recent decades, and also in areas with a long history of economic distress. Researchers find that wage growth rates are highly related to death rates - particularly in the lower wage scales (Betz and Jones, 2018)

\footnotetext{
1 This region, federally-designated by the Appalachian Regional Commission (ARC), contains all of West Virginia and portions of twelve other states, and was formed in 1965 to address issues of persistent poverty and economic distress.
} 
and death rates are particularly high in communities with poor economic indicators (DHHR, 2015). Appalachia, in particular, has some of the highest rates of opioid death in the US. The economic costs of the epidemic from lost productivity and fatalities has been estimated at $\$ 504$ billion in the US in 2015 (Council of Economic Advisors report, 2017), and \$8.8 billion in WV alone (Brill, 2018).

Overall, while the question of how and why to invest in rural communities in America is a long running one (e.g., Carr and Kefalas, 2009; Stauber 2001, Glaeser and Gottlieb, 2008), clear answers have been difficult to find. This research attempts to fill this gap to try to identify how high rates of overdose death, and other factors affect population changes in key working-age demographic groups, which could have important implications for long-term economic vitality, particularly in smaller or more rural counties.

\subsection{Theoretical Framework}

As found in the literature review, there is a strong body of work relative to population changes in reaction to socio-economic factors. While the opioid epidemic shares many of these same socio-economic factors, they do not directly address the effect we are studying here. Massey et al. (1993) note that there is no single, coherent theory for migration or population change. De Hass (2010) examined theoretical drivers of population change, and notes that large scale impacts - what he describes as "force majeures" - such as wars and disasters often provide the initial starting impetus for population changes, and then longer term factors, such as employment opportunities and social capital maximizing networks (i.e. moving where family members already reside) take over. Further, De Hass notes that while many existing theories explain the expansion of already established population dynamics, they generally fail to explain their initial selective creation and trajectories.

A separate body of work models the utility-maximizing choice of locations by households, where households choose the location that provides them with the highest level of utility (Hunter, 2005; Dejong and Fawcett, 1981; Lee, 1966). This research suggests that individuals' express preferences for "amenities" or "disamenities", where in this context, a county with a high overdose death rate could be considered a "disamenity", which will affect their utility and may lead them to move (Brasington and Hite, 2005; Deller et al., 2001; McGranahan, 2008; Partridge, 2010; Partridge et al., 2017; Wasson et al., 2013). This provides a theoretical mechanism where a social concern could provide the rationale for moving, just as moving for a 
better job or better weather might also lead households to move, resulting in population changes.

\subsection{Data}

We use data from several sources to construct a panel of data for 3,108 counties in the 48 contiguous US states and the District of Columbia. Descriptions of the variables are included in Table 1-1, and summary statistics for all counties, and separately for urban and rural counties , are included in Table 1-2.

Variable Name

Population Change Rate
(\%)
Overdose Death Rate
(Deaths/100K)
Per Capita Disability
Receipts (\$)
Unemployment Rate \%
Labor Force
Participation Rate \%
Per Capita Income (\$)
\%-age High-
School/Some College
\%-age Bachelors Degree
or Higher
Social Capital
Dopulation Density
Job Shares \%
CBSA
Matural Amenity Score
Potrono to Nearest
Potro

\section{Description}

Percent Population Change over 3-year periods using data from 2005-2017. Total population change (+ = growth, - = loss) of the county over a period of time. Sub groups for ages 25-34, 35-44, and 25-44 are also examined.

From CDC data. Death rate/100,000 population over a period of time. 3-year moving average death rates are used. Lagged one period behind the population change. Data are from 2005-2017

One Year Lagged Per-Capita Disability Receipts. \$/person. From BEA Data 2005-2017

One Year Lagged Unemployment Rate. From BLS Data 2005-2017

One Year Lagged Labor Force Participation Rate. From BLS Data. 2005-2017

One Year Lagged Per Capita Income. From BEA. 2005-2017

One Year Lagged \% of Population with a High School Diploma up to a Bachelors Degree, All Ages. 2005-2017

One Year Lagged \% of Population with a Bachelors Degree or Higher, All Ages. 2005-2017 Index from Penn State. Between 0 and 1. Treated as a continuous variable (not indicator/dummy). 2005 and 2014 Data.

USDA ERA Natural Amenities Score. Raw Z-score used. (1999)

Number of Persons/Square Mile (2005-2017). Land Area from US Census Data.

Derived from EMSI County Level Data on Number of Jobs Per County by 2-Digit NAICS

Codes. Provides information on industry composition in a county. (2005-2017)

Distance in miles to nearest Core-Based Statistical Area (CBSA Definitions 2010) Using CBSA Definition As Indicator Variable.

Table 1-1. Description of Variables Used in this Analysis 
(1)
(2)

(3)
All Counties

Rural Counties Urban Counties

\begin{tabular}{lccc}
\multicolumn{1}{c}{ VARIABLES } & All Counties & Rural Counties & Urban Counties \\
& & & \\
\hline & & & \\
Total Population & 99,889 & 23,694 & 229,261 \\
Population Aged 25-34 & 13,462 & 2,743 & 31,663 \\
Population Aged 35-44 & 13,172 & 2,838 & 30,716 \\
Poplation Aged 25-44 & 26,634 & 5,581 & 62,380 \\
3-Year Moving Average Overdose & 11.81 & 10.85 & 13.45 \\
Death Rate/100k & 36,189 & 34,701 & 38,715 \\
Per Capita Income (\$) & 272.9 & 49.60 & 652.0 \\
Population Density & 110.9 & 114.4 & 105.0 \\
Per Capita Disability Recipts (\$) & 74.55 & 74.80 & 74.14 \\
Labor Force Participation Rate (\%) & 6.692 & 6.782 & 6.540 \\
Unemployment Rate (\%) & 61.90 & 63.52 & 59.15 \\
\%-age High School/Some College & 17.30 & 15.22 & 20.83 \\
\%-age Bachelors Degree or Higher & 0.0552 & -0.0771 & 0.280 \\
Natural Amenity - Z & -0.000511 & 0.283 & -0.481 \\
Social Capital Score & 5.048 & 6.492 & 2.596 \\
Ag and Forestry Jobshare & 1.490 & 1.943 & 0.722 \\
Mining and O\&G Jobshare & 10.84 & 11.12 & 10.36 \\
Manufacturing Jobshare & 10.71 & 10.45 & 11.15 \\
Retail Trade Jobshare & 10.57 & 10.25 & 11.12 \\
Healthcare Jobshare & 21.77 & 23.15 & 19.42 \\
Govt Jobshare & 55.68 & 54.08 & 58.38 \\
\% of Population Under 45 & 50.03 & 49.73 & 50.54 \\
\% of Population Female & 12,432 & 7,824 & 4,608 \\
Number of Observations & & &
\end{tabular}

Table 1-2. Summary Statistics

\subsubsection{Population Change}

We use population change at the county level as our outcome variable. While we are interested in migration, previous research has shown that population change is a good proxy for household net migration (Faggian et al., 2012; Rappaport, 2007), and data on population change by age groups are available at the county level (which migration is not). There is some debate on the applicability of net migration, or population change as a metric in regional studies (Rogers, 1990; Smith et al., 2006; Swanson, 2016), but these debates tend to depend on the scale of the analysis being performed. In our study, focused at the county level, versus the national level, population change is the most useful tool for estimating demographic impacts to a county. Population change data are from the National Institutes of Health "Surveillance, Epidemiology, 
and End Results" (SEER) program, which is based on inter- and post-censal data from the US Census. This data set provides annual county-level population change by age group from 1969-2017. We focus on three-year population changes during the period from 2008 to 2016 , primarily to provide numerical stability for the analysis, particularly for smaller, rural counties. Thus, we measure population changes for the years 2008-2010, 2011-2013, and 2013-2016. However, in sensitivity analyses (further described below), we test other timeframes. These population changes are then normalized to a percent change relative to the base population. This allows for easier comparison of effects between counties of different sizes. Error!

Reference source not found. Figure 1-1 Panel A contains a map showing the average threeyear population change by county. As shown, there is significant variation across space.

\subsubsection{Overdose Death Rate}

Overdose death rates are obtained from the CDC and their WISQARS ${ }^{2}$ system. We use a moving three-year average death rate which is rescaled to a death rate per 100,000 people. Three years are chosen to provide a measure of the sustained level of opioid-related deaths, and to help control for small population counties where a single death could cause a large single-year death rate. The overdose death data are lagged relative to the population change data, such that, for example, overdose data from 2005-2007 are used to predict population change from 2008-2010. The time period from 2005-2016 is our focus, as this corresponds to the increase in overdose deaths in the late 2000s (the "second wave") due to heroin use. The CDC data were obtained via a special request, as publicly available county-level data from the CDC omit values in low population states to protect confidentiality. For example, Figure 1-2 illustrates the need for the more detailed data, where the histogram of county level death rates shows there is a large group of counties with death rates above $30 / 100,000$, a cutoff value typically used in publicly available data. It also shows that there are many counties and years with no deaths $(0 / 100,000)$.

From the raw data, we create categories of the death rates to use in our analysis. Table 1-3Error! Reference source not found. describes the breaks used to create these categories. The bins are selected to represent the distribution of the data, with Category 1 including the large number of counties with overdose death rates of 0/100,000. Category 2 includes counties with below average overdose death rates. Category 3 includes counties with death rates

\footnotetext{
${ }^{2}$ Web-based Injury Statistics Query and Reporting System. This database provides fatal and non-fatal injury, violent death, and cost of injury data.
} 
approximately one standard deviation above the average. Category 4 includes counties with death rates approximately two standard deviations above the average. Finally, Category 5 includes counties with death rates more than two standard deviations above the average. In our models, we combine Categories 1 and 2 to represent the "lowest overdose death counties" and consider how the other categories compare to this base group. Summary statistics for the counties included in each category are shown in Table 1-4, below. As illustrated in Figure 1-1 Panel $\mathrm{B}$, opioid death rates have a strong spatial and regional distribution.

\begin{tabular}{cc} 
& $\begin{array}{c}\text { Cutoff Levels } \\
3 \text { Year Moving Average } \\
\text { (Deaths/100,000) }\end{array}$ \\
\hline Overdose Category 1 (Zero) & $=0$ \\
Overdose Category 2 (Low) & $0<$ Death Rate $\leq 12$ \\
Overdose Category 3 (Medium) & $12<$ Death Rate $\leq 20$ \\
Overdose Category 4 (High) & $20<$ Death Rate $\leq 40$ \\
Overdose Category 5 (Very High) & Death Rate $\geq 40$
\end{tabular}

Table 1-3. Definitions of Opioid Overdose Death Rate Categories 


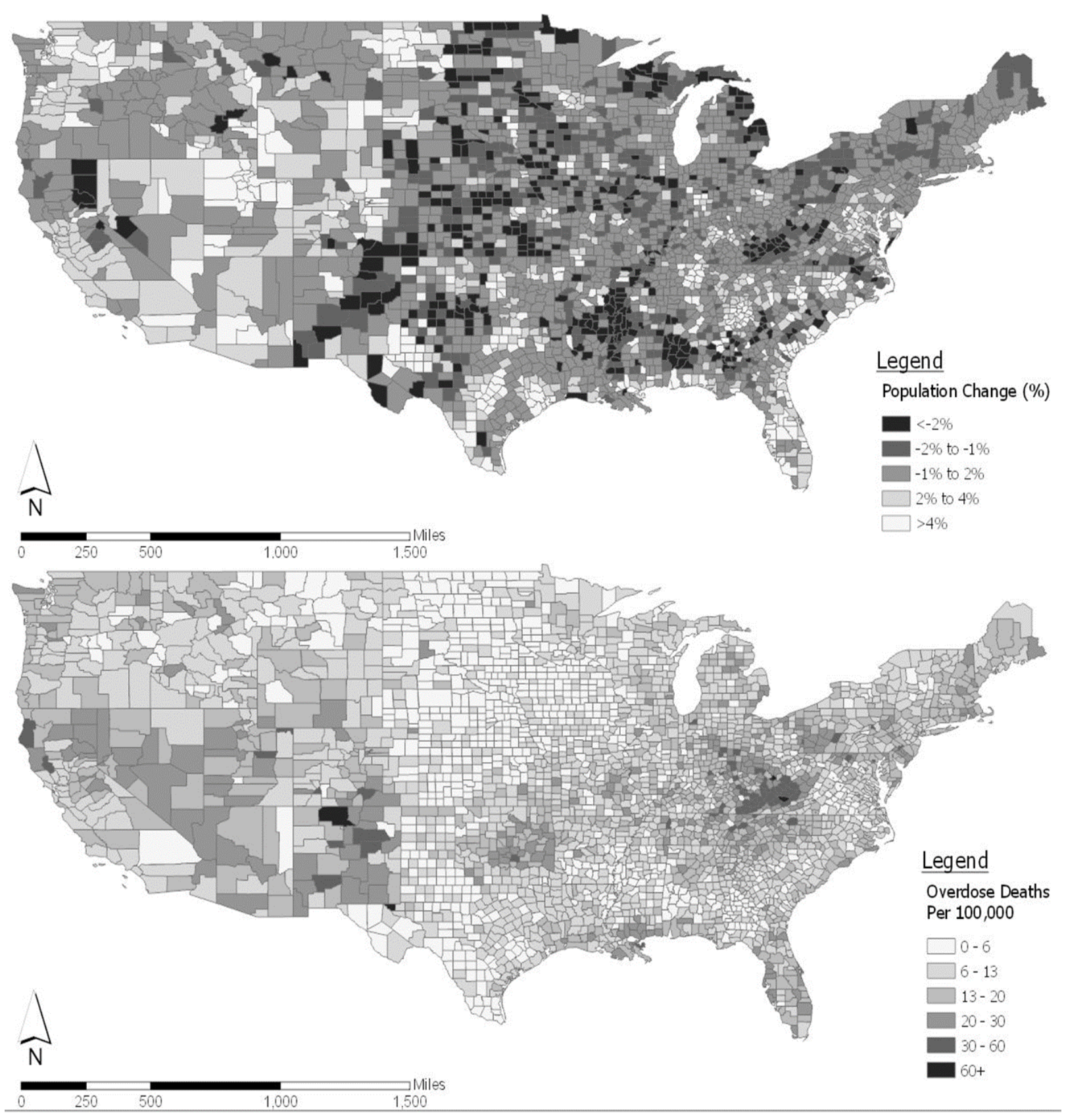

Figure 1-1. Panel A. 3-Year Average Population Change and Panel B. Average Annual Opioid Overdose Death Rate, US Counties. Source, Author's Calculations Based on US Census Data and US Centers for Disease Control Data 


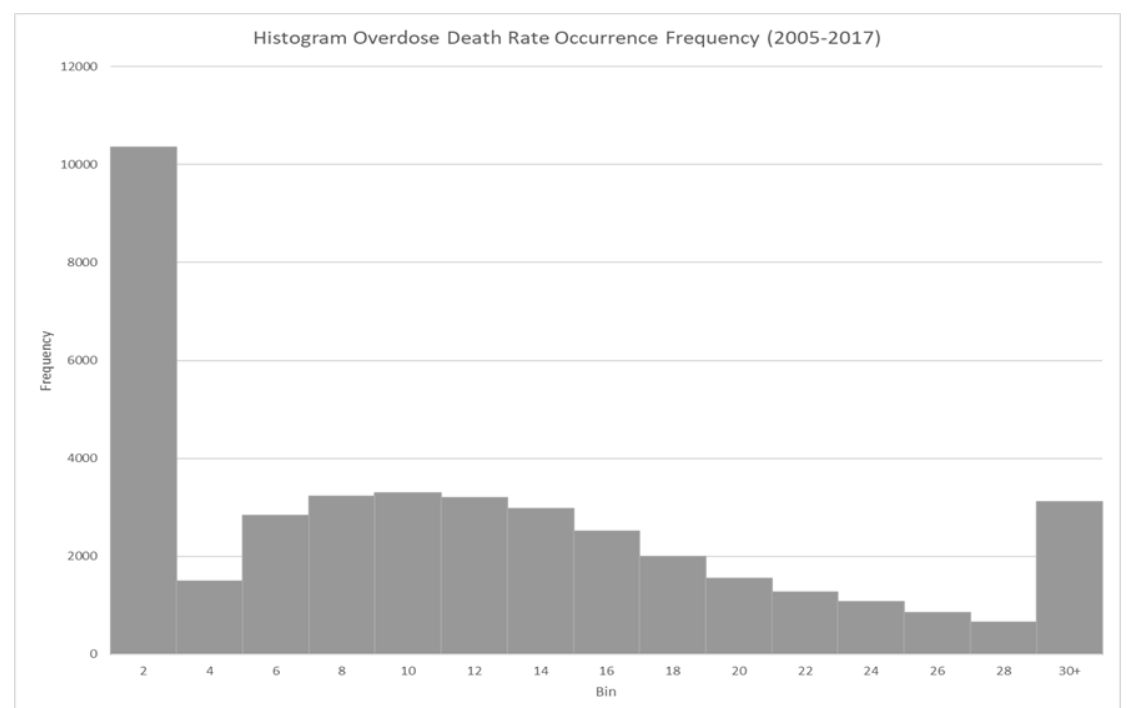

Figure 1-2. Opioid Overdose Death Rate Occurrence Frequency, CDC WISQARS Data. Source, Author's Calculations Based on CDC Data

\begin{tabular}{|c|c|c|c|c|c|}
\hline VARIABLES & $\begin{array}{c}\qquad(1) \\
\text { Category 1: } \\
\text { Death Rate = } \\
0 / 100,000\end{array}$ & $\begin{array}{c}(2) \\
\text { Category } 2 \text { : } \\
0< \\
\text { Death Rate } \\
<12 \text { / } 100,000\end{array}$ & $\begin{array}{c}(3) \\
\text { Category } 3: \\
12< \\
\text { Death Rate } \\
<20 / 100,000\end{array}$ & $\begin{array}{c}(4) \\
\text { Category 4: } \\
20< \\
\text { Death Rate } \\
<40 / 100,000 \\
\end{array}$ & $\begin{array}{c}\text { (5) } \\
\text { Category 5: } \\
\text { Death Rate } \\
>40 / 100,000\end{array}$ \\
\hline Total Population & 5,809 & 93,756 & 135,967 & 132,342 & 113,206 \\
\hline Population Aged 25-34 & 626 & 12,573 & 18,412 & 17,946 & 15,938 \\
\hline Population Aged 35-44 & 666 & 12,767 & 17,727 & 16,607 & 13,634 \\
\hline Poplation Aged 25-44 & 1,292 & 25,339 & 36,139 & 34,553 & 29,571 \\
\hline $\begin{array}{l}\text { 3-Year Moving Average Overdose } \\
\text { Death Rate/100k }\end{array}$ & 0 & 7.165 & 15.46 & 26.16 & 55.10 \\
\hline Per Capita Income (\$) & 39,170 & 35,698 & 36,112 & 35,739 & 35,211 \\
\hline Population Density & 10.86 & 277.8 & 329.6 & 348.8 & 428.9 \\
\hline Per Capita Disability Recipts (\$) & 112.6 & 101.6 & 109.7 & 128.6 & 239.0 \\
\hline Labor Force Participation Rate (\%) & 82.32 & 74.49 & 73.37 & 71.40 & 67.43 \\
\hline Unemployment Rate (\%) & 5.262 & 6.675 & 7.014 & 7.217 & 7.761 \\
\hline \%-age High School/Some College & 63.81 & 61.66 & 61.43 & 62.04 & 62.11 \\
\hline$\%$-age Bachelors Degree or Higher & 16.02 & 17.29 & 17.92 & 17.21 & 17.09 \\
\hline Natural Amenity - Z & -0.643 & -0.229 & 0.515 & 0.765 & 0.494 \\
\hline Social Capital Score & 1.480 & -0.0975 & -0.245 & -0.390 & -0.367 \\
\hline $\mathrm{Ag}$ and Forestry Jobshare & 13.46 & 4.800 & 3.244 & 2.619 & 2.151 \\
\hline Mining and O\&G Jobshare & 2.467 & 1.156 & 1.362 & 1.816 & 3.803 \\
\hline Manufacturing Jobshare & 6.721 & 12.15 & 10.90 & 9.905 & 7.283 \\
\hline Retail Trade Jobshare & 8.273 & 10.71 & 11.31 & 11.49 & 11.60 \\
\hline Healthcare Jobshare & 8.200 & 10.21 & 11.29 & 12.08 & 14.18 \\
\hline Govt Jobshare & 26.34 & 21.53 & 20.55 & 21.14 & 21.40 \\
\hline$\%$ of Population Under 45 & 51.50 & 56.86 & 55.95 & 54.54 & 54.30 \\
\hline$\%$ of Population Female & 49.36 & 50.01 & 50.19 & 50.30 & 50.40 \\
\hline Number of Observations & 1,372 & 5,938 & 3,055 & 1,612 & 455 \\
\hline
\end{tabular}

Table 1-4. Summary Statistics for Opioid Overdose Death Rate Categories 


\subsubsection{Other Controls}

To isolate the impact of overdose death rates on the population changes in a county, we also control for many factors previously shown to affect population change and migration. Importantly, many of these factors are also linked to opioid use and thus are included to minimize omitted variable bias in our estimates.

Disability has been found to have negative impacts on mobility (Partridge et al., 2012) for some age groups, but have confounding results in others (Findley, 1988). Disability also has a complex relationship to opioid use generally (Sites et al., 2014; Glazier and King, 2013). We use data on total disability payments to a county in a given year on a per-capita basis from the Bureau of Economic Analysis (BEA) as a proxy for the prevalence of disability in a county.

There is also evidence that opioid use is related to poorer socioeconomic conditions including unemployment, and the literature has found that residents migrate from areas of higher unemployment to lower in search of work, although these trends have diminished significantly in recent decades (Betz and Jones, 2018). To control for this, we include the annual unemployment rate from the Bureau of Labor Statistics (BLS).

Additionally, many economists have noted a disconnect between labor force participation rates and unemployment rates, particularly in rural places or in places that are historically dependent on manufacturing for employment. The labor force participation rate is the percentage of the working-age population who are either working or actively searching for work (Juhn and Potter, 2006). The literature and media have noted the disparity between the unemployment rate and the participation rate, particularly in rural areas, in Native American populations, and in the Appalachian region (Fields, 1976; Feir and Gillezeau, 2018; Stephens and Deskins, 2018). What this difference indicates is that a large portion of the population in these places has dropped out of the labor force, a possible sign of the lack of job prospects of the area, and a potential contributor to higher opioid (or other drug) use. The Labor Force Participation Rate used in this work is constructed using data from the BLS on the labor force in each county, divided by the total population that is 15-64 years old. Figure 1-3 illustrates US national unemployment and labor force participation rates for the period 2008-2018.

Industrial composition also may affect economic opportunities which could affect migration as well as opioid and other drug abuse. We draw upon unsuppressed detailed county-level data 
from EMSI, Inc., on industry employment at the four-digit NAICS industry code level. We aggregate industrial sectors generally to the two-digit NAICS level to construct job-shares that reflect the percentage of employment in that county in each industrial sector.

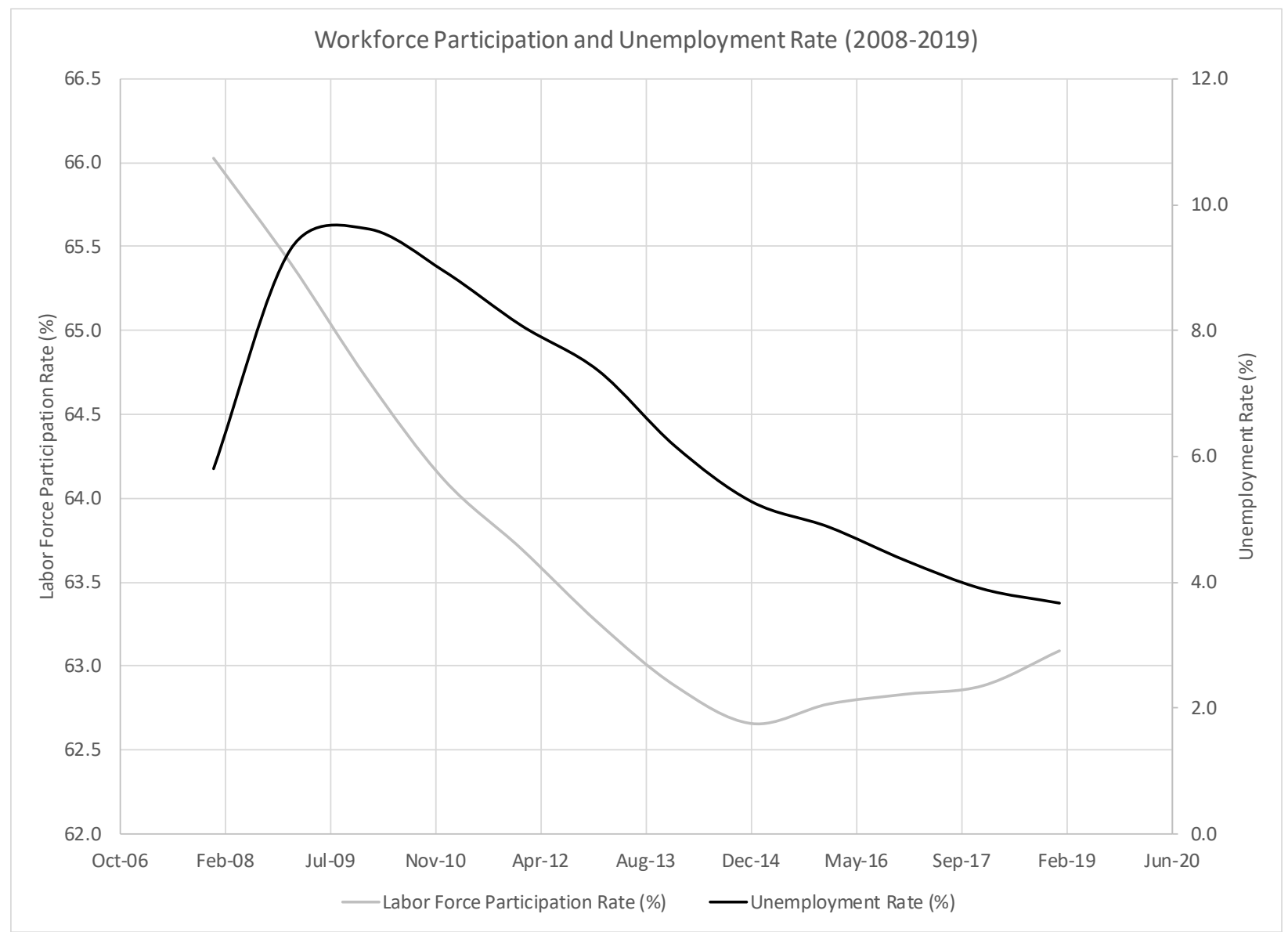

Figure 1-3. Labor force participation and Unemployment rates, 2008-2018. Source BLS Data

Given that national trends indicate that migration tends to flow from rural to urban areas, and that incomes tend to be higher in urban areas, we expect to find a relationship between incomes and population change. To control for this, we use per-capita income at the county-level using data from the BEA.

Educational attainment and returns to education can affect both opioid use and migration. Research shows there are larger incidences of opioid use and death in populations with less than a high school diploma, and that those with a high school diploma or higher are more mobile, and more likely to migrate (Knapp et al., 2013; Weber et al., 2007; Wozniak, 2010; Yankow, 2003). Additionally, as noted above, places with more highly skilled workers are likely 
to have better economic outcomes, and to attract more of the same types of people. Thus, we use data from the USDA- Economic Research Service (ERS) and Census/American Community Survey (ACS) data for our study period on the percentage of the population with a high school diploma up to a bachelor's degree ("some college"), and the percentage of the population with a bachelor's degree or higher. The population with less than a high school diploma was omitted.

It is expected that higher social capital may lead to less migration out of an area, as residents have more opportunities to be engaged and connected to their communities. To control for this, we use the Social Capital Index which includes the number of religious organizations; number of civic, business, and social associations; number of political and labor organizations; measures for recreational opportunities such as number of bowling or golf venues; and voter turnout, census response rate, and non-profit organizations all at the county level. This index is only available for years 2009 and 2013. For 2010-2012, a linear approximation between 2009 and 2013 is used. For 2014-2017 the values for 2013 are used (Rupasingha et al., 2006).

There is also strong evidence that an area having higher natural amenities may attract migrants, which may be a reason for migration into highly scenic rural areas. To control for this, we include the natural amenity score of each county from the USDA/ERS rankings (McGranahan, 1999).

As noted above, the previous literature has identified trends in population movement to urban areas. To control for urbanization, data on the land area and annual population from the U.S. Census are used to calculate the population density of each county. To further control for these rural-to-urban trends, we include an indicator variable for whether the subject county is a metro or non-metro county, as defined by whether or not it is part of a Core-Based Statistical Area (CBSA) in 2013, and the distance to the center of the nearest CBSA calculated using ArcGIS.

Data from the CDC show there are higher rates of overdose deaths in the Appalachian region and other parts of the industrial eastern US. A number of previous studies (Dorsey, 1991; Isserman and Rephann, 1993; Stephens and Partridge, 2011; Stephens et al., 2013, Stephens and Deskins, 2018) have also found evidence of an "Appalachian Effect" when considering other factors. A long running series of migration-focused research performed by Obermiller et al. $(2001,2004,2014)$ examines trends of rural-to-urban migration within the Appalachian region. It finds evidence that populations from outside the region move to rural counties within the 
region, but that "native" rural populations move to urban centers inside the region. They also find that people in poverty moved in, while those with higher education moved out - all trends of interest to us in this research. Relative to opioids in particular, Jonas et al. (2012) find that, in Appalachia, opioid use may be associated with increased social capital among drug users, elevating users within their social group, and increasing connections between users. To control for this, we include an indicator variable for the counties designated within the federal Appalachian Regional Commission (ARC) region. Figure 1-4 contains a map showing the ARC counties.

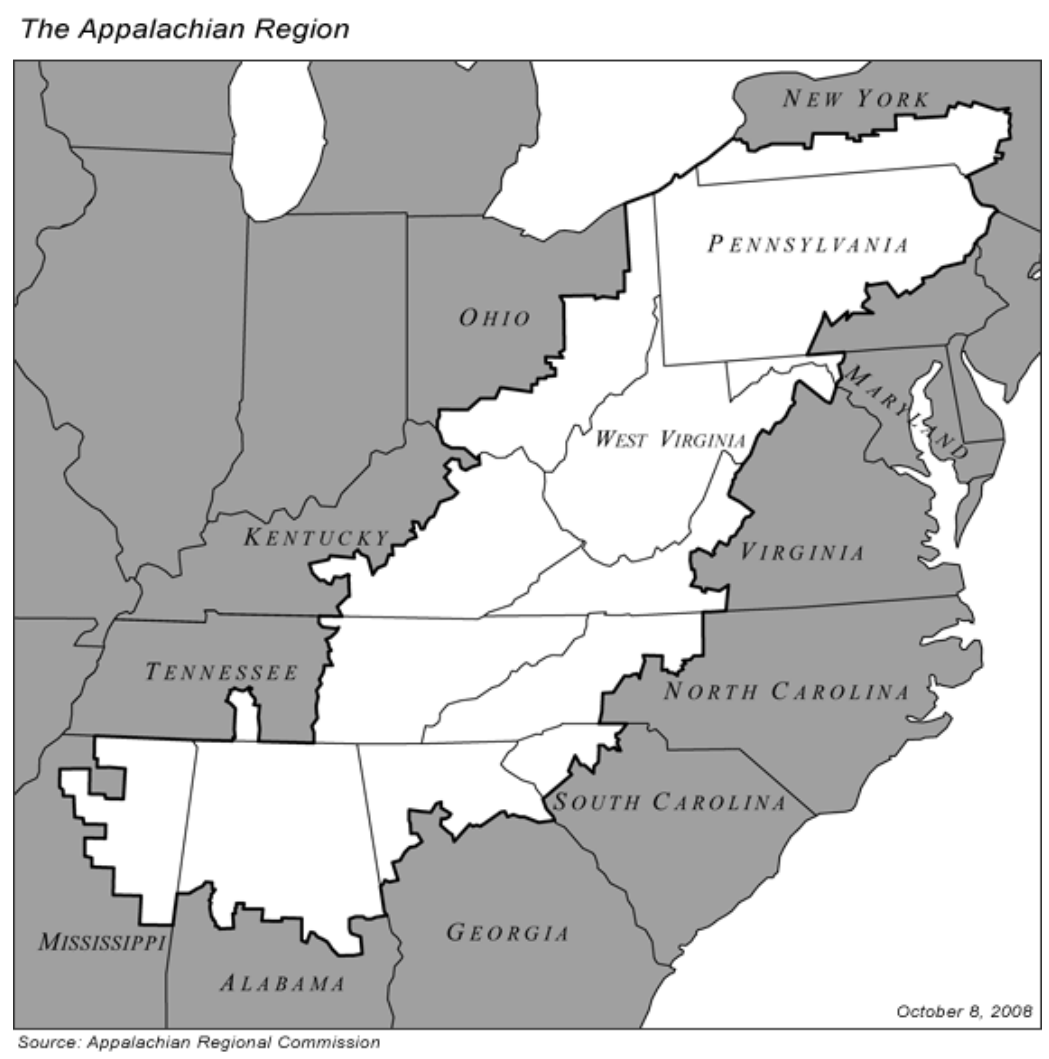

Figure 1-4. Appalachian Regional Commission Region. Source Appalachian Regional Commission

Upon examination of the geographic distribution of the effects of key variables of interest (notably, population change and opioid deaths), significant regional spatial trends emerge from the data that cross county and state borders. Other regional papers (Stephens and Deskins, 2018; Faggian et al., 2011) have identified similar trends that indicate that activity is not constrained by government borders. Using methods described by LeSage and Pace (2014), a five nearest neighbor spatial weight matrix is constructed and interacted with the 3-year opioid overdose death rate categories. This allows us to control for local spillovers of the opioid 
epidemic that might influence migration in nearby counties. Since economic opportunities also do not stop at county or state borders, we also control for spatial spillovers of our variables measuring industrial composition, labor force participation, and unemployment.

\subsection{Empirical Approach}

We model three-year population changes for each county $(i)$ as a result of three-year average opioid overdose rates using a panel of data. To better capture the causal effect of opioid deaths on population change, and to reduce confounding due to simultaneity between factors that could affect both population change and overdose death, we model the three-year population change as a function of the overdose death rates from lagged years within each county over time. For example, we examine population change between 2008 and 2010 as a function of the threeyear moving average of overdose deaths in 2005, 2006, and 2007, and other lagged controls, as shown in Equation (1). As noted above, overdose deaths are categorized into 5 categories, with the lowest two categories, representing death rates at or below the study average $(11.5 / 100,000)$ combined and used as our base or omitted group. Other control variables, as described in Table 1-1 are contained in the vector $X$ of explanatory variables. All time-varying control variables are lagged by one-year to minimize endogeneity. Additionally, to control for changes over time in industrial composition in the study counties that could lead to long-term population changes, such as the loss of a large employer or structural changes in an employment sector, we include 10-year lagged employment changes by industry. The equation also includes $\theta_{c}$, or county level fixed effects, to control for non-time varying factors that are different between counties and which would affect both the attractiveness of a place as well as potentially make it more susceptible to higher rates of overdose. Additionally, a state-time level interaction effect, $\theta_{s} . \theta_{y}$, is included to control for state-level changes over time that may vary, such as taxes or policies related to disability or health benefits, which could impact migration decisions, as well as policies that may affect overdose rates, such as state level prescription drug monitoring programs.

$$
\begin{gathered}
\text { Population Change }(3 \text { year })_{t i}=\beta_{0}+\beta_{1} \text { Category50pioidDeath }_{t i}+ \\
\beta_{2} \text { Category4OpioidDeath }_{t i}+\beta_{3} \text { Category3OpioidDeath }_{t i}+X_{t-1 i} \Gamma+\theta_{s} . \theta_{y}+\theta_{c}+\varepsilon_{i}
\end{gathered}
$$

We estimate equation (1) for the overall population as well as for specific age groups. Johnson and Winkler (2015) examined historical demographic data on migration and mobility by age from 
1950-2010, and found that migration generally peaked between ages 25 and 44 . As shown in Figure 1-5 (taken from Johnson and Winkler), which illustrates movement by age-group across the rural-urban continuum, there is a notable increase in migration for ages 25-44. At the same time, CDC data indicate that two age groups have the highest overdose death rates, 25-44 years old and 45-64 years old (as shown in Figure 1-6 for 2005-2017). However, as shown in Figure 1-7, the age group of 25-34 has the lowest overall death rate in the US and the age group of 35-44 is the third lowest; and both groups are not increased by births.

Thus, given our focus on migration, we concentrate on population change effects on age groups from 25-34 years old and 35-44 years old; as well as those two groups combined (25-44 years old), while comparing this to the effect on all ages (total population). Focusing on the narrower age groups helps increase the probability that our changes reflect migration and not natural population changes due to births or deaths.

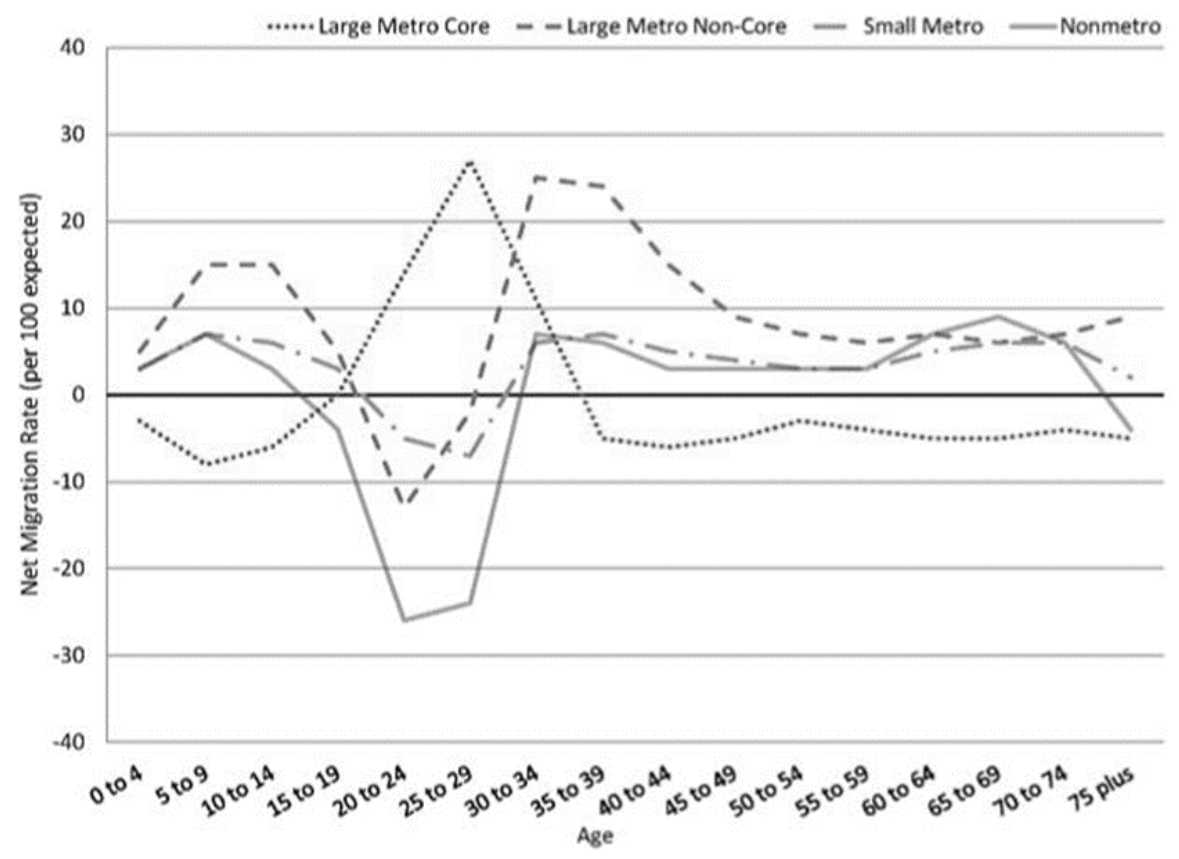

Figure 1-5. Median Age Specific Net Migration Rates Across the Rural-Urban Continuum, 2000-2010. From Johnson and Winkler, 2015, used under Creative Commons License 


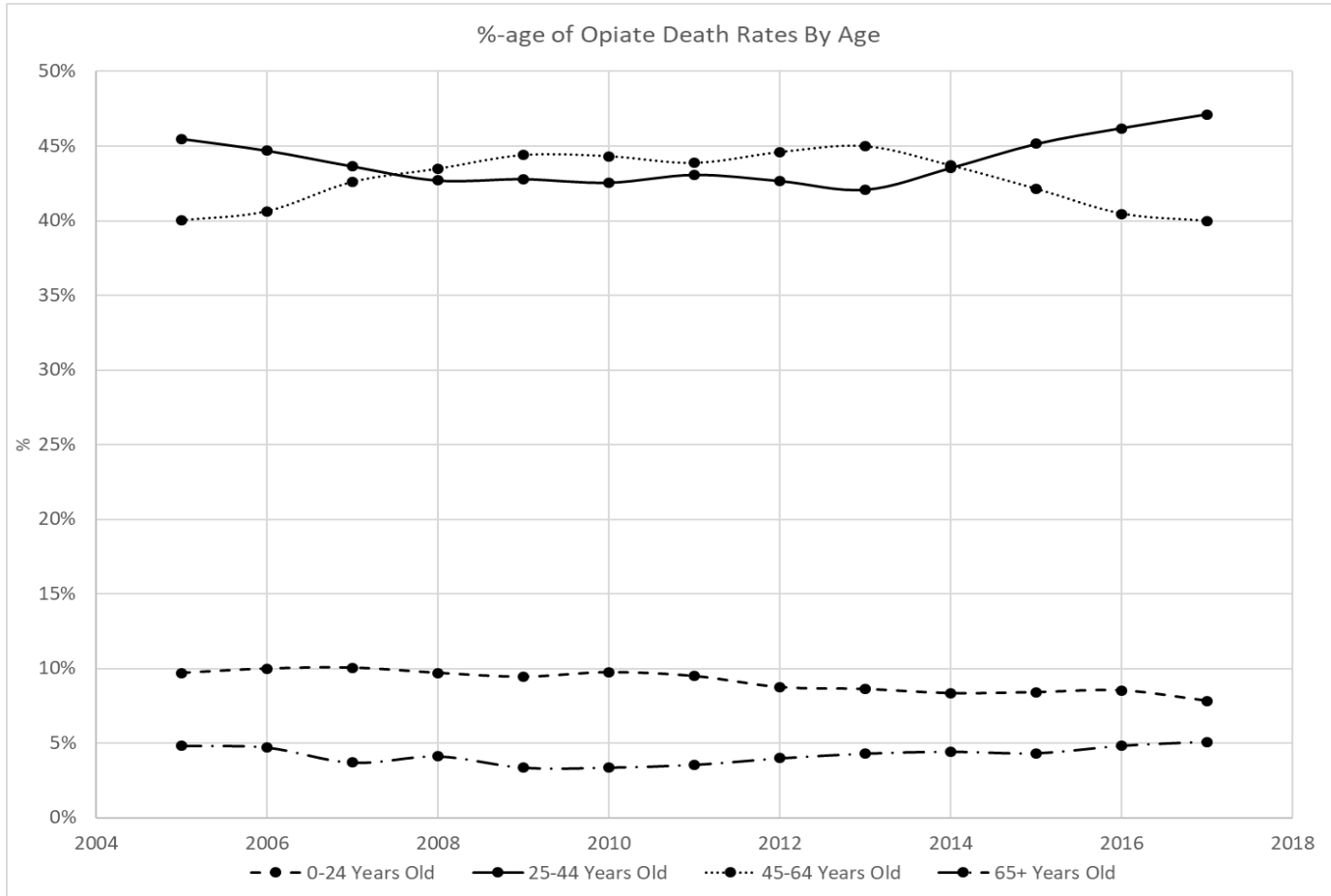

Figure 1-6. Opioid Death Rate Percentages by Age Group. Source, Author's Calculations Based On US Centers for Disease Control Data

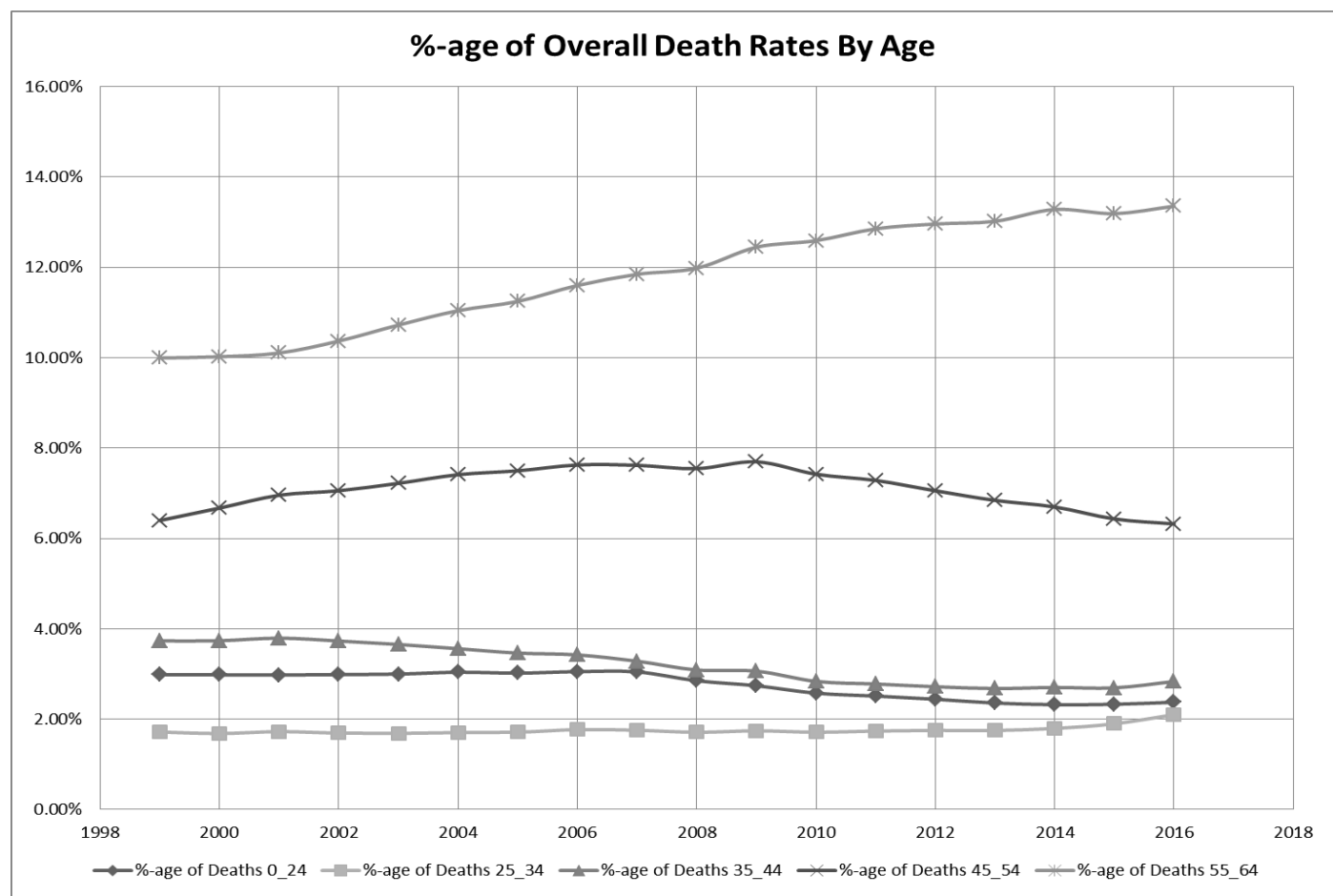

Figure 1-7. Overall Death Rate Percentages by Age Group. Source, Author's Calculations Based On US Centers for Disease Control Data 


\subsection{Robustness Checks}

A series of robustness and sensitivity checks are performed to build confidence in the model and our results. Principal among our robustness checks is a falsification test. In these tests, we model the effect of the lagged 3-year population change on the 3-year moving average overdose rate. For example, we examine overdose rates between 2011 and 2013 as a function of the three-year population change from 2008-2010. Other controls are as defined in the base specification. In this falsification test, no effect was found between 3-year population change rates and death rates.

\begin{tabular}{|c|c|c|c|c|c|c|}
\hline & VARIABLES & $\begin{array}{c}\text { 3-year } \\
\text { Moving } \\
\text { Average } \\
\text { Death } \\
\text { Rate }>40\end{array}$ & $\begin{array}{c}\text { 3-year } \\
\text { Moving } \\
\text { Average } \\
\text { Death Rate } \\
20-40 \\
\end{array}$ & $\begin{array}{c}\text { 3-year } \\
\text { Moving } \\
\text { Average } \\
\text { Death Rate } \\
12-20 \\
\end{array}$ & $\begin{array}{c}\text { 3-year } \\
\text { Moving } \\
\text { Average } \\
\text { Death Rate } \\
0.1-12 \\
\end{array}$ & $\begin{array}{c}\text { 3-year } \\
\text { Moving } \\
\text { Average } \\
\text { Death } \\
\text { Rate } 0 \\
\end{array}$ \\
\hline \multirow{5}{*}{ All Counties } & 3-Year Population Change/100k, all ages & $\begin{array}{c}5.62 \mathrm{e}-07 \\
(7.23 \mathrm{e}-07)\end{array}$ & $\begin{array}{c}9.23 e-08 \\
(1.18 e-06)\end{array}$ & $\begin{array}{c}-2.36 e-06^{*} \\
(1.39 e-06)\end{array}$ & $\begin{array}{c}3.03 e-06 * * \\
(1.50 e-06)\end{array}$ & $\begin{array}{l}-1.33 e-06 \\
(1.29 e-06)\end{array}$ \\
\hline & 3-Year Population Change/100k, Ages 25-34 & $\begin{array}{c}7.22 \mathrm{e}-09 \\
(3.10 \mathrm{e}-07)\end{array}$ & $\begin{array}{c}2.32 \mathrm{e}-07 \\
(3.36 \mathrm{e}-07)\end{array}$ & $\cdot 1.04 \mathrm{e}-06^{* * *}$ & $\begin{array}{c}1.37 \mathrm{e}-08 \\
(4.53 \mathrm{e}-07)\end{array}$ & $\begin{array}{l}7.85 \mathrm{e}-07 * \\
(4.68 \mathrm{e}-07)\end{array}$ \\
\hline & 3-Year Population Change/100k, Ages 35-44 & $\begin{array}{c}(3.10 \mathrm{e}-0 /) \\
9.86 \mathrm{e}-08\end{array}$ & $\begin{array}{c}(3.36 \mathrm{e}-0 /) \\
5.99 \mathrm{e}-08\end{array}$ & $\begin{array}{l}(4.01 \mathrm{e}-0 /) \\
-7.24 \mathrm{e}-07\end{array}$ & $\begin{array}{l}(4.53 \mathrm{e}-0 /) \\
1.37 \mathrm{e}-06 * *\end{array}$ & $\begin{array}{l}(4.68 \mathrm{e}-0 /) \\
-8.01 e-07\end{array}$ \\
\hline & & $(2.69 e-07)$ & $(4.85 e-07)$ & $(6.04 e-07)$ & $(6.82 \mathrm{e}-07)$ & $(6.60 e-07)$ \\
\hline & 3-Year Population Change/100k, Ages 25-44 & $\begin{array}{c}-2.27 \mathrm{e}-07 \\
(3.44 \mathrm{e}-07) \\
\end{array}$ & $\begin{array}{c}3.97 e-07 \\
(5.77 e-07) \\
\end{array}$ & $\begin{array}{c}-1.79 \mathrm{e}-06^{* *} \\
(6.99 \mathrm{e}-07) \\
\end{array}$ & $\begin{array}{l}1.32 \mathrm{e}-06^{*} \\
(7.88 \mathrm{e}-07) \\
\end{array}$ & $\begin{array}{r}3.01 \mathrm{e}-07 \\
(6.89 \mathrm{e}-07) \\
\end{array}$ \\
\hline \multirow{6}{*}{ Urban Counties } & 3-Year Population Change/100k, all ages & $\begin{array}{c}6.31 \mathrm{e}-07 \\
(8.35 \mathrm{e}-07)\end{array}$ & $\begin{array}{c}-6.14 \mathrm{e}-07 \\
(2.62 \mathrm{e}-06)\end{array}$ & $\begin{array}{c}7.53 e-07 \\
(2.85 e-06)\end{array}$ & $\begin{array}{l}-5.07 e-07 \\
(2.24 e-06)\end{array}$ & $\begin{array}{l}-2.63 e-07 \\
(9.55 e-07)\end{array}$ \\
\hline & 3-Year Population Change/100k, Ages 25-34 & $\begin{array}{l}-2.12 e-07 \\
(3.33 e-07)\end{array}$ & $\begin{array}{c}1.40 \mathrm{e}-06 \\
(8.67 \mathrm{e}-07)\end{array}$ & $\begin{array}{c}-4.48 \mathrm{e}-07 \\
(1.11 \mathrm{e}-06)\end{array}$ & $\begin{array}{l}-7.50 e-07 \\
(1.05 e-06)\end{array}$ & $\begin{array}{c}9.01 \mathrm{e}-09 \\
(5.17 \mathrm{e}-07)\end{array}$ \\
\hline & 3-Year Population Change/100k, Ages 35-44 & $7.94 e-07$ & $-1.18 e-07$ & $-1.22 \mathrm{e}-06$ & $1.34 \mathrm{e}-06$ & $-7.89 e-07$ \\
\hline & & $(5.20 \mathrm{e}-07)$ & $(1.29 e-06)$ & $(1.72 \mathrm{e}-06)$ & $(1.66 \mathrm{e}-06)$ & $(8.88 e-07)$ \\
\hline & 3-Year Population Change/100k, Ages 25-44 & $2.09 e-07$ & $1.42 \mathrm{e}-06$ & $-1.05 e-06$ & $1.08 \mathrm{e}-07$ & $-6.89 e-07$ \\
\hline & & $(4.91 \mathrm{e}-07)$ & $(1.29 \mathrm{e}-06)$ & $(1.64 \mathrm{e}-06)$ & $(1.57 e-06)$ & $(6.73 e-07)$ \\
\hline \multirow{8}{*}{ Rural Counties } & 3-Year Population Change/100k, all ages & $6.21 \mathrm{e}-07$ & $5.02 e-09$ & $-3.53 e-06 * *$ & $4.31 \mathrm{e}-06^{* *}$ & $-1.40 e-06$ \\
\hline & & $(9.82 \mathrm{e}-07)$ & $(1.26 \mathrm{e}-06)$ & $(1.67 e-06)$ & $(1.83 e-06)$ & $(1.88 \mathrm{e}-06)$ \\
\hline & 3-Year Population Change/100k, Ages 25-34 & $7.41 \mathrm{e}-08$ & $-7.13 e-08$ & $-9.66 \mathrm{e}-07^{* *}$ & $1.92 \mathrm{e}-07$ & $7.72 \mathrm{e}-07$ \\
\hline & & $(3.69 e-07)$ & $(3.63 e-07)$ & $(4.37 e-07)$ & $(5.14 e-07)$ & $(5.68 \mathrm{e}-07)$ \\
\hline & 3-Year Population Change/100k, Ages 35-44 & $-1.04 e-07$ & $-2.97 e-08$ & $-5.47 e-07$ & $1.20 \mathrm{e}-06$ & $-5.18 e-07$ \\
\hline & & $(3.04 \mathrm{e}-07)$ & $(5.30 e-07)$ & $(6.47 e-07)$ & $(7.49 e-07)$ & $(7.72 \mathrm{e}-07)$ \\
\hline & 3-Year Population Change/100k, Ages 25-44 & $-3.86 e-07$ & $-2.97 e-08$ & $-1.67 e-06 * *$ & $1.48 \mathrm{e}-06$ & $6.09 e-07$ \\
\hline & & $(4.19 e-07)$ & $(6.38 \mathrm{e}-07)$ & $(7.91 \mathrm{e}-07)$ & $(9.06 e-07)$ & $(8.69 e-07)$ \\
\hline
\end{tabular}

Robust standard errors in parentheses

$* * * \mathrm{p}<0.01, * * \mathrm{p}<0.05, * \mathrm{p}<0.1$

Full Results Shown in Appendix.

Model Specification Identical to Primary Results, with Exception of Population Change and Death Rate exchanged as Dependent/Predictive Variables. Other controls are as defined in the base specification.

Table 1-5. Falsification Test. 3-Year Population Changes Do Not Appear to Have Any Significant Effect on Death Rates (Max Effect 4E-6). 


\subsection{Results}

Results from equation (1) are presented in the following sections. We separately estimate 9 specifications, examining both the overall population and the restricted age groups (25-34, 3544, 25-44) for all counties and for rural and urban counties separately.

\subsubsection{Overall Results}

Overall results for population change relative to the overdose rate are shown in Table 1-6, for all counties, and urban and rural counties separately. Full results for the control variables are shown in Appendix A, Tables 1-3. All results include county fixed effects and state-year fixed effects. In Table 1-6, the population loss of the 25-34 year-old population for the highest death rate counties is large and statistically significant, indicating a population loss of approximately $1.9 \%$ of the 25-34 year-old population in places with a 3-year average death rate over $40 / 100,000$, compared to places with lower death rates. We also find some impacts from the next highest category of overdose death rates, or a $0.19 \%$ overall population loss in places with death rates over $20 / 100,000$, and a loss of $0.69 \%$ of the $25-34$ year-old population. The results also suggest that simply having some overdose deaths is not the problem, as there are no statistically significant effects for death rates at or slightly above the national average $(<20 / 100,000)$.

Other results as shown in Appendix A are generally as expected from the previous literature. For example, higher unemployment rates are associated with population losses and higher levels of education are associated with population gains. The spatial spillover variables also suggest that higher overdose death rates and higher unemployment rates in nearby counties have similar effects - in other words, both lead to population losses. 


\begin{tabular}{|c|c|c|c|c|c|}
\hline & & $\begin{array}{c}\text { 3-Year } \\
\text { Population } \\
\text { Change (\%) }\end{array}$ & $\begin{array}{c}\text { Age } 25-34 \\
\text { 3-Year } \\
\text { Population } \\
\text { Change } \\
(\%)\end{array}$ & $\begin{array}{c}\text { Age } 35-44 \\
\text { 3-Year } \\
\text { Population } \\
\text { Change } \\
(\%)\end{array}$ & $\begin{array}{c}\text { Age } 25-44 \\
\text { 3-Year } \\
\text { Population } \\
\text { Change } \\
(\%)\end{array}$ \\
\hline \multirow{3}{*}{ All Counties } & Overdose $>40 / 100 k$ (Category 5) & $\begin{array}{c}-0.353^{*} \\
(0.212)\end{array}$ & $\begin{array}{c}-1.913 * * * \\
(0.568)\end{array}$ & $\begin{array}{c}0.490 \\
(0.717)\end{array}$ & $\begin{array}{c}-0.963 * * \\
(0.397)\end{array}$ \\
\hline & Overdose $20-40 / 100 k$ (Category 4) & $\begin{array}{c}-0.191 * * * \\
(0.0696)\end{array}$ & $\begin{array}{c}-0.694 * * * \\
(0.198)\end{array}$ & $\begin{array}{l}-0.219 \\
(0.179)\end{array}$ & $\begin{array}{c}-0.470^{* * *} \\
(0.129)\end{array}$ \\
\hline & Overdose $12-20 / 100 k$ (Category 3 ) & $\begin{array}{l}-0.0250 \\
(0.0393) \\
\end{array}$ & $\begin{array}{r}-0.0462 \\
(0.114) \\
\end{array}$ & $\begin{array}{l}-0.0797 \\
(0.0925) \\
\end{array}$ & $\begin{array}{c}-0.0623 \\
(0.0769) \\
\end{array}$ \\
\hline \multirow{3}{*}{ Urban Counties } & Overdose $>40 / 100 k$ (Category 5) & $\begin{array}{c}-0.457^{* *} \\
(0.209)\end{array}$ & $\begin{array}{c}-1.638^{* * *} \\
(0.543)\end{array}$ & $\begin{array}{l}-0.257 \\
(0.463)\end{array}$ & $\begin{array}{c}-1.041 * * * \\
(0.379)\end{array}$ \\
\hline & Overdose $20-40 / 100 k$ (Category 4) & $\begin{array}{l}-0.0476 \\
(0.0772)\end{array}$ & $\begin{array}{l}-0.246 \\
(0.193)\end{array}$ & $\begin{array}{c}-0.307^{* *} \\
(0.137)\end{array}$ & $\begin{array}{c}-0.276 * * \\
(0.132)\end{array}$ \\
\hline & Overdose $12-20 / 100 k$ (Category 3 ) & $\begin{array}{c}0.0200 \\
(0.0438) \\
\end{array}$ & $\begin{array}{r}-0.0218 \\
(0.118) \\
\end{array}$ & $\begin{array}{c}0.0112 \\
(0.0855) \\
\end{array}$ & $\begin{array}{l}0.00390 \\
(0.0808) \\
\end{array}$ \\
\hline \multirow{3}{*}{ Rural Counties } & Overdose >40/100k (Category 5) & $\begin{array}{l}-0.197 \\
(0.295)\end{array}$ & $\begin{array}{c}-1.912 * * \\
(0.823)\end{array}$ & $\begin{array}{c}1.235 \\
(1.131)\end{array}$ & $\begin{array}{l}-0.665 \\
(0.579)\end{array}$ \\
\hline & Overdose $20-40 / 100 k$ (Category 4) & $\begin{array}{c}-0.284 * * * \\
(0.108)\end{array}$ & $\begin{array}{c}-1.128 * * * \\
(0.337)\end{array}$ & $\begin{array}{l}-0.0766 \\
(0.313)\end{array}$ & $\begin{array}{c}-0.605^{* * *} \\
(0.212)\end{array}$ \\
\hline & Overdose $12-20 / 100 k$ (Category 3 ) & $\begin{array}{c}-0.0559 \\
(0.0651)\end{array}$ & $\begin{array}{r}-0.0507 \\
(0.205)\end{array}$ & $\begin{array}{l}-0.268 \\
(0.170)\end{array}$ & $\begin{array}{l}-0.151 \\
(0.135)\end{array}$ \\
\hline
\end{tabular}

Robust standard errors in parentheses

$* * * \mathrm{p}<0.01, * * \mathrm{p}<0.05, * \mathrm{p}<0.1$

Full Results Shown in Appendix.

Table 1-6. Overall Results. 3-Year Population Change vs. 3-Year Moving Average Overdose Rates. Other Results Suppressed (Tables Available in Appendix A, Tables 1-3).

\subsubsection{Urban Counties Only}

Urban counties generally are the beneficiaries of in-migration. However, the results in Table 1-6 indicate that urban counties with high sustained overdose death rates are also experiencing population losses, both overall and in the youngest adult age group (25-34). For urban counties with death rates over $40 / 100,000$, populations are $1.6 \%$ lower in the $25-34$ year-old group, compared to low death-rate counties. Urban counties in the second highest death rate category also have lower populations of 35-44 year-olds and 25-44 year-olds, compared to places with low opioid overdose death rates. While the overall population losses could be due to higher levels of deaths from other causes (or lower birth rates), the estimates for 24-34 years olds provide evidence that opioids are creating a culture that is motivating young adults to leave, even in urban areas. 


\subsubsection{Rural Counties}

Policy-makers in rural areas are already alert to the trends of out-migration from rural to urban areas as well as to the outsized impact of the opioid crisis in some rural areas. But, previous research has not shown a link. Our results suggest that rural places with high overdose death rates are experiencing higher levels of population loss. And, similar to the previous results for all counties and for urban counties, the impact increases when a county has sustained high levels of overdose deaths. We also find strong effects in the "next highest" overdose category, which are counties with death rates between 20-40/100,000. Having over 20 deaths/100,000 (compared to low levels of deaths) is associated with a $0.28 \%$ population loss compared to lower death rate counties and a significant $1.1 \%$ loss in the $25-34$-year-old age group. In counties with sustained high death rates, these results become less clear, but the trends appear to continue for the age 25-34 population. Again, these are the age groups less likely to die from either overdose or other causes and not affected by births - thus most likely representing migration of young adults.

\subsection{State Level Population Change Estimates}

To quantify the results so they can be of use to policy-makers, we use the results above to calculate estimates of county-level population changes (i.e. losses) due to high overdose death rates, and aggregate those results to the state level. We calculate this only for counties which fall within a category with a statistically significant result. For example, for an urban county, with a Category 5 overdose death ranking, the population change is calculated as follows:

$$
\begin{gathered}
\text { if County }(i, t)=\text { Urban } \cap \text { Category } 5 \text { Opioid } \\
\text { Population Change }(i, t)=\frac{-0.457 * \text { County Population }(i, t)}{100}
\end{gathered}
$$

Where -0.457 is the coefficient on population change for an urban, Category 5 impacted county. These county level estimates are then aggregated for a state level estimate (4).

$$
\text { Population Change (state })=\sum_{t=1}^{n} \sum_{i=1}^{j} \text { Population Change }(i, t)
$$

The results for the overall population and the population ages 25-34 are shown in the last two columns of Table 1-7 to Table 1-9. 
Next, we use these estimates to quantify the economic impact over the 9 years included in our study of this problem outside of the more commonly discussed direct economic impacts, such as those in the 2017 report by the President's Council of Economic Advisors, which estimated impacts at $\$ 2.5$ trillion over 4 years. We assume each person lost would have earned $\$ 25,000$ annually (Council of Economic Advisors report, 2017).

$$
\text { Economic Impact }(\text { state })=\sum_{t=1}^{n} \sum_{i=1}^{j} \$ 25,000 * \text { Population Change }(i, t)(5)
$$

Table 1-7 illustrates the top 10 states with the highest forecasted percent population losses, Table 1-8 illustrates the top 10 states in terms of total estimated annual income losses, and Table 1-9 the states with the highest forecasted losses of 25-34 year olds. More complete county level tables are included in Appendix A.

As illustrated, the impacts on population change are high, particularly in the Appalachian states. Income effects also are high for Appalachian states, but Table 1-8 also shows the impact the opioid epidemic has had in states such as California. Significant in these findings is the impact on the 25-34 year-old population, particularly for West Virginia and Kentucky, where 1\% of the 25-34 year-old population is estimated to have left these states as a result of the opioid epidemic.

\begin{tabular}{|c|c|c|c|c|c|c|c|}
\hline State & $\begin{array}{c}\text { Population } \\
\text { (2017) }\end{array}$ & $\begin{array}{c}\text { Impacted } \\
\text { Population } \\
\text { (Cat 4/Cat } 5 \\
\text { Counties) } \\
(2017)\end{array}$ & $\begin{array}{c}\text { Fraction of } \\
\text { State } \\
\text { Population } \\
\text { Impacted (\%) }\end{array}$ & $\begin{array}{c}\text { Population } \\
25-34 \\
(2017)\end{array}$ & $\begin{array}{c}\text { Direct Income } \\
\text { Effect } \\
(x \$ 1,000,000)\end{array}$ & $\begin{array}{c}\text { Forecasted Total } \\
\text { Pop Change } \\
(\%)\end{array}$ & $\begin{array}{c}\text { Forecasted 25-34 } \\
\text { Pop Change } \\
(\%)\end{array}$ \\
\hline West Virginia & $1,815,857$ & 869,675 & $48 \%$ & 216,070 & $-\$ 317.50$ & $-0.30 \%$ & $-1.40 \%$ \\
\hline Kentucky & $4,454,189$ & $1,561,802$ & $35 \%$ & 580,996 & $-\$ 673.00$ & $-0.20 \%$ & $-1.07 \%$ \\
\hline Ohio & $11,658,609$ & $2,889,914$ & $25 \%$ & $1,523,761$ & $-\$ 423.30$ & $-0.12 \%$ & $-0.42 \%$ \\
\hline Pennsylvania & $12,805,537$ & $3,154,431$ & $25 \%$ & $1,688,589$ & $-\$ 388.30$ & $-0.11 \%$ & $-0.52 \%$ \\
\hline Maryland & $6,052,177$ & 702,647 & $12 \%$ & 837,918 & $-\$ 717.10$ & $-0.10 \%$ & $-0.44 \%$ \\
\hline New Mexico & $2,088,070$ & 123,456 & $6 \%$ & 281,932 & $-\$ 140.70$ & $-0.06 \%$ & $-0.22 \%$ \\
\hline Oklahoma & $3,930,864$ & 456,042 & $12 \%$ & 545,596 & $-\$ 183.50$ & $-0.05 \%$ & $-0.18 \%$ \\
\hline Montana & $1,050,493$ & 124,097 & $12 \%$ & 135,024 & $-\$ 55.66$ & $-0.04 \%$ & $-0.14 \%$ \\
\hline Missouri & $6,113,532$ & 531,997 & $9 \%$ & 820,863 & $-\$ 121.00$ & $-0.04 \%$ & $-0.18 \%$ \\
\hline Wyoming & 579,315 & 59,732 & $10 \%$ & 79,514 & $-\$ 16.31$ & $-0.04 \%$ & $-0.13 \%$ \\
\hline
\end{tabular}

Table 1-7. State Level Population Change - Highest Estimated Relative Population Losses, 2005-2017 


\begin{tabular}{|c|c|c|c|c|c|c|c|}
\hline State & $\begin{array}{c}\text { Population } \\
\text { (2017) }\end{array}$ & $\begin{array}{c}\text { Impacted } \\
\text { Population } \\
\text { (Cat 4/Cat } 5 \\
\text { Counties) } \\
\text { (2017) }\end{array}$ & $\begin{array}{l}\text { Fraction of } \\
\text { State } \\
\text { Population } \\
\text { Impacted (\%) }\end{array}$ & $\begin{array}{c}\text { Population } \\
25-34 \\
(2017)\end{array}$ & $\begin{array}{c}\text { Direct Income } \\
\text { Effect } \\
(x \$ 1,000,000)\end{array}$ & $\begin{array}{c}\text { Forecasted Total } \\
\text { Pop Change } \\
(\%)\end{array}$ & $\begin{array}{c}\text { Forecasted 25-34 } \\
\text { Pop Change } \\
\text { (\%) }\end{array}$ \\
\hline Maryland & $6,052,177$ & 702,647 & $12 \%$ & 837,918 & $-\$ 717.10$ & $-0.10 \%$ & $-0.44 \%$ \\
\hline Kentucky & 4,454,189 & $1,561,802$ & $35 \%$ & 580,996 & $-\$ 673.00$ & $-0.20 \%$ & $-1.07 \%$ \\
\hline Ohio & $11,658,609$ & $2,889,914$ & $25 \%$ & $1,523,761$ & $-\$ 423.30$ & $-0.12 \%$ & $-0.42 \%$ \\
\hline Pennsylvania & $12,805,537$ & $3,154,431$ & $25 \%$ & $1,688,589$ & $-\$ 388.30$ & $-0.11 \%$ & $-0.52 \%$ \\
\hline West Virginia & $1,815,857$ & 869,675 & $48 \%$ & 216,070 & $-\$ 317.50$ & $-0.30 \%$ & $-1.40 \%$ \\
\hline California & $39,573,146$ & 285,556 & $1 \%$ & $6,024,064$ & $-\$ 237.50$ & $-0.01 \%$ & $-0.02 \%$ \\
\hline Virginia & $8,470,020$ & 298,197 & $4 \%$ & $1,185,270$ & $-\$ 224.70$ & $-0.03 \%$ & $-0.11 \%$ \\
\hline North Carolina & $10,273,419$ & 451,748 & $4 \%$ & $1,370,247$ & $-\$ 217.00$ & $-0.02 \%$ & $-0.06 \%$ \\
\hline Tennessee & $6,715,984$ & 390,621 & $6 \%$ & 915,996 & $-\$ 207.10$ & $-0.03 \%$ & $-0.11 \%$ \\
\hline Oklahoma & $3,930,864$ & 456,042 & $12 \%$ & 545,596 & $-\$ 183.50$ & $-0.05 \%$ & $-0.18 \%$ \\
\hline
\end{tabular}

Table 1-8. State Level Population Change - Highest Estimated Income Losses, 2005-2017

\begin{tabular}{|c|c|c|c|c|c|c|c|}
\hline State & $\begin{array}{c}\text { Population } \\
\text { (2017) }\end{array}$ & $\begin{array}{c}\text { Impacted } \\
\text { Population } \\
\text { (Cat 4/Cat } 5 \\
\text { Counties) } \\
(2017)\end{array}$ & $\begin{array}{l}\text { Fraction of } \\
\text { State } \\
\text { Population } \\
\text { Impacted (\%) }\end{array}$ & $\begin{array}{c}\text { Population } \\
25-34 \\
(2017)\end{array}$ & $\begin{array}{c}\text { Direct Income } \\
\text { Effect } \\
(x \$ 1,000,000)\end{array}$ & $\begin{array}{c}\text { Forecasted Total } \\
\text { Pop Change } \\
(\%)\end{array}$ & $\begin{array}{c}\text { Forecasted 25-34 } \\
\text { Pop Change } \\
(\%)\end{array}$ \\
\hline West Virginia & $1,815,857$ & 869,675 & $48 \%$ & 216,070 & $-\$ 317.50$ & $-0.30 \%$ & $-1.40 \%$ \\
\hline Kentucky & 4,454,189 & $1,561,802$ & $35 \%$ & 580,996 & $-\$ 673.00$ & $-0.20 \%$ & $-1.07 \%$ \\
\hline Pennsylvania & $12,805,537$ & $3,154,431$ & $25 \%$ & $1,688,589$ & $-\$ 388.30$ & $-0.11 \%$ & $-0.52 \%$ \\
\hline Maryland & $6,052,177$ & 702,647 & $12 \%$ & 837,918 & $-\$ 717.10$ & $-0.10 \%$ & $-0.44 \%$ \\
\hline Ohio & $11,658,609$ & $2,889,914$ & $25 \%$ & $1,523,761$ & $-\$ 423.30$ & $-0.12 \%$ & $-0.42 \%$ \\
\hline New Mexico & $2,088,070$ & 123,456 & $6 \%$ & 281,932 & $-\$ 140.70$ & $-0.06 \%$ & $-0.22 \%$ \\
\hline Oklahoma & $3,930,864$ & 456,042 & $12 \%$ & 545,596 & $-\$ 183.50$ & $-0.05 \%$ & $-0.18 \%$ \\
\hline Missouri & $6,113,532$ & 531,997 & $9 \%$ & 820,863 & $-\$ 121.00$ & $-0.04 \%$ & $-0.18 \%$ \\
\hline Montana & $1,050,493$ & 124,097 & $12 \%$ & 135,024 & $-\$ 55.66$ & $-0.04 \%$ & $-0.14 \%$ \\
\hline Wyoming & 579,315 & 59,732 & $10 \%$ & 79,514 & $-\$ 16.31$ & $-0.04 \%$ & $-0.13 \%$ \\
\hline
\end{tabular}

Table 1-9. State Level Population Change - Highest Estimated 25-34 Year-old Population Losses, 2005-2017

\subsection{Conclusion and Policy Implications}

Understanding how the opioid epidemic may be linked to future economic outcomes at the local level is of interest to policy-makers and others. Importantly, those places already experiencing economic distress may be vulnerable to the opioid epidemic. Thus, we use a model to isolate the effect on population change due to opioid overdose deaths that controls for other factors that affect population change, uses lags to control for endogeneity, county fixed effects to control for time invariant local factors, and state-year fixed effects to control for time-varying policies and other factors. We also utilize a special tabulation of county-level data on opioid deaths that provides additional detail on the small counties which may be masked by data suppression in the publicly-available data. 
Our results suggest the places with high and sustained overdose death rates are experiencing population losses, especially among younger adult populations, aged between 25 and 34 years old. For this group, the losses are striking - in the presence of high death rates, these populations are expected to decrease by $1.6 \%$. These results have significant negative implications for counties with high overdose death rates, implications that would seemingly make the case for greatly expanded treatment and prevention programs, and for investments in programs that address the underlying economic and sociologic conditions that may contribute to high overdose death rates. For example, three of the top ten counties in terms of 25-34 yearold population loss due to the epidemic are in West Virginia, all in a region hard hit by the decline of the coal industry. The conservatively estimated cost to West Virginia due to population loss is over $\$ 317,000,000$ in the period from $2005-2017$. Our estimates suggest that a loss of $0.3 \%$ in population due to the opioid crisis in West Virginia\%, by aggregating forecasted population losses across the state, compared against total population loss of $0.7 \%$ in 2016-2017, according to US Census data.

For distressed regions, retaining highly-skilled younger workers appears to be linked to future economic vitality. Especially in rural places, the loss of youth (the export of people) is already a critical problem for the long-term health and sustainability of these communities. If high overdose deaths are contributing to their decisions to leave a place, then it is even more important to address the epidemic due to its multiplier effect on the future of the impacted communities. As noted in previous research, the answers for how to address economic issues in rural counties are as diverse as the people and places within them. Taking this into account, some policy suggestions are still evident. Notably, taking steps to ensure the retention and long-term stability of jobs and approaches to improve labor force participation seem to address both sides of this crisis - the "despair" of living in a place with no prospects, which also is likely to lead to reduced drug use. Second, concurrent investments in drug treatment and recovery efforts are an obvious response, and one that is already receiving attention from policy-makers. Our results are focused on death rates and their leading impacts on future population loss, and suggest that even marginal improvements in overdose death rates could have significant positive impacts on preventing population loss. 


\section{Water Contamination and Population Change: A Tipping Point in Distressed Communities?}

\subsection{Introduction}

Industrial accidents can permanently or temporarily cause environmental damage which may affect human health. In some regions, where economic conditions are already stagnant or in decline, an industrial accident may be the final straw leading residents to seek out new opportunities elsewhere, leading to outmigration and population loss.

One major industrial accident took place on January 9, 2014, when a storage tank, owned by Freedom Industries, ruptured, spilling approximately 10,000 gallons of 4-

methylcyclohexanemethanol (MCHM) into the Elk River, near Charleston, West Virginia (WV). This event is referred to locally as the Elk River Spill or the Freedom Industries Spill. The Elk River is the sole source of water utilized by West Virginia American Water (WVAW), the regional water company, to supply water to 300,000 residents in nine counties in the region (Whelton et al., 2014; Rosen et al., 2014). The effects of the spill were acute; a persistent licorice smell accompanied the water and symptoms of exposure included nausea, rash, vomiting, abdominal pain, headache, eye pain, and cough (Thomasson et al., 2017). Residents were ordered not to use the water for anything other than toilet flushing, and drinking bans lasted until January 18 , 2014, nine days after the spill occurred. In the two weeks after the spill (through January 23 , 2014), more than 2,000 people called the poison control center reporting exposure and more than 600 visited emergency rooms with reports of exposure and symptoms.

Recognizing the regional significance of this event, we examine the population impacts of this large-scale, but relatively short-duration, water contamination event. We also estimate what these population changes may mean economically in an area with declining economic fortunes and population retention concerns. Policy-makers and regulators may find it extremely valuable to have estimates of the economic impacts, especially when examined in comparison to both the regulatory costs, which could act as preventative measures to future incidents, and the punitive fines and settlements as reactionary measures. In other words, what is it worth to regulate or punish.

While the duration of the spill was relatively short, the economic and social costs were significant. A preliminary study by the Marshall University Center for Business Research 
estimated that the spill cost Charleston-area businesses more than $\$ 61$ million in the first month after the spill (Marshall, 2014). However, the loss of confidence in public institutions may be more significant. As noted by the National Institutes of Health (Manuel, 2014, page 2), "public faith was sorely tested by what was ... perceived as inaccurate, conflicting, and in some cases nonexistent communications from officials". As a result, the Elk River spill gained a reputation of "what not to do" in terms of risk communication, and brought critical scrutiny to how the West Virginia Department of Environmental Protection (WVDEP) conducted inspections and also raised questions about what responsibility the water provider, WVAW, had for distributing contaminated water to its customers.

In the aftermath, Freedom Industries was fined $\$ 900,000$ for the incident, but declared bankruptcy eight days after the trial (Mistich, 2016). The president and owner of the company were each sentenced to 30 days in jail and $\$ 20,000$ fines. All told, Freedom Industries was fined approximately $\$ 1$ million for its role in the spill. However, only approximately $\$ 40,000$ of those fines were paid. An additional class-action suit on behalf of at least 224,000 residents and 7,300 business owners for $\$ 151$ million was later settled in November 2016, but payments were not made to impacted residents until September 2018. Under that settlement, WVAW will pay up to $\$ 126$ million, and chemical distributor Eastman Chemical, who manufactures MCHM, will pay $\$ 25$ million (Good v. American Water Works Company, 2016). While as of January 2019 , these settlements had been paid, they resulted in only approximately $\$ 440$ per claim.

Our results show that this disaster had a significant effect on population loss in the counties most impacted by the spill, and therefore a significant forecasted economic impact in the region. We estimate that the long term impacts of population loss are likely more significant to the economic health of the region, and represent a larger economic loss than was levied in fines and settlements. Further, the counties most impacted represent a wide cross-section of economic and demographic diversity, strengthening our conclusion that these impacts are related to this incident, and not to other regional economic trends.

The impacted area, entirely contained in WV, is an area that has struggled for years with declines in both economic opportunity and quality of life factors (Meit et al., 2017). Notable to this is the closure of mines and the loss of mining and related jobs (Partridge et al., 2018). Additionally, this area has low work force participation rates (Stephens and Deskins, 2018), 
health outcomes that are at or near the worst in the US (Dwyer-Lindgren et al., 2017), and has been hard hit by the opioid crisis (Council of Economic Advisors report, 2017).

To estimate the impact, we first had to isolate which populations were actually affected by the spill. While WVAW is a large water service provider, servicing more than 550,000 customers in 11 counties, only a portion of its service area was affected. A map indicating the impacted area (and the nine counties surrounding Charleston) as defined by a class-action suit (Good v. American Water Works Company) is shown in Figure 2-1. In some of these affected counties, WVAW only services a small portion of its population. For example, while officially listed as one of the nine counties affected, Cabell County was relatively unaffected by the spill (Johnson, 2014) because the area impacted only serves about 5,000 residents out of the 96,000 residents in the county. Similarly, many residents in Putnam and Lincoln Counties had access to water from other, non-WVAW local water systems, and thus were relatively unaffected by the contamination. Our investigation takes advantage of this variation to better identify the true impacts of this spill, reflected by impacts in counties that had significantly affected water networks, versus those with lesser effects.

An additional complication is that determining the impact of the spill is tricky because of the small number of counties, thus many traditional empirical techniques are difficult to implement. To address this, we use the synthetic control method (Abadie et al., 2010) (SCM) to establish a baseline projection of population change for the nine counties that were directly impacted by water contamination. SCM allows us to construct a counterfactual based on the weighted average of comparison control counties with similar properties (Munasib and Rickman, 2015). We also use randomization or "placebo" tests to test the robustness of our results. 


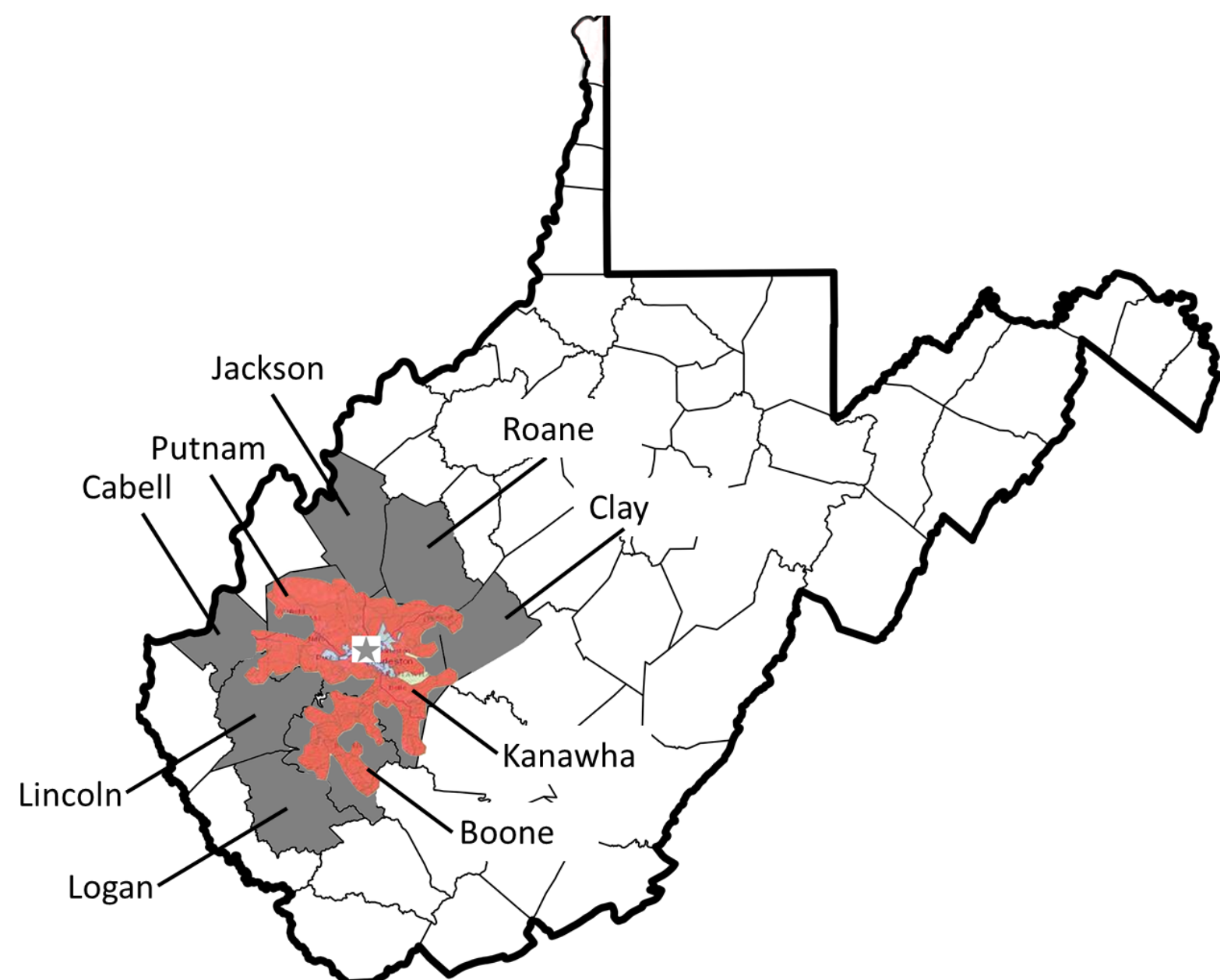

Figure 2-1. Affected Area of Elk River/Freedom Industries Spill Shown in Red. Star indicates source of the spill. Source wvwaterclaims.com

Several potential confounding factors also could be contributing to population changes during this period, including the significant decline in coal production, and its associated businesses as shown in Figure 2-2 which illustrates US and West Virginia coal production by year, with 2014 highlighted. Additionally, this region faced increases in opioid abuse and overdoses during this period. And, finally, there is the potential identification issue that all of the counties are located in West Virginia. To address these issues, in sensitivity analysis, we compare our treated counties to synthetic controls comprised of several other groups of potential donor counties. First, we compare them to other counties that are heavily dependent on coal for their economic base. We also perform a separate set of analyses using other counties in the Appalachian Regional Commission (ARC) region as our donor pool. The ARC region was designated by the U.S. government in the 1960s due to its persistent poverty and economic distress (Stephens and Partridge, 2011) and all of the nine counties affected by the spill are included in this region. 
Thus, other ARC counties should also provide a counterfactual that controls for historic and regional differences.

In what follows, we highlight the relevant background information and prior research. We next discuss our empirical approach and the data used in our analysis. We then present and examine the results. Finally, we conclude with a discussion of the economic impacts of our findings and their implications for future policy.

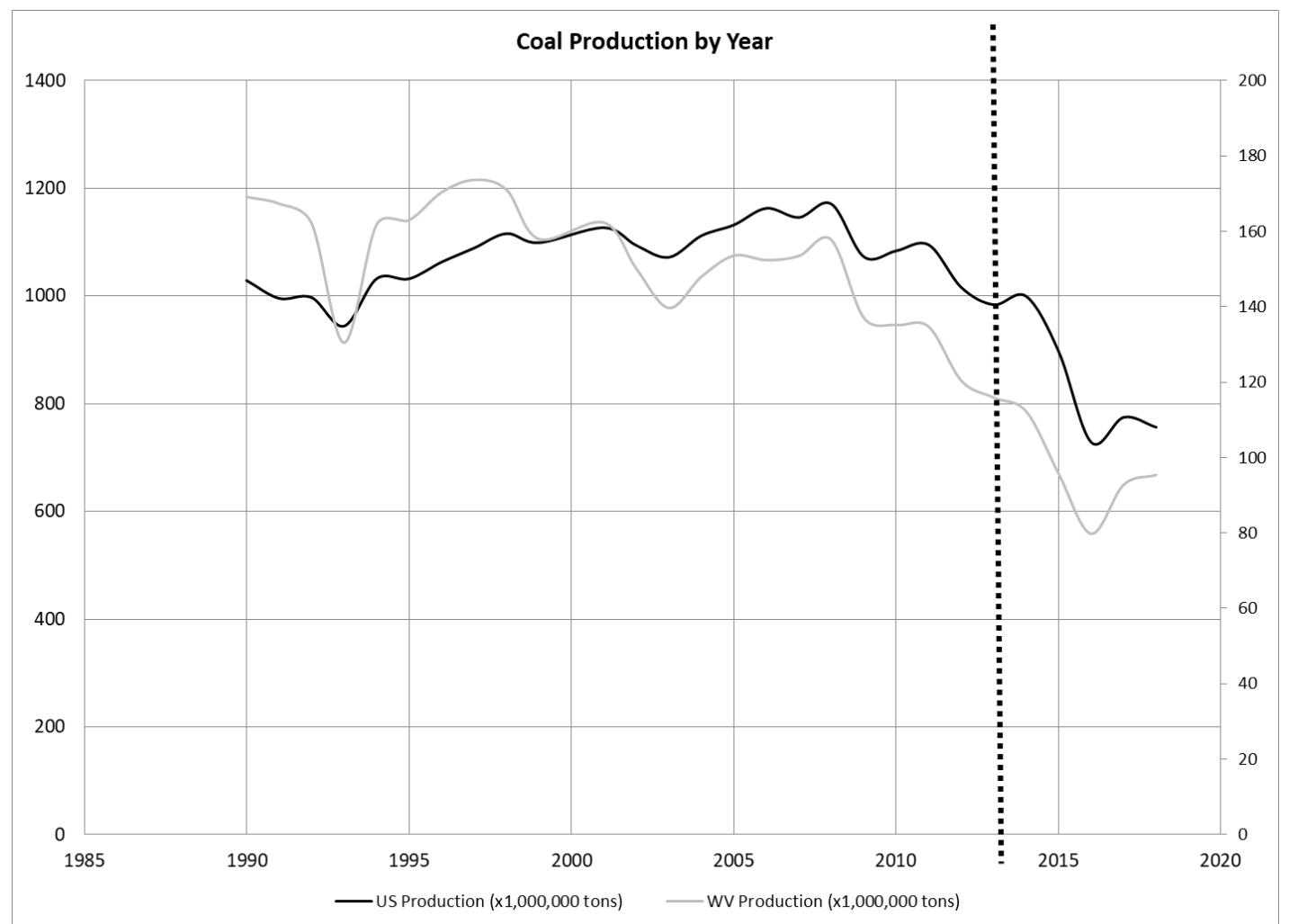

Figure 2-2. US and WV Coal Production by Year. Dotted Line for 2014.

\subsection{Background}

A relatively large body of research exists on the impact of major natural disasters and war on population changes or loss. In the discussions of population changes, it is useful to divide these changes in two distinct categories. The first type of population change is driven by normal, or "natural" changes in a person's life, such as having a family, or graduation from college and relocating for a career. In contrast to these "natural" population changes, "structural" population changes are caused by external events, such as a natural disaster or war. These natural and 
structural changes may often have opposite effects on population changes, leading to impacts whose ultimate cause can be difficult to identify (Jackson and Schaeffer, 2017).

In the cases of both natural disasters and war, population changes and migration can often be conceived of as simple movement to the next "safe place." In the natural disaster literature, examinations of Hurricanes Katrina (Fussell et al., 2009; Groen and Myers et al., 2008; Polivka, 2010) and Iniki (Coffman and Noy, 2011) find significant population losses as a result of these disasters, and that the effects are long-term; in other words, populations have not returned to pre-disaster levels more than 10 years after these storms. Cavallo et al. (2013) consider other large scale disasters, including earthquakes, and find that national-level impacts of these storms are more muted, but may precipitate political change or conflict that can have massive national impacts in certain cases. Boustan et al. (2012) examine the impacts of natural disasters on gross migration, focusing on impacts from 1920 to 1930 in "tornado alley," in the Great Plains of the United States (US), finding larger effects on deterring potential in-migrants than on motivating existing residents to out-migrate. Finally, there is a literature showing significant, negative, impacts on population from "slow" environmental disasters, such as drought (Findley, 1994) or sea-level rise (Hauer, 2017).

Examining war specifically, Abadie and Gardeazabal (2003) find significant decreases in population as a result of the Basque Civil War in Spain in the 1960s. More recently, the Syrian Civil War also led to population loss and migration (Yazgan et al., 2015). Relative to our investigation, these studies provide some projection that disasters can lead to large localized changes, including population losses.

Given the findings of research on natural disasters, the research on man-made disasters is more conflicted. In examining the Union Carbide disaster that killed an estimated 3,700 people in Bhopal, India, Dhara and Dhara (2002) find that population impacts were minimal after the disaster. More recently, Flint, Michigan's water contamination by lead occurred after many years of de-population in the city; and as Morckel and Rybarczyk (2018) show, while the health impacts of the contamination were significant, the effect on population change is unclear. Conversely, the Fukushima nuclear disaster after the 2011 earthquake and tsunami in Japan, has led to significant population loss in the city nearest the plant (Minamisoma, Japan), despite assurances from government officials that the area is safe for return. Horie et al. (2017) find that residents impacted by Fukushima may have been even more willing to leave the region if 
clear information about the specific risk levels in their area were readily available to them, especially when compared to the new area to which they were thinking of moving. Closest to the current study is Guilfoos et al. (2017), which examines per capita GDP and birth weight for the Charleston, WV, Metropolitan area following the Elk River Spill (or Freedom Industries Spill). While that study does not find statistically significant economic impacts, the study was performed relatively quickly after the accident, only looked at outcomes through 2015 , and only included pre-treatment data starting in 2009; thus more research may be needed.

The elements of distress and distrust are important to our research. Schade et al. (2016) describe how the Elk River Spill led to psychological distress and resulted in widespread distrust of government officials and the public water system in the impacted region. Examining a significant water pollution event in Martin County, Kentucky, Scott et al. (2012) observe that residents expressed a desire to live elsewhere, and a distrust of governmental officials and regulatory agencies. These results suggest that these types of events may result in residents choosing to relocate, particularly if public trust is eroded in the ability of regulatory agencies and officials to prevent or adequately respond to future events.

When viewed through the lens of an environmental shock, incidents such as this will likely cause residents to reevaluate their options in a way that they otherwise would not. While the costs related to relocating are substantial, these costs are a type of "self-investment" in a resident's human capital (Greenwood, 1985; Kennan and Walker, 2011). As described by Schultz (1961), these costs are more easily and readily borne by younger people - the personal costs are lower, and the years to recoup the investment are longer.

The factors that might incentivize a migration decision are diverse. Perhaps the most significant contributor for movement and residence choices is opportunity (Burns and Hotchkiss, 2019; Chetty and Hendren I and II, 2016; Davis and Haltiwanger, 2014; Dao et al., 2017; Kennan and Walker 2011; Knapp and White, 2016; Rodgers and Rodgers, 1997; Weber et al., 2007; Wilson, 2017; Wozniak, 2010; Yankow, 2003). For example, Chetty and Hendren II (2016) find that moving to better neighborhoods early in life has a significant positive impact on lifetime outcomes for the children that have relocated, and that simply growing up in a "better" county could lead to an increase in income by $10 \%$ over a lifetime. For places with historically poor economic and social outcomes, such as those in the Appalachian region, this would suggest that relocating is a highly rational choice for residents of those places. In this framework, these 
choices are tempered by other direct and indirect factors - notably, that in many cases "better" counties and cities also have higher costs of living and more competitive housing and employment markets.

Related to this is a large body of work examining the impacts of poverty on migration in the US and globally. This is relevant for this study since the ARC region was designated due to its persistent poverty. In general, the impact of poverty on migration decisions is straightforward. People move to places with higher opportunity from places with lower opportunity. This intuitive finding is complicated for people most impacted by poverty - if they lack the resources, they cannot make an expensive decision to move (Winters, 2004). Frey et al. (1996) find the strongest incentives for a poor resident population to relocate are driven by effects of labor market competition. If the competition for jobs is high, a person is more likely to choose to relocate. The impacts in rural places are also more complicated, and reflect tradeoffs between moving from places with lower-costs of living, and higher levels of social connectivity to more expensive places with higher opportunity (Weber et al., 2005).

A second significant external factor that would impact a migration decision is the presence of natural amenities, either in the place of current residence, or in the potential target new residence (Deller et al., 2001; McGranahan, 2008; Partridge, 2010; Partridge et al., 2017; Wasson et al., 2013). Of further relevance to this study, this effect is reversed in places with a damaged environmental reputation. Brasington and Hite (2005) find that proximity to polluted sites decreases housing values, and that people with higher incomes and higher education levels demand higher environmental quality. Thus, in the face of environmental degradation, they might leave.

Other conditions about a region may also affect the choice to migration. For example, recent research finds that the opioid epidemic may have disproportionate impacts on population change, particularly among younger populations (Taylor, 2020). Other research shows that the opioid epidemic has had significant impacts on rural counties and small cities when compared to larger cities (Keyes et al., 2014; Monnat and Rigg, 2018). Recent research also finds strong relationships between lower population density (rurality), lower educational attainment, higher unemployment and lower incomes and increasing overdose death rates (Boardman et al., 2001; Case and Deaton, 2017; Cerda et al., 2017; Goetz and Davlasheridze, 2018; Rossen et al., 
2009; Song, 2017). All of these factors are known to have impacts on migration decisions and population changes.

This, then, presents a dangerous situation for a local economic development planner or policymaker in an area faced with one of these shocks, particularly if the region is already facing economic difficulties or other social headwinds. If residents take the opportunity to examine whether other, more favorable options might exist, it becomes more likely that they will decide the benefits of relocating outweigh the costs, leading to a population loss in the impacted community.

\subsection{Theoretical Framework}

Population change and migration dynamics are complex topics, with conflicting theories for change and expected impacts. While human capital models can provide insights into labor economics (individual labor market decisions), they do not provide the same explanatory power for population changes (Greenwood, 1997). As described in the literature review above, there are multiple facets affecting these decisions, ranging from economic and cost of living considerations to family (Mincer, 1978) and natural amenities desires (McGranahan, 1999 \& 2010) - and often these forces are at odds with each other. Focusing more specifically on the impacts of disasters, Cavallo et al. (2013) note that classical growth theories do not provide clear answers on whether natural disasters impact on economic growth. Traditional models predict that capital destruction should not affect technological progress and that disasters may provide a catalyst for reinvestment (Caballero and Hammour, 1991 and 1996; Metcalfe, 1998). By contrast, other endogenous growth models predict that destruction of physical or human capital results in a lower growth path (Aghion et al., 1998). The literature examining structural migrations such as war or disasters is relatively young. De Hass (2010) finds that large scale events, such as war or disaster, often provide the initial "push" for population changes, and then more classical economic factors take over and define the persistence of those changes. Ruiz and Vargas-Silva (2013) define a utility style framework for discussing the impact of displacement on the new community, but find that there is still a need for more studies on the impacts to communities of origin - precisely the impact we wish to study.

In a related literature, the theoretical impact of environmental factors on migration is reasonably well established (Hunter, 2005; Dejong and Fawcett, 1981; Lee, 1966). Based on utility maximization, these frameworks provide perhaps the simplest way to think about these highly 
complex decisions. Simply defined, households are expected to maximize the value (or utility) of their location, and make decisions about whether to stay or leave based on which outcome provides the highest level of utility. Based on other research that suggests that individuals express preferences for natural or community amenities, an environmental or natural disaster could be considered a utility reducing "disamenity" (Brasington and Hite, 2005; Deller et al., 2001; McGranahan, 2008; Partridge, 2010; Partridge et al., 2017; Wasson et al., 2013). This provides a theoretical mechanism where an environmental concern can provide the initial force, similar to a natural disaster or war, for a migration decision.

\subsection{Data}

Our data set includes the counties in the 48 contiguous US during the period 1990 to 2017 . Our "treated" counties are the nine counties either entirely or partially affected by the Elk River spill, all within WV.

To measure the effect of contamination on population changes, we use data on county population to construct the population ratio for each county, calculated as the ratio of the current population in that county to its population in the first year of the study, 1990, which provides a measure of the change in population in that county. We use the population ratio because it allows for comparison between counties with different population levels.

The synthetic control method (SCM - further described below) is used to construct a synthetic control county for each treated county. The predictors we use to construct the synthetic control counties are selected based on factors that have been found to impact population change and migration in the prior literature (e.g., Betz et al., 2015; Chetty and Hendren, 2016; Darchen and Tremblay, 2010; Dao et al., 2017; Faggian and Franklin, 2014; Frenkel et al. 2013; Glaeser et al., 1995; Johnson et al., 2015; Kaplan and Schulhofer-Wohl, 2017; Kennan and Walker 2011; Kelchen and Webber, 2018; Mills and Hazarika, 2001; Molloy et al., 2017; Partridge et al., 2012; Partridge and Tsvetkova, 2018).

From the US Census, we use information on the population, population density, gender and age compositions in each county (US Census, SEER, 2019). As a measure of urbanization, we also include the distance to the nearest Core-Based Statistical Area (CBSA) (using the 2013 definition). From the US Bureau of Economic Analysis (BEA), we use data to quantify the economic status and health of a county, including per capita income and disability receipts (US 
BEA, 2019). Controlling for disability is important because Partridge et al. (2012) find that disability can negatively affect mobility and the impacted region has some of the highest disability rates in the country (Census, 2017). Other data include those on education, natural amenities, and social cohesion within a county. We control for educational attainment using data from the US Department of Agriculture - Economic Research Service (USDA-ERS). Previous research finds connections between increasing educational attainment and positive economic development, particularly for places with higher levels of college graduates (Faggian and Franklin, 2014; Glaeser et al., 1995; Partridge et al., 2005; Shapiro, 2005; Simon et al., 2002). At the same time, workers are attracted to places with higher employment stability and a more educated populace (Betz et al., 2015; Frey, 1995).

We use the raw natural amenities score as developed by McGranahan at USDA-ERS (1999) to control for the natural environment. A related literature examines the choices that workers make in the tradeoff of quality of place versus career opportunities. In general, this literature finds that high-skilled workers are attracted to places with a higher quality of life, including better access to leisure and cultural activities, particularly once they have established their careers (Dahl and Sorenson, 2006; Darchen and Tremblay, 2010; Florida, 2000; Gyourko et al., 1997; Shapiro 2005). Further, proximity to work, and to daily needs such as shopping are strong predictors of location choice for high-skilled workers, particularly when combined with considerations for housing affordability (Frenkel et al., 2013; Lawton, 2013). Based on these findings, we utilize the social capital index as a measure for "goodness" of community, as developed by Rupasingha et al. (2006).

Historically, industry composition and changes in employment, unemployment and labor force participation have been associated with population change (Betz and Partridge, 2012; Frey, 2017; Ganong and Shoag, 2017; Hansen et al., 2003; Hyatt et al., 2018; Weber et al., 2005). Further, recent work by Bondonio (2018) finds that natural disasters in the US can lead to lower employment growth - and that the impacts are more dramatic and longer lasting for counties that have lower incomes and higher unemployment before the disaster. For this particular study area, all of the study counties are contained in southwestern West Virginia, an area that has been adversely impacted by lower demand for coal for power generation, and accompanying labor disruptions. While coal employment is a relatively low component of the overall region's employment, it is unevenly distributed, ranging from $0 \%$ to more than $20 \%$ of total employment in the treated counties. Thus, coal mining employment may have an impact on economic 
outcomes in this area. Figure 2-3 illustrates summary information on coal employment for the state of West Virginia and for the impacted region in aggregate.
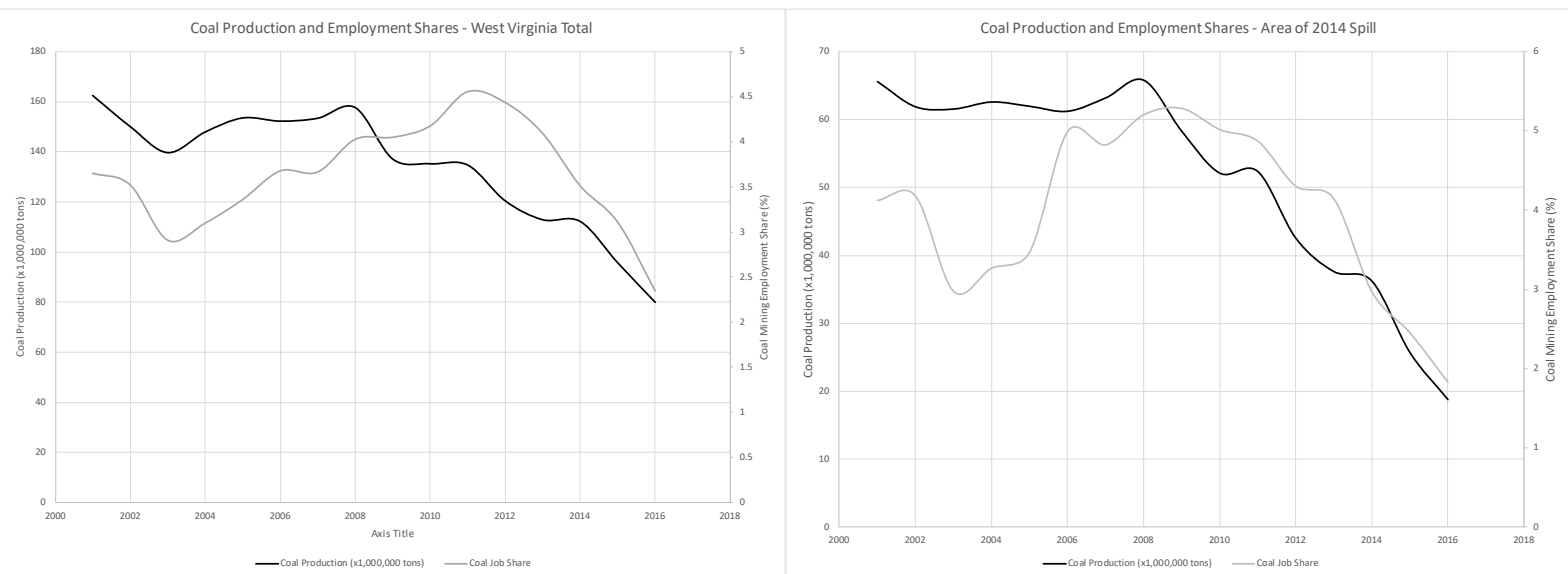

Figure 2-3. Coal Production and Employment for West Virginia (left) and spill impacted area (right), 2001-2014.

We use both Standard Industrial Classifications (SIC) data and North American Industry Classification System (NAICS) data to construct variables to control for industry composition and specific industry wage information. The SIC data from 1990 to 2000 are from the BEA, and the NAICS data from 2001 to 20017 are from EMSI, Inc. (which provides unsuppressed detailed county-level data on industry employment at the four-digit NAICS industry code level). Since the categories are not directly comparable, we construct a crosswalk between them. To control for other economic factors, we use data on unemployment rates and labor force participation rates from the US Bureau of Labor Statistics. This is important as counties in WV have some of the lowest levels of labor force participation (Stephens and Deskins, 2018).

Data from the U.S. Centers for Disease Control (CDC) show there are higher rates of overdose death in the Appalachian region and other parts of the industrial eastern US, and recent research suggests that high overdose rates may contribute to higher rates of migration, particularly for younger populations (Taylor, 2020). Thus, we control for opioid overdose death rates using data obtained via a special request from the CDC. ${ }^{3}$

\footnotetext{
${ }^{3}$ The data used were obtained from via a special request since the publicly available data are top-coded, and mask the tremendous variation in rates at the higher levels. The data come from the WISQARS system, the Web-based Injury Statistics Query and Reporting System. This database provides fatal and non-fatal injury, violent death, and cost of injury data.
} 
Table 2-1 lists all of the variables used in this study and provides a brief description of the data set. Table 2-2 includes summary statistics of our key variables for each of the counties potentially affected by the Elk River Spill.

Variable Name

Total Population (persons)

Unemployment Rate (\%)

Per Capita Income (\$)

\% Population with High School Degree or Some College

\% Population with Bachelors Degree or Higher

Per Capita Disability Receipts (\$)

Population Density (person/sq mi)

Job Shares (\%)

Labor Force Participation Rate (\%)

Age Shares (\%)

Gender Share (\%)

Social Capital Score

Natural Amenity Score

MCHM Impacted County

Opioid Death Category

Distance to Core Business Statistical Area

\section{Description}

Total population by county, by year.

Uses Census/SEER Data. 1990-2017

Unemployment rate by county, by year.

From BLS Data 1990-2017

Per Capita income by county, by year.

From BEA Data. 1990-2017

$\%$ of Population with a High School Diploma up to a Bachelors Degree, All Ages. Decennial Census Data 1990, 2000, Annual Data 2009-2017 from USDA-ERS

$\%$ of Population with a Bachelors Degree or Higher, All Ages. Decennial Census Data 1990, 2000, Annual Data 2009-2017 from USDA-ERS

Per Capita Disability receipts by county, by year. \$/Person. From BEA Data. 1990-2017

Number of Persons/Square Mile. Land Area from US Census Data

Derived from SIC and NAICS codes. Developed a 10-Category "Crosswalk" Set of Codes to Allow Comparison Across Years. NAICS codes replaced SIC codes in 1997. County level data on fraction of employment in each industry sector.

Labor Force Participation Rate. From BLS Data. 1990-2017

Percent of Population from ages 0-44 years old. From Census data. 1990-2017

Percent of Population that is female. From Census data. 1990-2017

Index from Penn State. Between 0 and 1. Treated as a continuous variable (not indicator). 2009 and 2014 data.

USDA-ERA Natural Amenities Score. Raw Z-Score Used.

Utilize literature (Multiple Sources) to identify MCHM effected counties in WV

Categorical variables for overdose death rates, in deaths per 100,000 population. Category 1 (Zero): 0 Deaths/100,000 in a given year

Category 2 (Low): $0<$ Death Rate $\leq 12$

Category 3 (Medium): $12<$ Death Rate $\leq 20$

Category 4 (High): $20<$ Death Rate $\leq 40$

Category 5 (Very High): Death Rate $>40$ Deaths/100,000 in a given year

Distance, in kilometers, from study county to nearest CBSA designated county.

Table 2-1. Data Summary Table 


\begin{tabular}{|c|c|c|c|c|c|c|c|c|c|}
\hline & Boone & Cabell & Clay & Jackson & Kanawha & Lincoln & Logan & Putnam & Roane \\
\hline VARIABLES & FIPS 54005 & FIPS 54011 & FIPS 54015 & FIPS 54035 & FIPS 54039 & FIPS 54043 & FIPS 54045 & FIPS 54079 & FIPS 54087 \\
\hline Total Population & 25,048 & 96,549 & 9,758 & 28,125 & 197,354 & 21,754 & 37,900 & 52,193 & 15,034 \\
\hline $\begin{array}{l}\text { Unemployment Rate } \\
\qquad(\%)\end{array}$ & 8.949 & 5.937 & 11.63 & 7.865 & 5.743 & 10.12 & 9.408 & 5.667 & 11.14 \\
\hline $\begin{array}{l}\text { Per Capita Income } \\
\text { (\$) }\end{array}$ & 22,594 & 27,465 & 18,496 & 23,244 & 31,845 & 18,859 & 23,808 & 29,189 & 20,480 \\
\hline $\begin{array}{l}\text { High School/Some College } \\
\qquad(\%)\end{array}$ & 48.55 & 47.14 & 46.46 & 50.17 & 47.98 & 46.07 & 49.63 & 48.29 & 49.15 \\
\hline $\begin{array}{c}\text { Bachelors or Higher } \\
\text { (\%) }\end{array}$ & 5.982 & 16.92 & 6.081 & 10.76 & 17.11 & 5.645 & 6.460 & 16.12 & 7.012 \\
\hline $\begin{array}{c}\text { Per Capita } \\
\text { Disability Receipts } \\
\text { (\$) }\end{array}$ & 467.8 & 495.0 & 313.4 & 236.0 & 369.9 & 380.6 & 586.9 & 360.6 & 170.9 \\
\hline $\begin{array}{l}\text { Population Density } \\
\text { (persons/sq mi) }\end{array}$ & 50.14 & 343.8 & 28.65 & 60.50 & 219.5 & 49.85 & 83.93 & 150.5 & 31.17 \\
\hline $\begin{array}{c}\text { Share Jobs } 2121 \\
\text { (Coal Mining) } \\
(\%)\end{array}$ & 20.10 & 0.000338 & 7.885 & 0 & 0.774 & 0.123 & 6.644 & 0.00221 & 0 \\
\hline $\begin{array}{c}\text { Share Jobs } 800 \\
\text { (Finance and Real Estate) } \\
(\%)\end{array}$ & 2.266 & 4.187 & 1.781 & 3.827 & 6.237 & 1.561 & 2.258 & 4.685 & 4.174 \\
\hline $\begin{array}{c}\text { Share Jobs } 900 \\
\text { (Services, Health Care, } \\
\text { Education) } \\
(\%)\end{array}$ & 23.00 & 45.80 & 28.83 & 31.90 & 43.40 & 28.53 & 34.37 & 31.37 & 29.57 \\
\hline $\begin{array}{c}\text { Share Jobs } 999 \\
\text { (Government) } \\
(\%)\end{array}$ & 21.38 & 14.75 & 29.76 & 17.08 & 19.49 & 28.00 & 18.88 & 12.27 & 19.21 \\
\hline $\begin{array}{l}\text { Labor Force Participation } \\
\qquad(\%)\end{array}$ & 53.10 & 66.98 & 55.60 & 67.47 & 73.26 & 52.27 & 52.11 & 73.26 & 58.75 \\
\hline Percent Population & & & & & & & & & \\
\hline $\begin{array}{c}\text { Below } 44 \\
(\%)\end{array}$ & 59.02 & 59.68 & 59.33 & 57.30 & 56.52 & 59.65 & 58.09 & 60.45 & 56.21 \\
\hline Percent Population & & & & & & & & & \\
\hline $\begin{array}{c}\text { Female } \\
(\%)\end{array}$ & 50.41 & 51.47 & 50.07 & 50.72 & 51.99 & 50.34 & 50.80 & 50.86 & 50.53 \\
\hline Social Capitol & -0.916 & -0.185 & -0.952 & -0.237 & 0.320 & -1.056 & -0.799 & -0.392 & -0.836 \\
\hline Natural Amenity Score & -1.900 & 0.110 & -0.510 & -0.0800 & -0.120 & -1.050 & -1.030 & -0.430 & -1.660 \\
\hline Distance to CBSA & 0 & 0 & 0 & 29.82 & 0 & 0 & 31.35 & 0 & 33.83 \\
\hline Opiate Score & 4.769 & 4.846 & 2.385 & 2.846 & 4.385 & 4.385 & 5 & 3.077 & 2.615 \\
\hline
\end{tabular}

Table 2-2. Summary Statistics of Nine-County Study Region in WV 


\subsection{Methodology}

In order to estimate the impact of the Elk River Spill on the affected region, we use the synthetic control methodology (SCM) (Abadie et al., 2003, 2010). This methodology allows us to consider the impact on the nine counties (in other words, where only a few observations are treated) which is incompatible with traditional regression and related methods. After matching on pretreatment variables we are able to compare the population ratio in the spill-affected counties to their synthetic matches (further explained below). A comparison of the counterfactual and the actual outcome provides an estimate of what population impacts have occurred as a result of this large scale water pollution incident. We estimate the impact on each county separately, and then aggregate these results to provide a broader picture of the impact on the entire affected region.

Relevant to our research, the SCM has been used in other papers to assess the impact of large scale natural disasters (Cavallo et al.,2013; Coffman and Noy, 2011). Additionally, the SCM has been used in other county-level investigations including an examination of the economic impacts of the shale gas and tight oil boom (Munasib and Rickman, 2015) and a study on the impact on birthweights and gross domestic product (GDP) of Kanawha County, WV, after the same Elk River Spill (Guilfoos et al., 2017). Robbins et al. (2016), like this study, also use the approach for a relatively small number of sub-state areas. These studies provide some inspiration for our approach.

In general, synthetic control methods are best used when evaluating the effect of an intervention or event and combine difference-in-difference and matching techniques. SCM uses a databased procedure to calculate weights assigned to each control observation based on preintervention characteristics. This makes clear the contribution of each control unit to the total counterfactual. Additionally, SCM methods can help minimize uncertainty about the effect when there is a relatively small set of "treated" observations (i.e. counties), especially when compared to classic difference-in-difference approaches (Bertrand et al., 2004). To further reduce uncertainty in our treatment effect, we apply a randomization (placebo) test which is further described below (Abadie et al., 2010).

The synth code in STATA software, developed by Abadie et al. (2014), is utilized for this analysis. This code is well-established and has been utilized in many studies, but has a limitation in that potential control groups larger than approximately 1,500 control units (in our 
case, counties) cause the software to crash. To avoid this situation, we use a pool of 1,400 potential control counties in our analysis. To select the 1,400 counties, we use a "nearest neighbor" matching technique, matching our affected counties to their 1,400 closest matches on population density, per-capita incomes, disability receipts, unemployment and labor force participation rates, educational attainment, age composition, gender composition and industry composition in $1990,2000,2005$, and 2010 . As a robustness check, and to help ensure that our results are not biased by the selection of potential control counties, a second group of 1,400 randomly selected counties was also used for a second set of synthetic controls. In both cases, we restrict the donor pool to eliminate any treated counties or any counties within 25-miles of a treated county. Additionally, several counties in Louisiana experienced large population changes as a result of being impacted by Hurricane Katrina in 2005. Given the overlap of our study period, we also exclude counties from Louisiana from our pool of potential control counties.

Next, using our pool of 1,400 potential control counties, we develop synthetic control counterfactuals. The literature notes the importance of lagged values of the outcome variable as important predictors for the outcome variable (Abadie and Gardeazabal, 2003; Abadie et al., 2010). In our case, lagged values of raw population are used as predictors. These lagged values include the effects of other variables, even if they are not directly included, and can greatly strengthen the predictive power of the model. As a caution, Kaul et al., (2017) demonstrate that using all of the lagged values for the outcome variable will eliminate the effect of all other predictors, leading to a condition where the same synthetic control state can be created regardless of the other predictors, biasing the synthetic outcome in the post-treatment period. Following these findings, we use every other lag of our key variables. The key variables used to construct the synthetic matches include total population, unemployment rate, per capita income, educational attainment, disability receipts, population density, industry composition (including the share of coal mining), labor force participation, age composition, gender composition, social capital, natural amenity score, distance to the nearest CBSA, and opioid overdose rankings.

We also conduct a number of other robustness checks and sensitivity analysis. We use SCM again with both potential sets of control counties (nearest neighbor and random) where all pretreatment covariates (as defined above) are averaged over the pre-treatment period (from 1990 to the treatment year, 2014), to generate another set of synthetic matches. A sample result for 
Kanawha County, WV, illustrating the different sample pools and model specifications versus the actual changes in population ratio, is shown below in Figure 2-4.

Given the confounding issues of the decline in mining as well as the fact that all of the counties are in WV; we also use the method to compare our treated counties to two other potential groups of counties as an extended placebo test. First, we use other heavily coal dependent counties from the extended region, West Virginia, eastern Kentucky, and southwestern Virginia, plus counties in the top 10 for coal production in 2014, including counties in Montana, New Mexico, Pennsylvania, Illinois and Wyoming. We also run a more restricted set of synthetic controls, where our matching pool is limited only to counties within the Appalachian Regional Commission identified region.

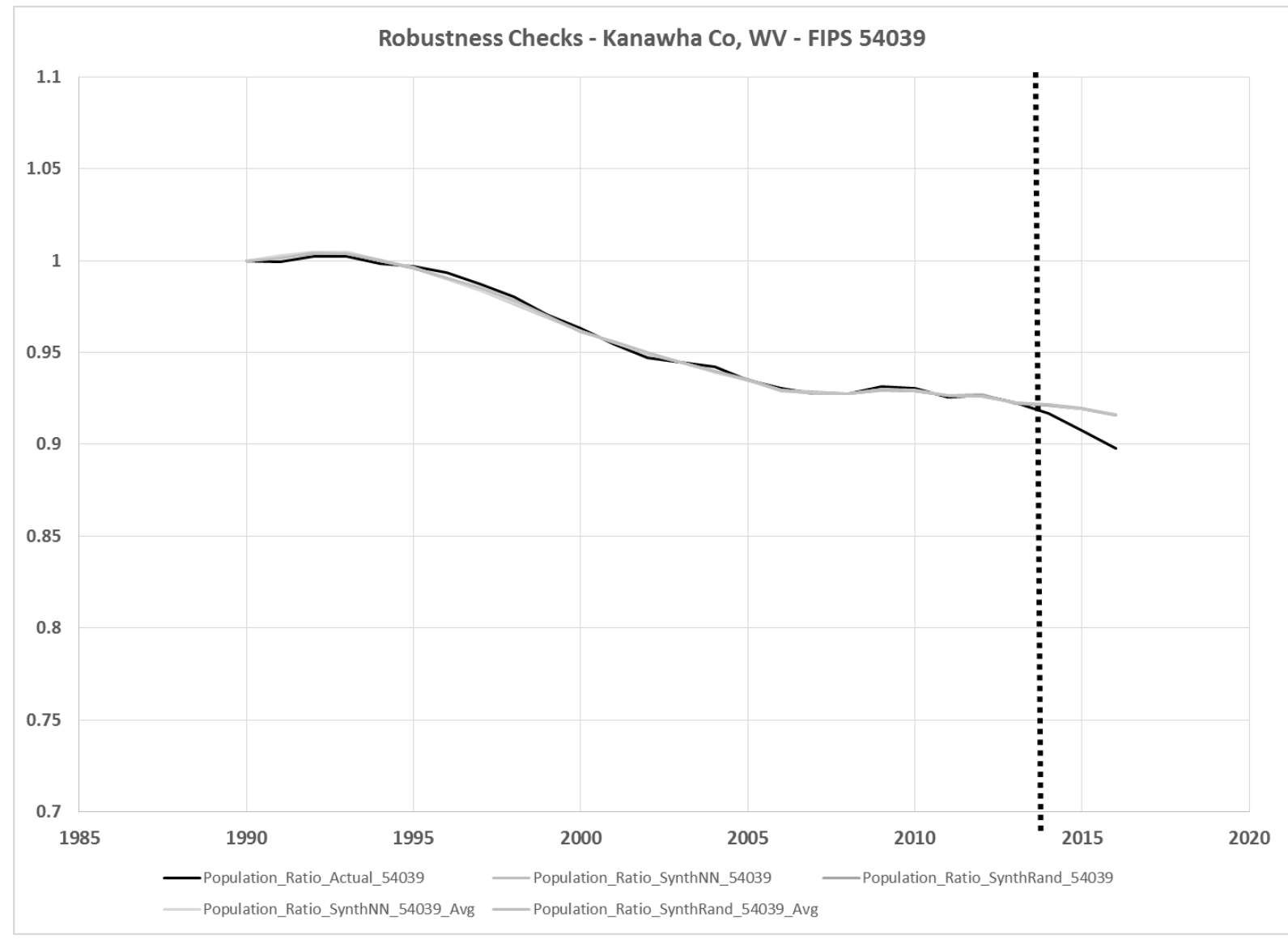

Figure 2-4. Example of Changed Sample Pools and Model Specification on Synthetic County Output.

After generation of the synthetically-controlled matched counties, we perform a difference-indifference calculation, using the technique described by Bohn et al. (2014). 


$$
\Delta_{T R}=\left|\bar{Y}_{T R, a c t u a l}^{\text {Post }}-\bar{Y}_{T R, \text { synthetic }}^{\text {Post }}\right|-\left|\bar{Y}_{T R, \text { actual }}^{\text {Pre }}-\bar{Y}_{T R, \text { synthetic }}^{\text {Pre }}\right|
$$

We first calculate the average of the post-intervention actual outcome of the treatment county $\left(\bar{Y}_{T R, a c t u a l}^{\text {Post }}\right)$ and the post-intervention outcome of the counterfactual (synthetic) $\left(\bar{Y}_{T R, \text { synthetic }}^{\text {Post }}\right)$. Similarly, $\bar{Y}_{T R \text {,actual }}^{\text {Pre }}$ is the average of the pre-intervention actual outcome of the treatment county, and $\bar{Y}_{T R, \text { synthetic }}^{\text {Pre }}$ is the average of the pre-intervention outcome of the counterfactual. As a first result, if $\Delta_{T R}>0$ then we can say that the outcome in a treated county has changed "in response" to the intervention (i.e. water contamination), and can examine those outcomes in more detail.

As a second step, we compare this treatment effect relative to the pre-treatment fit, as measured by the Mean Squared Prediction Error (MSPE), where error is calculated as

$$
e_{i}=Y_{i T R, a c t u a l}^{P r e}-Y_{i T R, \text { synthetic }}^{\text {Pre }}
$$

and MSPE is then calculated as

$$
M S P E=\frac{\sum_{i=1}^{n} e_{i}^{2}}{n}
$$

(Abadie et al. 2015, Abadie et al. 2010)

Finally, utilizing approaches as outlined in the literature (Abadie et al., 2010; Bertrand et al., 2004; Bohn et al., 2014; Buchmueller et al., 2011), we apply a full significance test. This approach is typically referred to as "placebo" testing, and serves to answer the fundamental question of "how often would we obtain an effect from this incident as large as that if we chose a place at random" (Munasib and Rickman, 2015, pg. 7). This process involves the creation of a synthetic match for each county that was matched to our treated counties from the donor pool (i.e. those counties that make up the synthetic controls), and then following the same procedure outlined above in equations 1 -3. We then calculate the "difference-in-difference rank", following Abadie et al. (2010) and using our treated counties and these donor/placebo counties. This is simply the ranking of the difference-in-difference estimates calculated using Eq 1 for the treated county and donor counties that have comparable mean squared predictive errors. Finally, using the approach of Bohn et al. (2014), we calculate a joint significance score. This allows us to 
examine the distribution of the potential treatment effects. By comparing where the actual result falls in this distribution, we can calculate the significance of the actual result, versus the untreated control counties. This distribution of "placebo" difference-in-difference estimates provides the equivalent of a sampling distribution for the treatment effect $\left(\Delta_{T R}\right)$. This empirical cumulative density function (CDF) is derived for each treated county, and a p-value from a onetailed test that $\Delta_{T R}>0$ can be found using this CDF. Combined, these tests provide evidence of whether the treatment effect is "real" or if we are calculating a random effect unrelated to the water contamination.

\subsection{Results}

Results for the DID rank, joint score, and CDF analysis for each county are contained in Appendix B. In what follows, we describe the results for each county. We then conclude with an examination of the impact across the study region.

\subsubsection{Impacted Counties - Kanawha County}

Kanawha County has the highest concentration of WVAW water service and the largest population in our study area. The water intake for WVAW is located on the Elk River in Kanawha County. Kanawha County is also the state capitol, a metropolitan county with the most diverse economy, the highest per capita income, highest labor force participation rate (73\%), highest level of college attainment (17\%), and second lowest unemployment rate in our study group (5.7\%). Service industries, including education and healthcare, are the leading industrial sectors. Coal mining employment is low in Kanawha County, accounting for only an average of $0.76 \%$ of jobs during our study period. The location of Kanawha County and the synthetic control results of the base (1400 nearest neighbors) and ARC Counties only as potential donors are shown in Figure 2-5. 


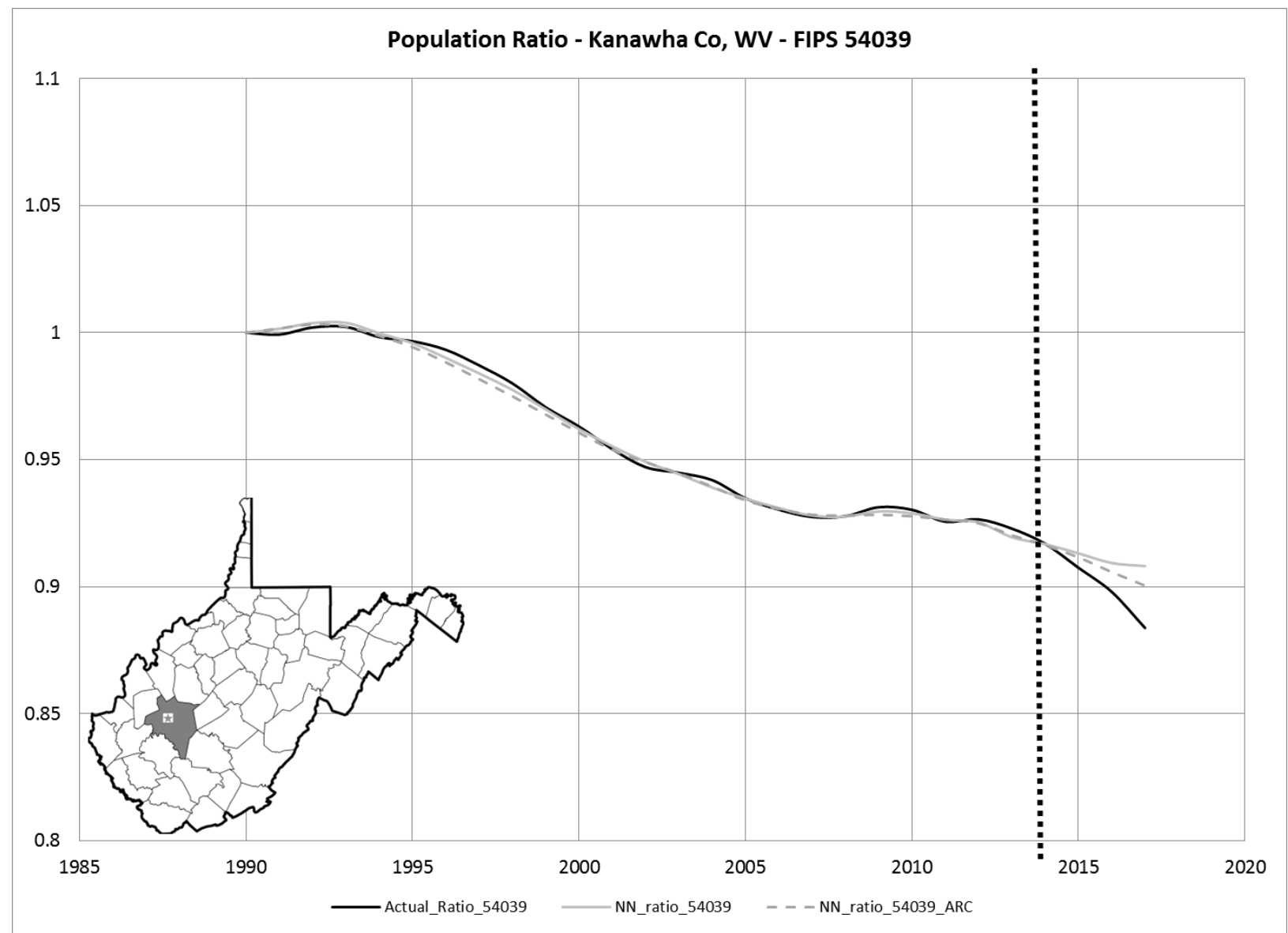

Figure 2-5. Kanawha County Location and Synthetic Control vs. Actual Population Ratio

Kanawha County lost significant population during the study period, down 3.6\% (approximately 7,000 persons). Compared to the (base) synthetic Kanawha County, the population is lower, by 5,000 people, than would be expected, a relative loss of $3 \%$. This result would appear to indicate that despite several structural strengths - an educated population, high wages, an urban center, and a relatively low dependence on coal, that the county was negatively affected by the spill.

\subsubsection{Putnam County}

Putnam County also has a high concentration of WVAW service and has the third largest population in our study region. Putnam is also an urban county, with a highly diverse economy, the lowest unemployment rate $(5.67 \%)$ and highest labor force participation rate $(73 \%)$, and the second highest per capita income and youngest population. Service industries, including education and healthcare, are the leading industrial sectors in Putnam County, and in our study period, there is no coal mining employment. The location of Putnam County and the results of 
the synthetic control (using the 1400 nearest neighbor and the ARC only counties as potential donors) are shown in Figure 2-6.

Putnam County's population grew steadily throughout the period before 2014 , and was relatively stable during the study period. While some of the synthetic control results suggest that Putnam County's population is lower than would be predicted, the ARC model did a relatively poor job of fitting the pre-treatment data and predicted a statistically insignificant treatment effect $\left(\Delta_{T R}<0\right)$. Putnam County is a somewhat atypical Appalachian County, with different industrial mixes and lower college attainment, which may have led to poorer matching in the ARC restricted models. Thus, the results for Putnam County are inconclusive.

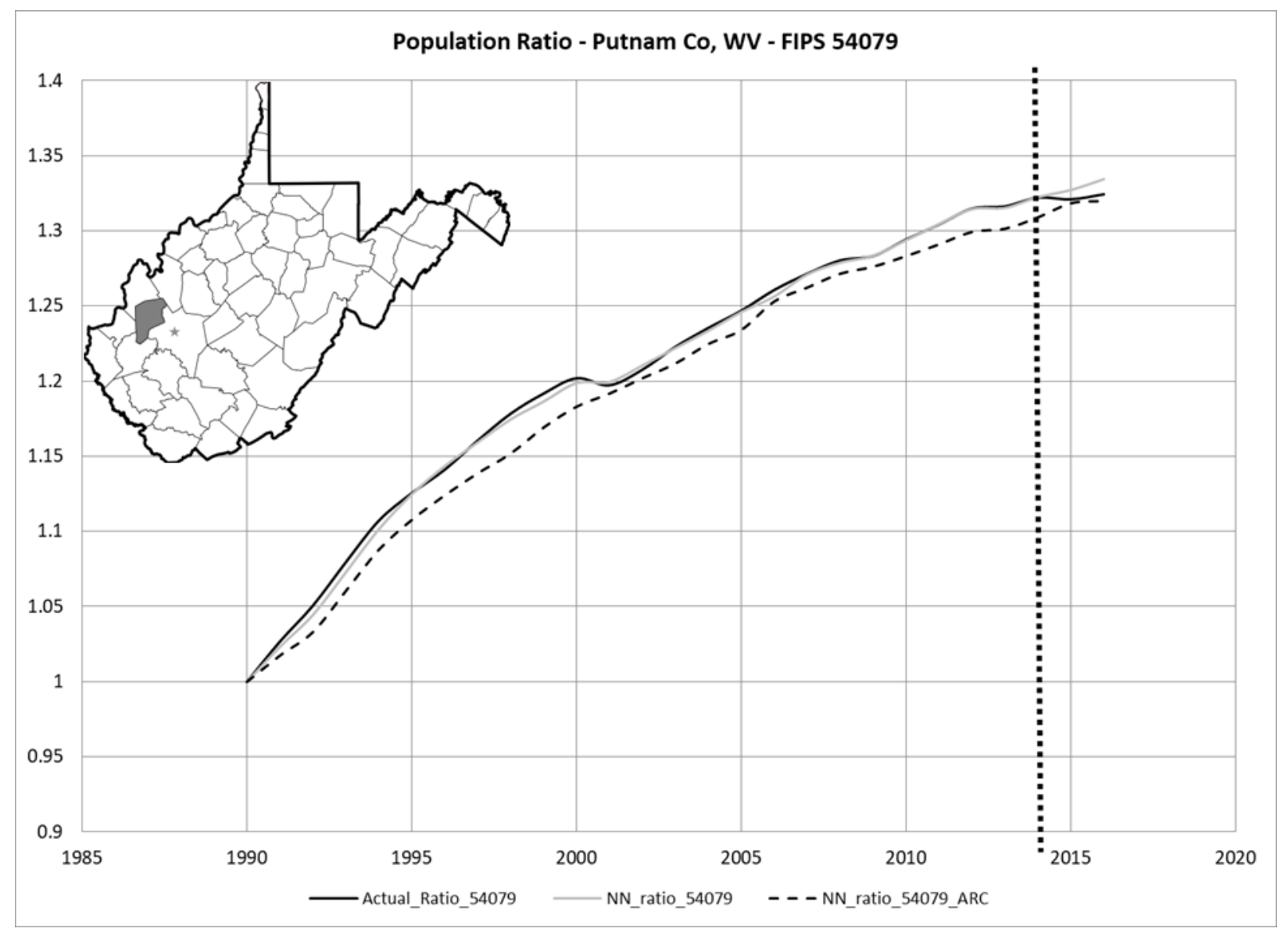

Figure 2-6. Putnam County Location and Synthetic Control vs. Actual Population Ratio

\subsubsection{Boone County}

Boone County was heavily disrupted by this spill. Boone County is an urban county which neighbors Kanawha County. Boone County is heavily dependent on coal mining for 
employment and has the highest share of mining jobs in our study region - $20 \%$ of jobs during the study period. Labor force participation is low at $53 \%$ and the county has the second lowest rate of college attainment in our study region, with less than $6 \%$ of the population having a college degree. Due to its economic status it has been classified as "distressed" by the Appalachian Regional Commission.

The location of Boone County and the results of the synthetic controls with an overlay of annual coal employment job shares are shown in Figure 2-7.

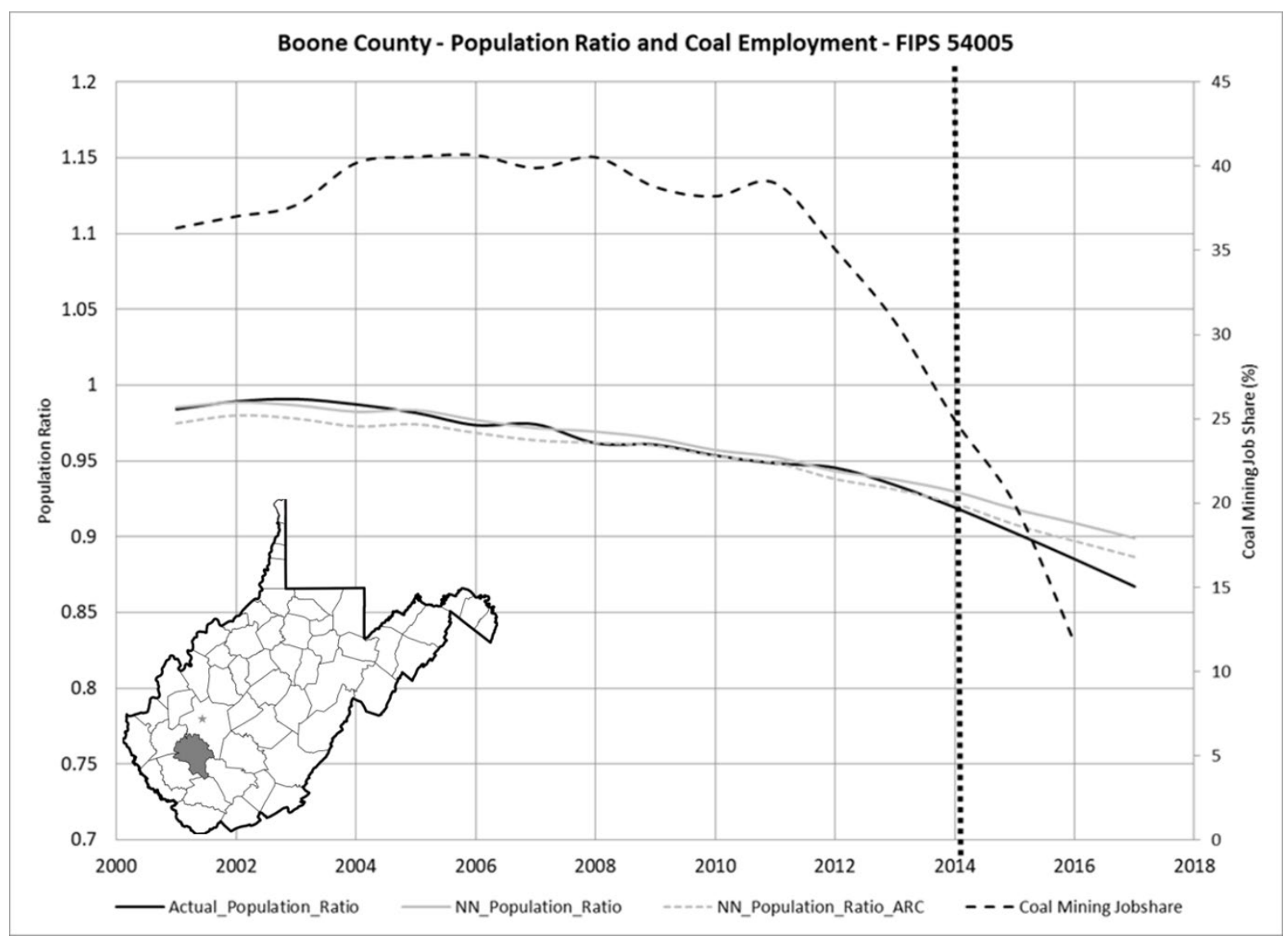

Figure 2-7. Boone County Location and Synthetic Control vs. Actual Population Ratio. Coal Mining Jobshares shown for comparison on the right axis.

Boone County lost significant population during the study period, down 6\% (approximately 1,300 people). Compared to the synthetic Boone County, the population is estimated to be lower, by 550 people, than would be expected, a loss of approximately $2.3 \%$. This result is complicated by the impact of coal mine closures and the decline of coal as an industry in this region, but even when compared to counties from the region (ARC Counties), the population estimates are consistent. As a final robustness check, we used coal dependent counties as a placebo group, 
and Boone County ranked highly for difference-in-difference effect, even when compared to other heavily coal dependent counties (Appendix B). This result suggests that given the other economic issues and weaknesses present in the county, that perhaps this incident was a "tipping point" event, leading to further population loss than might be expected.

\subsubsection{Lincoln County}

Lincoln County is a metropolitan county which neighbors Kanawha County. Only a few small communities near the border with Kanawha County are serviced by the WVAW and were impacted by the spill. Lincoln County has been classified as "distressed" by the ARC and has the lowest levels of high school and college attainment, and the second lowest per capita income. Service industries, including education and healthcare are the leading industrial sectors in Lincoln County. There is only a small coal mining job base, only $0.13 \%$ of the jobs in the county are in coal mining; however, the labor force participation rate is low (52\%), and the unemployment rate is second highest in the study region at $10 \%$.

The location of Lincoln County and the results of the synthetic control are shown in Figure 2-8.

The results from the synthetic control using the full sample of nearest neighbor counties and for the ARC restricted donor pools found no significant difference-in-difference effect $\left(\Delta_{T R}<0\right)$. Thus, probably as expected given the limited direct impact on the county from the spill, it does not appear that the Elk River Spill had any effect on the population in Lincoln County. 


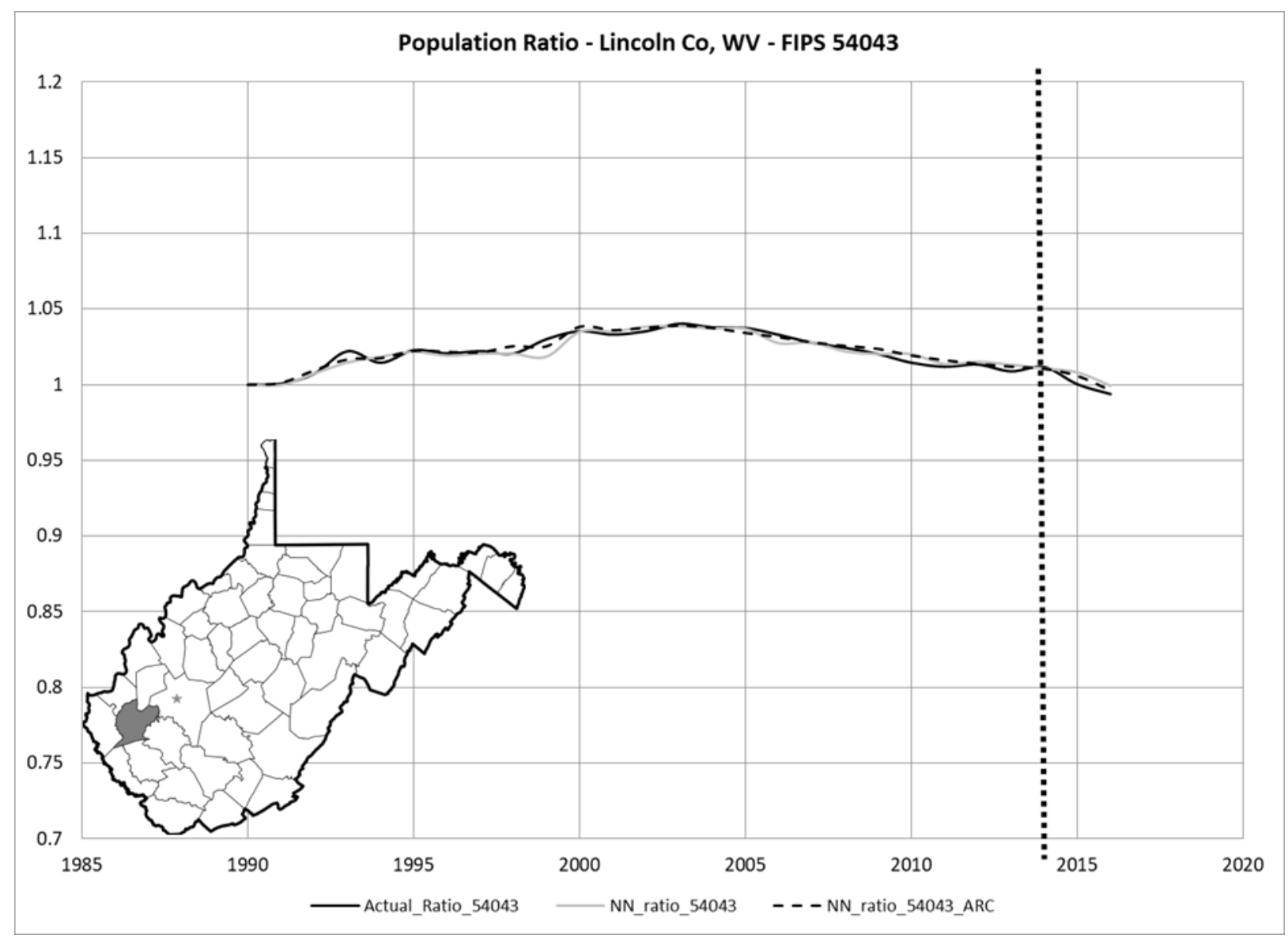

Figure 2-8. Lincoln County Location and Synthetic Control vs. Actual Population Ratio

\subsubsection{Cabell County}

Cabell County was only slightly disrupted by the Elk River spill, mostly at the far-eastern edge of the county, in a town called Culloden, the only town in the county serviced by the impacted WVAW network. Cabell County is a metropolitan county and home to Marshall University, a large public university. Cabell County has the highest population densities and the highest share of service-based employment in the study region. There was no coal mining employment in Cabell County in our study period.

The results from the synthetic control using the full sample of counties and for the ARC restricted models found no significant difference-in-difference effect $\left(\Delta_{T R}<0\right)$ on population in our study period. Thus, probably as expected, given the limited direct impact on the county from the spill, it does not appear that the Elk River Spill had any effect on the population in Cabell County. 


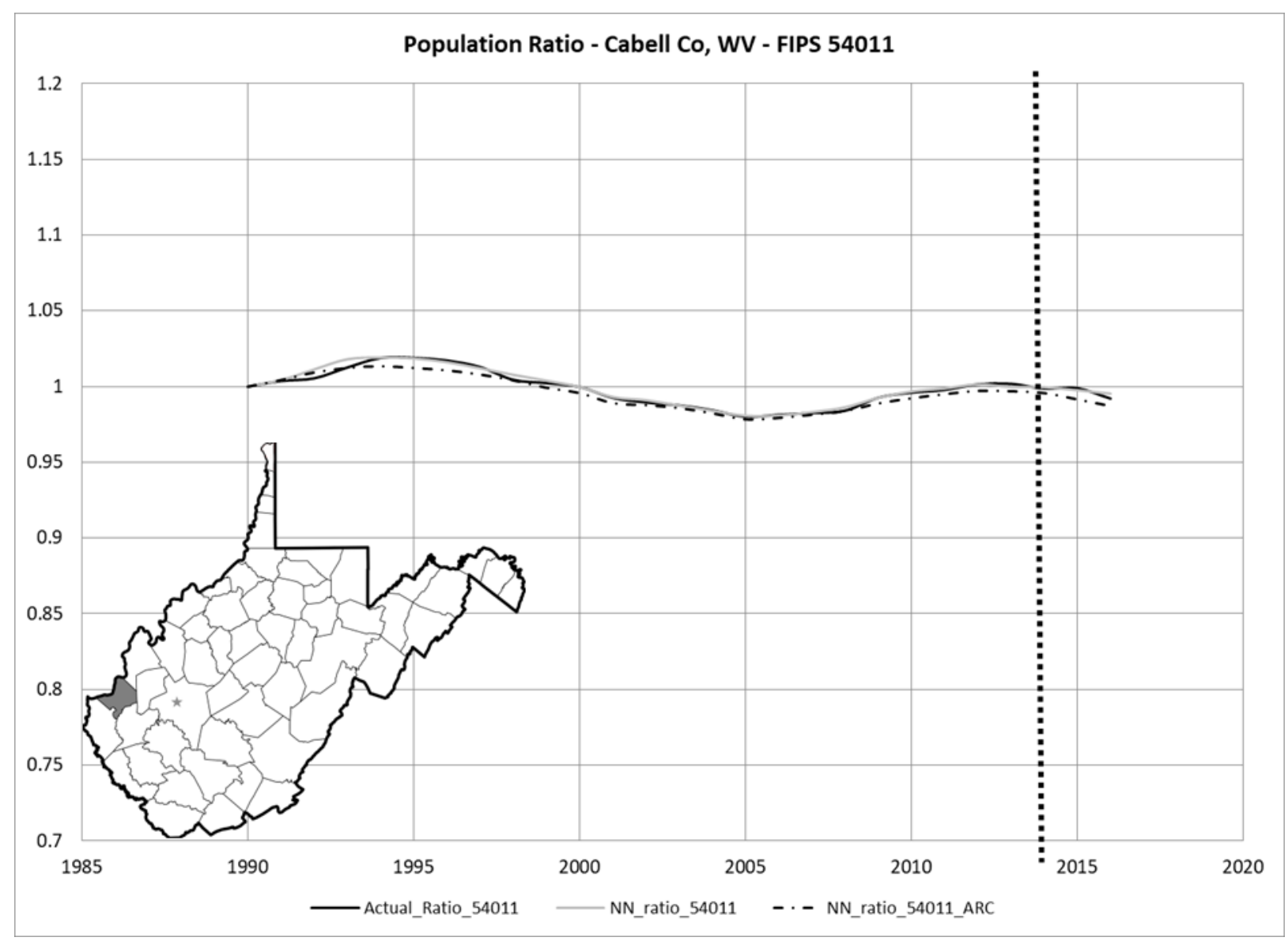

Figure 2-9. Cabell County and Synthetic Control vs. Actual Population Ratio

\subsubsection{Logan County}

Logan County was only marginally disrupted by this spill, primarily at the north-eastern border with Boone County, in a small area with impacted WVAW service. Logan County is a rural county and has been classified as "distressed" by the ARC. Logan County has a moderate level of coal mining employment, the third highest level in our study region at $6.5 \%$ of total employment. Labor force participation is the lowest in the study region at $52 \%$, and Logan County has the highest rate of disability payments.

The location of Logan County and the results of the synthetic controls with an overlay of annual coal employment job shares from 2001-2014 are shown in Figure 2-10. Logan County lost significant population during the study period, down 7\% (approximately 2,400 persons). Compared to the synthetic Logan County, the population is estimated to be 800 people fewer than would be expected, a loss of approximately $2.3 \%$. This result is complicated by the impact of coal mine closures and the decline of coal as an industry in this region, but even when 
compared to counties from the region (ARC Counties), the population estimates are very consistent. As a final robustness check, Logan County was compared to the coal county placebo group, and ranked highly for the difference-in-difference effect, even when compared to other heavily coal dependent counties (Appendix B). This result is somewhat unexpected, given the minimal water network disruption, but perhaps can be explained by the connectivity of Logan County to two highly impacted counties, Boone and Kanawha. The primary transportation corridor in Logan County is US Highway 119, which connects Charleston to Logan County, and provides access to shopping, health care, and entertainment opportunities in both Boone and Kanawha Counties from Logan County. This result suggests that given the other economic issues and weaknesses present in the county, perhaps this incident was also a "tipping point" event, leading to further population losses than might have been expected.

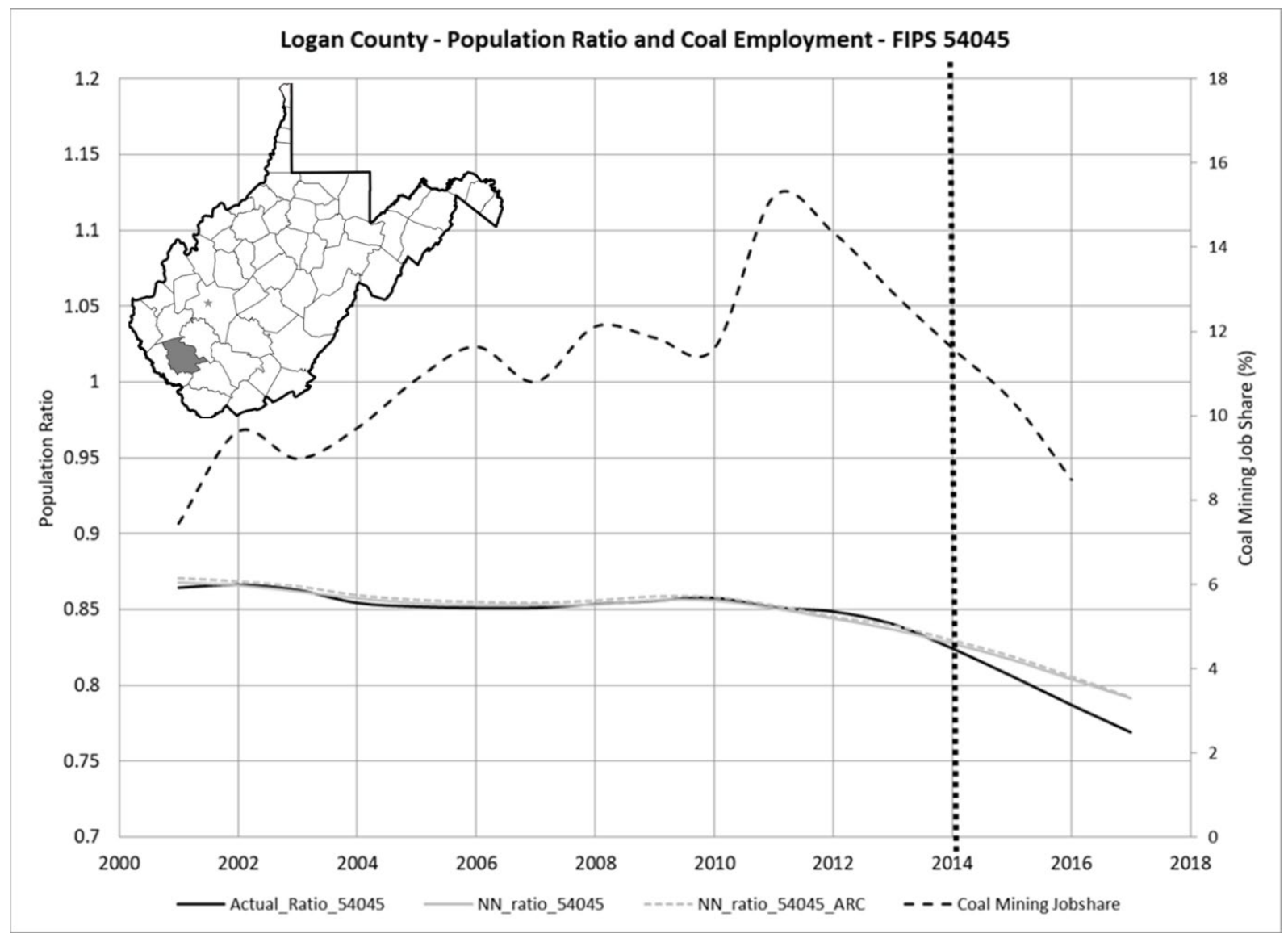

Figure 2-10. Logan County Location and Synthetic Control vs. Actual Population Ratio. Coal Mining Jobshares shown for comparison on the right axis

\subsubsection{Clay County}

Clay County is a metropolitan county neighboring Kanawha County. Only a few small communities along the Kanawha County line have WVAW service. Clay County has been 
classified as "distressed" by the ARC, has the smallest population and population density, highest unemployment rate, lowest per capita income, and low levels of high school and college attainment, at $46 \%$ and $6 \%$ of the population. Government is the largest employment sector in the county, followed closely by education and healthcare. Clay County has a moderate level of coal mining jobs, at $8 \%$ of total employment. Labor force participation is relatively low at $55 \%$.

The location of Clay County and the results of the synthetic controls are shown in Figure 2-11. The results from the synthetic controls found no significant difference-in-difference effect $\left(\Delta_{T R}<0\right)$ on population in our study period. Thus, probably as expected given the limited direct impact on the county from the spill, it does not appear that the Elk River Spill had any effect on the population in Clay County.

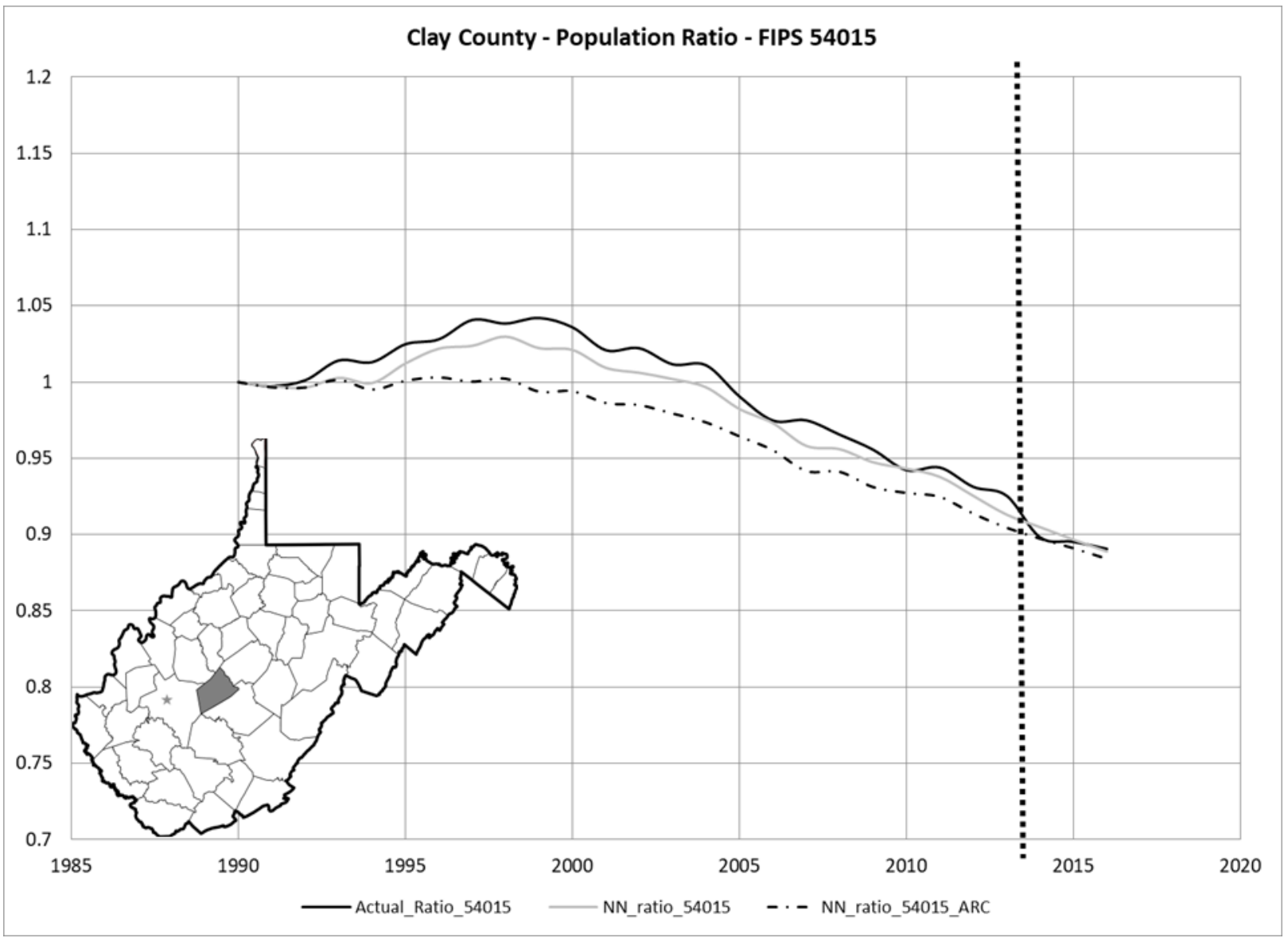

Figure 2-11. Clay County and Synthetic Control vs. Actual Population Ratio 


\subsubsection{Jackson County}

Jackson County suffered only minor disruptions from the MCHM spill, at the border with Kanawha County, due to low service coverage from WVAW. Jackson County is a rural county and has the highest levels of high school attainment in our study group and a relatively high level of labor force participation, at $67 \%$. As with many of our study counties, the highest employment sectors are healthcare and education, but Jackson County also has a high share of manufacturing employment, the highest in our study region. There was no coal mining employment in Jackson County in our study period.

The results from the synthetic controls found no significant difference-in-difference effect $\left(\Delta_{T R}<0\right)$ on the population in Jackson County in our study period. Thus, probably as expected given the limited direct impact on the county from the spill, it does not appear that the Elk River Spill had any effect on the population in Jackson County.

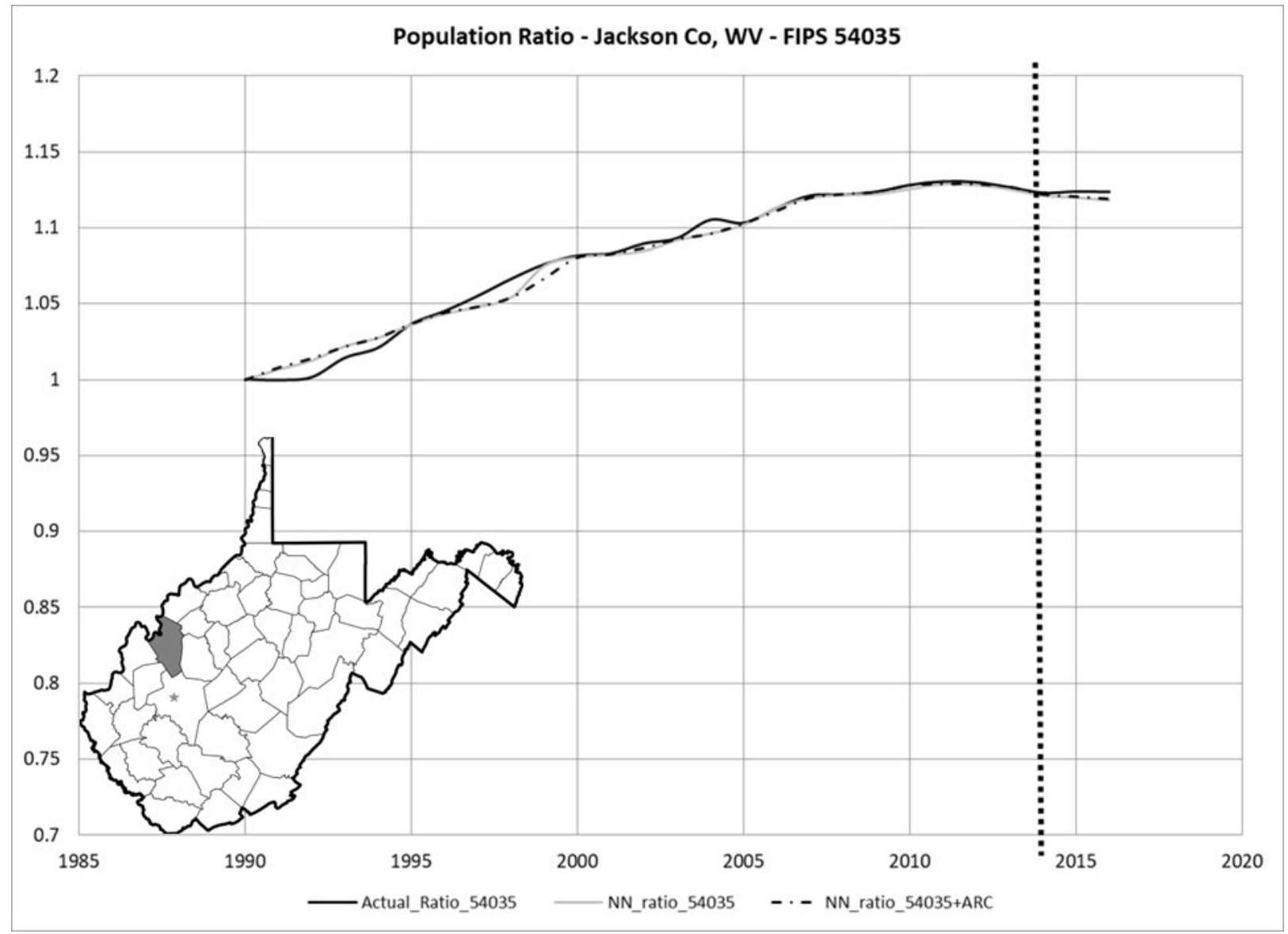

Figure 2-12. Jackson County Location and Synthetic Control vs. Actual Population Ratio 


\subsubsection{Roane County}

Roane County suffered only minor disruptions from the MCHM spill, at the border with Kanawha County, due to low service coverage from WVAW. Roane County is a rural county with the second smallest population and population density in the region. Roane County is considered to be economically distressed by the ARC, having the second highest unemployment rate in our study region along with a low labor force participation rate, at $59 \%$. It also has the oldest population in our study region. Employment is concentrated in the retail, healthcare and educational, and governmental sectors. Roane County had no coal mining employment in our study period. The location of Roane and the results of the synthetic controls are shown in Figure 2-13.

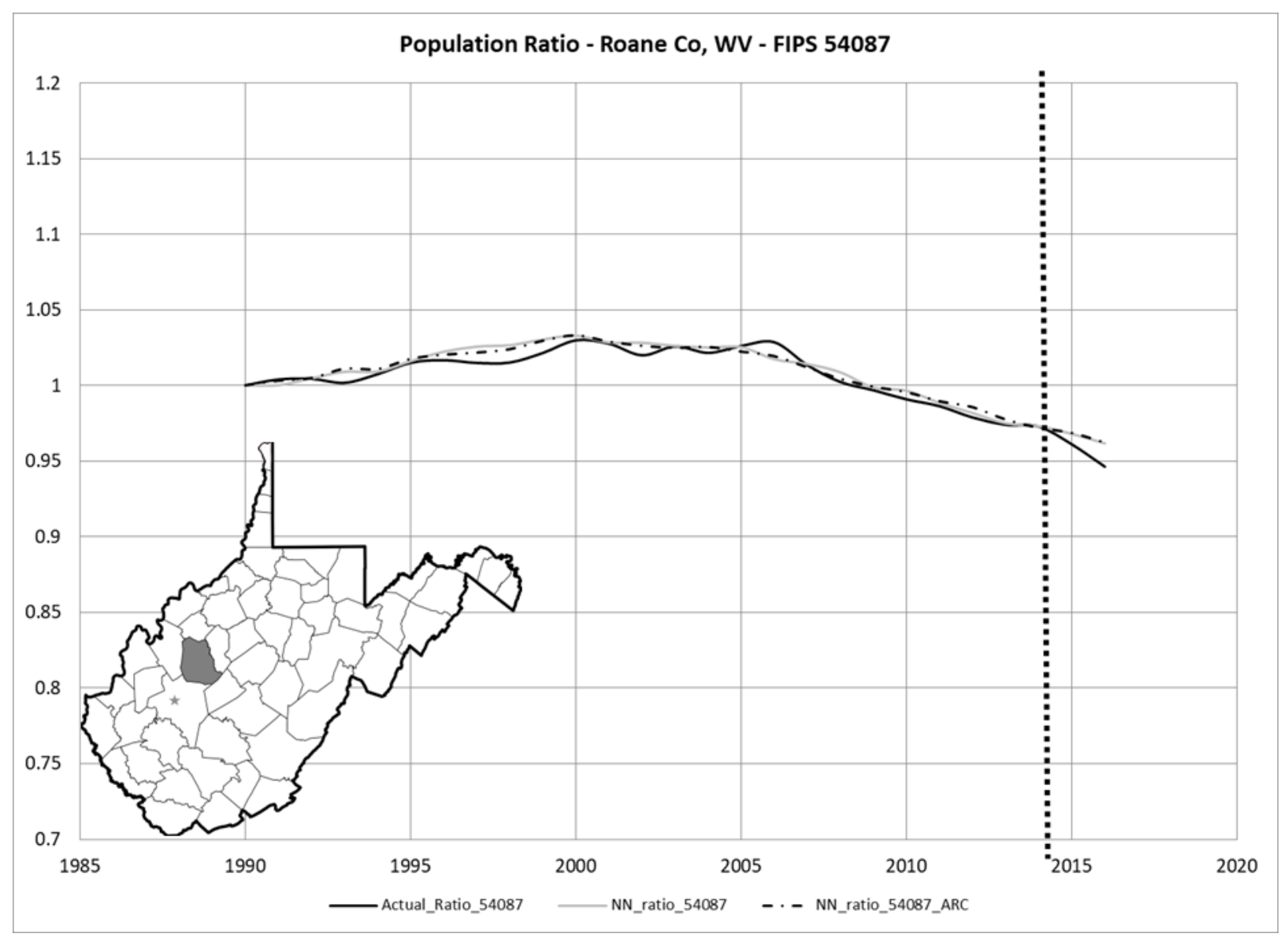

Figure 2-13. Roane County Location and Synthetic Control vs. Actual Population Ratio

Despite the results which suggest that Roane County had a statistically significant population loss compared to the synthetic Roane County, Roane County's results are the least robust in a placebo analysis, with a significance between $35-75 \%$. Thus, since Roane County had little 
direct impact (due to only a small area having WVAW service), we cannot make any conclusions about the impact from the Elk River Spill.

\subsection{Regional Effects}

Overall, this incident appears to have had significant, long-term impacts on the populations of the region, at least in Kanawha, Boone, and Logan counties. While earlier results were presented as population ratio changes, we can also directly examine population changes across the impacted region. In the results below, we aggregate the effects found for counties with a statistically significant result to evaluate the regional impact. If we exclude counties that did not reach the initial test for significance $\left(\Delta_{T R}<0\right)$ and with inconclusive placebo tests, the overall population of the three affected counties declines by 10,000 people from 2014 to 2017, on a population of approximately 250,000 in 2014 . The synthetically-modeled region forecasts a decline of 4,000 people, suggesting these counties were worse off after this spill. (see Figure 2-14)

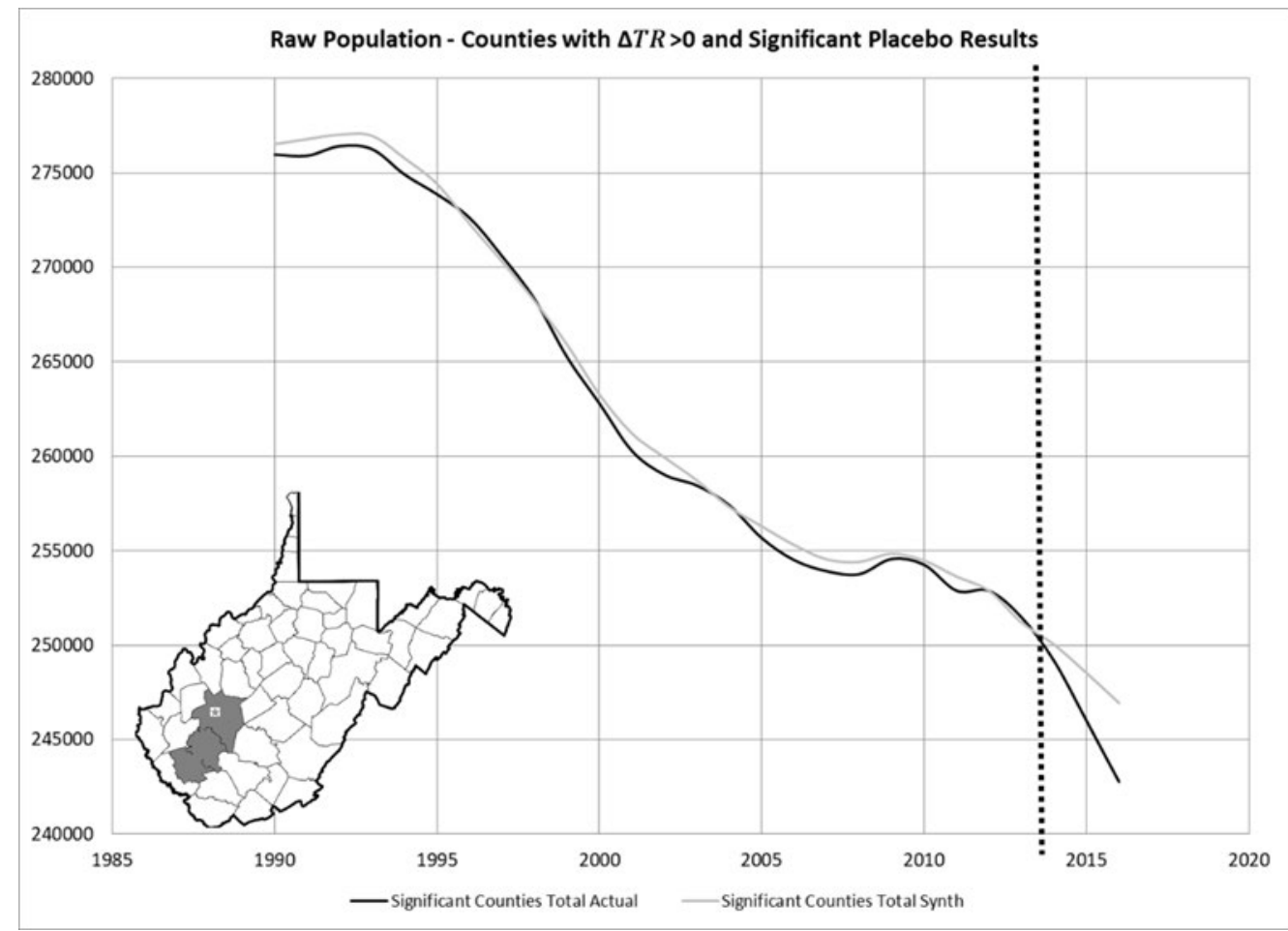

Figure 2-14. Total Population Actual and Synthetic For Three Counties With $\Delta_{T R}>0$, Significant Placebo Tests Only 
While this region had been steadily losing population throughout the study period, a notable inflection point is seen beginning in 2014, coinciding with the dates of the spill in January 2014. For a region with widespread economic issues, this incident appears to have represented a tipping-point type incident, pushing residents that may not have moved (or may not have moved for some time) to leave the region.

\subsection{Economic Impacts}

A key goal of this study is to estimate the economic impact from this incident due to the population change. This is in addition to those costs related to environmental cleanup or punitive fines. At the time of this writing, Freedom Industries and its associated executives have been fined approximately $\$ 1,000,000$ for their role in the spill, but the majority of these fines will never be collected, due to the bankruptcy filing of the company. Further settlements of $\$ 151$ million were awarded in 2016 from Eastman Chemical and WVAW, equating to approximately $\$ 440$ per person affected by the spill (Mistich, 2016; Hersher, 2016). Looking at the three counties with statistically significant population changes, we estimate population effects of a loss of 6,400 people in the study region, with a loss of 5,000 people in Kanawha County alone. If we assume a per-capita income of $\$ 25,000$ /person (less than the lowest per capita income in the study counties), we estimate that the direct income-related losses from this disaster in the three key impacted counties (Kanawha, Boone, and Logan) are between $\$ 40$ and $\$ 80$ million per year, or $\$ 160$ million from 2015 to 2017, purely based on the income loss (see Table 2-3). The lag in population effect, where the highest observed population change occurs in 2017 , is also somewhat expected, in part because the choice to migrate is costly, and likely responds with a lag to changed circumstances (Greenwood, 1985). While this estimate is significant, it likely understates the true economic impact of these population losses.

As an example of potential impacts from these population losses, a large body of literature has examined "brain drain" - the loss of talent from typically rural or economically depressed regions (Beine et al., 2001; Domina, 2006; Gibson and McKenzie, 2012; Hansen et al., 2003; Hawley and Rork, 2013; Hunter and Sutton, 2004; Kelchen and Webber, 2018; Marre and Rupasingha 2019; Petrin et al., 2014; Sherman and Sage, 2011; Stephens et al., 2013; Weber et al., 2007). In this work, a notable consistent finding is that policies that seek to minimize talent loss may be more important than policies that seek to attract talent. Additionally, internal migration in the US has been at persistently low levels for decades (Frey, 2017) and has been lower than expected across all demographic, socioeconomic groups, and geographic areas (Johnson et al., 2015; 
Kaplan and Schulhofer-Wohl, 2017; Mills and Hazarika, 2001; Molloy et al., 2011, 2017; Partridge, 2010; Partridge et al., 2012; Rupasingha et al., 2015). These findings suggest that for a region impacted by an incident such as this, the best course of action is prevention, rather than reaction - because once the resident has made a choice to relocate, it is increasingly difficult to attract a new resident to replace them, particularly for places with poorer socioeconomic conditions.

The results from Kanawha County support this analysis, as it is the county with the highest levels of educational attainment and most diverse workforce. Of further importance in this finding is remembering that the Elk River spill was considered a severe, but relatively short term contamination event. The spill was discovered on January 9, 2014, with an emergency "do not use" order issued the same day and the emergency order was ended on February 28, 2014, less than two months from the start of the incident. Given the magnitude of deciding to leave a place, the population change effect that we identify is significant for such a "short" duration event.

\begin{tabular}{ccccc} 
& 2015 & 2016 & 2017 & Total \\
\hline Population Loss (Persons) & -1669 & -1646 & -3141 & -6456 \\
Income Effect $(\times 1,000,000)$ & $-\$ 41.72$ & $-\$ 41.14$ & $-\$ 78.53$ & $-\$ 161.39$ \\
$\begin{array}{c}\$ 25,000 \text { Per Capita Income }) \\
\text { WV GDP in Study Year }\end{array}$ & $\$ 70,281$ & $\$ 69,721$ & $\$ 73,163$ & $\$ 213,165$ \\
$\quad \begin{array}{c}\text { (X 1,000,000) } \\
\text { \% Loss Relative to GDP }\end{array}$ & $-0.06 \%$ & $-0.06 \%$ & $-0.11 \%$ & $-0.08 \%$
\end{tabular}

Table 2-3. Estimated Population Loss Income Effect from Impacted Counties

\subsection{Conclusion}

For counties in economically-lagging regions, loss of population is an ongoing concern. If changes in industrial composition and economic opportunity are leading people to migrate elsewhere, then these counties may be at an ongoing economic disadvantage in terms of future economic growth. Under such conditions, could a man-made environmental disaster lead to a tipping point, resulting in further population loss?

Our analysis uses the synthetic control method to analyze the population change in nine counties in West Virginia that were at least partially impacted by the 2014 Elk River Spill. The SCM method allows us to analyze the impact on only a few counties. By utilizing a base model 
and supplemental models to address possible endogeneities, our analysis finds that Kanawha County is the most significantly impacted county, with lesser effects farther away from the spill, where the footprint of the impacted water supply infrastructure was smaller. As further proof of our approach, we find little or no effect in counties where only small portions of the population were covered by the water supply from WVAW.

In a region suffering from multiple economic headwinds, our results suggest that, in the absence of the contamination, these counties would have declined more slowly, and that this incident may have represented a "tipping point" event for many residents in this area. The economic impacts of this contamination event are significant. In addition to the typical costs due to the cost of cleanup or the amount of fines or punitive damages identified in the aftermath of the event, there are other economic costs due to population losses, which are likely larger and longer lasting. Compared to the synthetic counties, our results suggest that the population in these counties is between 2,000 and 5,000 people smaller per year in our study window of 2015-2017. If each of these "lost" people earned just $\$ 25,000$ during these three years, the aggregate loss of income would be in excess of $\$ 160$ million, suggesting that the $\$ 1$ million in mostly uncollected punitive fines and $\$ 151$ million in settlements to date do not adequately cover the economic impacts to this region. Further, if the population losses are among the more highly educated or in the key working ages - both groups that are shown to have the highest mobility - then these costs likely understate the true negative impacts relative to future economic development and prosperity.

Our results make an important contribution to environmental policy across the nation by helping to put a value on the prevention of environmental disasters. Our findings suggest that policies to prevent such disasters would pay off by preventing further economic deterioration in the region. In considering new environmental regulations, policy-makers may want to consider these benefits which may more than outweigh any costs. 


\section{A Case Study on Fear: The impact of PFOA water contamination and environmental risk on county level population change}

\subsection{Introduction}

The impacts of environmental contamination from industrial processes have only recently been understood, and typically only enter the public eye following high-profile and high-impact incidents, such as the Cuyahoga River Fire in 1969 (Stradling and Stradling, 2008), or large contamination incidents such as Times Beach (Hites, 2011) and Love Canal (Adeola, 2011) which led to the evacuation of those towns in the 1970s and 1980s. Since the creation of the US Environmental Protection Agency (EPA) in 1970, heightened awareness and responsibility for these types of environmental contamination events has existed, yet large incidents still occur.

Perfluorooctanoic Acid (PFOA), also known as C8 is a chemical which was developed in the late 1940s with widespread applications, most notably as a water and oil repellent and in the manufacture of non-stick cookware and stain-resistant clothing and fabrics, and marketed under the trade names "Teflon" and "Scotch Guard". PFOA and other perfluorocarbon compounds are extremely persistent in the environment, and are found in the groundwater and surface water worldwide (Yamashita et al., 2008), and have been proven present in the blood and tissues in animal species throughout the world (Tao et al., 2006). Beginning in the 1950s, PFOA was manufactured by DuPont in industrial quantities at the Washington Works chemical facility in Wood County, near Parkersburg, West Virginia (WV). Between 1950 and 2003, DuPont is estimated to have dumped, poured, and released more than 1.7 million pounds of PFOA into the area around the Washington Works facility (Mordock, 2016).

In 2004, the EPA filed suit against DuPont alleging "widespread contamination" of PFOA near the Parkersburg plant. In 2005, the suit was settled resulting in $\$ 10.25$ million in civil penalties, the largest civil penalty the EPA had ever obtained to that point (Ryan, 2005). In 2001, area residents also sued DuPont for water contamination, and, in late 2004, DuPont agreed to a $\$ 107.6$ million settlement with six public water districts in WV and Ohio, along with a class of not-publicly released private citizens, provided they could prove water contamination of their wells or drinking water supplies (Leach et al. v DuPont, 2005). This settlement included $\$ 20$ 
million for installation of water treatment technologies in the six impacted water districts and the establishment of an independent panel - the "C8 Science Panel" - to determine if there was a "probable link" between PFOA exposure and adverse health effects (Fletcher et al., 2012). The C8 Science Panel enrolled over 69,000 study participants in 10 counties in 2005 and 2006, and conducted extensive data collection including demographics, medical diagnoses, and laboratory testing (Frisbee et al., 2009). Final reports from the panel were released in 2012, establishing a probable link to six disease categories, including cancer and thyroid disease (C8sciencepanel.org). The extended time period over which information was released presents a challenge to our research, as starting with initial findings in 2005, and running through the release of the C8 Science Panel Results in 2012, there is a seven-year period of imperfect information about the impact of PFOA on residents of these counties.

The impacted area in Ohio and West Virginia is also part of the Appalachian Region in the Eastern US, an area that has struggled with declines in both economic opportunity and "quality of life" factors. The federally-designated Appalachian Regional Commission (ARC) region, contains all of West Virginia and portions of twelve other states, and was formed in 1965 to address issues of persistent poverty. While the ARC region has experienced some economic gains since then, portions of it have been negatively affected by recent trends. Part of this is due to overall national economic trends, such as a loss of manufacturing and mining jobs (Partridge et al., 2018); however, other critical issues are also more acute in this region, with opioid deaths, lower work force participation rates (Stephens et al., 2018) and health outcomes that are at or near the worst in the US.

This study examines the population impacts of this large-scale and long-duration water contamination event. Related to the direct population impact is developing an understanding about what these population changes may mean economically in an area with diminished economic fortunes and long-standing concerns relative to population retention. The value of this work to policy-makers and regulators is in the estimation of these economic impacts, particularly when compared to the cost of stricter regulations, which could prevent future incidents, or when compared to reactionary punitive fines and settlements.

To examine the population impacts, we use the synthetic control method (Abadie et al., 2010) (SCM) to establish a baseline projection for the five counties that were directly impacted by water contamination, as indicated by their inclusion in the 2005 settlement, and an additional 
five counties that are neighbors to the Washington Works facility, but did not have any known direct water contamination, yet were included in the C8 Science Panel health screenings. Given the relatively small number of "treated" counties (i.e. impacted by PFOA), typical empirical techniques would be difficult to implement. SCM allows us to construct a counterfactual based on the weighted average of comparison control counties with similar properties (Munasib and Rickman, 2015). We also use randomization or "placebo" tests for inference, which improves on standard error based regression models. As noted earlier, since this incident includes a long period of imperfect information, from 2005-2013, we further contribute to the literature by developing techniques that improve on SCM in order to establish the timing and magnitude of the impact of this event when the timing is uncertain.

Using our results, we are then able to estimate direct population impacts in the impacted and neighboring counties, and use those population changes to estimate the economic impact in the region. Our results indicate that this disaster had a significant effect on population in the impacted counties, some counties lost population due to this event and some counties did not grow as much as might have been expected (had this event not taken place).

In what follows, we discuss the relevant background information and prior research. We next present the empirical approach and the data used in our analysis. We then present and discuss the results. Finally, we conclude with a discussion of the economic impacts of our findings and their implications for future policy.

\subsection{Background}

Much of the existing research on population loss from large "discrete" time events focuses on events such as the outbreak of a major war or the occurrence of a major natural disaster. In the natural disaster literature, examinations of Hurricanes Iniki (Coffman and Noy, 2011) and Katrina (Fussell et al., 2009; Groen and Polivka, 2010; Myers et al., 2008) find significant and long-term population loss as a result of these disasters, and that after more than a decade, populations have not returned to pre-disaster levels. Work by Cavallo et al. (2013) considers other large scale disasters, including earthquakes, finding that the effects at the national level are more muted - emphasizing that the impacts are more dramatic and long-term at the local level than at the more aggregate national level. Examining more historic events, Boustan et al. (2012) study the migration impacts of tornados in the Great Plains region of the United States (US), and find that these storms did more to deter in-migration than to accelerate out-migration. 
Finally, some studies show that long-term and slow-developing disasters, such as drought or sea-level rise also lead to significant, negative, population changes (Findley, 1994; Hauer, 2017).

In the literature related to wars, the results are similar. Several studies find that the Basque Civil War in 1960s and the Syrian Civil War of the late 2010s both led to significant decreases in population (Abadie and Gardeazabal, 2003; Yazgan et al., 2015). In the cases of both natural disasters and war, population changes and migration can often be conceived of as simple movement to the next "safe place". Relative to our investigation, these studies provide some projection that localized disasters can lead to large localized changes, including population losses.

Given the preceding literature, however, the other research on man-made disasters is cloudy and conflicted. Dhara and Dhara (2002) examine the Bhopal, India Union Carbide disaster that killed an estimated 3,700 people, and find that long term population impacts were minimal post disaster. Flint, Michigan, had suffered many years of depopulation before the contamination of the water supply with lead, and while the health impacts of the contamination were significant, the effect on population change is unclear (Morckel and Rybarczyk, 2018). By comparison, the 2011 earthquake and tsunami, and subsequent nuclear disaster at Fukushima, in Japan, have led to significant population loss in the city nearest the plant (Minamisoma, Japan). Populations in the region near the Fukushima Daiichi nuclear plant are down more than a third from the predisaster level, despite announcements from the government that the area is safe for return (Zhang et al., 2014). In fact, Horie et al. (2017) find that residents near Fukushima may have been even more willing to move, if clear information about the specific risk levels in their area was readily available to them, especially when compared against the new areas to which they were thinking of moving. The results of these prior studies are especially relevant to our study, where population change may be affected by unknown health risks of living in the area, psychological distress and distrust after the event, an existing lack of economic vitality, and a leading industry that renders the area less attractive to residents.

The element of distress and distrust is important for this discussion. Schade et al. (2016) describe how industrial water pollution events "affected psychological well-being and resulted in widespread distrust of the public water system" after a spill impacting Charleston, WV, in 2014. Describing yet another water pollution event in Martin County, Kentucky, Scott et al. (2012) also 
state; "we found that the residents... expressed a desire to live elsewhere, and a distrust of... regulatory agencies." The effects of the Washington Works PFOA incident have also impacted public trust; the duration of this "spill" stretched over decades before any regulatory action was taken, and the persistence of this chemical in water supplies is expected to last for decades more.

This incident, then, can be thought of as an environmental shock, and would provide an impetus for residents to evaluate whether a migration decision would impact them positively or not. The costs for a move are significant, both in direct costs and in other indirect costs, such as lost efficiency, or loss of a social support network in the new place, and would not be undertaken unless a person felt that there would be sufficient personal return to justify the costs. (Greenwood, 1985; Kennan and Walker, 2011; Schultz, 1961). While the discussion of what factors provide a sufficient "return" on these personal investments has as many answers as possible impacted residents, there are several larger trends that can provide some guidance.

Historically, one of the most significant contributors to the movement and residence choices of high-skilled workers is opportunity (Burns and Hotchkiss, 2019; Chetty and Hendren I and II, 2016; Davis and Haltiwanger, 2014; Knapp and White, 2016; Rodgers and Rodgers, 1997; Weber et al., 2007; Wilson, 2017; Wozniak, 2010; Yankow, 2003; Dao et al., 2017; Kennan and Walker 2011). Chetty and Hendren (2016, II) find that moving to better neighborhoods in childhood has significant positive impacts for those same children as adults, including higher incomes, and that the sooner those changes are made, the greater the impacts to both them and their children. For places with historically poor economic and social outcomes, this would suggest that moving sooner, rather than later, is the best choice for many residents of those places - an attitude which echoes those identified in the rural educational attainment and postsecondary guidance research of Sherman and Sage (2011).

A second major contributor to a residence choice are "amenities" for outdoor recreation or other leisure activities, and these amenities are strong predictors of both migration and economic growth (Deller et al., 2001; McGranahan, 2008; Partridge, 2010; Partridge et al., 2017; Wasson et al., 2013). Similarly, there is also a negative effect from places with damaged environmental legacies (Both in urban and rural areas). Brasington and Hite (2005) find both that proximity to polluted sites lowers housing values, and that increasing levels of income and education drive a higher demand for environmental quality. Other literature compares the impact of quality of 
place on a worker's choice of locations, as compared with career opportunities. Research has repeatedly found that high-skilled workers are attracted to places with higher quality leisure and cultural activities, but these studies have tended to focus on cities and places with relatively large concentrations of both amenities and skilled workers. Thus, their applicability to rural areas is unclear (Darchen and Tremblay, 2010; Florida, 2000; Gyourko et al., 1997; Shapiro 2005).

Recent research finds that the opioid epidemic may have disproportionate impacts on population change among younger populations (Taylor, 2020). The opioid epidemic in the US has disproportionately impacted rural counties compared to more urban areas (Keyes et al., 2014; Monnat and Rigg, 2018), and research has shown a strong link between factors that have historically been linked to migration decisions, and opioid death rates, including factors such as lower incomes, lower educational attainment, higher unemployment and lower population density (rurality) (Boardman et al., 2001; Cerda et al., 2017; Case and Deaton, 2017; Goetz and Davlasheridze, 2018; Rossen et al., 2009; Song, 2017).

These factors combined define a perilous set of conditions for policy-makers and other officials in areas impacted by incidents such as this one - an incident both long lasting and with serious health risks, in a relatively rural region with other socioeconomic concerns. If residents view the risks and costs of staying in the region as significantly higher than the costs of a relocation, then population loss from the impacted region is a likely outcome.

\subsection{Theoretical Framework}

Cavallo et al. (2013), perform a significant review of the impacts on economic growth of natural disasters, and find that many classical theories do not provide clear-cut answers, concluding that only when a disaster is followed by radical political revolution, is national GDP impacted. Research on the fundamental economic frameworks that would explain the economic outcomes of disasters is relatively limited, relatively young, and do not provide clear guidance about how a society or a country might respond in the face of a natural disaster. A more developed body of theoretical work exists in the impact of environmental considerations on migration decisions (Hunter, 2005; Dejong and Fawcett, 1981; Lee, 1966). These approaches are based on a utility-maximization framework, where households are expected to make decisions that would maximize the utility of their location. In this context, where nice weather or views would be considered an "amenity", and thus increase utility, an environmental or natural disaster could be 
considered a "disamenity" and decrease utility (Brasington and Hite, 2005; Deller et al., 2001; McGranahan, 2008; Partridge, 2010; Partridge et al., 2017; Wasson et al., 2013). Assuming rational choice, this provides a theoretical mechanism where increasing utility by escaping a "disamenity" may involve a decision to leave a place, similar to moving for a better job or better weather.

\subsection{Data}

We examine the possible impact of the PFOA water contamination on ten counties, seven in WV and three in Ohio. These are the counties included in the C8 Science Panel health effects studies, which either had direct impacts from PFOA contamination or are neighboring counties to the Washington Works facility at the center of this incident, and have populations that work and commute to the areas impacted. Figure 3-1 shows the location of the counties and Table 3-1 lists the counties with some descriptive information.

\begin{tabular}{cccc} 
State & County & Population in 2005 & Impacted Water Districts \\
\hline Ohio & Athens & 63,433 & $\begin{array}{c}\text { Little Hocking Water District } \\
\text { Ohio }\end{array}$ \\
Meigs & 23,112 & $\begin{array}{c}\text { Tuppers Plains Water District } \\
\text { Pomeroy, Ohio }\end{array}$ \\
Ohio & Washington & 62,230 & Little Hocking Water District \\
Best Virginia & Cabell & 94,776 & None Ohio \\
West Virginia & Jackson & 28,168 & None \\
West Virginia & Mason & 25,666 & Mason County Public Service District \\
West Virginia & Pleasants & 7,554 & None \\
West Virginia & Ritchie & 10,382 & None \\
West Virginia & Wirt & 5,793 & None \\
West Virginia & Wood & 87,058 & Lubeck Public Service District
\end{tabular}

Table 3-1. Impacted Counties, 2005 Populations, Directly Impacted Water Districts 


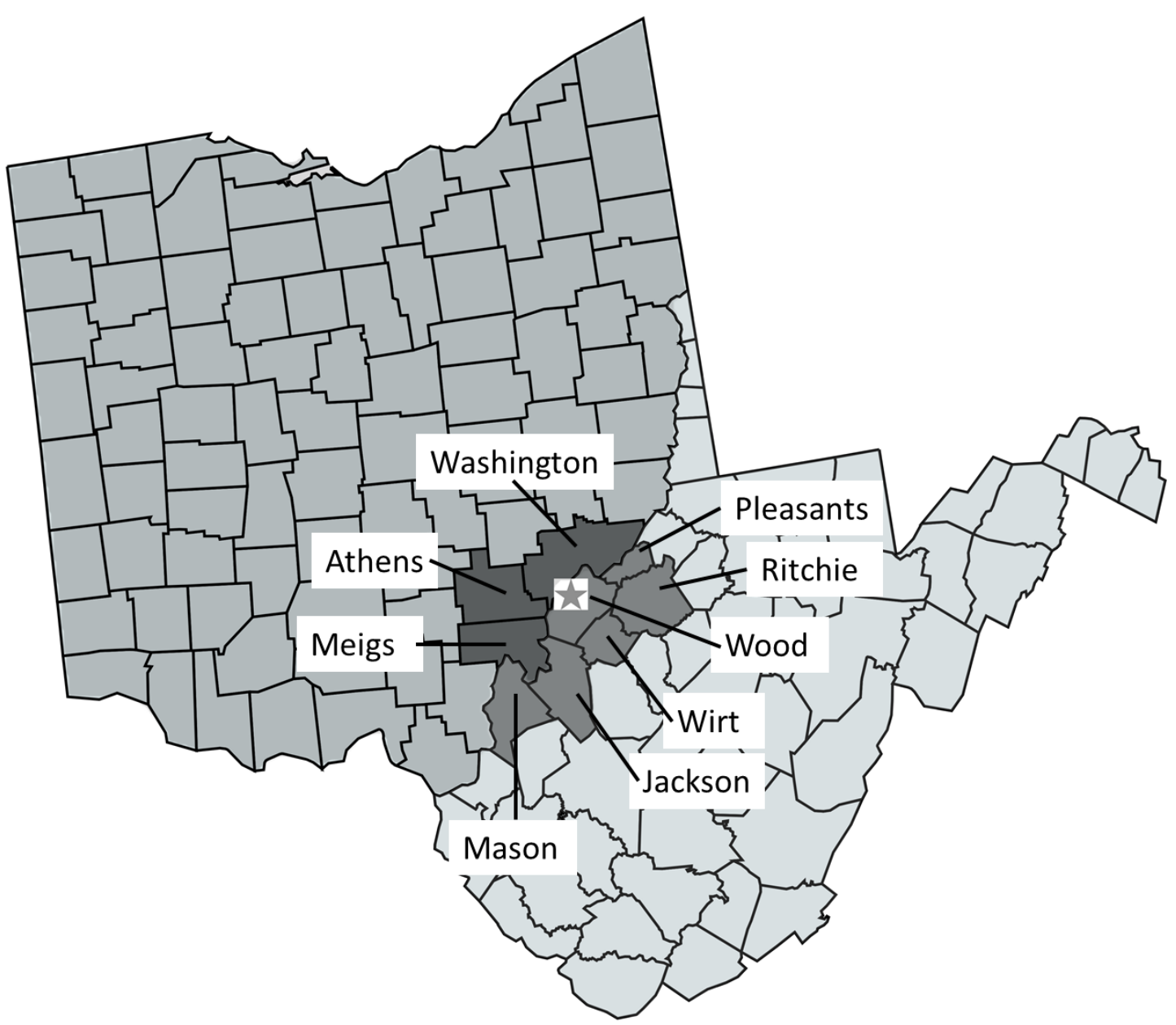

Figure 3-1. Counties in Ohio (dark grey) and West Virginia (light grey) included in C8 Science Panel Analysis. Star indicates location of Washington Works Facility.

Our direct outcome measure is raw population, while other outcome measures are calculated from this result to allow cross-county comparisons. Notably, we calculate the population ratio for each county, which is the ratio of the current population in that county to its population in the first year of the study, 1990. This measures the change in population in that county. We utilize the population ratio as it allows for comparison between counties with different population levels.

Using the SCM method (further explained below), we match our impacted counties with other US counties on a number of factors. 
Our data set spans the period from 1990 to 2017, and includes county-level data for the 48 contiguous US. Variables used to create our matches are those that have been shown to impact population and migration, as discussed above. As population is the primary variable of interest, we gathered information on the raw population, population density, gender and age compositions in each county (US Census, SEER, 2019). Hansen et al. (2003) point out that the most significant components in retaining skilled workers are competitive salaries and benefits, and while this runs contrary to many economic development approaches that emphasize lower costs, it does provide a clear mechanism to attract or retain skilled workers - simply offer nationally competitive salaries. Thus we include per-capita income and per-capita disability receipts (US BEA, 2019). Disability is included both because of income related effects, but also as it has been found to have impacts on mobility (Findley, 1988; Partridge et al., 2012). Also significant to population change, we control for educational attainment using data from the US Department of Agriculture - Economic Research Service (USDA-ERS). For example, a significant body of previous research illustrates a strong link between positive economic development and the number of college graduates in a region (Glaeser et al., 1995; Partridge et al., 2005; Shapiro, 2005; Simon et al., 2002; Faggian and Franklin, 2014). At the same time, the largest predictors to attracting college graduates are the levels of educational attainment in the new place and employment stability (Betz et al., 2015; Frey, 1995). We also capture the overall effects of rural-to-urban migration trends by including distance to the nearest Core Based Statistical Area (CBSA) using the 2013 definition.

Historically, changes in unemployment have been strongly associated with population changes. Additionally, research by Stephens and Deskins (2018) shows that this region has high levels of labor force participation which may not be captured by the unemployment rate. Bondonio (2018) investigated how natural disasters in the US can lead to lower employment growth, and finds that the impacts are more intense and last longer in counties that have lower incomes and higher unemployment before the disaster. We include the unemployment rate and labor force participation rate from the US Bureau of Labor Statistics.

For industry composition and specific industry wage information, we utilized both North American Industry Classification System (NAICS) and Standard Industrial Classifications (SIC) data. The NAICS data are from EMSI, Inc., and the SIC data are from the BEA. While both classifications include similar data, they are not directly comparable. In our study, we utilize an author-developed crosswalk to combine data across time, utilizing both Standard Industrial 
Classifications (SIC) codes, from 1990-2000, and North American Industry Classification System (NAICS) codes, from 2001-2017.

The impact of community attachment also likely plays a strong role, and rural residents may have stronger attachments to their community, yet their decisions to stay are strongly influenced by their perceptions of local economic conditions (Petrin et al., 2014). Thus we control for this using the social capital index (Rupasingha et al., 2006).

As prior research has shown that growth in rural areas can be affected by the presence of natural amenities, which also could be especially negatively impacted by environmental contamination, we control for this using the natural amenity index (McGranahan, 1999).

Finally, since recent research suggests that high overdose death rates may contribute to higher rates of migration, particularly for younger populations (Taylor, 2020), we control for this using an index for overdose death. This index categorizes counties on a 5-category system, with Category 1 representing zero deaths in a given year, Category 2 representing counties with death rates below the national average, and then Categories 3, 4, and 5 representing one-, two, and more than two-standard deviations above the national average. All of these indices reflect a measure of utility or disutility to residents in those communities.

Table 3-2 lists all of the variables used in this study and provides a brief description of the data set. 
Variable Name

Total Population (persons)

Unemployment Rate (\%)

Per Capita Income (\$)

\section{Description}

Total population by county, by year.

Uses Census/SEER Data. 1990-2016

Unemployment rate by county, by year.

From BLS Data 1990-2016

Per Capita income by county, by year.

From BEA Data. 1990-2016
\% Population with High School Degree or Some College

\% Population with Bachelors Degree or Higher

Per Capita Disability Receipts (\$)

Population Density (person/sq mi)

Job Shares (\%)

Labor Force Participation Rate (\%)

Age Shares (\%)

Gender Share (\%)

Social Capital Score

Natural Amenity Score

Opioid Death Category

Distance to Core Business Statistical Area

C8 Impacted County
$\%$ of Population with a High School Diploma up to a Bachelors Degree, All Ages. Decennial Census Data 1990, 2000, Annual Data 2009-2016 from USDA-ERS

$\%$ of Population with a Bachelors Degree or Higher, All Ages. Decennial Census Data 1990, 2000, Annual Data 2009-2016 from USDA-ERS

Per Capita Disability receipts by county, by year. \$/Person. From BEA Data. 1990-2016

Number of Persons/Square Mile. Land Area from US Census Data

Derived from SIC and NAICS codes. Developed a 10-Category "Crosswalk" Set of Codes to Allow Comparison Across Years. NAICS codes replaced SIC codes in 1997. County level data on fraction of employment in each industry sector.

Labor Force Participation Rate. From BLS Data. 1990-2016

Percent of Population from ages 0-44 years old. From Census data. 1990-2016

Percent of Population that is female. From Census data. 1990-2016

Index from Penn State. Between 0 and 1. Treated as a continuous variable (not indicator). 2009 and 2014 data.

USDA-ERA Natural Amenities Score. Raw Z-Score Used.

Categorical variables for overdose death rates, in deaths per 100,000 population. Category 1 (Zero): 0 Deaths/100,000 in a given year Category 2 (Low): $0<$ Death Rate $\leq 12$

Category 3 (Medium): $12<$ Death Rate $\leq 20$

Category 4 (High): $20<$ Death Rate $\leq 40$

Category 5 (Very High): Death Rate $>40$ Deaths/100,000 in a given year

Distance, in kilometers, from study county to nearest CBSA designated county. Utilize literature (C8 Science Panel, Multiple Sources) to identify C8 effected counties in WV and $\mathrm{OH}$.

Table 3-2. Data Summary Table.

\subsection{Methodology}

To conduct our analysis we use the synthetic control method (SCM) (Abadie et al., 2003, 2010) to estimate the impact of the PFOA contamination. We use the population ratio as our key outcome variable and compare the population ratio constructed using the synthetically-matched counties to the actual population ratio in the counties. A comparison of the actual outcome to this synthetic counterfactual provides an estimate of what population impacts have occurred as 
a result of this long-term water pollution incident. In our models, we estimate the impact on each county separately and then can aggregate the effects for the entire impacted region.

Recent, relevant county-level investigations using synthetic control have included an analysis of the likely economic impacts of shale energy development (Munasib and Rickman, 2015) and an examination of birthweights and gross domestic product (GDP) in Kanawha County, WV, after a water contamination event (Guilfoos, 2017), and they provide some inspiration for our approach. Robbins et al. (2016), like this study, also use the approach for a relatively small number of substate areas. Finally, there are papers that use synthetic control methods to assess the impact of large scale natural disasters. Using the SCM, Cavallo et al. (2013) conclude that large natural disasters tend not to affect economic growth at a national scale. However, Coffman and Noy (2011) show that natural disasters can have dramatic localized economic impacts - and more relevant to this research - demonstrate the impact on population change, and the application of this approach at a county level.

Overall, synthetic control methods are best used to evaluate the impact of an event or policy intervention, and combine aspects of difference-in-difference and matching approaches. SCM uses pre-intervention characteristics on a pool of potential donor observations to generate a data-based synthetic "control" which can then be compared to the treated sample of interest. In this process, weights are assigned to each contributor to the synthetic match to develop a counterfactual. A significant strength of this analysis is that it allows the construction of a robust counterfactual, a weighted control that is more similar to the treated group of counties, with similar trends in the pre-treatment period. A further strength of SCM approaches is that they can help minimize uncertainty about the effect when there is a relatively small set of "treated" units (in this case, counties). This strength is the notable advantage when compared to classic difference-in-difference approaches (Bertrand et al., 2004).

We utilize STATA software and the "Synth" code package as developed by Abadie et al. (2014). The "Synth" code has a key limitation where control groups larger than approximately 1,500 control units (in our case, counties) will cause the software to crash. To avoid this limitation, we develop a pool of 1,400 potential control counties in our analysis using a "nearest neighbor" matching technique, matched on population density, per-capita incomes, disability receipts, unemployment and labor force participation rates, educational attainment, age composition, gender composition and industry composition in 1990, 2000, and 2005 . For robustness, a 
second group of 1,400 randomly selected counties were also used as potential controls to demonstrate that the models are unbiased. In all cases, we restrict the potential pool to eliminate any county within 25-miles of any treated county. Additionally, several counties in Louisiana experienced unusually large population changes as a result of Hurricane Katrina in 2005. Given the overlap of our treatment period, we exclude counties from Louisiana from our pool of potential control counties. To further reduce uncertainty in our treatment effect, we apply a randomization (placebo) test which is further described below (Abadie et al., 2010).

After selecting our pool of 1,400 potential control counties we utilize the SCM to construct our counterfactual. As noted by Abadie and Gardeazabal (2003) and Abadie et al. (2010), lagged values of the outcome variable - in our case, raw population - are important in the prediction of the outcome variable. These lagged values include effects of predictor variables, even if they are not included, and can significantly improve the predictive power of the model. However, Kaul et al., (2017) demonstrate that the model can be biased when it uses all of the lagged values for the outcome variable. If all of the pre-treatment values of the outcome variable are used, the synthetic control state can be re-created regardless of other predictor's values. Kaul et al. (2017) also notes that if these other predictors help forecast the outcome, then their omission can bias the synthetic outcome in the post treatment period. Following these findings, we use every other lag of our key variables as predictors. As noted in the data section above, our key factors used for matching are total population, age composition, disability receipts, distance to the nearest CBSA, educational attainment, gender composition, industry composition, labor force participation, the natural amenity score, per capita income, population density, the social capital index, and the unemployment rate. We then estimate the model using our two potential donor pools, the pool constructed using nearest neighbor matching and the random pool.

We then conduct additional analyses (explained below) using the nearest neighbor matched results, as they were selected to be the "closer", which should lead to more accurate results (Abadie et al., 2015). As a final robustness check, we use SCM again on both the nearest neighbor and random sets of control counties with a second model specification. In this second specification, all pre-treatment covariates (as defined above) are averaged over the pretreatment period, which changes depending on the potential treatment year we are examining (further described below). A sample result for Washington County, Ohio, using a treatment year 
of 2006, and illustrating the different sample pools and model specifications versus the actual changes in population ratio, is shown below in Figure 3-2.

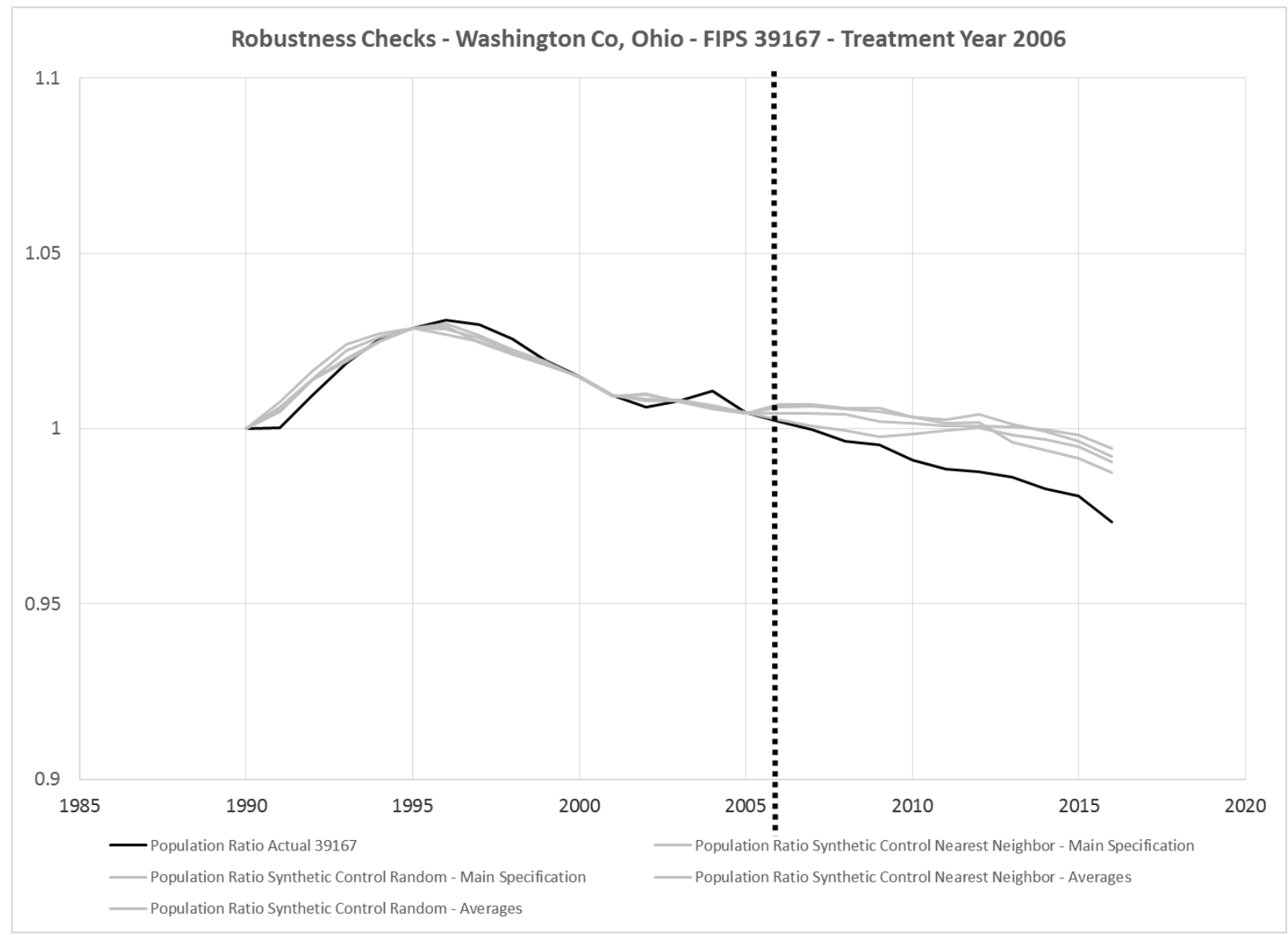

Figure 3-2. Example of Changed Sample Pools and Model Specification on Synthetic County Output.

The previous literature outlines various approaches for evaluating the significance of the synthetic estimates; however, we have the additional challenge of trying to identify when the "treatment" occurs in this event. While this event has a clear before time period (EPA fines levied, creation of C8 Science Panel - 2005) and a clear after time period (C8 Science Panel finds probable link to disease from exposure - 2013), they are separated by a long period of imperfect information. To identify the timing of the treatment, we thus estimate effects using the SCM for each of the years 2005-2012 for each of the treated counties. In these estimates, the pre-treatment period is updated for each additional year studied. For example, if 2009 is the treatment year, all years up to and including 2008 are included in the pre-treatment effects. If 2012 is the treatment year, all years up to and including 2011 are included in the pre-treatment effects. 
After generation of the synthetically-controlled matched counties, we then perform a differencein-difference calculation, using the technique described by Bohn et al. (2014).

$$
\Delta_{T R}=\left|\bar{Y}_{T R, \text { actual }}^{\text {Post }}-\bar{Y}_{T R, \text { synthetic }}^{\text {Post }}\right|-\left|\bar{Y}_{T R, \text { actual }}^{\text {Pre }}-\bar{Y}_{T R, \text { synthetic }}^{\text {Pre }}\right|
$$

With this approach, we calculate the average of the post-intervention actual outcome of the treatment county $\left(\bar{Y}_{T R, a c t u a l}^{\text {Post }}\right)$ and the post-intervention outcome of the counterfactual (synthetic) $\left(\bar{Y}_{T R, \text { synthetic }}^{\text {Post }}\right)$. Similarly, $\bar{Y}_{T R \text {, actual }}^{\text {Pre }}$ is the average of the pre-intervention actual outcome of the treatment county, and $\bar{Y}_{T R \text {,synthetic }}^{P r e}$ is the average of the pre-intervention outcome of the counterfactual. If $\Delta_{T R}>0$ then we can say that the outcome has changed "in response" to the intervention (i.e. water contamination), and can examine those outcomes in more detail (Taylor, 2020).

Prior research (Abadie et al., 2015, Abadie et al., 2010) suggest a method to further test the statistical significance of this effect, by comparing this treatment effect relative to the pretreatment fit, as measured by the Mean Squared Prediction Error (MSPE). Where error is calculated as

$$
e_{i}=Y_{i T R, a c t u a l}^{P r e}-Y_{i T R, \text { synthetic }}^{\text {Pre }}
$$

and MSPE is then calculated as

$$
M S P E=\frac{\sum_{i=1}^{n} e_{i}^{2}}{n}
$$

If too late of a period is selected, then the effect will have been absorbed into the forecast, and will disappear $\left(\Delta_{T R}<0\right)$. If too early of a period is selected, then the magnitude of the estimated effect may be inaccurate.

In order to determine the timing of the effect, for each of these synthetic matches, we then apply a simple scoring rubric, calculating a raw "score" for the model in each county, in each year. This rubric uses the difference-in-difference calculation from Eq 1 divided by the mean-square prediction error from Eq 3. This provides a single measure of the minimized pre-treatment error and maximized treatment effect. We then examine the scores for trends to identify more precisely when the treatment effect occurs. 


$$
\text { Score }=\frac{\Delta_{T R}}{M S P E}
$$

Finally, we then apply a full significance test, utilizing approaches as outlined in the literature (Bohn et al., 2014; Abadie et al., 2010; Buchmueller et al., 2011; Bertrand et al., 2004). To do so, we apply the same specification for our synthetic control model to each county that was matched to our treated counties from the donor pool (i.e. those counties that make up the synthetic controls) and then calculate the difference-in-difference (Eq 1) for each of those counties. This approach is typically referred to as "placebo" testing. In this testing, counties that are known not to have been effected by the treatment being studied (i.e. counties unaffected by this spill) are synthetically modeled and compared to their actual result. Performing this step allows us to address the fundamental question of whether we obtain an effect in the treated/study county that is as large as a place chosen at random (Munasib and Rickman, 2015). Following the example of Abadie et al. (2010), we then calculate the "difference-in-difference rank", comparing our treated counties and these donor/placebo counties. This is simply the ranking of the difference-in-difference values calculated using Eq 1 for both the treated county and donor counties that have comparable mean squared predictive errors. Finally, it is possible to calculate a joint significance score using the distribution of "placebo" difference-in-difference estimates (Bohn et al., 2014). This distribution provides the equivalent of a sampling distribution for the treatment effect $\left(\Delta_{T R}\right)$. This empirical cumulative density function (CDF) is derived for each potential treatment year, and a p-value from a onetailed test that $\Delta_{T R}>0$ can be found using this CDF. These tests together provide evidence of whether the treatment effect is "real" or if we are calculating a random effect unrelated to the water contamination.

\subsection{Results}

As described above, synthetic controls for all 10 counties are created across the 9-year time window (2005-2013), and examined for significance $\left(\Delta_{T R}>0\right)$, and then used to calculate a "score" (eq. 2). In this first step, 8 of 10 counties were found to have consistent statistically significant effects with $\Delta_{T R}>0$. A key question in our study is better identification of the treatment period - i.e. where in time the treatment effect occurs, given the uncertainty between the announcement of settlements and the final findings of the C8 science panel, linking these chemicals to health effects. Using our derived score, we can help to identify this treatment 
period. The highest score for each of the 8 counties was then tabulated by year, and notably, the effect seems to occur in the earlier half of our study period, with all of the highest scores occurring before 2009 (Table 3-3). This suggests that households in this region were already concerned about the problems before all of the information was publicly available. Using these results, we restrict our placebo analyses to the years 2005-2009. Based on the results of our placebo tests, we find that our most statistically significant results, as indicated by DID rank and by joint significance score, occur in the period between 2005 and 2007 . We focus on 2006 as the "treatment year", but also provide the range of outcomes from 2005-2007 for reference. Graphs presented are for the 2006 year, and we utilize 2006 in the presentation of the regional impacts. Results for the DID rank, joint score, and CDF analysis for each county are contained in Appendix C (Table 1).

\begin{tabular}{|c|c|c|c|c|c|c|c|c|c|}
\hline Year & 2005 & 2006 & 2007 & 2008 & 2009 & 2010 & 2011 & 2012 & 2013 \\
\hline $\begin{array}{c}\text { Highest } \\
\text { Score }\end{array}$ & 3 & 1 & 3 & 1 & 0 & 0 & 0 & 0 & 0 \\
\hline
\end{tabular}

Table 3-3. Occurrence of highest score (Score $=\Delta_{T R}$ MSPE) by year.

In what follows, we first examine the impact of this incident on the counties that are known to have been directly impacted by water contamination, notably those with water districts included in the 2005 settlement (Leach V. DuPont, 2005). Then, we examine neighboring counties that were included in the C8 Science Panel health studies. We conclude with an examination of the impact across the study region. Summary statistics for the counties included in this study are shown in Table 3-4. 


\begin{tabular}{|c|c|c|c|c|c|c|c|c|c|c|}
\hline & $\begin{array}{c}\text { Athens Co, } \\
\text { OH }\end{array}$ & $\begin{array}{c}\text { Meigs Co, } \\
\text { OH }\end{array}$ & $\begin{array}{l}\text { Washington } \\
\text { Co, } \mathrm{OH}\end{array}$ & $\begin{array}{l}\text { Cabell Co, } \\
\text { WV }\end{array}$ & $\begin{array}{l}\text { Jackson Co, } \\
\text { WV }\end{array}$ & $\begin{array}{l}\text { Mason Co, } \\
\text { WV }\end{array}$ & $\begin{array}{l}\text { Pleasants Co, } \\
\text { WV }\end{array}$ & $\begin{array}{l}\text { Ritchie Co, } \\
\text { WV }\end{array}$ & $\begin{array}{l}\text { Wirt Co, } \\
\text { WV }\end{array}$ & $\begin{array}{l}\text { Wood Co, } \\
\text { WV }\end{array}$ \\
\hline & Fips 39009 & Fips 39105 & Fips 39167 & Fips 54011 & Fips 54035 & Fips 54053 & Fips 54073 & Fips 54085 & Fips 54105 & Fips 54107 \\
\hline Total Population & 63,068 & 23,361 & 62,477 & 96,549 & 28,125 & 26,337 & 7,597 & 10,259 & 5,697 & 87,238 \\
\hline Unemployment Rate (\%) & 6.687 & 10.61 & 6.962 & 5.937 & 7.865 & 10.12 & 8.729 & 9.264 & 11.48 & 6.488 \\
\hline Per Capita Income (\$) & 21,727 & 21,486 & 26,241 & 27,465 & 23,244 & 21,616 & 25,236 & 21,232 & 19,263 & 27,139 \\
\hline $\begin{array}{l}\text { High School/Some College } \\
\text { (\%) }\end{array}$ & 51.06 & 52.34 & 54.93 & 47.14 & 50.17 & 51.73 & 57.49 & 52.58 & 54.25 & 52.10 \\
\hline Bachelors or Higher (\%) & 15.76 & 7.660 & 11.48 & 16.92 & 10.76 & 7.313 & 7.936 & 7.301 & 7.373 & 12.93 \\
\hline $\begin{array}{l}\text { Per Capita Disability } \\
\text { Receipts (\$) }\end{array}$ & 156.5 & 190.5 & 164.7 & 495.0 & 236.0 & 271.0 & 223.1 & 223.0 & 197.6 & 293.8 \\
\hline $\begin{array}{l}\text { Population Density } \\
\text { (persons/sq mi) }\end{array}$ & 125.0 & 54.34 & 98.98 & 343.8 & 60.50 & 61.10 & 58.42 & 22.74 & 24.49 & 238.4 \\
\hline $\begin{array}{l}\text { Share Jobs } 100 \\
\text { (Agriculture) (\%) }\end{array}$ & 0.904 & 6.833 & 1.454 & 0.299 & 2.123 & 6.023 & 1.747 & 2.346 & 5.363 & 0.451 \\
\hline $\begin{array}{l}\text { Share Jobs } 200 \\
\text { (Mining) (\%) }\end{array}$ & 0.850 & 4.308 & 1.847 & 0.225 & 0.942 & 0.678 & 1.725 & 13.86 & 3.297 & 0.419 \\
\hline $\begin{array}{l}\text { Share Jobs } 300 \\
\text { (Construction) (\%) }\end{array}$ & 3.639 & 8.896 & 6.967 & 4.460 & 5.057 & 5.435 & 5.640 & 4.890 & 7.196 & 5.315 \\
\hline $\begin{array}{c}\text { Share Jobs } 400 \\
\text { (Manufacturing) (\%) }\end{array}$ & 2.468 & 3.466 & 14.43 & 8.861 & 17.37 & 8.965 & 15.11 & 25.46 & 12.76 & 9.326 \\
\hline $\begin{array}{c}\text { Share Jobs } 500 \\
\text { (Transportation and } \\
\text { Utilities) } \\
(\%)\end{array}$ & 1.478 & 2.566 & 5.004 & 2.613 & 3.357 & 12.65 & 10.48 & 3.287 & 2.650 & 3.354 \\
\hline $\begin{array}{c}\text { Share Jobs } 600 \\
\text { (Wholesale Trades) (\%) }\end{array}$ & 1.403 & 1.003 & 3.248 & 3.629 & 3.041 & 1.754 & 1.260 & 2.399 & 0.479 & 2.374 \\
\hline $\begin{array}{c}\text { Share Jobs } 700 \\
\text { (Retail Trades) (\%) }\end{array}$ & 13.13 & 16.59 & 12.90 & 15.17 & 15.31 & 11.10 & 8.508 & 9.122 & 10.73 & 17.05 \\
\hline $\begin{array}{c}\text { Share Jobs } 800 \\
\text { (Finance and Real Estate) } \\
(\%)\end{array}$ & 3.216 & 3.998 & 4.286 & 4.187 & 3.827 & 2.629 & 2.855 & 3.182 & 3.191 & 4.997 \\
\hline $\begin{array}{c}\text { Share Jobs } 900 \\
\text { (Services, Health Care, } \\
\text { Education) (\%) }\end{array}$ & 31.89 & 26.09 & 37.85 & 45.80 & 31.90 & 28.32 & 29.59 & 19.02 & 24.22 & 40.73 \\
\hline $\begin{array}{l}\text { Share Jobs } 999 \\
\text { (Government) (\%) }\end{array}$ & 41.01 & 26.25 & 12.01 & 14.75 & 17.08 & 22.45 & 23.08 & 16.44 & 30.13 & 15.98 \\
\hline $\begin{array}{l}\text { Labor Force Participation } \\
\text { (\%) }\end{array}$ & 58.16 & 59.94 & 76.34 & 66.98 & 67.47 & 58.84 & 62.56 & 66.98 & 60.53 & 72.26 \\
\hline $\begin{array}{l}\text { Percent Population } \\
\text { Below } 44(\%)\end{array}$ & 71.39 & 58.17 & 57.44 & 59.68 & 57.30 & 56.86 & 57.73 & 55.36 & 57.84 & 57.27 \\
\hline $\begin{array}{l}\text { Percent Population } \\
\text { Female }(\%)\end{array}$ & 50.26 & 51.00 & 51.13 & 51.47 & 50.72 & 51.65 & 47.13 & 50.21 & 49.76 & 51.77 \\
\hline Social Capitol & -0.00319 & -0.207 & 0.283 & -0.185 & -0.237 & -0.194 & -0.124 & -0.508 & -0.663 & 0.307 \\
\hline Natural Amenity Score & -0.0100 & -3.230 & 0.210 & 0.110 & -0.0800 & -0.0500 & -0.120 & -2.420 & -0.340 & -0.190 \\
\hline Distance to CBSA & 0 & 26.48 & 0 & 0 & 29.82 & 0 & 0 & 21.89 & 0 & 0 \\
\hline 3-Year Overdose Category & 3.231 & 2.615 & 2.462 & 4.846 & 2.846 & 4.154 & 2.231 & 2.077 & 2 & 3.462 \\
\hline
\end{tabular}

Table 3-4. Summary Statistics of Study Counties

\subsection{Directly Impacted Counties}

We first examine those counties that are known to have been directly impacted by water contamination, in other words, those with water districts included in the 2005 settlement (Leach V. DuPont, 2005). For counties in Ohio, it is believed that air emissions from the Washington Works plant deposited on the ground surface and leached into ground water causing contamination. For counties in WV, the contamination appears to be due to a mix of both air 
emissions and intentional dumping at waste sites near the Washington Works facility and nearby landfills.

\subsubsection{Athens County, Ohio}

Athens County, Ohio, includes portions of the Little Hocking Water District. Athens County has the youngest population in the study group (69\% of the population is below age 44 ) and has the highest share of government jobs. This is likely due to the presence of a large state university, Ohio University, which also contributes to Athens County having the second highest rate of college attainment in our study group. The location of Athens County and the results of the synthetic control for 2006 are shown in Figure 3-3.

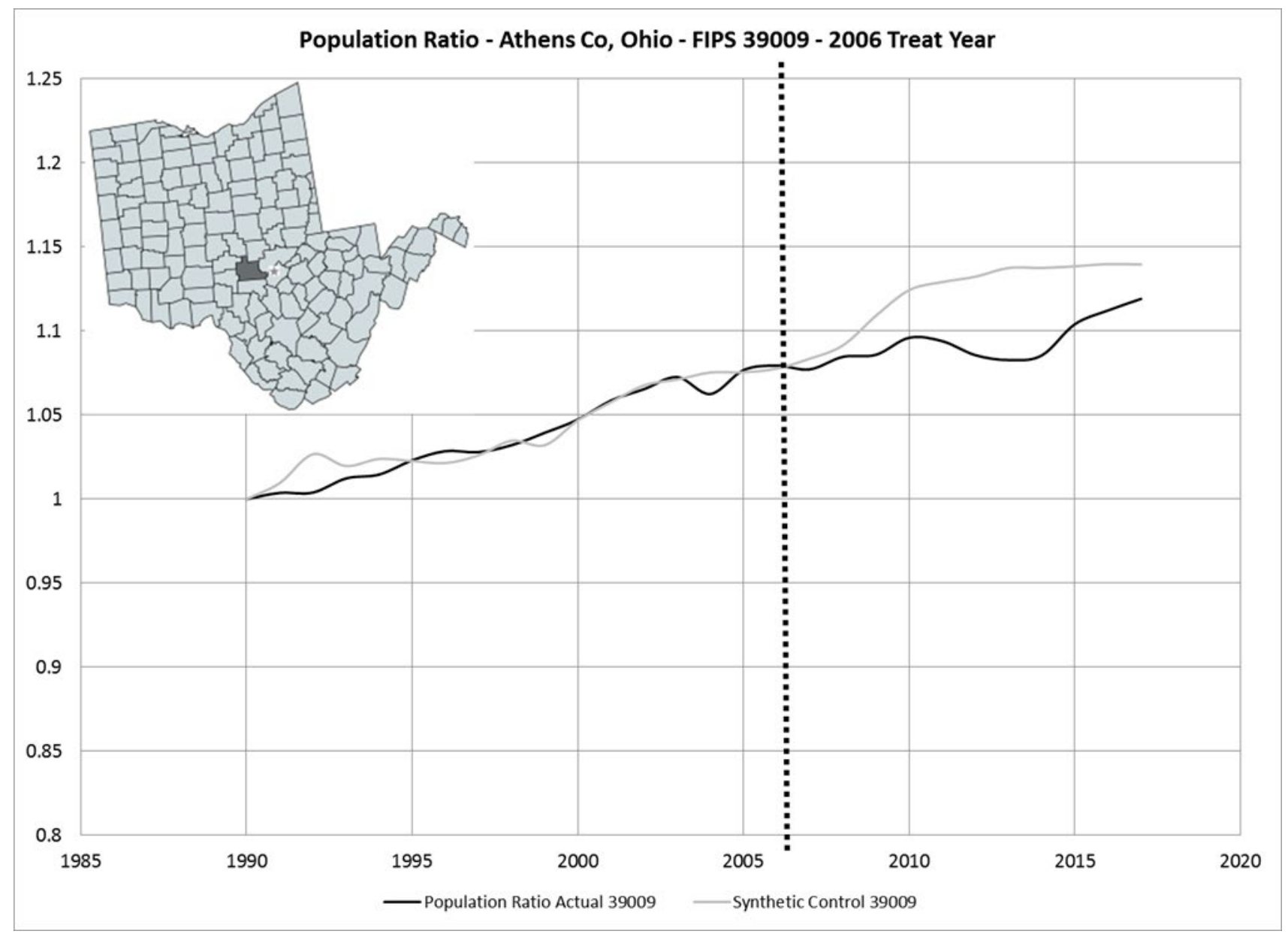

Figure 3-3. Athens County Location and Synthetic Control vs. Actual Population Ratio

While Athens County grew by approximately 2,300 people from 2006-2017, Ohio University enrollment growth accounts for more than 3,500 during that same time. However, based on our 
analysis, overall, Athens County did not grow as expected - the population growth was 1,900 people smaller (3\%) versus what would have been expected had this spill not occurred.

\subsubsection{Meigs County, Ohio}

Meigs County, Ohio, includes the Tuppers Plains Water District and Pomeroy, Ohio, both noted in the 2005 settlement. Meigs County has the highest shares of agricultural and extractive industries (mining, oil and gas) in the study group. The location of Meigs County and the results of the synthetic control for 2006 are shown in Figure 3-4. From 2006-2017, Meigs County's population remained relatively stable, falling by approximately 500 people on a population base of roughly 23,000 . The synthetic control forecasts a net effect of the spill is a population difference of about 680 fewer people.

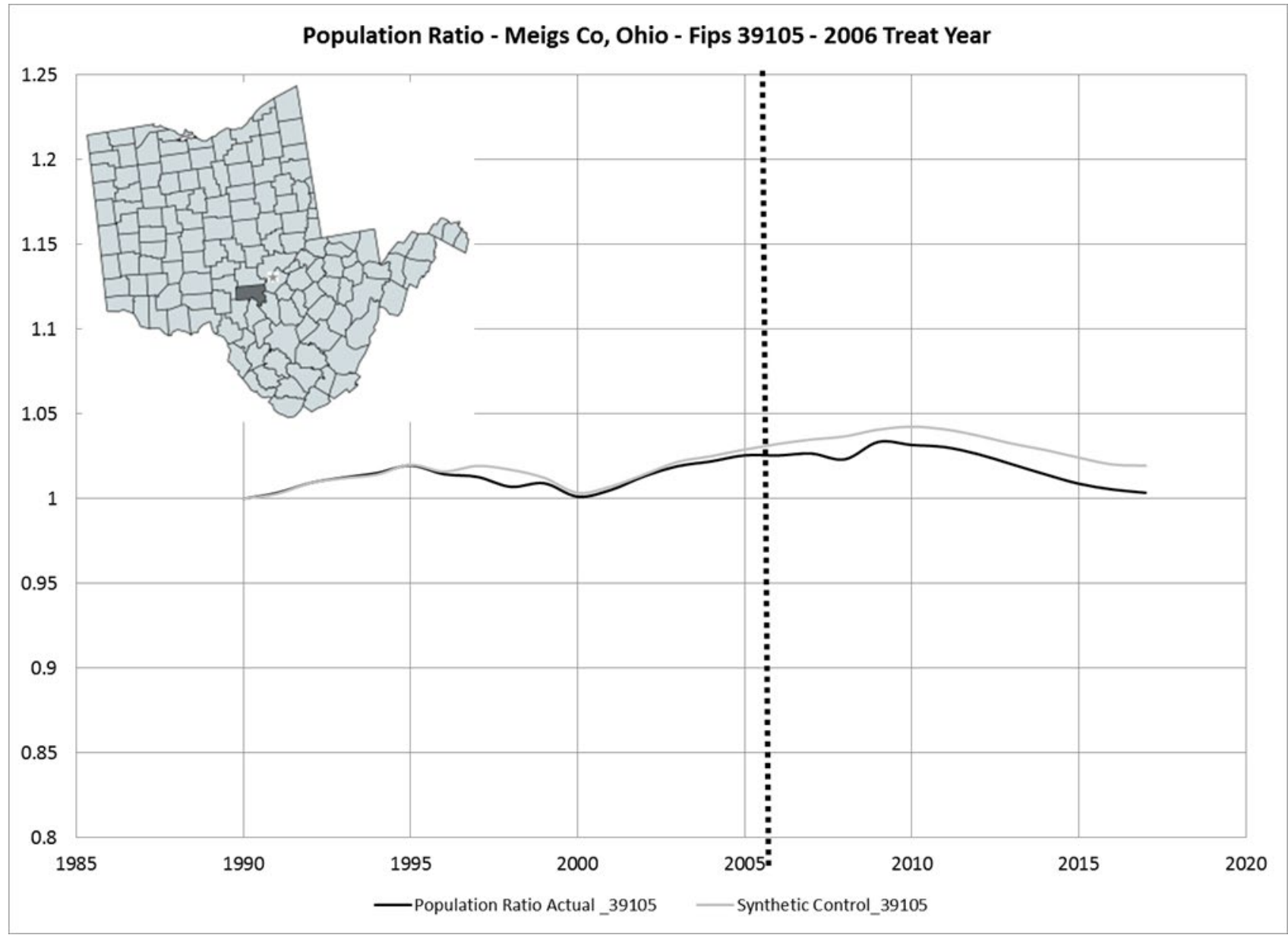

Figure 3-4. Meigs County and Synthetic Control vs. Actual Population Ratio 


\subsubsection{Washington County, Ohio}

Washington County, Ohio, includes the majority of the Little Hocking Water District and Belpre, Ohio, both noted in the 2005 settlement, and is directly across the Ohio River from the Washington Works plant that is believed to be the source of the PFOA. Washington County has the highest labor force participation and lowest share of government employment in our study pool, with a high concentration of manufacturing and service employment. The location of Washington County and the results of the synthetic control for 2006 are shown in Figure 3-5.

From 2006-2017, Washington County's population dropped $3 \%$ or roughly 2,000 people. The synthetic control forecasts a relatively level population during this period, declining $1.6 \%$ from 2006-2017. Thus, it appears the net effect of the contamination is large, a loss of $-1,300$ people over the study period.

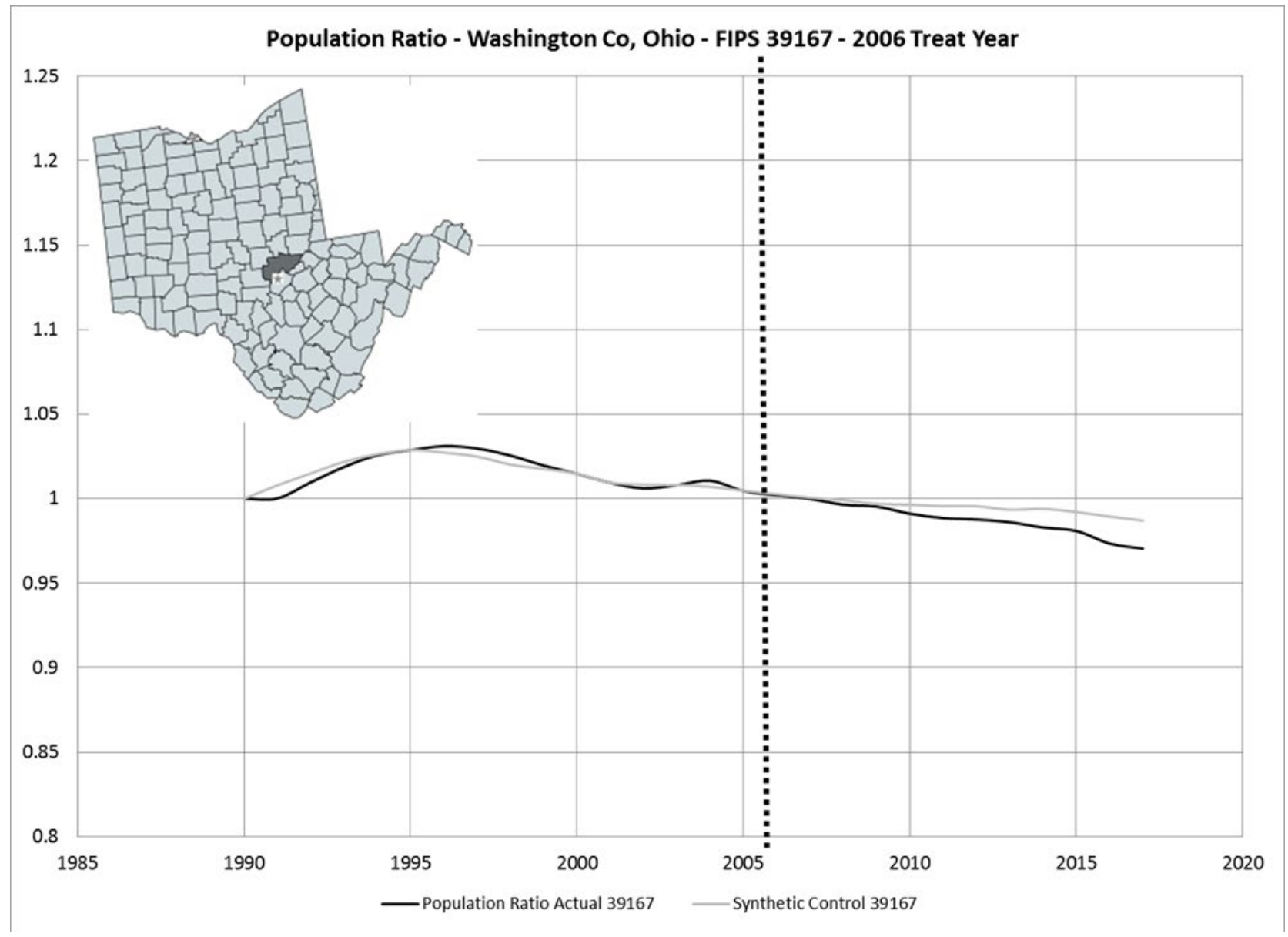

Figure 3-5. Washington County and Synthetic Control vs. Actual Population Ratio 


\subsubsection{Mason County, West Virginia}

Mason County, West Virginia, was included in the 2005 settlement, notably from industrial dumping at the Letart Landfill, which was utilized by DuPont from the 1960s until 1995. Leaching from this landfill is suspected to be the primary pathway for water contamination in aquifers serving the Mason County Public Service District (PSD). Mason has a high concentration of transportation and utilities jobs, the highest in the study. The location of Mason County and the results of the synthetic control for 2006 are shown in Figure 3-6.

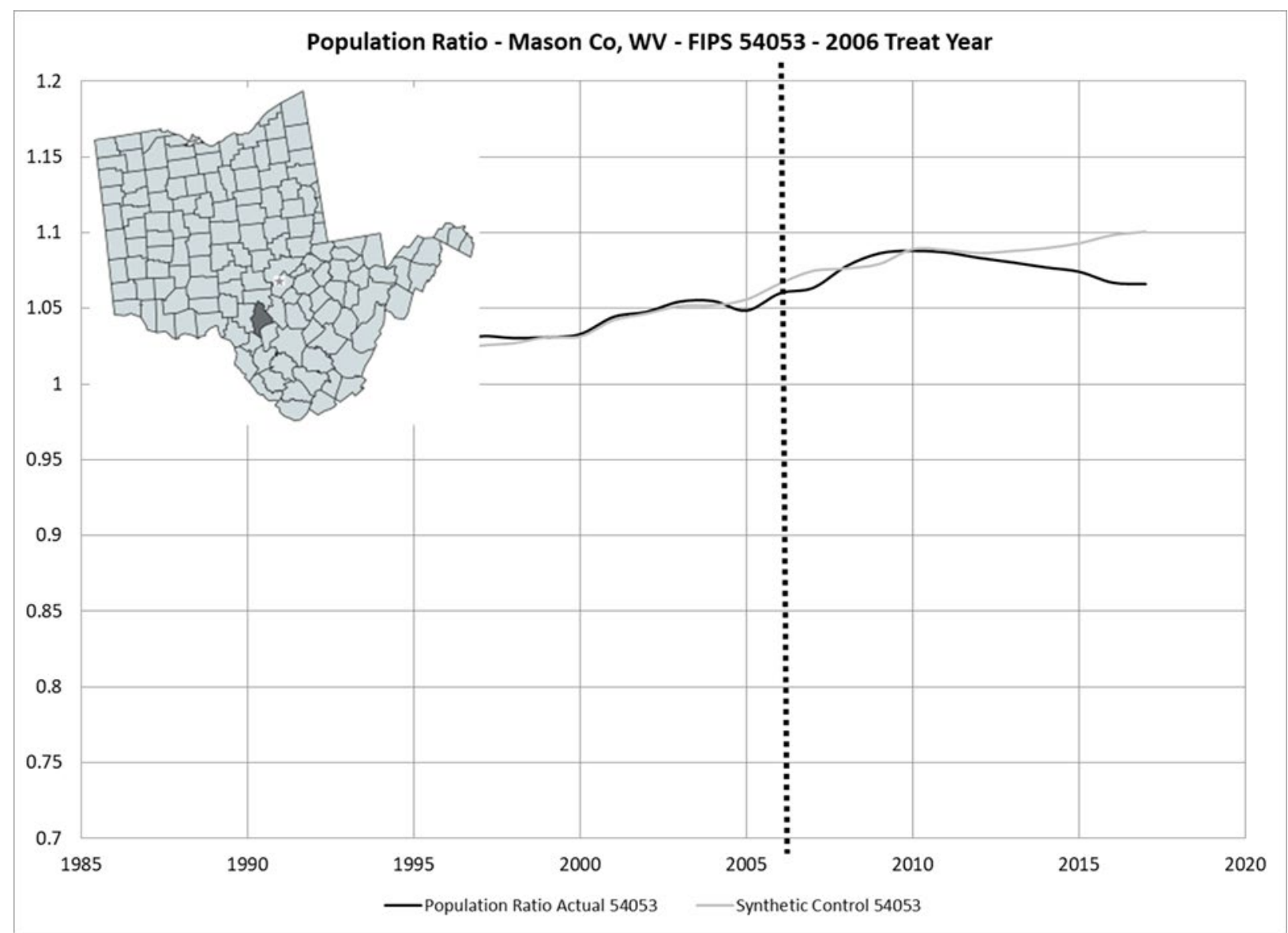

Figure 3-6. Mason County Location and Synthetic Control vs. Actual Population Ratio

Mason County presents an interesting case study - the Mason County Public Service District was included in the 2005 Settlement, but filters were not installed until mid-2009. Overall, the results of our robustness checks suggest that there a weak effect on this county starting in 2006, but inspection of the results show that the synthetic and actual start to diverge in 2009. As a spot examination, a specific case with treatment applied in 2009 was performed. The results are intriguing, with a reasonably high statistical significance. (Appendix C). As 2009 is 
outside of our core study window, these results are not included in our regional analysis. Mason County's population grew marginally, 0.6\% (150 persons) from 2006 to 2017, compared with minor growth forecasted by the synthetic control. The net difference is roughly 600 fewer people compared to its synthetic counterpart over the study period.

\subsubsection{Wood County, West Virginia}

Wood County, West Virginia, is "ground zero" for this study, home to the Washington Works facility, and to the Lubeck PSD. Water contamination in Wood County occurred through multiple pathways, including onsite dumping, air emissions, off-site dumping at nearby landfills, and leaching from on-site ponds into the Lubeck PSD aquifer. Wood County is a metropolitan county, which includes Parkersburg, WV, and has the highest college attainment rate in our study group among counties without a major college. Wood County also has the second highest per capita income in our study group. The location of Wood County and the results of the synthetic control for 2006 are shown in Figure 3-7.

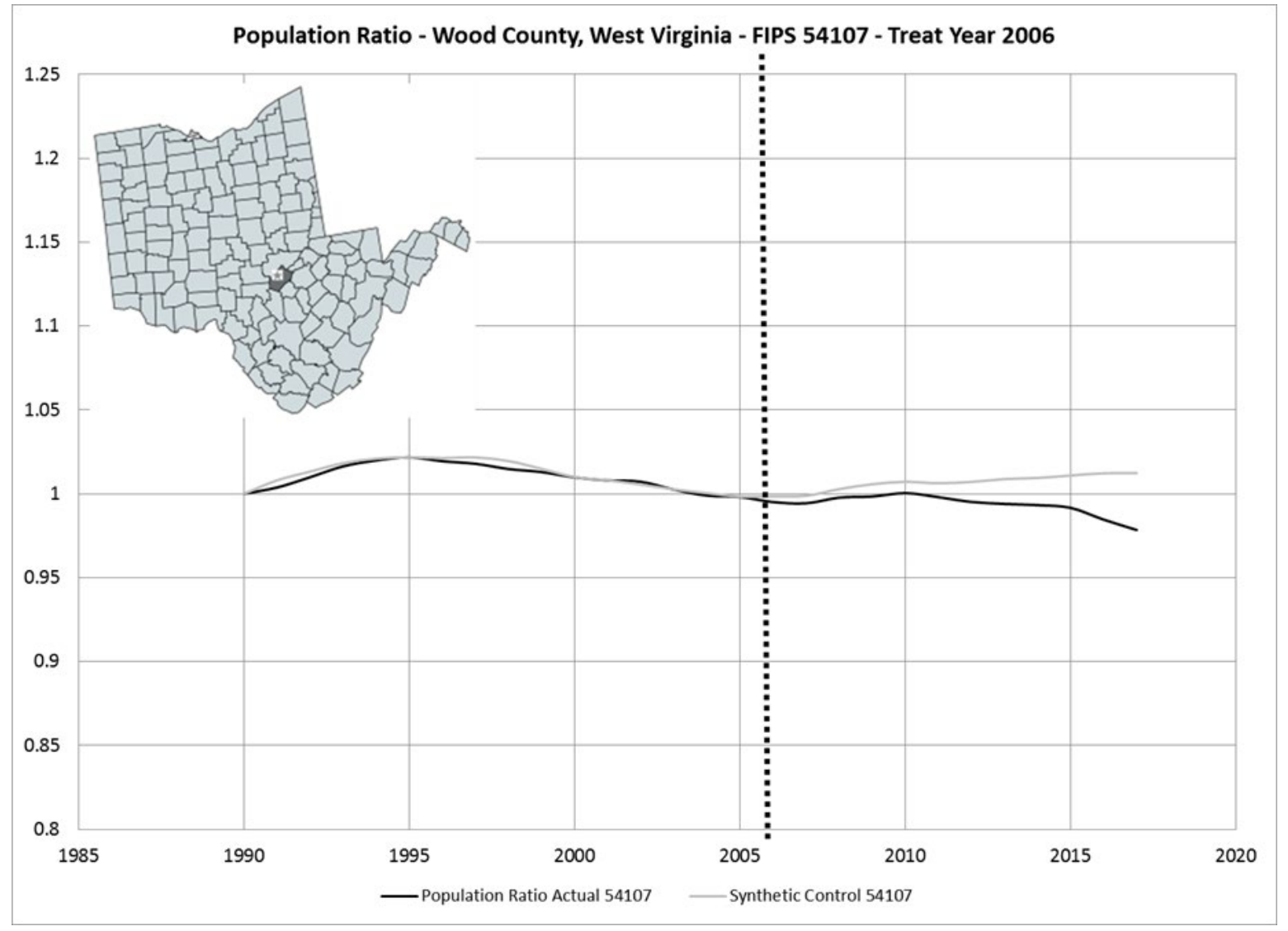

Figure 3-7. Wood County Location and Synthetic Control vs. Actual Population Ratio 
Wood County lost significant population during the study period, down 1.7\% (approximately 1,400 persons), but more striking is the comparison to the synthetically predicted result. Compared to the synthetic Wood County, the population is estimated at 2,900 fewer people than would be expected, a loss of $3.3 \%$, in other words, the synthetic Wood County was projected to grow during this time period. Wood County has several structural strengths, relative to population growth - an educated population, high wages, and an urban center - but still suffered from population decline.

\subsection{Indirectly Effected Counties}

\subsubsection{Cabell County, West Virginia}

Cabell County, West Virginia, is the county farthest away from the Washington Works plant to be included in the C8 Panel, and was not directly impacted by water contamination. Cabell County is home to Marshall University, with an enrollment of over 16,000 students in 2005 , and is the county in our study with the largest population. Cabell County also has the highest percapita income, highest rate of college attainment, highest population density, and second youngest population in the study group. These trends are also likely reflected in an industry composition that is heavily dependent on services and education. The location of Cabell County and the results of the synthetic control for 2006 are shown in Figure 3-8.

The results for Cabell County are significant, however, what is notable is that they are positive versus negative - the synthetic control forecasts a lower growth in population than was actually observed. Cabell County's population was stable $(0.14 \%$ change $)$, versus the prediction of a population loss. While it is unclear what might have contributed to this unpredicted growth, it is conceptually possible that persons displaced by this spill in other counties could have relocated to this region, due to its strengths (higher educated population, higher incomes, etc.) noted previously. 


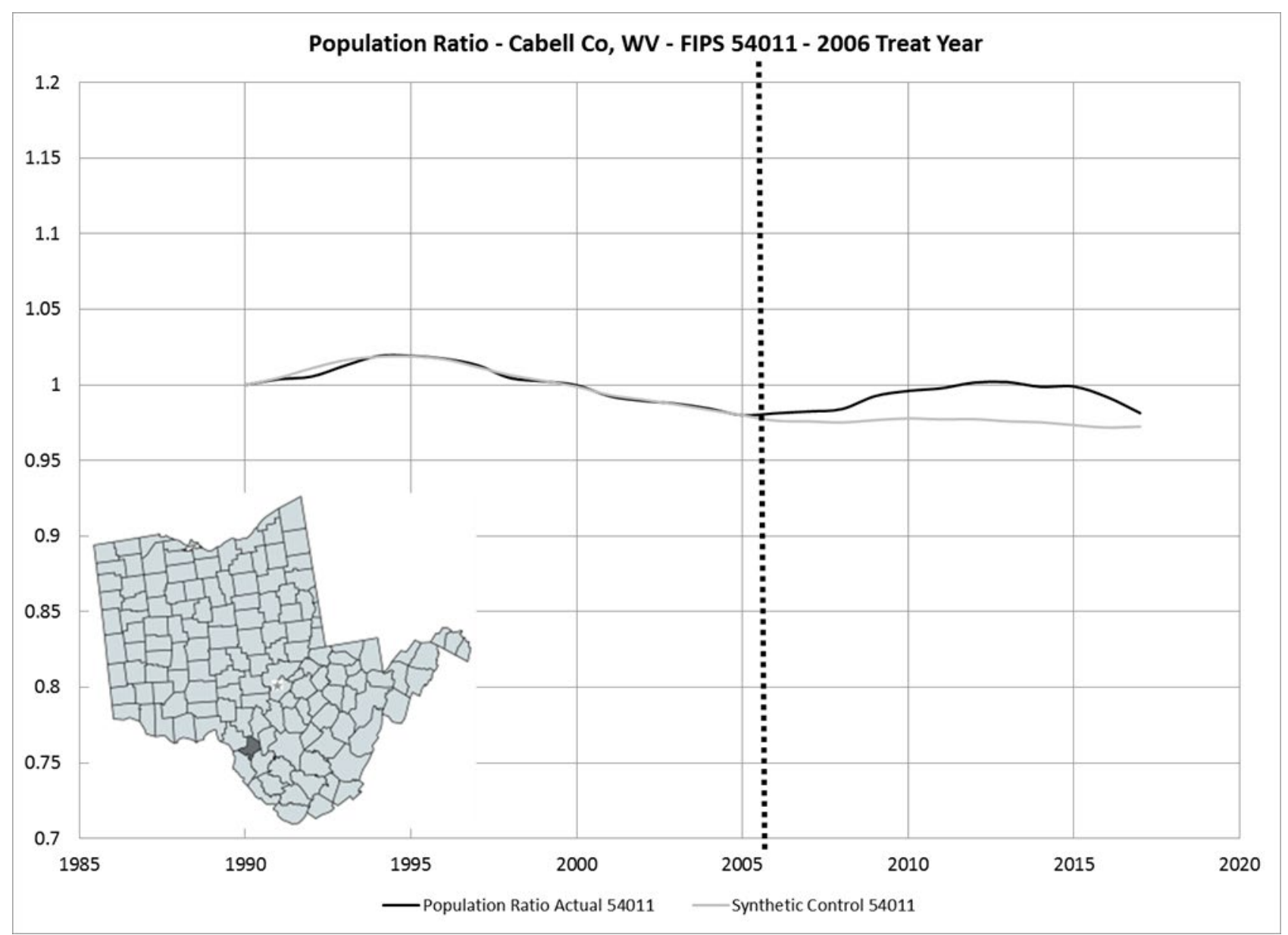

Figure 3-8. Cabell County Location and Synthetic Control vs. Actual Population Ratio

\subsubsection{Jackson County, West Virginia}

Jackson County, West Virginia, presented a bit of confusion at the outset of this study.

Bounded on three sides by counties directly impacted by water contamination, it was not clear why Jackson County was not included in the post-spill cleanup settlements. Further research (Lyons, 2007) found that while industrial waste from the Washington Works facility was trucked through Jackson County, it was never dumped or disposed of there. Jackson County was included in the C8 Panel Study because of these incidents. The location of Jackson County and the results of the synthetic control are shown in Figure 3-9. The results from the initial synthetic control found no significant difference-in-difference effect $\left(\Delta_{T R}<0\right)$. This also helps to build confidence in our approach - in a county that is not expected to have any significant impacts, none are predicted. 


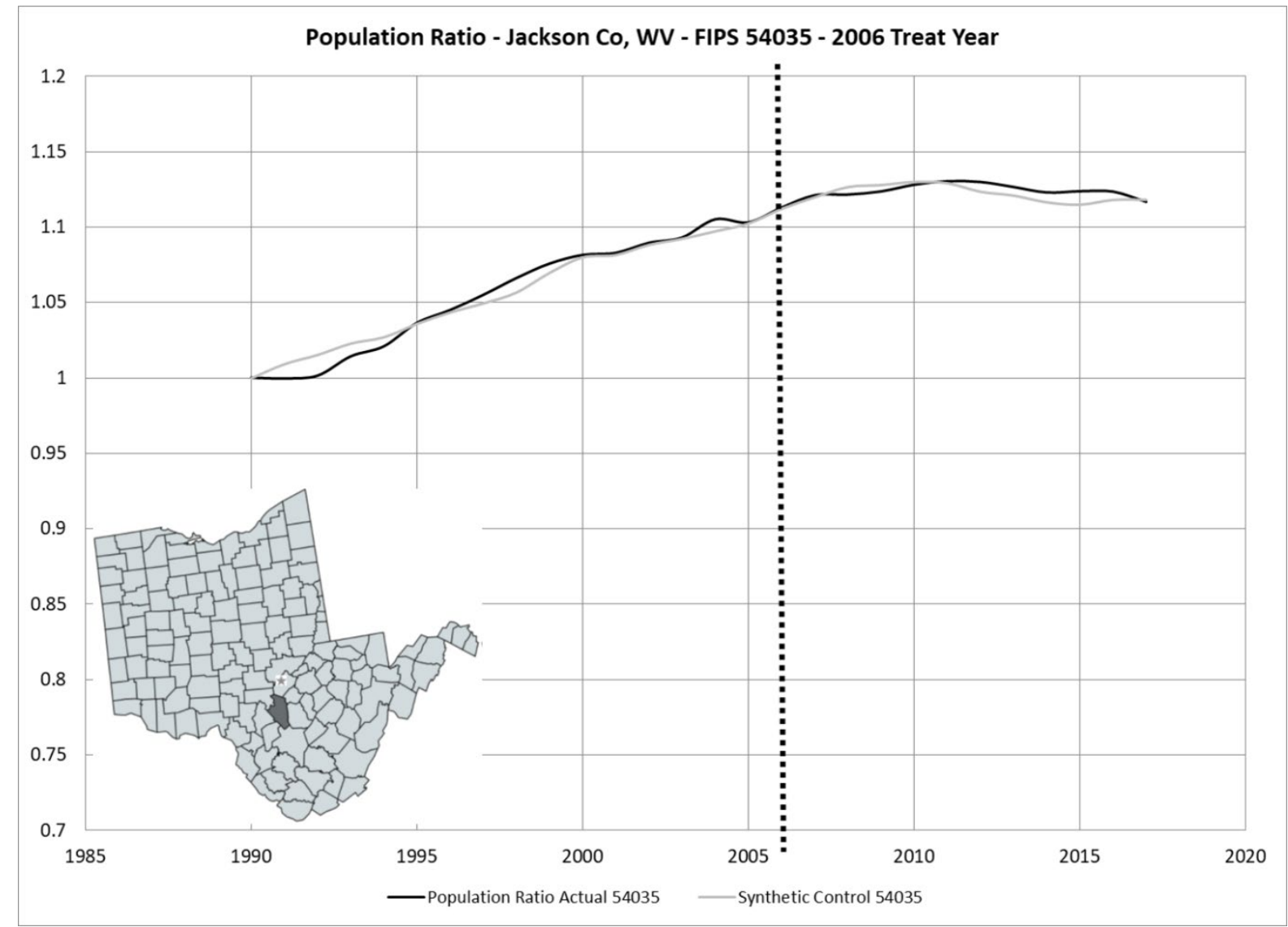

Figure 3-9. Jackson County Location and Synthetic Control vs. Actual Population Ratio

\subsubsection{Pleasants County, West Virginia}

Pleasants County, West Virginia, is directly upriver along the Ohio River from the Washington Works plant. No publicly available data indicates water pollution in this county, but many residents of Pleasants County are commuters to affected counties in the region. Pleasants County has the second smallest overall population in our study group and the highest rate of high-school attainment. The location of Pleasants County and the results of the synthetic control are shown in Figure 3-10.

Pleasants County's population was relatively stable during the study period, but was significantly lower than those predicted by the synthetic Pleasants County. The synthetic Pleasants County is forecasted to have grown significantly in the study period, leading to a net loss of nearly $6 \%$ of the total county population. This could be due to effects that "should have" happened in nearby Wood County, West Virginia, which was also forecasted for growth. Many residents in Pleasants County commute to Wood and Washington Counties, and the economic fortunes of Pleasants are in many ways linked to these larger neighboring counties. 


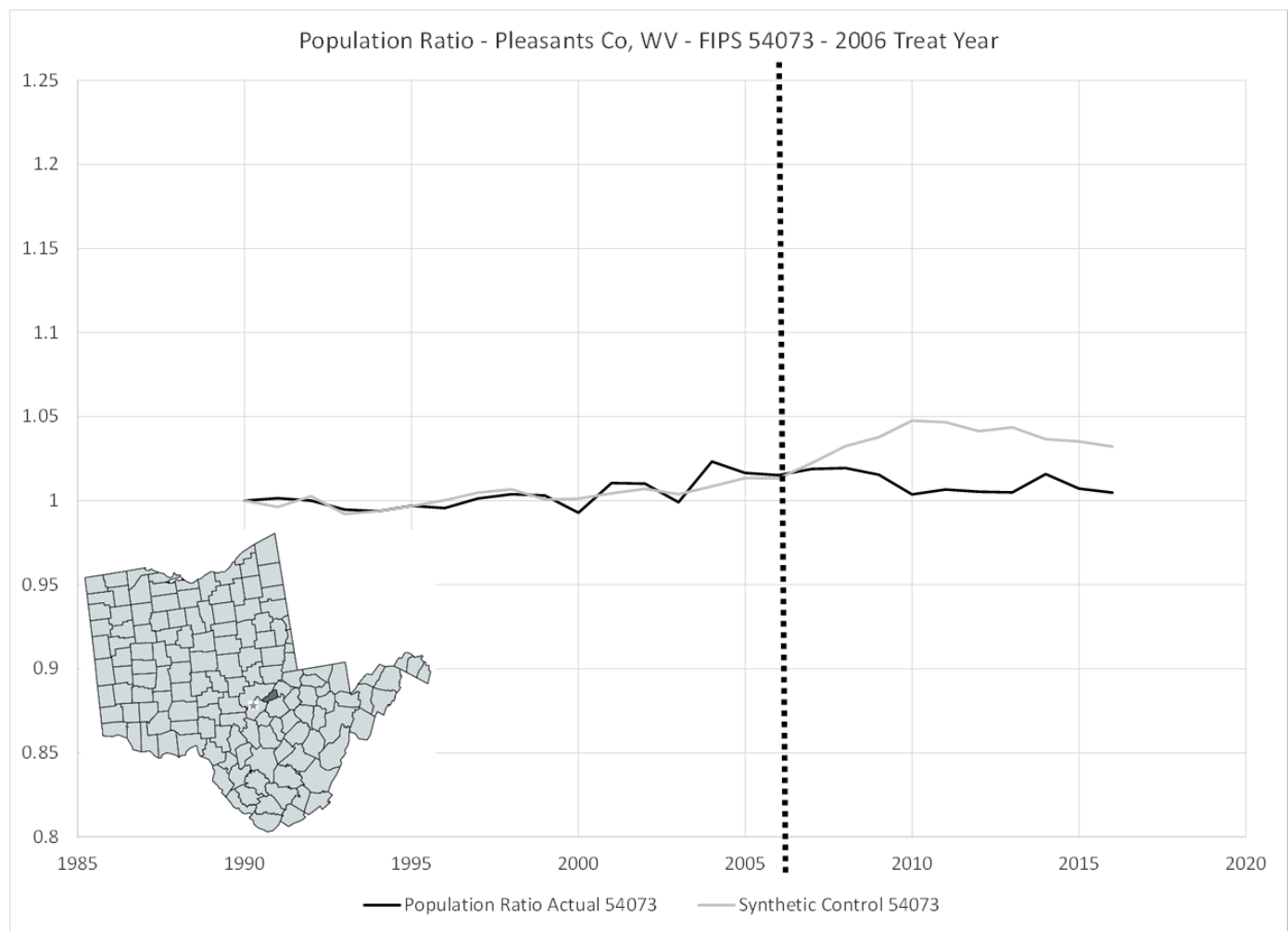

Figure 3-10. Pleasants County Location and Synthetic Control vs. Actual Population Ratio

\subsubsection{Ritchie County, West Virginia}

Ritchie County, West Virginia is a neighbor to Wood County, but inland and upslope from the Washington Works facility. Ritchie County has the oldest population in our study group, with $52 \%$ of the population over 44 years of age. It is also the least densely populated county in the study. The location of Ritchie County and the results of the synthetic control are shown in Figure 3-11.

While the results from the initial synthetic control were significant enough to move into full placebo testing, the results were of low significance (Appendix $C$ ). Thus, we cannot conclude anything about the results, which is somewhat expected. Ritchie County does not share a water supply or aquifers with any of the directly impacted counties and is up gradient/upstream from these events, providing a buffer to pollution impacts on its sources of water. Further, given the county demographics, with older, rural people, who are among some of the least likely to move, this effect is not surprising. 


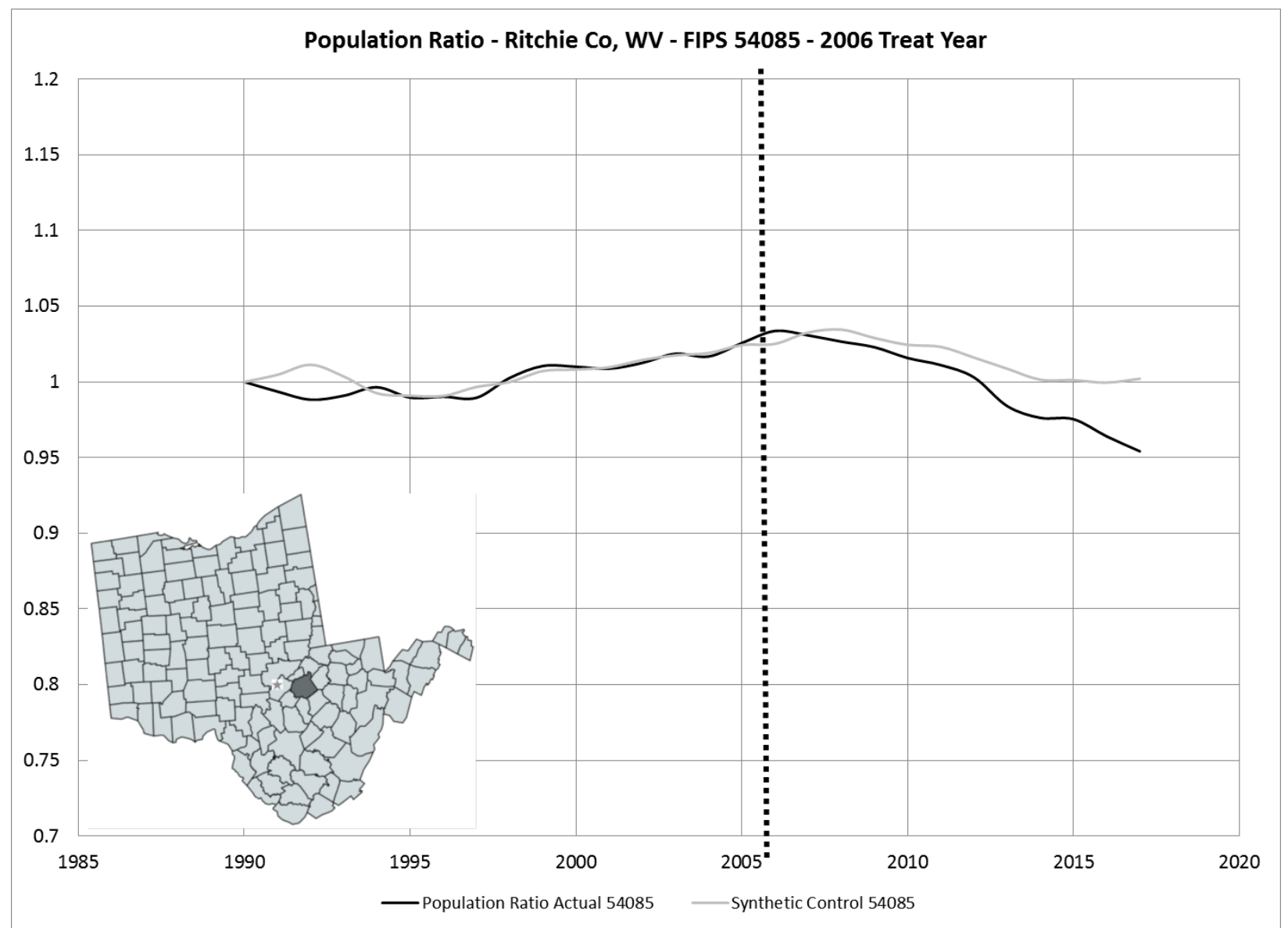

Figure 3-11. Ritchie County Location and Synthetic Control vs. Actual Population Ratio

\subsubsection{Wirt County, West Virginia}

Wirt County, West Virginia, is also a neighbor to Wood County, but inland and upslope from the Washington Works facility. Wirt County is the smallest county in our study group, with the lowest per-capita incomes and the second lowest rate of college attainment. The location of Wirt County and the results of the synthetic control are shown in Figure 3-12.

The results from the initial synthetic control found no significant difference-in-difference effect $\left(\Delta_{T R}<0\right)$. As with Ritchie County, this result was also expected. Wirt County does not share a water supply or aquifers with any of the directly impacted counties and is up gradient/upstream from these events, providing a buffer to pollution impacts on its sources of water. 


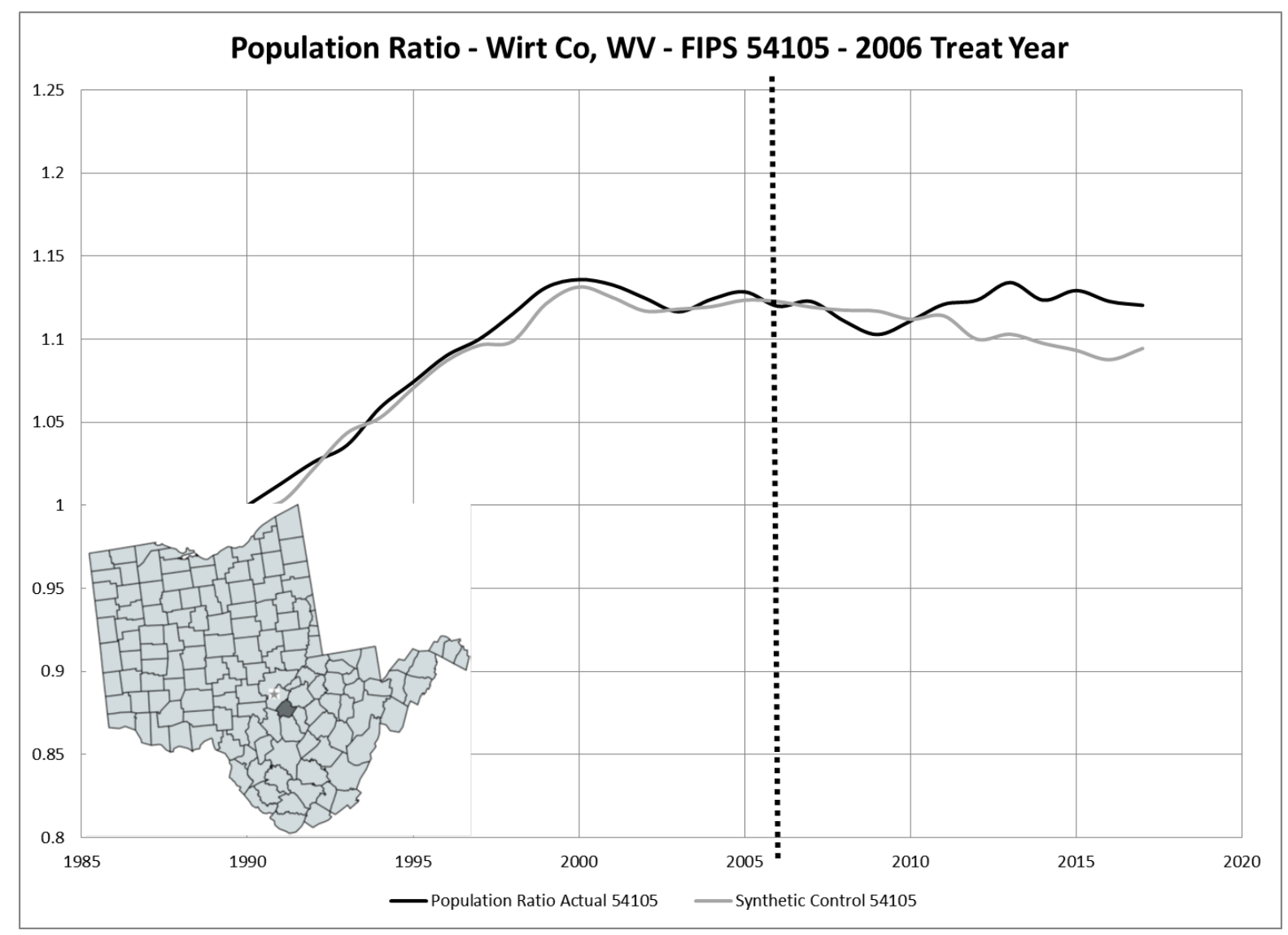

Figure 3-12. Wirt County Location and Synthetic Control vs. Actual Population Ratio

\subsection{Regional Effects}

Overall, this incident appears to have had significant, long-term impacts on the population of the region. While earlier results were presented as population ratio changes, we can also directly examine population changes across the 10-county region. In the results below, we aggregate the effects found for counties with a statistically significant result to evaluate the regional impact. Across the 10-county region, we found statistically significant results for 7-counties. In this 7county region, the population is relatively steady, changing by 400 people on a population of more than 340,000 from 2006-2017. What is striking is this outcome compared to the synthetically-modeled region. The synthetic region is projected to have had a significant population increase, approximately 8,000 in this same period. Figure 3-13 shows the actual versus modeled populations for the region. Finally, for those counties directly impacted by the PFOA contamination, we see that the predicted population effects greatly follow these counties (Figure 3-14). 


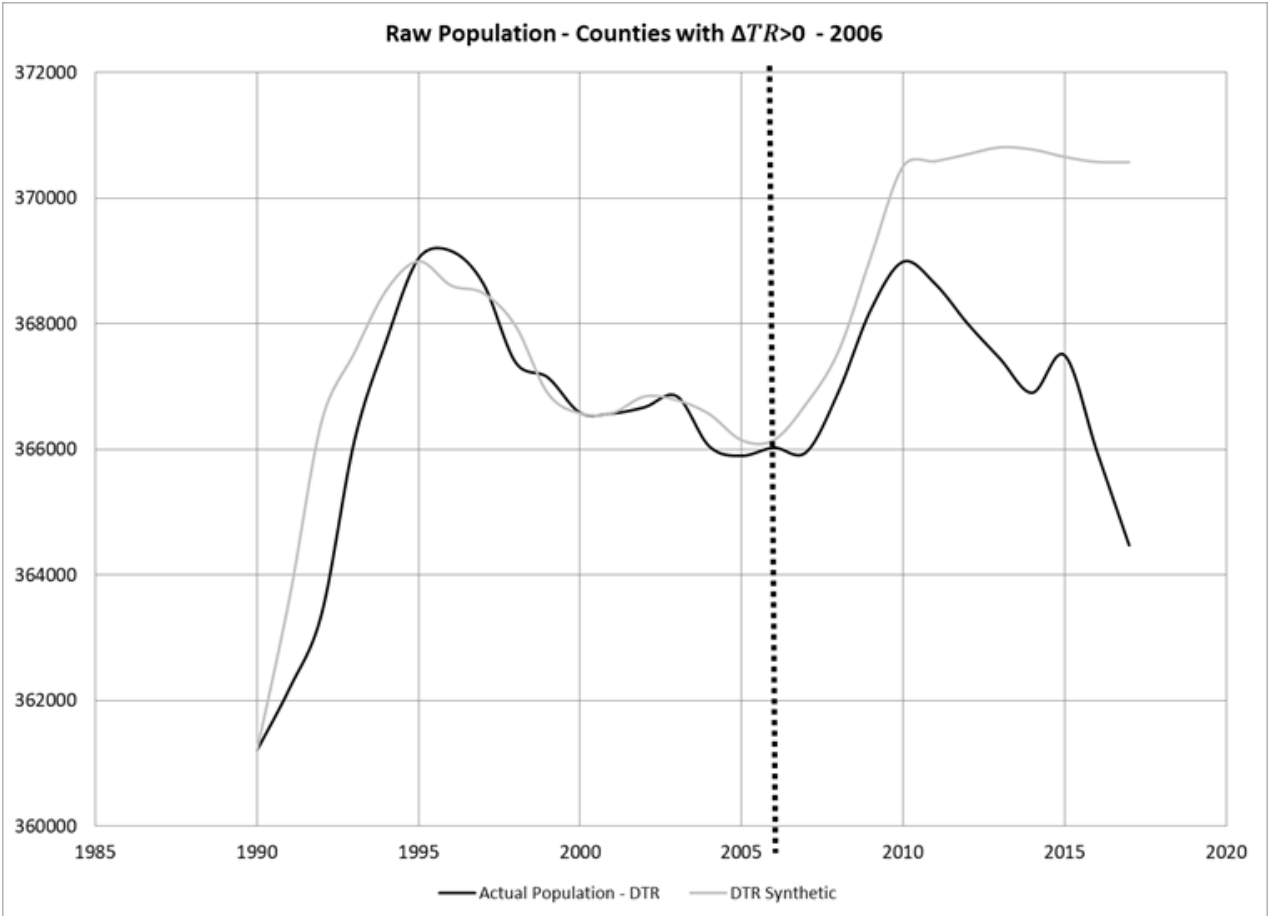

Figure 3-13. Total Population Actual and Synthetic for Counties With $\Delta T R>0$ Only

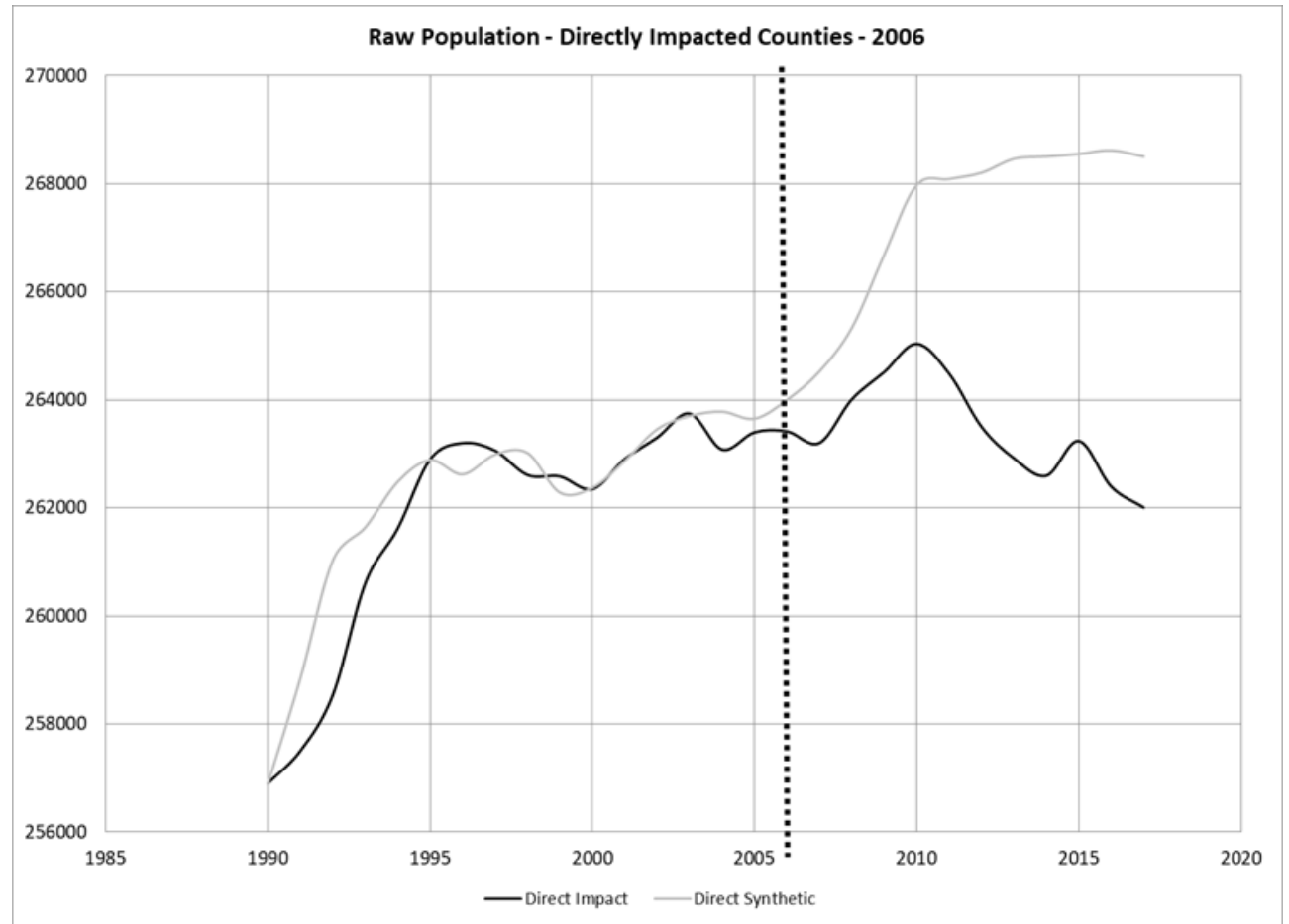

Figure 3-14. Total Population Actual and Synthetic for Counties Directly Impacted by C8 Spill

It is important to note that many of the counties that were impacted did not lose significant population, but were forecasted by their synthetic counterparts to have grown during the period 
of the study. This is a key finding. This region has generally been known for population losses in many cases due to the demographic and economic forces noted earlier, such as changing industrial composition, changes in incomes, and the general trend of rural-to-urban change. However, our model suggests that, without this spill, the population in this area would have grown.

\subsection{Population Impacts within Age Groups}

While understanding overall population impacts is a key result of this study, understanding which age groups are the most likely to be impacted provides further value to policy-makers or regulators. Utilizing the 2006 treatment year, as described above, we use inter-censal age group estimates and uncertainty measures provided by the US Census, to estimate the age proportions of our synthetic populations, and the margins of uncertainty for those estimates, in the counties for which we found statistically significant effects. Pleasants County, the smallest population county in this group, is omitted as the margin of error was larger than the estimated effect. A top level examination of the age 25-54 population, synthetic estimates, and margins of error is shown in Table 3-5.

\begin{tabular}{|c|c|c|c|c|c|c|}
\hline & $\begin{array}{c}\text { Athens Co, } \\
\text { Ohio }\end{array}$ & $\begin{array}{l}\text { Meigs Co, } \\
\text { Ohio }\end{array}$ & $\begin{array}{c}\text { Washington Co, } \\
\text { Ohio }\end{array}$ & $\begin{array}{c}\text { Cabell Co, } \\
\text { West Virginia }\end{array}$ & $\begin{array}{l}\text { Pleasants Co, } \\
\text { West Virginia }\end{array}$ & $\begin{array}{c}\text { Wood Co, } \\
\text { West Virginia }\end{array}$ \\
\hline Actual Population 25-54 & 21794 & 8562 & 21308 & 34006 & 3005 & 31492 \\
\hline MOE 25-54 & $+/-300$ & $+/-187$ & $+/-177$ & $+/-136$ & $+/-163$ & $+/-163$ \\
\hline Synthetic Proportional Population 25-54 & 22359 & 9028 & 22543 & 34361 & 3183 & 33488 \\
\hline Robust Estimates & Yes & Yes & Yes & Yes & No & Yes \\
\hline Population Effect - 25-54 & $565+/-300$ & $466+/-187$ & $1235+/-177$ & $355+/-136$ & N/A & $1996+/-163$ \\
\hline Total Population Effect & -1919 & -683 & -1300 & 1109 & N/A & -2892 \\
\hline$\%$ Impact of $25-54$ & $29 \%$ & $68 \%$ & $95 \%$ & $-32 \%$ & N/A & $69 \%$ \\
\hline
\end{tabular}

Table 3-5. Population Estimates 25-54

For counties where these age-level estimates are statistically significant compared to the margin of error, the impact on the working-age population impacts is estimated at between $29 \%$ and $95 \%$ of the total population change estimates. This indicates that the impact to working age populations is significant, which likely has a large economic impact.

\subsection{Economic Impacts}

A key outcome of this study is an attempt to gauge the economic impact from this incident due to the population change. This is in addition to those costs related to environmental cleanup or punitive fines. At this time of this writing, DuPont had settled for approximately $\$ 775$ million in lawsuits related to PFOA (in total, across the US), including the $\$ 105$ million settlement used as 
the starting point for this study. Looking at counties with directly impacted water districts around the Washington Works facility, we estimate population effects of between $-5,700$ and $-7,400$ people in our key treatment window of 2005-2007, when compared with the forecasted synthetic region. In other words, a region that is not gaining as much population as predicted. If we assume a per-capita income of $\$ 25,000 /$ person (less than the lowest per capita income in the study counties), we estimate that the direct income-related loss effect of this disaster in the five directly impacted counties is about $\$ 1.4$ billion in the time frame from 2006-2017, nearly an order of magnitude greater than the amount in the 2005 settlement.

Table 3-6 lists the direct income effect per year when the five counties with a significant impact are compared to the synthetic counties.

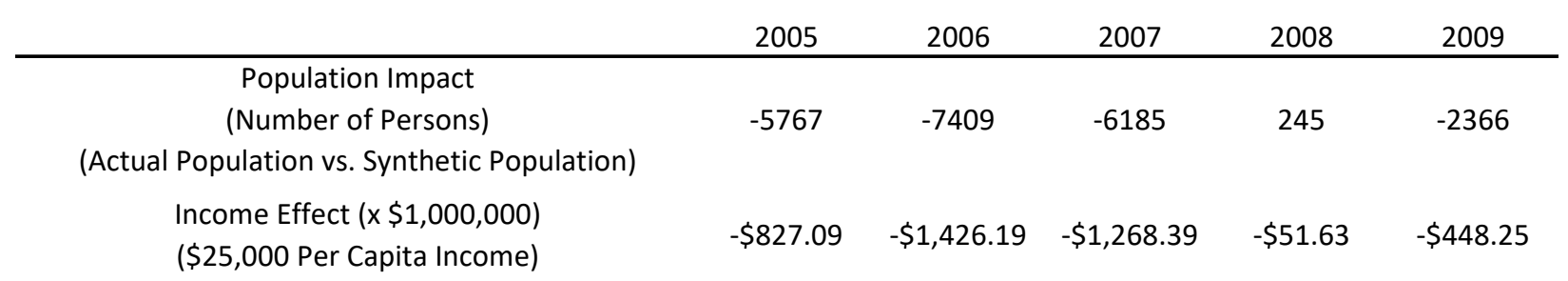

Table 3-6. Forecasted Population Direct Income Effect from Impacted Counties

While this estimate is significant, it also likely understates the true economic impact of these population effects. From the prior literature, it should be re-emphasized that those most likely to relocate are those ablest to do so - those with more education or work potential, those that are younger, and those with the economic ability to make an expensive decision to choose to leave the area. Many researchers have examined the loss of younger and college educated residents, particularly from rural places - a phenomenon known as "brain drain", and have found that it is more efficient to minimize talent flight than to increase talent attraction, particularly for smaller, more rural regions (Beine et al., 2001; Domina, 2006; Gibson and McKenzie, 2012; Hansen et al., 2003; Hawley and Rork, 2013; Hunter and Sutton, 2004; Kelchen and Webber, 2018; Petrin et al., 2014; Sherman and Sage, 2011; Stephens et al., 2013; Weber et al., 2007; Marre and Rupasingha 2019). As a compounding issue, internal migration in the US is at historically low levels, has declined steadily since the early $1980 \mathrm{~s}$, (Frey, 2017) and has been lower across all demographic, socioeconomic groups, and geographic areas for decades. (Molloy et al., 2011, 2017; Partridge, 2010; Partridge et al., 2012; Rupasingha et al., 2015; Kaplan and Schulhofer-Wohl, 2017; Johnson et al., 2015; Mills and Hazarika, 2001) 
What these findings combined suggest is that the best time to attract a resident is $\underline{\text { before }}$ they have made the choice to relocate, as the forces that lead to migration are at their lowest strength in decades. This is doubly true in regions that may have lagging socio-economic characteristics, and trebly so in rural areas with these issues. Further, from the prior literature, it should be re-emphasized that those most likely to relocate are those ablest to do so - those with more education or work potential, those that are younger, and those with the economic ability to make an expensive decision to choose to leave the area - and, our estimates on the working-age population suggest that it is those who are younger that are leaving.

\subsection{Conclusion}

For counties in lagging regions, loss of population is an ongoing concern. If changes in industrial composition and economic opportunity are leading people to migrate elsewhere, then rural counties, especially, may be at an ongoing economic disadvantage in terms of future economic growth. Under such conditions could a man-made environmental disaster lead to a tipping point and result in further population loss?

Our analysis uses the SCM to analyze the population change in 10 counties in Ohio and West Virginia that were potentially impacted by PFOA water contamination from DuPont's Washington Works. SCM allows us to analyze the impact on only a few counties by creating synthetic controls from a pool of 1,400 U.S. counties. However, while the "incident" has clear "Before" and "After" markers, the period in which information is released leads to an extended or fuzzy treatment period, ranging from 2005-2013. The paper makes an important contribution to the SCM literature by developing a method to identify the timing of the treatment. We develop a scoring tool determine a narrower treatment window, and then perform a full set of robustness and placebo tests. Based on these results, it appears that the period 2005-2009 is the key period of interest, with 2006 as the peak treatment year.

We find that the effect primarily occurs in counties that were directly impacted by this water contamination, as identified by water districts included in the 2005 Leach v. DuPont settlement. As further proof of our approach, we find no effect in other, nearby counties.

Importantly, our results suggest that, in the absence of the contamination, many of these counties would have grown. Thus, the economic impacts of this contamination event are 
significant. In addition to the typical costs due to the cost of cleanup or the amount of fines or punitive damages identified in the aftermath of the event, there are other economic costs due to population losses. Compared to the synthetic counties, our results suggest that the population in these counties is between 5,700 and 7,400 people fewer in 2005 and 2006, and that many of these are of working age (between 25 and 54). If each of these "lost" people earned just $\$ 25,000$ from 2005 or 2006 to 2017 , the aggregate loss of income is between $\$ 800$ million and $\$ 1.4$ billion, suggesting that the $\$ 105$ million in settlements and $\$ 10.5$ million in EPA fines do not cover the full impact on this region.

Our findings also suggest the positive impacts of policies to prevent such disasters would pay dividends by preventing further economic deterioration in the region. In considering new environmental regulations, policy-makers may want to consider these benefits which are likely to outweigh any costs. 


\section{Bibliography}

Abadie, A., \& Gardeazabal, J. (2003). The economic costs of conflict: A case study of the Basque Country. American Economic Review, 93(1), 113-132.

Abadie, A., Diamond, A., \& Hainmueller, J. (2010). Synthetic control methods for comparative case studies: Estimating the effect of California's tobacco control program. Journal of the American Statistical Association, 105(490), 493-505.

Abadie, A., Diamond, A., \& Hainmueller, J. (2014). SYNTH: STATA module to implement synthetic control methods for comparative case studies. Statistical Software Components S457334, Department of Economics, Boston College. 2014.

Abadie, A., Diamond, A., \& Hainmueller, J. (2015). Comparative politics and the synthetic control method. American Journal of Political Science, 59(2), 495-510.

Adeola, F. O. (2011). Hazardous wastes, industrial disasters, and environmental health risks: Local and global environmental struggles. Springer.

Aghion, P., Ljungqvist, L., Howitt, P., Howitt, P. W., Brant-Collett, M., \& García-Peñalosa, C. (1998). Endogenous growth theory. MIT press.

Albala-Bertrand, J. M. (1993). Political economy of large natural disasters: with special reference to developing countries. OUP Catalogue.

Artz, G. M. (2003). Rural area brain drain: Is it a reality?. Choices, 18(316-2016-7035), 11-16.

Austin, B. A., Glaeser, E. L., \& Summers, L. H. (2018). Jobs for the Heartland: Place-based policies in 21st century America (No. w24548). National Bureau of Economic Research. https://www.nber.org/papers/w24548

Beine, M., Docquier, F., \& Rapoport, H. (2001). Brain drain and economic growth: theory and evidence. Journal of Development Economics, 64(1), 275-289.

Bertrand, M., Duflo, E., \& Mullainathan, S. (2004). How much should we trust differences-indifferences estimates?. The Quarterly Journal of Economics, 119(1), 249-275.

Betz, M. R., \& Jones, L. E. (2018). Wage and employment growth in America's drug epidemic: Is all growth created equal?. American Journal of Agricultural Economics, 100(5), 13571374.

Betz, M. R., \& Partridge, M. D. (2013). Country road take me home: Migration patterns in Appalachian America and place-based policy. International Regional Science Review, 36(3), 267-295.

Betz, M. R., Partridge, M. D., \& Fallah, B. (2016). Smart cities and attracting knowledge workers: Which cities attract highly-educated workers in the 21st century?. Papers in Regional Science, 95(4), 819-841.

Boardman, J. D., Finch, B. K., Ellison, C. G., Williams, D. R., \& Jackson, J. S. (2001). Neighborhood disadvantage, stress, and drug use among adults. Journal of Health and Social Behavior, 151-165. 
Bohn, S., Lofstrom, M., \& Raphael, S. (2014). Did the 2007 Legal Arizona Workers Act reduce the state's unauthorized immigrant population?. Review of Economics and Statistics, 96(2), 258-269.

Bondonio, D., \& Greenbaum, R. T. (2018). Natural disasters and relief assistance: Empirical evidence on the resilience of US counties using dynamic propensity score matching. Journal of Regional Science, 58(3), 659-680.

Boustan, L. P., Kahn, M. E., \& Rhode, P. W. (2012). Moving to higher ground: Migration response to natural disasters in the early twentieth century. American Economic Review, 102(3), 238-44.

Brasington, D. M., \& Hite, D. (2005). Demand for environmental quality: a spatial hedonic analysis. Regional Science and Urban Economics, 35(1), 57-82.

Brill, A., (2018). New State-Level Estimates of the Economic Burden of the Opioid Epidemic. http://www.aei.org/publication/new-state-level-estimates-of-the-economic-burden-of-theopioid-epidemic/. Accessed February 5, 2020.

Burns, K., \& Hotchkiss, J. L. (2019). Migration Constraints and disparate responses to changing job opportunities. FRB Atlanta Working Paper 2019-1, Federal Reserve Bank of Atlanta. Revised 13 May 2019.

C8 Science Panel Probable Link Reports [website]. C8 Science Panel (updated 29 October 2012). Retrieved from http://www.c8sciencepanel.org/prob link.html. Accessed April 13, 2020.

Caballero, R. J., \& Hammour, M. L. (1991). The cleansing effect of recessions (No. w3922). National Bureau of Economic Research. https://prod.nber.org/papers/w3922

Caballero, R. J., \& Hammour, M. L. (1996). On the timing and efficiency of creative destruction. Quarterly Journal of Economics, 111(3), 805-852.

Carr, P. J., \& Kefalas, M. J. (2009). Hollowing out the middle: The rural brain drain and what it means for America. Beacon Press.

Case, A., \& Deaton, A. (2015). Rising morbidity and mortality in midlife among white nonHispanic Americans in the 21st century. Proceedings of the National Academy of Sciences, 112(49), 15078-15083.

Case, A., \& Deaton, A. (2018). Deaths of despair redux: a response to Christopher Ruhm (pp. 1-4). Mimeo. http://www.princeton.edu/ deaton/downloads/Case and Deaton Comment on CJRuh $\underline{\mathrm{m} \text { Jan 2018.pdf }}$

Cavallo, E., Galiani, S., Noy, I., \& Pantano, J. (2013). Catastrophic natural disasters and economic growth. Review of Economics and Statistics, 95(5), 1549-1561.

Cerdá, M., Gaidus, A., Keyes, K. M., Ponicki, W., Martins, S., Galea, S., \& Gruenewald, P. (2017). Prescription opioid poisoning across urban and rural areas: identifying vulnerable groups and geographic areas. Addiction, 112(1), 103-112. 
Chem spill economic impact is $\$ 61$ million, study says. The Charleston Gazette, online edition

(4 February 2014). Available: http://www.wvgazette.com/News/201402040102 [accessed 20 January 2020].

Chen, Y., \& Rosenthal, S. S. (2008). Local amenities and life-cycle migration: Do people move for jobs or fun?. Journal of Urban Economics, 64(3), 519-537.

Chetty, R., \& Hendren, N. (2016). The impacts of neighborhoods on intergenerational mobility II: County-level estimates (No. w23002). National Bureau of Economic Research. https://www.nber.org/papers/w23002

Chetty, R., \& Hendren, N. (2018). The impacts of neighborhoods on intergenerational mobility I: Childhood exposure effects. Quarterly Journal of Economics, 133(3), 1107-1162.

Coffman, M., \& Noy, I. (2012). Hurricane Iniki: measuring the long-term economic impact of a natural disaster using synthetic control. Environment and Development Economics, 17(2), 187-205.

Council of Economic Advisers (US). (2017). The underestimated cost of the opioid crisis. Executive Office of the President of the United States, Council of Economic Advisers.

Dahl, M. S., \& Sorenson, O. (2010). The social attachment to place. Social Forces, 89(2), 633658.

Dao, M., Furceri, D., \& Loungani, P. (2017). Regional labor market adjustment in the United States: trend and cycle. Review of Economics and Statistics, 99(2), 243-257.

Darchen, S., \& Tremblay, D. G. (2010). What attracts and retains knowledge workers/students: The quality of place or career opportunities? The cases of Montreal and Ottawa. Cities, 27(4), 225-233.

Davis, S. J., \& Haltiwanger, J. (2014). Labor market fluidity and economic performance (No. w20479). National Bureau of Economic Research.

De Haas, H. (2010). The internal dynamics of migration processes: A theoretical inquiry. Journal of Ethnic and Migration Studies, 36(10), 1587-1617.

De Hass, H. (2010). Migration and development: A theoretical perspective 1. International Migration Review, 44(1), 227-264.

DeJong, G. F., \& Fawcett, J. (1981). Multidisciplinary frameworks and models of migration decision making. Migration Decision Making: Multidisciplinary Approaches to Microlevel Studies in Developed and Developing Countries, eds. GF De Jong and RW Gardner, 1358.

Deller, S. C., Tsai, T. H., Marcouiller, D. W., \& English, D. B. (2001). The role of amenities and quality of life in rural economic growth. American Journal of Agricultural Economics, 83(2), 352-365.

Dhara, V. R., \& Dhara, R. (2002). The Union Carbide disaster in Bhopal: a review of health effects. Archives of Environmental Health: An International Journal, 57(5), 391-404.

Domina, T. (2006). What clean break?: Education and nonmetropolitan migration patterns, 1989-2004. Rural Sociology, 71(3), 373-398. 
Dorsey, S. (1991). The strange case of the missing West Virginia labor force. Growth and Change, 22(3), 49-65.

Douglas, S. (1997). Estimating relative standard of living in the United States using crossmigration data. Journal of Regional Science, 37(3), 411-436.

Dwyer-Lindgren, L., Bertozzi-Villa, A., Stubbs, R. W., Morozoff, C., Mackenbach, J. P., van Lenthe, F. J., \& Murray, C. J. (2017). Inequalities in life expectancy among US counties, 1980 to 2014: temporal trends and key drivers. JAMA internal medicine, 177(7), 10031011.

Erfanian, E., Grossman, D., \& Collins, A. R. (2019). The Impact of Naloxone Access Laws on Opioid Overdose Deaths in the US. Review of Regional Studies, 49(1), 45-72.

Faggian, A., \& Franklin, R. S. (2014). Human capital redistribution in the USA: the migration of the college-bound. Spatial Economic Analysis, 9(4), 376-395.

Faggian, A., Olfert, M. R., \& Partridge, M. D. (2011). Inferring regional well-being from individual revealed preferences: the 'voting with your feet' approach. Cambridge Journal of Regions, Economy and Society, 5(1), 163-180.

Feir, D., \& Gillezeau, R. (2018). Return to the Homeland? The impact of the Great Recession on employment outcomes and labor mobility for Native Americans. Journal of Economics, Race, and Policy, 1(2-3), 60-74.

Fields, G. S. (1976). Labor force migration, unemployment and job turnover. The Review of Economics and Statistics, 407-415.

Findley, S. E. (1988). The directionality and age selectivity of the health-migration relation: Evidence from sequences of disability and mobility in the United States. International Migration Review, 22(3), 4-29.

Findley, S. E. (1994). Does drought increase migration? A study of migration from rural Mali during the 1983-1985 drought. International Migration Review, 28(3), 539-553.

Florida, R. (2002). The economic geography of talent. Annals of the Association of American geographers, 92(4), 743-755.

Freedom Industries and former Freedom Industries plant manager sentenced for roles in chemical spill. (2016, February 4). Retrieved from https://www.justice.gov/usao$\mathrm{sdwv} / \mathrm{pr} /$ freedom-industries-and-former-freedom-industries-plant-manager-sentencedroles-chemical

Frenkel, A., Bendit, E., \& Kaplan, S. (2013). Residential location choice of knowledge-workers: The role of amenities, workplace and lifestyle. Cities, 35, 33-41.

Frey, W. H. (1995). Immigration and internal migration 'flight' from US metropolitan areas: Toward a new demographic Balkanisation. Urban Studies, 32(4-5), 733-757.

Frey, W. H. (2017). Census shows a revival of pre-recession migration flows. The Avenue. https://www.brookings.edu/blog/the-avenue/2017/03/30/census-shows-a-revival-of-prerecession-migration-flows/ 
Frisbee, S. J., Brooks Jr, A. P., Maher, A., Flensborg, P., Arnold, S., Fletcher, T., \& Halverson, J. A. (2009). The C8 health project: design, methods, and participants. Environmental Health Perspectives, 117(12), 1873-1882.

Fussell, E., Sastry, N., \& VanLandingham, M. (2010). Race, socioeconomic status, and return migration to New Orleans after Hurricane Katrina. Population and Environment, 31(1-3), 20-42.

Gabriel, S. A., \& Rosenthal, S. S. (2004). Quality of the business environment versus quality of life: do firms and households like the same cities?. Review of Economics and Statistics, 86(1), 438-444.

Ganong, P., \& Shoag, D. (2017). Why has regional income convergence in the US declined?. Journal of Urban Economics, 102, 76-90.

Gibson, J., \& McKenzie, D. (2012). The economic consequences of 'brain drain' of the best and brightest: Microeconomic evidence from five countries. The Economic Journal, 122(560), 339-375.

Glaeser, E. L., \& Gottlieb, J. D. (2008). The economics of place-making policies (No. w14373). National Bureau of Economic Research. https://www.nber.org/papers/w14373

Glaeser, E. L., Scheinkman, J., \& Shleifer, A. (1995). Economic growth in a cross-section of cities. Journal of Monetary Economics, 36(1), 117-143.

Glazier, R. E., \& Kling, R. N. (2013). Recent trends in substance abuse among persons with disabilities compared to that of persons without disabilities. Disability and Health Journal, $6(2), 107-115$.

Goetz, S. J., \& Davlasheridze, M. (2017). Explaining spatial disparities in drug overdoses, 19702014 (No. 2054-2017-5998). Agricultural and Applied Economics Association (AAEA) 2018 Allied Social Sciences Association (ASSA) Annual Meeting, January 5-7, 2018, Philadelphia, Pennsylvania

Goetz, S. J., Partridge, M. D., \& Stephens, H. M. (2018). The economic status of rural America in the President Trump era and beyond. Applied Economic Perspectives and Policy, 40(1), 97-118.

Good v. AMERICAN WATER WORKS COMPANY, INC., Civil Action No. 2: 14-01374 (S.D.W. Va. Sept. 26, 2016).

Greenwood, M. J. (1997). Internal migration in developed countries. Handbook of population and family economics, $1,647-720$.

Groen, J. A., \& Polivka, A. E. (2010). Going home after Hurricane Katrina: Determinants of return migration and changes in affected areas. Demography, 47(4), 821-844.

Guilfoos, T., Kell, D., Boslett, A., \& Hill, E. L. (2017). The economic and health effects of the 2014 chemical spill in the Elk River, West Virginia. American Journal of Agricultural Economics, 100(2), 609-624.

Gupta, R. (2017, August). West Virginia Drug Overdose Deaths Historical Overview 2001-2015. Retrieved from http://dhhr.wv.gov/oeps/disease/ob/documents/opioid/wv-drugoverdoses-2001_2015.pdf. 
Gyourko, J., Kahn, M., \& Tracy, J. (1999). Quality of life and environmental comparisons. Handbook of regional and urban economics, 3, 1413-1454.

Hansen, S. B., Ban, C., \& Huggins, L. (2003). Explaining the "brain drain" from older industrial cities: The Pittsburgh region. Economic Development Quarterly, 17(2), 132-147.

Hauer, M. E. (2017). Migration induced by sea-level rise could reshape the US population landscape. Nature Climate Change, 7(5), 321.

Hawley, Z. B., \& Rork, J. C. (2013). The case of state funded higher education scholarship plans and interstate brain drain. Regional Science and Urban Economics, 43(2), 242249.

Hersher, R., \& Associated Press. (n.d.). E \$151 Million Settlement Deal Reached Over West Virginia Water Poisoning. Retrieved from https://www.npr.org/sections/thetwoway/2016/11/01/500086140/-151-million-settlement-deal-reached-over-west-virginiawater-poisoning.

Hites, R. A. (2011). Dioxins: an overview and history.

Horie, S., \& Managi, S. (2017). Why do people stay in or leave Fukushima?. Journal of Regional Science, 57(5), 840-857.

Horwich, G. (2000). Economic lessons of the Kobe earthquake. Economic Development and Cultural Change, 48(3), 521-542

House of Commons, International Development Committee. 2004. Migration and Development: How to Make Migration Work for Poverty Reduction. Sixth Report of Session 2003-04. The Stationary Office Limited: London.

Hunter, L. M. (2005). Migration and environmental hazards. Population and Environment, 26(4), 273-302.

Hunter, L. M., \& Sutton, J. (2004). Examining the association between hazardous waste facilities and rural "Brain drain”. Rural Sociology, 69(2), 197-212.

Hyatt, H., McEntarfer, E., Ueda, K., \& Zhang, A. (2018). Interstate Migration and Employer-toEmployer Transitions in the United States: New Evidence From Administrative Records Data. Demography, 55(6), 2161-2180.

Isserman, A. M., \& Rephann, T. J. (1993). Geographical and gender differences in labor force participation: is there an Appalachian effect?. Growth and Change, 24(4), 539-578.

Jack W. Leach, et al. v. E. I. du Pont de Nemours and Company and Lubeck Public Service District, Case No. 01-C-608

Jackson, R., \& Schaeffer, P. (Eds.). (2017). Regional Research Frontiers-Vol. 1: Innovations, Regional Growth and Migration. Springer.

Johnson, C. (2014, January 11). Spill affects some local areas. Retrieved from https://www.herald-dispatch.com/news/spill-affects-some-local-areas/article_0644cba4e2c2-5b3d-98a9-b577702ceab4.htm 
Johnson, K. M., \& Winkler, R. L. (2015). Migration signatures across the decades: Net migration by age in US counties, 1950-2010. Demographic Research, 32, 1065.

Jonas, A. B., Young, A. M., Oser, C. B., Leukefeld, C. G., \& Havens, J. R. (2012). OxyContin® as currency: OxyContin $®$ use and increased social capital among rural Appalachian drug users. Social Science \& Medicine, 74(10), 1602-1609.

Juhn, C., \& Potter, S. (2006). Changes in labor force participation in the United States. Journal of Economic Perspectives, 20(3), 27-46.

Kahn, M. E. (2005). The death toll from natural disasters: the role of income, geography, and institutions. Review of Economics and Statistics, 87(2), 271-284.

Kaplan, G., \& Schulhofer-Wohl, S. (2017). Understanding the long-run decline in interstate migration. International Economic Review, 58(1), 57-94.

Kaul, A., Klößner, S., Pfeifer, G., \& Schieler, M. (2015). Synthetic control methods: Never use all pre-intervention outcomes together with covariates. MPRA Paper 83790, University Library of Munich, Germany

Kelchen, R., \& Webber, D. A. (2018). Examining the interstate mobility of recent college graduates. Educational Researcher, 47(3), 213-215.

Kennan, J. and Walker, J. R. (2011), The Effect of Expected Income on Individual Migration Decisions. Econometrica, 79: 211-251. doi:10.3982/ECTA4657

Keyes, K. M., Cerdá, M., Brady, J. E., Havens, J. R., \& Galea, S. (2014). Understanding the rural-urban differences in nonmedical prescription opioid use and abuse in the United States. American Journal of Public Health, 104(2), e52-e59.

Knapp, T. A., \& White, N. E. (2016). The Effect of Youth Poverty Rates and Migration on Adult Wages. Journal of Regional Science, 56(2), 239-256.

Knapp, T. A., White, N. E., \& Wolaver, A. M. (2013). The returns to migration: the influence of education and migration type. Growth and Change, 44(4), 589-607.

Krueger, A. B. (2017). Where have all the workers gone? An inquiry into the decline of the US labor force participation rate. Brookings papers on economic activity, 2017(2), 1.

Lawton, P., Murphy, E., \& Redmond, D. (2013). Residential preferences of the 'creative class'?. Cities, 31, 47-56.

Lee, E. S. (1966). A theory of migration. Demography, 3(1), 47-57.

LeSage, J. P. (2014). What regional scientists need to know about spatial econometrics. Available at SSRN 2420725.

LeSage, J. P., \& Pace, R. K. (2014). Interpreting spatial econometric models. Handbook of Regional Science, 1535-1552.

Ludke, R. L., \& Obermiller, P. J. (2014). Recent trends in Appalachian migration, 2005-2009. Journal of Appalachian Studies, 20(1), 24-42. 
Lukacs, H. A., Sawe, N., \& Ulibarri, N. (2017). Risk, uncertainty, and institutional failure in the 2014 West Virginia chemical spill. Case Studies in the Environment, 1(1), 1-7.

Lyons, C. (2007). Stain-resistant, nonstick, waterproof, and lethal: the hidden dangers of C8. Greenwood Publishing Group.

Manuel J. (2014). Crisis and emergency risk communication lessons from the Elk River spill. Environmental Health Perspectives, 122(8), A214-A219. https://doi.org/10.1289/ehp.122-A214.

Map of Appalachia. (n.d.). Retrieved from https://www.arc.gov/research/MapsofAppalachia.asp?MAP_ID=31

Map. (n.d.). Retrieved from https://www.wvwaterclaims.com/map/

Marré, A. W., \& Rupasingha, A. School quality and rural in-migration: Can better rural schools attract new residents?. Journal of Regional Science.

Marshall University Center for Business and Economic Research. 2014. "CBER Calculates Impact from Chemical Spill into Elk River." Marshall University Center for Business and Economic Research. http://mediad.publicbroadcasting.net/p/wvpn/files/201402/CBER PR WaterUsageBan 0 2.04.14.pdf.

Massey, D. S., Arango, J., Hugo, G., Kouaouci, A., Pellegrino, A., \& Taylor, J. E. (1993). Theories of international migration: A review and appraisal. Population and Development Review, 431-466.

Massey, D. S., Gross, A. B., \& Shibuya, K. (1994). Migration, segregation, and the geographic concentration of poverty. American Sociological Review, 425-445.

McGranahan, D. A., Cromartie, J., \& Wojan, T. R. (2010). Nonmetropolitan outmigration counties: Some are poor, many are prosperous. USDA-ERS Economic Research Report, (107). https://www.ers.usda.gov/webdocs/publications/44770/8062 err107.pdf?v=41056

McGranahan, David A. Natural amenities drive rural population change. No. 1473-2016-120765. 1999.

Meit, M., Heffernan, M., Tanenbaum, E., \& Hoffmann, T. (2017). Appalachian diseases of despair. Appalachian Regional Commission.

Metcalfe, J. S. (1998). Evolutionary economics and creative destruction (Vol. 1). Psychology Press.

Mills, B., \& Hazarika, G. (2001). The migration of young adults from non-metropolitan counties. American Journal of Agricultural Economics, 83(2), 329-340.

Mincer, J. (1978). Family migration decisions. Journal of Political Economy, 86(5), 749-773.

Mistich, D., \& Associated Press. (n.d.). Ex-Freedom Industries Owner Sentenced to 30 Days in Jail, \$20,000 Fine. Retrieved from https://www.wvpublic.org/post/ex-freedom-industriesowner-sentenced-30-days-jail-20000-fine. 
Molloy, R., Smith, C. L., \& Wozniak, A. (2011). Internal migration in the United States. Journal of Economic Perspectives, 25(3), 173-96.

Molloy, R., Smith, C. L., \& Wozniak, A. (2017). Job changing and the decline in long-distance migration in the United States. Demography, 54(2), 631-653.

Morckel, V., \& Rybarczyk, G. (2018). The effects of the water crisis on population dynamics in the City of Flint, Michigan. Cities \& Health, 2(1), 69-81.

Mordock, J. (2016). Taking on DuPont: Illnesses, deaths blamed on pollution from W. Va. Plant. The [Delaware] News Journal, April, 1.

Moy, E., Garcia, M. C., Bastian, B., Rossen, L. M., Ingram, D. D., Faul, M., \& lademarco, M. F. (2017). Leading causes of death in nonmetropolitan and metropolitan areas-United States, 1999-2014. MMWR Surveillance Summaries, 66(1), 1.

Munasib, A., \& Rickman, D. S. (2015). Regional economic impacts of the shale gas and tight oil boom: A synthetic control analysis. Regional Science and Urban Economics, 50, 1-17.

Myers, C. A., Slack, T., \& Singelmann, J. (2008). Social vulnerability and migration in the wake of disaster: the case of Hurricanes Katrina and Rita. Population and Environment, 29(6), 271-291.

"NAICS Data." Emsi, www.economicmodeling.com/data/.

National Institutes of Health, Surveillance, Epidemiology, and End Results Program (2018). Download U.S. Population Data - SEER Population Data. Retrieved from https://seer.cancer.gov/popdata/download.html.

Natural Amenities Scale. (n.d.). Retrieved from https://www.ers.usda.gov/data-products/naturalamenities-scale.aspx

Nord, M. (1998). Poor people on the move: County-to-county migration and the spatial concentration of poverty. Journal of Regional Science, 38(2), 329-351.

Noy, I. (2009). The macroeconomic consequences of disasters. Journal of Development Economics, 88(2), 221-231.

Obermiller, P. J., \& Howe, S. R. (2001). New paths and patterns of Appalachian migration, 1975-1990. Journal of Appalachian Studies, 7(2), 331-348.

Obermiller, P. J., \& Howe, S. R. (2004). Moving mountains: Appalachian migration patterns, 1995-2000. Journal of Appalachian Studies, 10(3), 359-371.

Partridge, M. D. (2010). The duelling models: NEG vs amenity migration in explaining US engines of growth. Papers in Regional Science, 89(3), 513-536.

Partridge, M. D., \& Rickman, D. S. (2003). Do we know economic development when we see it?. Review of Regional Studies, 33(1), 17-39.

Partridge, M. D., \& Rickman, D. S. (2005). High-poverty nonmetropolitan counties in America: Can economic development help?. International Regional Science Review, 28(4), 415440. 
Partridge, M. D., Rickman, D. S., Ali, K., \& Olfert, M. R. (2008). The geographic diversity of US nonmetropolitan growth dynamics: A geographically weighted regression approach. Land Economics, 84(2), 241-266.

Partridge, M. D., Rickman, D. S., Olfert, M. R., \& Ali, K. (2012). Dwindling US internal migration: Evidence of spatial equilibrium or structural shifts in local labor markets?. Regional Science and Urban Economics, 42(1-2), 375-388.

Partridge, M., \& Tsvetkova, A. (2017). Road to Despair and the Geography of the America Left Behind (No. 2054-2017-6005).

Pender, John. (2019). US Department of Agriculture - Economic Research Service. CountyLevel Data Sets. USDA ERS - Retrieved from www.ers.usda.gov/data-products/countylevel-data-sets/

Petrin, R. A., Schafft, K. A., \& Meece, J. L. (2014). Educational sorting and residential aspirations among rural high school students: What are the contributions of schools and educators to rural brain drain?. American Educational Research Journal, 51(2), 294-326.

Rappaport, J. (2002). Why are population flows so persistent?. FRB of Kansas City Working Paper, (99-13). http://www.kansascityfed.org/publicat/reswkpap/PDF/RWP99 13.pdf

Rappaport, J. (2007), Moving to nice weather. Regional Science and Urban Economics, 37(3), 375-398.

Rigg, K. K., Monnat, S. M., \& Chavez, M. N. (2018). Opioid-related mortality in rural America: geographic heterogeneity and intervention strategies. International Journal of Drug Policy, 57, 119-129.

Robbins, M. W., Saunders, J., \& Kilmer, B. (2017). A framework for synthetic control methods with high-dimensional, micro-level data: evaluating a neighborhood-specific crime intervention. Journal of the American Statistical Association, 112(517), 109-126.

Rodgers, J. L., \& Rodgers, J. R. (1997). The economic impact of rural-to-urban migration in the United States: Evidence for male labor-force participants. Social Science Quarterly, 937954.

Rogers, A. (1990). Requiem for the net migrant. Geographical Analysis, 22(4), 283-300.

Rosen, J. S., Whelton, A. J., McGuire, M. J., Clancy, J. L., Bartrand, T., Eaton, A., \& Adams, C. (2014). The crude MCHM chemical spill in Charleston, W. Va. Journal-American Water Works Association, 106(9), 65-74.

Rossen, L. M., Khan, D., \& Warner, M. (2013). Trends and geographic patterns in drugpoisoning death rates in the US, 1999-2009. American Journal of Preventive Medicine, 45(6), e19-e25.

Ruhm, C. J. (2017). Geographic variation in opioid and heroin involved drug poisoning mortality rates. American Journal of Preventive Medicine, 53(6), 745-753.

Ruiz, I., \& Vargas-Silva, C. (2013). The economics of forced migration. The Journal of Development Studies, 49(6), 772-784. 
Rupasingha, A., Goetz, S. J., \& Freshwater, D. (2006). The production of social capital in US counties. The Journal of Socio-economics, 35(1), 83-101.

Rupasingha, A., Liu, Y., \& Partridge, M. (2015). Rural bound: determinants of metro to nonmetro migration in the United States. American Journal of Agricultural Economics, 97(3), $680-700$.

Rural-Urban Continuum Codes. (n.d.). Retrieved from https://www.ers.usda.gov/dataproducts/rural-urban-continuum-codes/

Ryan, D. (2005, December 14). Reference News Release: EPA Settles PFOA Case Against DuPont for Largest Environmental Administrative Penalty in Agency History. Retrieved from www.epa.gov/enforcement/reference-news-release-epa-settles-pfoa-case-againstdupont-largest-environmental

Schade, C. P., Wright, N., Gupta, R., Latif, D. A., Jha, A., \& Robinson, J. (2015). Self-reported household impacts of large-scale chemical contamination of the public water supply, Charleston, West Virginia, USA. PloS one, 10(5), e0126744.

Scott, S. L., McSpirit, S., Breheny, P., \& Howell, B. M. (2012). The long-term effects of a coal waste disaster on social trust in Appalachian Kentucky. Organization \& Environment, 25(4), 402-418.

Scott, S. L., McSpirit, S., Hardesty, S., \& Welch, R. (2005). Post disaster interviews with Martin County citizens:" Gray clouds" of blame and distrust. Journal of Appalachian Studies, 11(1/2), 7-29.

Shapiro, J. M. (2006). Smart cities: quality of life, productivity, and the growth effects of human capital. The Review of Economics and Statistics, 88(2), 324-335.

Sherman, J., \& Sage, R. (2011). Sending Off All Your Good Treasures: Rural Schools, BrainDrain, and Community Survival in the Wake of Economic Collapse. Journal of Research in Rural Education, 26.

Simon, C. J., \& Nardinelli, C. (2002). Human capital and the rise of American cities, 1900-1990. Regional Science and Urban Economics, 32(1), 59-96.

Sites, B. D., Beach, M. L., \& Davis, M. A. (2014). Increases in the use of prescription opioid analgesics and the lack of improvement in disability metrics among users. Regional Anesthesia \& Pain Medicine, 39(1), 6-12.

Smith, S. K., Tayman, J., \& Swanson, D. A. (2006). State and local population projections: Methodology and analysis. Springer Science \& Business Media.

Song, Z. (2017). Mortality quadrupled among opioid-driven hospitalizations, notably within lower-income and disabled white populations. Health Affairs, 36(12), 2054-2061.

Stauber, K. N. (2001). Why Invest in Rural America--And How? A Critical Public Policy Question for the 21st Century. Economic Review, Federal Reserve Bank of Kansas City, vol. $86(\mathrm{Q} I \mathrm{I})$, pages $57-87$

Stephens, H. M., \& Deskins, J. (2018). Economic distress and labor market participation. American Journal of Agricultural Economics, 100(5), 1336-1356. 
Stephens, H. M., \& Partridge, M. D. (2011). Do entrepreneurs enhance economic growth in lagging regions?. Growth and Change, 42(4), 431-465.

Stephens, H. M., Partridge, M. D., \& Faggian, A. (2013). Innovation, entrepreneurship and economic growth in lagging regions. Journal of Regional Science, 53(5), 778-812.

Stradling, D., \& Stradling, R. (2008). Perceptions of the burning river: deindustrialization and Cleveland's Cuyahoga River. Environmental History, 13(3), 515-535.

Tao, L., Kannan, K., Kajiwara, N., Costa, M. M., Fillmann, G., Takahashi, S., \& Tanabe, S. (2006). Perfluorooctanesulfonate and related fluorochemicals in albatrosses, elephant seals, penguins, and polar skuas from the Southern Ocean. Environmental Science \& Technology, 40(24), 7642-7648.

Taylor, S., (2020). Three Essays In Applied Econometrics: Understanding Population Changes (Unpublished doctoral dissertation). West Virginia University, Morgantown, West Virginia, United States.

Thomasson, E. D., Scharman, E., Fechter-Leggett, E., Bixler, D., Ibrahim, S. F., Duncan, M. A. \& Pizon, A. (2017). Acute health effects after the Elk River chemical spill, West Virginia, January 2014. Public Health Reports, 132(2), 196-202.

US Bureau of Economic Analysis (2018). Personal Income by County, Metro, and Other Areas. Retrieved from www.bea.gov/data/income-saving/personal-income-county-metro-andother-areas

US Bureau of Labor Statistics (2018). Local Area Unemployment Statistics Home Page. Retrieved from www.bls.gov/Lau/

US Census Bureau. (2017, May 16). Educational Attainment. Retrieved from https://www.census.gov/topics/education/educational-attainment.html

Wasson, J. R., McLeod, D. M., Bastian, C. T., \& Rashford, B. S. (2013). The effects of environmental amenities on agricultural land values. Land Economics, 89(3), 466-478.

Weber, B., Jensen, L., Miller, K., Mosley, J., \& Fisher, M. (2005). A critical review of rural poverty literature: Is there truly a rural effect?. International Regional Science Review, 28(4), 381-414.

Weber, B., Marre, A., Fisher, M., Gibbs, R., \& Cromartie, J. (2007). Education's effect on poverty: The role of migration. Review of Agricultural economics, 29(3), 437-445.

Whelton, A. J., McMillan, L., Novy, C. R., White, K. D., \& Huang, X. (2017). Case study: the crude MCHM chemical spill investigation and recovery in West Virginia USA.

Environmental Science: Water Research \& Technology, 3(2), 312-332.

Wilson, R. (2017). Moving to jobs: The role of information in migration decisions. Available at SSRN 3071104.

WISQARS $^{\mathrm{TM}}$. (n.d.). Retrieved from https://wisqars.cdc.gov:8443/cdcMapFramework/mapModulelnterface.jsp

Wozniak, A. (2010). Are college graduates more responsive to distant labor market opportunities?. Journal of Human Resources, 45(4), 944-970. 
Yamashita, N., Taniyasu, S., Petrick, G., Wei, S., Gamo, T., Lam, P. K., \& Kannan, K. (2008). Perfluorinated acids as novel chemical tracers of global circulation of ocean waters. Chemosphere, 70(7), 1247-1255.

Yazgan, P., Utku, D. E., \& Sirkeci, I. (2015). Syrian crisis and migration. Migration Letters, 12(3), 181-192.

Zhang, H., Yan, W., Oba, A., \& Zhang, W. (2014). Radiation-driven migration: the case of Minamisoma City, Fukushima, Japan, after the Fukushima nuclear accident. International Journal of Environmental Research and Public Health, 11(9), 9286-9305. 


\section{Appendix A - Topic 1 - The Opioid Crisis and Economic Distress: The Consequences for Population Change}

\section{Appendix A - Table 1. All Counties Complete Results. Coefficients for county level fixed effects} are suppressed.

\begin{tabular}{|c|c|c|c|c|}
\hline VARIABLES & $\begin{array}{c}(1) \\
\\
\text { 3-Year } \\
\text { Population } \\
\text { Change (\%) } \\
\end{array}$ & $\begin{array}{c}(2) \\
\text { Age } 25-34 \\
3-Y e a r \\
\text { Population } \\
\text { Change } \\
(\%)\end{array}$ & $\begin{array}{c}(3) \\
\text { Age } 35-44 \\
\text { 3-Year } \\
\text { Population } \\
\text { Change } \\
(\%) \\
\end{array}$ & $\begin{array}{c}(4) \\
\text { Age } 25-44 \\
3-Y e a r \\
\text { Population } \\
\text { Change } \\
(\%)\end{array}$ \\
\hline Per Capita Disability Recipts (\$) 3yr Lag & $\begin{array}{c}0.00140 \\
(0.00180)\end{array}$ & $\begin{array}{l}-0.0117 * * \\
(0.00572)\end{array}$ & $\begin{array}{l}-0.000476 \\
(0.00386)\end{array}$ & $\begin{array}{l}-0.00587 * \\
(0.00321)\end{array}$ \\
\hline Labor Force Participation Rate (\%) 3yr Lag & $\begin{array}{c}0.0107 \\
(0.00799)\end{array}$ & $\begin{array}{c}0.0287 \\
(0.0267)\end{array}$ & $\begin{array}{l}0.0499 * * \\
(0.0245)\end{array}$ & $\begin{array}{c}0.0443 * * \\
(0.0186)\end{array}$ \\
\hline Unemployment Rate (\%) 3-yr Lag & $\begin{array}{c}-0.188 * * * \\
(0.0273)\end{array}$ & $\begin{array}{c}-0.504 * * * \\
(0.0802)\end{array}$ & $\begin{array}{c}0.0203 \\
(0.0635)\end{array}$ & $\begin{array}{c}-0.267 * * * \\
(0.0532)\end{array}$ \\
\hline Per Capita Income (\$) 3yr Lag & $\begin{array}{l}1.65 e-05 * \\
(9.39 e-06)\end{array}$ & $\begin{array}{c}5.09 e-05 \\
(3.36 e-05)\end{array}$ & $\begin{array}{c}-5.95 e-05 * * \\
(2.46 e-05)\end{array}$ & $\begin{array}{c}2.61 e-06 \\
(1.75 e-05)\end{array}$ \\
\hline \%-age High School/Some College 3yr Lag & $\begin{array}{c}0.0535 * * * \\
(0.0130)\end{array}$ & $\begin{array}{l}0.115 * * * \\
(0.0437)\end{array}$ & $\begin{array}{l}0.107 * * \\
(0.0425)\end{array}$ & $\begin{array}{c}0.104 * * * \\
(0.0283)\end{array}$ \\
\hline \%-age Bachelors Degree or Higher 3yr lag & $\begin{array}{c}0.0742 * * * \\
(0.0166)\end{array}$ & $\begin{array}{l}0.166 * * * \\
(0.0532)\end{array}$ & $\begin{array}{l}0.153 * * \\
(0.0778)\end{array}$ & $\begin{array}{l}0.140 * * * \\
(0.0347)\end{array}$ \\
\hline Social Capital Score & $\begin{array}{c}0.108 \\
(0.0976)\end{array}$ & $\begin{array}{l}0.379 \\
(0.240)\end{array}$ & $\begin{array}{l}-0.286 \\
(0.428)\end{array}$ & $\begin{array}{l}0.0575 \\
(0.185)\end{array}$ \\
\hline$\%$ of Population Under 45 & $\begin{array}{c}0.938 * * * \\
(0.0809)\end{array}$ & $\begin{array}{c}1.555 * * * \\
(0.188)\end{array}$ & $\begin{array}{c}2.913 * * * \\
(0.348)\end{array}$ & $\begin{array}{c}2.112 * * * \\
(0.164)\end{array}$ \\
\hline$\%$ of Population Female & $\begin{array}{c}-0.937 * * * \\
(0.299)\end{array}$ & $\begin{array}{c}-4.134 * * * \\
(1.122)\end{array}$ & $\begin{array}{c}-2.016 * \\
(1.225)\end{array}$ & $\begin{array}{c}-3.201 * * * \\
(1.120)\end{array}$ \\
\hline L3 Ag and Forestry Jobshare & $\begin{array}{c}0.0398 \\
(0.0248)\end{array}$ & $\begin{array}{l}0.151 * * \\
(0.0676)\end{array}$ & $\begin{array}{l}0.124 * \\
(0.0719)\end{array}$ & $\begin{array}{l}0.119 * * \\
(0.0492)\end{array}$ \\
\hline L3 Mining and O\&G Jobshare & $\begin{array}{l}-0.104 * * * \\
(0.0259)\end{array}$ & $\begin{array}{c}-0.287 * * * \\
(0.0943)\end{array}$ & $\begin{array}{l}-0.0309 \\
(0.0618)\end{array}$ & $\begin{array}{c}-0.162 * * * \\
(0.0560)\end{array}$ \\
\hline L3 Manufacturing Jobshare & $\begin{array}{l}-0.0210 \\
(0.0140)\end{array}$ & $\begin{array}{l}-0.0395 \\
(0.0446)\end{array}$ & $\begin{array}{l}0.0585 * \\
(0.0350)\end{array}$ & $\begin{array}{r}-0.00607 \\
(0.0285)\end{array}$ \\
\hline L3 Retail Trade Jobshare & $\begin{array}{c}0.0806 * * * \\
(0.0281)\end{array}$ & $\begin{array}{l}0.0440 \\
(0.0776)\end{array}$ & $\begin{array}{l}0.183^{*} \\
(0.111)\end{array}$ & $\begin{array}{c}0.0873 \\
(0.0532)\end{array}$ \\
\hline L3 Healthcare Jobshare & $\begin{array}{c}0.0845 * * * \\
(0.0163)\end{array}$ & $\begin{array}{l}0.122 * * \\
(0.0554)\end{array}$ & $\begin{array}{l}0.123 * * \\
(0.0480)\end{array}$ & $\begin{array}{l}0.126 * * * \\
(0.0379)\end{array}$ \\
\hline L3 Govt Jobshare & $\begin{array}{l}0.00723 \\
(0.0207)\end{array}$ & $\begin{array}{c}0.0406 \\
(0.0673)\end{array}$ & $\begin{array}{l}-0.0530 \\
(0.0680)\end{array}$ & $\begin{array}{l}0.0111 \\
(0.0444)\end{array}$ \\
\hline L10 Ag and Forestry Jobshare & $\begin{array}{l}0.00794 \\
(0.0179)\end{array}$ & $\begin{array}{l}-0.120 * * \\
(0.0577)\end{array}$ & $\begin{array}{l}0.142 * * * \\
(0.0511)\end{array}$ & $\begin{array}{c}0.0125 \\
(0.0356)\end{array}$ \\
\hline L10 Mining and O\&G Jobshare & $\begin{array}{l}-0.193 * * * \\
(0.0349)\end{array}$ & $\begin{array}{c}-0.486 * * * \\
(0.0849)\end{array}$ & $\begin{array}{c}-0.0966 \\
(0.103)\end{array}$ & $\begin{array}{c}-0.281 * * * \\
(0.0607)\end{array}$ \\
\hline L10 Manufacturing Jobshare & $\begin{array}{l}-0.0170 * \\
(0.00970)\end{array}$ & $\begin{array}{l}-0.126 * * * \\
(0.0293)\end{array}$ & $\begin{array}{l}0.0414 \\
(0.0317)\end{array}$ & $\begin{array}{c}-0.0344 * \\
(0.0191)\end{array}$ \\
\hline L10 Retail Trade Jobshare & $\begin{array}{l}-0.0296 \\
(0.0226)\end{array}$ & $\begin{array}{l}-0.0540 \\
(0.0722)\end{array}$ & $\begin{array}{c}-0.00856 \\
(0.0602)\end{array}$ & $\begin{array}{l}-0.0263 \\
(0.0442)\end{array}$ \\
\hline L10 Healthcare Jobshare & $\begin{array}{l}0.0166 \\
(0.0197)\end{array}$ & $\begin{array}{l}-0.0273 \\
(0.0529)\end{array}$ & $\begin{array}{l}-0.0381 \\
(0.0646)\end{array}$ & $\begin{array}{l}-0.00636 \\
(0.0347)\end{array}$ \\
\hline Spatially Lagged L3jobshare11 & $\begin{array}{c}0.0883 * * * \\
(0.0336)\end{array}$ & $\begin{array}{c}0.221 * * \\
(0.112)\end{array}$ & $\begin{array}{c}0.0699 \\
(0.0905)\end{array}$ & $\begin{array}{l}0.153 * * \\
(0.0624)\end{array}$ \\
\hline Spatially Lagged L3jobshare21 & $\begin{array}{l}-0.154 * * * \\
(0.0433)\end{array}$ & $\begin{array}{c}-0.342 * * \\
(0.142)\end{array}$ & $\begin{array}{l}-0.188^{*} \\
(0.107)\end{array}$ & $\begin{array}{c}-0.282 * * * \\
(0.0969)\end{array}$ \\
\hline Spatially Lagged L3jobshare3133 & $\begin{array}{c}0.0236 \\
(0.0229)\end{array}$ & $\begin{array}{l}-0.0530 \\
(0.0676)\end{array}$ & $\begin{array}{c}0.0663 \\
(0.0562)\end{array}$ & $\begin{array}{c}0.0108 \\
(0.0455)\end{array}$ \\
\hline Spatially Lagged L3jobshare4445 & $\begin{array}{l}0.138 * * * \\
(0.0495)\end{array}$ & $\begin{array}{c}0.348 * * \\
(0.165)\end{array}$ & $\begin{array}{c}-0.176 \\
(0.119)\end{array}$ & $\begin{array}{l}0.0999 \\
(0.0952)\end{array}$ \\
\hline Spatially Lagged L3jobshare62 & $\begin{array}{c}0.277 * * * \\
(0.0324)\end{array}$ & $\begin{array}{c}0.594 * * * \\
(0.104)\end{array}$ & $\begin{array}{l}0.511 * * * \\
(0.0820)\end{array}$ & $\begin{array}{c}0.555 * * * \\
(0.0668)\end{array}$ \\
\hline Spatially Lagged L3jobshare90 & $\begin{array}{l}0.161 * * * \\
(0.0285)\end{array}$ & $\begin{array}{l}0.233^{* * *} * \\
(0.0892)\end{array}$ & $\begin{array}{l}0.311 * * * \\
(0.0729)\end{array}$ & $\begin{array}{l}0.274 * * * \\
(0.0547)\end{array}$ \\
\hline Spatially Lagged Overdose $>40 / 100 k$ (Category 5) & $\begin{array}{r}-0.0698 \\
(0.364)\end{array}$ & $\begin{array}{c}-1.803 \\
(1.145)\end{array}$ & $\begin{array}{c}1.240 \\
(0.881)\end{array}$ & $\begin{array}{l}-0.261 \\
(0.705)\end{array}$ \\
\hline Spatially Lagged Overdose 20-40/100k (Category 4) & $\begin{array}{l}-0.335 \\
(0.215)\end{array}$ & $\begin{array}{c}-1.605 * * \\
(0.702)\end{array}$ & $\begin{array}{l}0.803 \\
(0.576)\end{array}$ & $\begin{array}{l}-0.471 \\
(0.451)\end{array}$ \\
\hline Spatially Lagged Overdose 12-20/100k (Category 3) & $\begin{array}{l}-0.0563 \\
(0.179)\end{array}$ & $\begin{array}{l}-0.861 \\
(0.587)\end{array}$ & $\begin{array}{l}0.823 * \\
(0.469)\end{array}$ & $\begin{array}{l}-0.0192 \\
(0.379)\end{array}$ \\
\hline Spatially Lagged L2inci3yr_cat2 & $\begin{array}{l}-0.160 \\
(0.163)\end{array}$ & $\begin{array}{c}-1.237 * * \\
(0.546)\end{array}$ & $\begin{array}{l}0.376 \\
(0.460)\end{array}$ & $\begin{array}{l}-0.450 \\
(0.353)\end{array}$ \\
\hline Spatially Lagged Labor Force Participation Rate (\%) & $\begin{array}{c}-0.0336 * * * \\
(0.0127)\end{array}$ & $\begin{array}{l}-0.0562 \\
(0.0406)\end{array}$ & $\begin{array}{l}-0.0521 \\
(0.0328)\end{array}$ & $\begin{array}{l}-0.0596 * * \\
(0.0262)\end{array}$ \\
\hline Spatially Lagged Unemployment Rate (\%) & $\begin{array}{c}-0.367 * * * \\
(0.0382)\end{array}$ & $\begin{array}{c}-0.783^{* * *} * \\
(0.114)\end{array}$ & $\begin{array}{c}-0.523^{* * * *} \\
(0.105)\end{array}$ & $\begin{array}{c}-0.653 * * * \\
(0.0768)\end{array}$ \\
\hline Population Density & $\begin{array}{c}-0.000807 * * * \\
(0.000309)\end{array}$ & $\begin{array}{c}-0.00357 * * * \\
(0.00101)\end{array}$ & $\begin{array}{c}-0.00543 * * * \\
(0.000787)\end{array}$ & $\begin{array}{c}-0.00494 * * * \\
(0.000724)\end{array}$ \\
\hline Constant & $\begin{array}{c}-12.69 \\
(15.10)\end{array}$ & $\begin{array}{c}112.6 * * \\
(51.43)\end{array}$ & $\begin{array}{l}-78.45 \\
(63.15)\end{array}$ & $\begin{array}{c}30.37 \\
(50.32)\end{array}$ \\
\hline $\begin{array}{l}\text { Observations } \\
\text { R-squared }\end{array}$ & $\begin{array}{c}12,432 \\
0.830 \\
\end{array}$ & $\begin{array}{c}12,432 \\
0.629\end{array}$ & $\begin{array}{l}12,432 \\
0.735\end{array}$ & $\begin{array}{c}12,432 \\
0.738 \\
\end{array}$ \\
\hline
\end{tabular}

Robust standard errors in parentheses

$* * * \mathbf{p}<0.01, * *$ p<0.05, * p<0.1

Coefficients for County Fixed Effects Are Suppressed 
Appendix A - Table 2. Urban Counties Complete Results. Coefficients for county level fixed effects are suppressed.

\begin{tabular}{|c|c|c|c|c|}
\hline VARIABLES & $\begin{array}{c}\text { (1) } \\
\text { 3-Year } \\
\text { Population } \\
\text { Change (\%) }\end{array}$ & $\begin{array}{c}(2) \\
\text { Age 25-34 } \\
\text { 3-Year } \\
\text { Population } \\
\text { Change } \\
(\%)\end{array}$ & $\begin{array}{c}(3) \\
\text { Age } 35-44 \\
\text { 3-Year } \\
\text { Population } \\
\text { Change } \\
(\%)\end{array}$ & $\begin{array}{c}(4) \\
\text { Age } 25-44 \\
\text { 3-Year } \\
\text { Population } \\
\text { Change } \\
(\%)\end{array}$ \\
\hline Per Capita Disability Recipts (\$) 3yr Lag & $\begin{array}{l}0.00447 * \\
(0.00251)\end{array}$ & $\begin{array}{c}0.00972 \\
(0.00608)\end{array}$ & $\begin{array}{l}-0.00108 \\
(0.00568)\end{array}$ & $\begin{array}{c}0.00535 \\
(0.00449)\end{array}$ \\
\hline Labor Force Participation Rate (\%) 3yr Lag & $\begin{array}{c}-0.00223 \\
(0.0107)\end{array}$ & $\begin{array}{l}0.00982 \\
(0.0299)\end{array}$ & $\begin{array}{c}0.0311 \\
(0.0208)\end{array}$ & $\begin{array}{c}0.0189 \\
(0.0206)\end{array}$ \\
\hline Unemployment Rate (\%) 3-yr Lag & $\begin{array}{c}-0.270 * * * \\
(0.0376)\end{array}$ & $\begin{array}{c}-0.580 * * * \\
(0.0947)\end{array}$ & $\begin{array}{c}-0.0169 \\
(0.0712)\end{array}$ & $\begin{array}{c}-0.320 * * * \\
(0.0656)\end{array}$ \\
\hline Per Capita Income (\$) 3yr Lag & $\begin{array}{l}-8.21 \mathrm{e}-06 \\
(1.27 \mathrm{e}-05)\end{array}$ & $\begin{array}{c}-0.000162 * * * \\
(4.03 e-05)\end{array}$ & $\begin{array}{c}7.59 \mathrm{e}-06 \\
(2.70 \mathrm{e}-05)\end{array}$ & $\begin{array}{c}-7.02 \mathrm{e}-05 * * * \\
(2.66 \mathrm{e}-05)\end{array}$ \\
\hline \%-age High School/Some College 3yr Lag & $\begin{array}{c}0.0602 * * * \\
(0.0180)\end{array}$ & $\begin{array}{c}0.118^{*} \\
(0.0626)\end{array}$ & $\begin{array}{c}0.0984 * * * \\
(0.0359)\end{array}$ & $\begin{array}{l}0.104 * * \\
(0.0404)\end{array}$ \\
\hline$\%$-age Bachelors Degree or Higher 3yr lag & $\begin{array}{l}0.138 * * * \\
(0.0361)\end{array}$ & $\begin{array}{c}0.252 * * * \\
(0.0847)\end{array}$ & $\begin{array}{c}0.0811 \\
(0.0512)\end{array}$ & $\begin{array}{l}0.186 * * * \\
(0.0543)\end{array}$ \\
\hline Social Capital Score & $\begin{array}{c}-0.240 * * * \\
(0.0586)\end{array}$ & $\begin{array}{c}-0.438 * * \\
(0.182)\end{array}$ & $\begin{array}{c}-0.604 * * * \\
(0.132)\end{array}$ & $\begin{array}{c}-0.586 * * * \\
(0.119)\end{array}$ \\
\hline$\%$ of Population Under 45 & $\begin{array}{c}0.669 * * * \\
(0.0639)\end{array}$ & $\begin{array}{c}0.894 * * * \\
(0.171)\end{array}$ & $\begin{array}{c}2.146 * * * \\
(0.155)\end{array}$ & $\begin{array}{c}1.502 * * * \\
(0.112)\end{array}$ \\
\hline$\%$ of Population Female & $\begin{array}{l}-0.397 \\
(0.270)\end{array}$ & $\begin{array}{c}-1.700 * * \\
(0.750)\end{array}$ & $\begin{array}{l}-0.455 \\
(0.367)\end{array}$ & $\begin{array}{c}-1.185 * * \\
(0.468)\end{array}$ \\
\hline L3 Ag and Forestry Jobshare & $\begin{array}{c}0.0745 * * \\
(0.0327)\end{array}$ & $\begin{array}{c}0.490 * * * \\
(0.117)\end{array}$ & $\begin{array}{l}-0.131 \\
(0.118)\end{array}$ & $\begin{array}{c}0.209 * * * \\
(0.0762)\end{array}$ \\
\hline L3 Mining and O\&G Jobshare & $\begin{array}{c}-0.0770 * * \\
(0.0340)\end{array}$ & $\begin{array}{c}-0.282 * \\
(0.161)\end{array}$ & $\begin{array}{c}0.0906 \\
(0.0852)\end{array}$ & $\begin{array}{l}-0.110 \\
(0.105)\end{array}$ \\
\hline L3 Manufacturing Jobshare & $\begin{array}{c}-0.00692 \\
(0.0131)\end{array}$ & $\begin{array}{l}0.0727 * \\
(0.0394)\end{array}$ & $\begin{array}{c}0.0289 \\
(0.0320)\end{array}$ & $\begin{array}{c}0.0552 * * \\
(0.0274)\end{array}$ \\
\hline L3 Retail Trade Jobshare & $\begin{array}{l}-0.00908 \\
(0.0243)\end{array}$ & $\begin{array}{l}-0.0805 \\
(0.0848)\end{array}$ & $\begin{array}{c}0.102 \\
(0.0657)\end{array}$ & $\begin{array}{c}0.0214 \\
(0.0535)\end{array}$ \\
\hline L3 Healthcare Jobshare & $\begin{array}{c}0.0724 * * * \\
(0.0186)\end{array}$ & $\begin{array}{l}0.116 * * \\
(0.0545)\end{array}$ & $\begin{array}{c}0.0924 * * \\
(0.0435)\end{array}$ & $\begin{array}{c}0.112 * * * \\
(0.0382)\end{array}$ \\
\hline L3 Govt Jobshare & $\begin{array}{c}-0.0464 * * \\
(0.0187)\end{array}$ & $\begin{array}{c}-0.167 * * \\
(0.0691)\end{array}$ & $\begin{array}{l}-0.0426 \\
(0.0541)\end{array}$ & $\begin{array}{c}-0.119 * * * \\
(0.0425)\end{array}$ \\
\hline L10 Ag and Forestry Jobshare & $\begin{array}{l}-0.0572 * \\
(0.0324)\end{array}$ & $\begin{array}{l}-0.173 \\
(0.117)\end{array}$ & $\begin{array}{c}0.0501 \\
(0.0995)\end{array}$ & $\begin{array}{l}-0.0812 \\
(0.0723)\end{array}$ \\
\hline L10 Mining and O\&G Jobshare & $\begin{array}{c}-0.305 * * * \\
(0.0622)\end{array}$ & $\begin{array}{c}-0.597 * * * \\
(0.179)\end{array}$ & $\begin{array}{l}-0.254 \\
(0.164)\end{array}$ & $\begin{array}{c}-0.416 * * * \\
(0.120)\end{array}$ \\
\hline L10 Manufacturing Jobshare & $\begin{array}{l}-0.0107 \\
(0.0113)\end{array}$ & $\begin{array}{c}-0.105 * * * \\
(0.0344)\end{array}$ & $\begin{array}{c}0.109 * * * \\
(0.0266)\end{array}$ & $\begin{array}{c}-0.000263 \\
(0.0224)\end{array}$ \\
\hline L10 Retail Trade Jobshare & $\begin{array}{c}0.000887 \\
(0.0274)\end{array}$ & $\begin{array}{c}-0.131 \\
(0.0829)\end{array}$ & $\begin{array}{c}0.112^{*} \\
(0.0578)\end{array}$ & $\begin{array}{l}-0.00490 \\
(0.0567)\end{array}$ \\
\hline L10 Healthcare Jobshare & $\begin{array}{l}-0.0239 \\
(0.0261)\end{array}$ & $\begin{array}{l}-0.0877 \\
(0.0740)\end{array}$ & $\begin{array}{l}-0.0707 \\
(0.0529)\end{array}$ & $\begin{array}{l}-0.0744 \\
(0.0479)\end{array}$ \\
\hline Spatially Lagged L3jobshare11 & $\begin{array}{l}-0.0146 \\
(0.0512)\end{array}$ & $\begin{array}{c}-0.251 * * \\
(0.127)\end{array}$ & $\begin{array}{l}-0.0557 \\
(0.0963)\end{array}$ & $\begin{array}{l}-0.168 * \\
(0.0887)\end{array}$ \\
\hline Spatially Lagged L3jobshare21 & $\begin{array}{c}-0.191 * * * \\
(0.0496)\end{array}$ & $\begin{array}{c}-0.628 * * * \\
(0.153)\end{array}$ & $\begin{array}{l}-0.0641 \\
(0.105)\end{array}$ & $\begin{array}{c}-0.366 * * * \\
(0.109)\end{array}$ \\
\hline Spatially Lagged L3jobshare3133 & $\begin{array}{l}0.00422 \\
(0.0286)\end{array}$ & $\begin{array}{l}-0.145 * \\
(0.0780)\end{array}$ & $\begin{array}{c}0.0844 \\
(0.0543)\end{array}$ & $\begin{array}{l}-0.0351 \\
(0.0533)\end{array}$ \\
\hline Spatially Lagged L3jobshare4445 & $\begin{array}{c}0.151 * * * \\
(0.0479)\end{array}$ & $\begin{array}{c}0.189 \\
(0.143)\end{array}$ & $\begin{array}{c}-0.0993 \\
(0.104)\end{array}$ & $\begin{array}{c}0.0501 \\
(0.0928)\end{array}$ \\
\hline Spatially Lagged L3jobshare62 & $\begin{array}{c}0.142 * * * \\
(0.0392)\end{array}$ & $\begin{array}{c}0.243 * * \\
(0.107)\end{array}$ & $\begin{array}{c}\mathbf{0 . 3 6 6 * * *} \\
(0.0805)\end{array}$ & $\begin{array}{c}0.313 * * * \\
(0.0762)\end{array}$ \\
\hline Spatially Lagged L3jobshare90 & $\begin{array}{c}0.0502 \\
(0.0331)\end{array}$ & $\begin{array}{l}-0.0138 \\
(0.0847)\end{array}$ & $\begin{array}{l}0.141 * * \\
(0.0663)\end{array}$ & $\begin{array}{c}0.0629 \\
(0.0585)\end{array}$ \\
\hline Spatially Lagged Overdose $>40 / 100 k$ (Category 5) & $\begin{array}{l}0.232 \\
(0.455)\end{array}$ & $\begin{array}{l}-0.487 \\
(1.146)\end{array}$ & $\begin{array}{c}2.212 * * \\
(0.956)\end{array}$ & $\begin{array}{c}0.836 \\
(0.785)\end{array}$ \\
\hline Spatially Lagged Overdose 20-40/100k (Category 4) & $\begin{array}{l}-0.529 * \\
(0.278)\end{array}$ & $\begin{array}{l}-0.664 \\
(0.742)\end{array}$ & $\begin{array}{l}0.256 \\
(0.592)\end{array}$ & $\begin{array}{l}-0.259 \\
(0.500)\end{array}$ \\
\hline Spatially Lagged Overdose 12-20/100k (Category 3) & $\begin{array}{l}-0.299 \\
(0.248)\end{array}$ & $\begin{array}{l}-0.519 \\
(0.662)\end{array}$ & $\begin{array}{c}0.218 \\
(0.528)\end{array}$ & $\begin{array}{l}-0.162 \\
(0.443)\end{array}$ \\
\hline Spatially Lagged L2inci3yr_cat2 & $\begin{array}{c}-0.459 * * \\
(0.229)\end{array}$ & $\begin{array}{l}-1.047^{*} \\
(0.621)\end{array}$ & $\begin{array}{l}-0.303 \\
(0.515)\end{array}$ & $\begin{array}{r}-0.713^{*} \\
(0.416)\end{array}$ \\
\hline Spatially Lagged Labor Force Participation Rate (\%) & $\begin{array}{c}0.0161 \\
(0.0147)\end{array}$ & $\begin{array}{c}0.0407 \\
(0.0379)\end{array}$ & $\begin{array}{r}-0.00234 \\
(0.0288)\end{array}$ & $\begin{array}{c}0.0164 \\
(0.0263)\end{array}$ \\
\hline Spatially Lagged Unemployment Rate (\%) & $\begin{array}{c}-0.236 * * * \\
(0.0461)\end{array}$ & $\begin{array}{c}-0.877 * * * \\
(0.120)\end{array}$ & $\begin{array}{c}-0.339 * * * \\
(0.0922)\end{array}$ & $\begin{array}{c}-0.619 * * * \\
(0.0850)\end{array}$ \\
\hline Population Density & $\begin{array}{c}-0.000645 * * \\
(0.000313)\end{array}$ & $\begin{array}{l}-0.00168 * \\
(0.000968)\end{array}$ & $\begin{array}{c}-0.00614 * * * \\
(0.000801)\end{array}$ & $\begin{array}{c}-0.00423 * * * \\
(0.000725)\end{array}$ \\
\hline Constant & $\begin{array}{l}-22.87 \\
(14.21)\end{array}$ & $\begin{array}{c}44.31 \\
(40.17)\end{array}$ & $\begin{array}{c}-115.2 * * * \\
(24.38)\end{array}$ & $\begin{array}{l}-28.79 \\
(24.40)\end{array}$ \\
\hline $\begin{array}{l}\text { Observations } \\
\text { R-squared }\end{array}$ & $\begin{array}{l}7,824 \\
0.876\end{array}$ & $\begin{array}{l}7,824 \\
0.696\end{array}$ & $\begin{array}{l}7,824 \\
0.854\end{array}$ & $\begin{array}{l}7,824 \\
0.804\end{array}$ \\
\hline
\end{tabular}


Appendix A - Table 3. Rural Counties Complete Results. Coefficients for county level fixed effects are suppressed.

\begin{tabular}{|c|c|c|c|c|}
\hline VARIABLES & $\begin{array}{c}\text { (1) } \\
\text { 3-Year } \\
\text { Population } \\
\text { Change (\%) }\end{array}$ & $\begin{array}{c}(2) \\
\text { Age } 25-34 \\
\text { 3-Year } \\
\text { Population } \\
\text { Change } \\
(\%) \\
\end{array}$ & $\begin{array}{c}(3) \\
\text { Age } 35-44 \\
\text { 3-Year } \\
\text { Population } \\
\text { Change } \\
(\%) \\
\end{array}$ & $\begin{array}{c}(4) \\
\text { Age } 25-44 \\
\text { 3-Year } \\
\text { Population } \\
\text { Change } \\
(\%) \\
\end{array}$ \\
\hline Per Capita Disability Recipts (\$) 3yr Lag & $\begin{array}{c}7.65 e-05 \\
(0.00226)\end{array}$ & $\begin{array}{c}-0.0177 * * \\
(0.00779)\end{array}$ & $\begin{array}{l}-0.00122 \\
(0.00507)\end{array}$ & $\begin{array}{c}-0.00940 * * \\
(0.00406)\end{array}$ \\
\hline Labor Force Participation Rate (\%) 3yr Lag & $\begin{array}{c}0.0151 \\
(0.0111)\end{array}$ & $\begin{array}{c}0.0265 \\
(0.0380)\end{array}$ & $\begin{array}{c}0.0570 \\
(0.0375)\end{array}$ & $\begin{array}{l}0.0525 * \\
(0.0274)\end{array}$ \\
\hline Unemployment Rate (\%) 3-yr Lag & $\begin{array}{c}-0.117 * * * \\
(0.0368)\end{array}$ & $\begin{array}{c}-0.449 * * * \\
(0.119)\end{array}$ & $\begin{array}{c}0.0501 \\
(0.0980)\end{array}$ & $\begin{array}{c}-0.225 * * * \\
(0.0767)\end{array}$ \\
\hline Per Capita Income (\$) 3yr Lag & $\begin{array}{c}3.48 e-05 * * * \\
(1.18 \mathrm{e}-05)\end{array}$ & $\begin{array}{c}\text { 0.000180*** } \\
(4.31 \mathrm{e}-05)\end{array}$ & $\begin{array}{c}-8.08 e-05 * * \\
(3.42 e-05)\end{array}$ & $\begin{array}{c}5.36 e-05 * * \\
(2.17 e-05)\end{array}$ \\
\hline \%-age High School/Some College 3yr Lag & $\begin{array}{c}\text { 0.0681*** } \\
(0.0159)\end{array}$ & $\begin{array}{l}0.133 * * \\
(0.0521)\end{array}$ & $\begin{array}{l}0.126 * * \\
(0.0604)\end{array}$ & $\begin{array}{c}0.123 * * * \\
(0.0343)\end{array}$ \\
\hline \%-age Bachelors Degree or Higher 3yr lag & $\begin{array}{c}0.0496 * * * \\
(0.0164)\end{array}$ & $\begin{array}{l}0.151 * * \\
(0.0602)\end{array}$ & $\begin{array}{c}0.172 * \\
(0.0974)\end{array}$ & $\begin{array}{c}0.128 * * * \\
(0.0392)\end{array}$ \\
\hline Social Capital Score & $\begin{array}{c}0.315 * * \\
(0.130)\end{array}$ & $\begin{array}{c}0.779 * * \\
(0.326)\end{array}$ & $\begin{array}{l}-0.0243 \\
(0.620)\end{array}$ & $\begin{array}{l}0.421 * \\
(0.251)\end{array}$ \\
\hline$\%$ of Population Under 45 & $\begin{array}{l}1.085 * * * \\
(0.112)\end{array}$ & $\begin{array}{l}2.093 * * * \\
(0.264)\end{array}$ & $\begin{array}{l}\text { 3.315*** } \\
(0.510)\end{array}$ & $\begin{array}{l}2.531 * * * \\
(0.244)\end{array}$ \\
\hline$\%$ of Population Female & $\begin{array}{l}-1.045 * * * \\
(0.342)\end{array}$ & $\begin{array}{c}-4.809 * * * \\
(1.255)\end{array}$ & $\begin{array}{c}-2.535 * \\
(1.490)\end{array}$ & $\begin{array}{c}-3.790 * * * \\
(1.313)\end{array}$ \\
\hline L3 Ag and Forestry Jobshare & $\begin{array}{c}0.0410 \\
(0.0292)\end{array}$ & $\begin{array}{c}0.0796 \\
(0.0770)\end{array}$ & $\begin{array}{l}0.203 * * \\
(0.0902)\end{array}$ & $\begin{array}{c}0.112 * \\
(0.0602)\end{array}$ \\
\hline L3 Mining and O\&G Jobshare & $\begin{array}{c}-0.0872 * * \\
(0.0347)\end{array}$ & $\begin{array}{l}-0.241 * * \\
(0.0979)\end{array}$ & $\begin{array}{l}-0.0398 \\
(0.0798)\end{array}$ & $\begin{array}{r}-0.134 * * \\
(0.0586)\end{array}$ \\
\hline L3 Manufacturing Jobshare & $\begin{array}{c}-0.0492 * * \\
(0.0213)\end{array}$ & $\begin{array}{c}-0.150 * * \\
(0.0684)\end{array}$ & $\begin{array}{c}0.0577 \\
(0.0575)\end{array}$ & $\begin{array}{c}-0.0795 * \\
(0.0439)\end{array}$ \\
\hline L3 Retail Trade Jobshare & $\begin{array}{c}0.137 * * * \\
(0.0461)\end{array}$ & $\begin{array}{c}0.123 \\
(0.117)\end{array}$ & $\begin{array}{c}0.201 \\
(0.194)\end{array}$ & $\begin{array}{c}0.112 \\
(0.0858)\end{array}$ \\
\hline L3 Healthcare Jobshare & $\begin{array}{c}0.0850 * * * \\
(0.0238)\end{array}$ & $\begin{array}{c}0.130 \\
(0.0861)\end{array}$ & $\begin{array}{c}0.123 \\
(0.0801)\end{array}$ & $\begin{array}{l}0.128 * * \\
(0.0588)\end{array}$ \\
\hline L3 Govt Jobshare & $\begin{array}{c}0.0328 \\
(0.0312)\end{array}$ & $\begin{array}{c}0.136 \\
(0.0960)\end{array}$ & $\begin{array}{c}-0.0806 \\
(0.113)\end{array}$ & $\begin{array}{c}0.0622 \\
(0.0684)\end{array}$ \\
\hline L10 Ag and Forestry Jobshare & $\begin{array}{c}0.0248 \\
(0.0199)\end{array}$ & $\begin{array}{l}-0.110 * \\
(0.0640)\end{array}$ & $\begin{array}{c}0.167 * * * \\
(0.0609)\end{array}$ & $\begin{array}{c}0.0325 \\
(0.0401)\end{array}$ \\
\hline L10 Mining and O\&G Jobshare & $\begin{array}{c}-0.138 * * * \\
(0.0388)\end{array}$ & $\begin{array}{c}-0.383 * * * \\
(0.0910)\end{array}$ & $\begin{array}{c}-0.0434 \\
(0.121)\end{array}$ & $\begin{array}{c}-0.206 * * * \\
(0.0682)\end{array}$ \\
\hline L10 Manufacturing Jobshare & $\begin{array}{l}-0.0112 \\
(0.0145)\end{array}$ & $\begin{array}{c}-0.105 * * \\
(0.0433)\end{array}$ & $\begin{array}{l}-0.0110 \\
(0.0516)\end{array}$ & $\begin{array}{l}-0.0417 \\
(0.0281)\end{array}$ \\
\hline L10 Retail Trade Jobshare & $\begin{array}{c}-0.0482 \\
(0.0345)\end{array}$ & $\begin{array}{l}0.0297 \\
(0.111)\end{array}$ & $\begin{array}{l}-0.133 \\
(0.100)\end{array}$ & $\begin{array}{c}-0.0460 \\
(0.0679)\end{array}$ \\
\hline L10 Healthcare Jobshare & $\begin{array}{l}0.0439 * \\
(0.0250)\end{array}$ & $\begin{array}{c}0.0389 \\
(0.0696)\end{array}$ & $\begin{array}{l}-0.0222 \\
(0.0879)\end{array}$ & $\begin{array}{c}0.0462 \\
(0.0448)\end{array}$ \\
\hline Spatially Lagged L3jobshare11 & $\begin{array}{c}0.152 * * * \\
(0.0421)\end{array}$ & $\begin{array}{c}0.476 * * * \\
(0.147)\end{array}$ & $\begin{array}{c}0.164 \\
(0.123)\end{array}$ & $\begin{array}{c}0.333 * * * \\
(0.0797)\end{array}$ \\
\hline Spatially Lagged L3jobshare21 & $\begin{array}{c}-0.168 * * * \\
(0.0620)\end{array}$ & $\begin{array}{l}-0.187 \\
(0.197)\end{array}$ & $\begin{array}{l}-0.260 * \\
(0.157)\end{array}$ & $\begin{array}{c}-0.240 * \\
(0.129)\end{array}$ \\
\hline Spatially Lagged L3jobshare3133 & $\begin{array}{c}0.0208 \\
(0.0355)\end{array}$ & $\begin{array}{l}-0.0460 \\
(0.110)\end{array}$ & $\begin{array}{c}0.0469 \\
(0.0974)\end{array}$ & $\begin{array}{l}0.00817 \\
(0.0712)\end{array}$ \\
\hline Spatially Lagged L3jobshare4445 & $\begin{array}{c}0.0944 \\
(0.0899)\end{array}$ & $\begin{array}{c}0.435 \\
(0.307)\end{array}$ & $\begin{array}{l}-0.289 \\
(0.222)\end{array}$ & $\begin{array}{l}0.0961 \\
(0.171)\end{array}$ \\
\hline Spatially Lagged L3jobshare62 & $\begin{array}{c}0.350 * * * \\
(0.0480)\end{array}$ & $\begin{array}{c}0.820 * * * \\
(0.165)\end{array}$ & $\begin{array}{c}0.590 * * * \\
(0.136)\end{array}$ & $\begin{array}{c}0.697 * * * \\
(0.101)\end{array}$ \\
\hline Spatially Lagged L3jobshare90 & $\begin{array}{c}0.249 * * * \\
(0.0430)\end{array}$ & $\begin{array}{c}0.468 * * * \\
(0.146)\end{array}$ & $\begin{array}{c}0.481 * * * \\
(0.128)\end{array}$ & $\begin{array}{c}0.481 * * * \\
(0.0916)\end{array}$ \\
\hline Spatially Lagged Overdose $>40 / 100 k$ (Category 5) & $\begin{array}{l}0.229 \\
(0.534)\end{array}$ & $\begin{array}{l}-1.085 \\
(1.900)\end{array}$ & $\begin{array}{c}1.378 \\
(1.409)\end{array}$ & $\begin{array}{c}0.195 \\
(1.115)\end{array}$ \\
\hline Spatially Lagged Overdose 20-40/100k (Category 4) & $\begin{array}{r}-0.0984 \\
(0.321)\end{array}$ & $\begin{array}{l}-1.494 \\
(1.115)\end{array}$ & $\begin{array}{c}1.249 \\
(0.951)\end{array}$ & $\begin{array}{l}-0.232 \\
(0.709)\end{array}$ \\
\hline Spatially Lagged Overdose 12-20/100k (Category 3) & $\begin{array}{l}0.0784 \\
(0.249)\end{array}$ & $\begin{array}{l}-0.572 \\
(0.875)\end{array}$ & $\begin{array}{c}1.016 \\
(0.721)\end{array}$ & $\begin{array}{c}0.245 \\
(0.563)\end{array}$ \\
\hline Spatially Lagged L2inci3yr_cat2 & $\begin{array}{l}0.0594 \\
(0.219)\end{array}$ & $\begin{array}{c}-0.836 \\
(0.790)\end{array}$ & $\begin{array}{c}0.614 \\
(0.677)\end{array}$ & $\begin{array}{c}-0.0803 \\
(0.504)\end{array}$ \\
\hline Spatially Lagged Labor Force Participation Rate (\%) & $\begin{array}{c}-0.0688 * * * \\
(0.0192)\end{array}$ & $\begin{array}{l}-0.127 * \\
(0.0653)\end{array}$ & $\begin{array}{l}-0.0939 * \\
(0.0548)\end{array}$ & $\begin{array}{c}-0.113 * * * \\
(0.0409)\end{array}$ \\
\hline Spatially Lagged Unemployment Rate (\%) & $\begin{array}{c}-0.373 * * * \\
(0.0599)\end{array}$ & $\begin{array}{c}-0.509 * * * \\
(0.190)\end{array}$ & $\begin{array}{c}-0.581 * * * \\
(0.185)\end{array}$ & $\begin{array}{c}-0.549 * * * \\
(0.123)\end{array}$ \\
\hline Population Density & $\begin{array}{c}0.670 * * * \\
(0.0657)\end{array}$ & $\begin{array}{c}0.932 * * * \\
(0.126)\end{array}$ & $\begin{array}{c}0.676 * * * \\
(0.125)\end{array}$ & $\begin{array}{c}0.828 * * * \\
(0.102)\end{array}$ \\
\hline Constant & $\begin{array}{c}-34.55 * * \\
(17.58)\end{array}$ & $\begin{array}{c}77.49 \\
(56.70)\end{array}$ & $\begin{array}{l}-86.88 \\
(77.98)\end{array}$ & $\begin{array}{c}9.100 \\
(57.75)\end{array}$ \\
\hline Observations & 4,608 & 4,608 & 4,608 & 4,608 \\
\hline R-squared & 0.768 & 0.608 & 0.666 & 0.707 \\
\hline
\end{tabular}

Robust standard errors in parentheses

$* * *$ p $<0.01, * *$ p $<0.05, * p<0.1$

Coefficients for County Fixed Effects Are Suppressed 
Appendix A - Table 4. State Level Effects

\begin{tabular}{|c|c|c|c|c|c|c|c|}
\hline State & $\begin{array}{c}\text { Population } \\
\text { (2017) }\end{array}$ & $\begin{array}{c}\text { Impacted } \\
\text { Population } \\
\text { (Cat 4/Cat } 5 \\
\text { Counties) } \\
(2017) \\
\end{array}$ & $\begin{array}{c}\text { Fraction of } \\
\text { State } \\
\text { Population } \\
\text { Impacted (\%) }\end{array}$ & $\begin{array}{c}\text { Population } \\
25-34 \\
(2017)\end{array}$ & $\begin{array}{c}\text { Direct Income } \\
\text { Effect } \\
(x \$ 1,000,000)\end{array}$ & $\begin{array}{l}\text { Forecasted Total } \\
\text { Pop Change } \\
\text { (\%) }\end{array}$ & $\begin{array}{c}\text { Forecasted 25-34 } \\
\text { Pop Change } \\
\text { (\%) }\end{array}$ \\
\hline Alabama & $4,874,747$ & 149,468 & $3 \%$ & 640,302 & $-\$ 105.30$ & $-0.02 \%$ & $-0.07 \%$ \\
\hline Arizona & $7,016,270$ & 20,601 & $0 \%$ & 955,894 & $-\$ 10.23$ & $0.00 \%$ & $0.00 \%$ \\
\hline Arkansas & $3,004,279$ & 78,758 & $3 \%$ & 395,464 & $-\$ 35.60$ & $-0.01 \%$ & $-0.03 \%$ \\
\hline California & $39,573,146$ & 285,556 & $1 \%$ & $6,024,064$ & $-\$ 237.50$ & $-0.01 \%$ & $-0.02 \%$ \\
\hline Colorado & $5,607,154$ & 118,230 & $2 \%$ & 870,662 & $-\$ 35.53$ & $-0.01 \%$ & $-0.03 \%$ \\
\hline Connecticut & $3,588,184$ & - & $0 \%$ & 444,198 & $\$ 0.00$ & $0.00 \%$ & $0.00 \%$ \\
\hline Delaware & 961,939 & - & $0 \%$ & 129,278 & $\$ 0.00$ & $0.00 \%$ & $0.00 \%$ \\
\hline District Of Columbia & 693,972 & - & $0 \%$ & 162,602 & $\$ 0.00$ & $0.00 \%$ & $0.00 \%$ \\
\hline Florida & $20,984,400$ & 528,943 & $3 \%$ & $2,742,680$ & $-\$ 170.90$ & $-0.01 \%$ & $-0.04 \%$ \\
\hline Georgia & $10,429,379$ & 159,063 & $2 \%$ & $1,453,326$ & $-\$ 88.45$ & $-0.01 \%$ & $-0.02 \%$ \\
\hline Idaho & $1,716,943$ & 47,376 & $3 \%$ & 225,719 & $-\$ 19.14$ & $-0.01 \%$ & $-0.02 \%$ \\
\hline Illinois & $12,802,023$ & 176,431 & $1 \%$ & $1,776,073$ & $-\$ 29.11$ & $0.00 \%$ & $-0.02 \%$ \\
\hline Indiana & $6,666,818$ & 203,485 & $3 \%$ & 868,804 & $-\$ 66.40$ & $-0.02 \%$ & $-0.06 \%$ \\
\hline lowa & $3,145,711$ & 26,722 & $1 \%$ & 395,643 & $-\$ 7.60$ & $0.00 \%$ & $-0.01 \%$ \\
\hline Kansas & $2,913,123$ & 91,307 & $3 \%$ & 383,787 & $-\$ 28.69$ & $-0.01 \%$ & $-0.04 \%$ \\
\hline Kentucky & $4,454,189$ & $1,561,802$ & $35 \%$ & 580,996 & $-\$ 673.00$ & $-0.20 \%$ & $-1.07 \%$ \\
\hline Louisiana & $4,684,333$ & 85,321 & $2 \%$ & 679,687 & $-\$ 47.08$ & $-0.01 \%$ & $-0.02 \%$ \\
\hline Maine & $1,335,907$ & 102,863 & $8 \%$ & 158,413 & $-\$ 14.70$ & $-0.03 \%$ & $-0.08 \%$ \\
\hline Maryland & $6,052,177$ & 702,647 & $12 \%$ & 837,918 & $-\$ 717.10$ & $-0.10 \%$ & $-0.44 \%$ \\
\hline Massachusetts & $6,859,819$ & - & $0 \%$ & 973,931 & $\$ 0.00$ & $0.00 \%$ & $0.00 \%$ \\
\hline Michigan & $9,962,311$ & 240,875 & $2 \%$ & $1,269,103$ & $-\$ 109.00$ & $-0.01 \%$ & $-0.03 \%$ \\
\hline Minnesota & $5,576,606$ & 15,829 & $0 \%$ & 757,175 & $-\$ 4.50$ & $0.00 \%$ & $0.00 \%$ \\
\hline Mississippi & $2,984,100$ & 59,110 & $2 \%$ & 393,592 & $-\$ 31.79$ & $-0.01 \%$ & $-0.03 \%$ \\
\hline Missouri & $6,113,532$ & 531,997 & $9 \%$ & 820,863 & $-\$ 121.00$ & $-0.04 \%$ & $-0.18 \%$ \\
\hline Montana & $1,050,493$ & 124,097 & $12 \%$ & 135,024 & $-\$ 55.66$ & $-0.04 \%$ & $-0.14 \%$ \\
\hline Nebraska & $1,920,076$ & 27,037 & $1 \%$ & 255,515 & $-\$ 11.77$ & $0.00 \%$ & $-0.01 \%$ \\
\hline Nevada & $2,998,039$ & 38,290 & $1 \%$ & 440,358 & $-\$ 22.47$ & $-0.01 \%$ & $-0.03 \%$ \\
\hline New Hampshire & $1,342,795$ & 48,064 & $4 \%$ & 163,419 & $-\$ 3.41$ & $-0.01 \%$ & $-0.03 \%$ \\
\hline New Jersey & $9,005,644$ & - & $0 \%$ & $1,171,073$ & $\$ 0.00$ & $0.00 \%$ & $0.00 \%$ \\
\hline New Mexico & $2,088,070$ & 123,456 & $6 \%$ & 281,932 & $-\$ 140.70$ & $-0.06 \%$ & $-0.22 \%$ \\
\hline New York & $19,849,399$ & 75,485 & $0 \%$ & $2,936,919$ & $-\$ 21.52$ & $0.00 \%$ & $-0.01 \%$ \\
\hline North Carolina & $10,273,419$ & 451,748 & $4 \%$ & $1,370,247$ & $-\$ 217.00$ & $-0.02 \%$ & $-0.06 \%$ \\
\hline North Dakota & 755,393 & 18,313 & $2 \%$ & 114,253 & $-\$ 1.30$ & $-0.01 \%$ & $-0.03 \%$ \\
\hline Ohio & $11,658,609$ & $2,889,914$ & $25 \%$ & $1,523,761$ & $-\$ 423.30$ & $-0.12 \%$ & $-0.42 \%$ \\
\hline Oklahoma & $3,930,864$ & 456,042 & $12 \%$ & 545,596 & $-\$ 183.50$ & $-0.05 \%$ & $-0.18 \%$ \\
\hline Oregon & $4,142,776$ & 99,527 & $2 \%$ & 587,032 & $-\$ 27.90$ & $-0.01 \%$ & $-0.03 \%$ \\
\hline Pennsylvania & $12,805,537$ & $3,154,431$ & $25 \%$ & $1,688,589$ & $-\$ 388.30$ & $-0.11 \%$ & $-0.52 \%$ \\
\hline Rhode Island & $1,059,639$ & - & $0 \%$ & 145,146 & $\$ 0.00$ & $0.00 \%$ & $0.00 \%$ \\
\hline South Carolina & $5,024,369$ & - & $0 \%$ & 665,507 & $\$ 0.00$ & $0.00 \%$ & $0.00 \%$ \\
\hline South Dakota & 869,666 & 28,091 & $3 \%$ & 113,605 & $-\$ 14.08$ & $-0.01 \%$ & $-0.05 \%$ \\
\hline Tennessee & $6,715,984$ & 390,621 & $6 \%$ & 915,996 & $-\$ 207.10$ & $-0.03 \%$ & $-0.11 \%$ \\
\hline Texas & $28,304,596$ & 190,997 & $1 \%$ & $4,162,040$ & $-\$ 66.24$ & $0.00 \%$ & $-0.01 \%$ \\
\hline Utah & $3,101,833$ & 193,203 & $6 \%$ & 457,423 & $-\$ 99.09$ & $-0.03 \%$ & $-0.09 \%$ \\
\hline Vermont & 623,657 & - & $0 \%$ & 72,980 & $\$ 0.00$ & $0.00 \%$ & $0.00 \%$ \\
\hline Virginia & $8,470,020$ & 298,197 & $4 \%$ & $1,185,270$ & $-\$ 224.70$ & $-0.03 \%$ & $-0.11 \%$ \\
\hline Washington & $7,405,743$ & 90,644 & $1 \%$ & $1,117,379$ & $-\$ 33.16$ & $0.00 \%$ & $-0.01 \%$ \\
\hline West Virginia & $1,815,857$ & 869,675 & $48 \%$ & 216,070 & $-\$ 317.50$ & $-0.30 \%$ & $-1.40 \%$ \\
\hline Wisconsin & $5,795,483$ & 46,271 & $1 \%$ & 731,360 & $-\$ 10.86$ & $0.00 \%$ & $-0.01 \%$ \\
\hline Wyoming & 579,315 & 59,732 & $10 \%$ & 79,514 & $-\$ 16.31$ & $-0.04 \%$ & $-0.13 \%$ \\
\hline
\end{tabular}


Appendix A - Table 5. County Results - Highest Income Effects

\begin{tabular}{|c|c|c|c|c|c|c|c|}
\hline State & County & Overdose Rate & $\begin{array}{l}\text { Population } \\
\text { (2017) }\end{array}$ & $\begin{array}{l}\text { Population 25-34 } \\
\text { (2017) }\end{array}$ & $\begin{array}{c}\text { Direct Income } \\
\text { Effect }(x \$ 1,000)\end{array}$ & $\begin{array}{c}\text { Forecasted Total } \\
\text { Pop Change } \\
(\%) \\
\end{array}$ & $\begin{array}{c}\text { Forecasted 25-34 } \\
\text { Pop Change } \\
(\%)\end{array}$ \\
\hline Maryland & Baltimore & 55.29 & 832468 & 117424 & $-\$ 707,585$ & $-0.68 \%$ & $-3.01 \%$ \\
\hline Pennsylvania & Philadelphia & 36.23 & 1580863 & 299645 & $-\$ 180,614$ & $-0.46 \%$ & $-1.64 \%$ \\
\hline Pennsylvania & Allegheny & 29.28 & 1223048 & 187381 & $-\$ 139,733$ & $-0.46 \%$ & $-1.64 \%$ \\
\hline Ohio & Hamilton & 30.34 & 813822 & 123387 & $-\$ 92,979$ & $-0.46 \%$ & $-1.64 \%$ \\
\hline New Mexico & Rio Arriba & 63.74 & 39159 & 4549 & $-\$ 86,789$ & $-1.86 \%$ & $-6.65 \%$ \\
\hline California & Lake & 37.61 & 64246 & 7312 & $-\$ 73,374$ & $-1.37 \%$ & $-4.67 \%$ \\
\hline Alabama & Walker & 28.37 & 64058 & 7525 & $-\$ 68,029$ & $-0.94 \%$ & $-3.24 \%$ \\
\hline Kentucky & Bell & 56.79 & 26894 & 3354 & $-\$ 61,909$ & $-1.91 \%$ & $-6.50 \%$ \\
\hline Ohio & Summit & 22.39 & 541228 & 71759 & $-\$ 61,835$ & $-0.46 \%$ & $-1.64 \%$ \\
\hline Ohio & Montgomery & 43.10 & 531542 & 71571 & $-\$ 60,729$ & $-0.46 \%$ & $-1.64 \%$ \\
\hline Florida & Walton & 17.69 & 68376 & 8512 & $-\$ 57,907$ & $-0.45 \%$ & $-1.79 \%$ \\
\hline Virginia & Wise & 26.13 & 38586 & 5273 & $-\$ 55,399$ & $-1.19 \%$ & $-4.64 \%$ \\
\hline California & Lassen & 29.12 & 31163 & 5735 & $-\$ 46,062$ & $-1.21 \%$ & $-4.76 \%$ \\
\hline Kentucky & Pike & 41.42 & 58883 & 6686 & $-\$ 45,891$ & $-0.60 \%$ & $-6.88 \%$ \\
\hline Ohio & Jackson & 25.45 & 32449 & 4035 & $-\$ 44,588$ & $-1.15 \%$ & $-4.51 \%$ \\
\hline Florida & Manatee & 26.38 & 385571 & 40781 & $-\$ 44,051$ & $-0.46 \%$ & $-1.64 \%$ \\
\hline West Virginia & Cabell & 66.97 & 94958 & 11774 & $-\$ 43,929$ & $-0.92 \%$ & $-3.35 \%$ \\
\hline Ohio & Butler & 28.05 & 380604 & 44648 & $-\$ 43,484$ & $-0.46 \%$ & $-1.64 \%$ \\
\hline Kentucky & Campbell & 39.27 & 92488 & 13734 & $-\$ 41,960$ & $-0.91 \%$ & $-3.22 \%$ \\
\hline Kentucky & Boyd & 39.03 & 47979 & 5775 & $-\$ 39,357$ & $-0.93 \%$ & $-3.35 \%$ \\
\hline Kentucky & Harlan & 32.14 & 26713 & 3290 & $-\$ 39,178$ & $-1.21 \%$ & $-4.64 \%$ \\
\hline Virginia & Russell & 25.14 & 27048 & 2931 & $-\$ 38,525$ & $-1.18 \%$ & $-4.82 \%$ \\
\hline Ohio & Adams & 26.70 & 27726 & 3039 & $-\$ 38,403$ & $-1.16 \%$ & $-4.63 \%$ \\
\hline Kentucky & Fayette & 29.07 & 321959 & 50577 & $-\$ 36,784$ & $-0.46 \%$ & $-1.64 \%$ \\
\hline Tennessee & Claiborne & 25.71 & 31609 & 3893 & $-\$ 36,365$ & $-0.86 \%$ & $-3.26 \%$ \\
\hline Florida & Bradford & 19.89 & 27038 & 4019 & $-\$ 36,275$ & $-0.88 \%$ & $-3.53 \%$ \\
\hline West Virginia & Raleigh & 49.66 & 75022 & 9265 & $-\$ 35,353$ & $-0.93 \%$ & $-3.34 \%$ \\
\hline Missouri & St. Louis & 42.80 & 996726 & 61909 & $-\$ 35,261$ & $-0.14 \%$ & $-1.64 \%$ \\
\hline North Carolina & Cherokee & 28.50 & 28087 & 2511 & $-\$ 34,949$ & $-0.83 \%$ & $-3.34 \%$ \\
\hline Virginia & Buchanan & 33.03 & 21514 & 2394 & $-\$ 32,175$ & $-1.23 \%$ & $-5.13 \%$ \\
\hline North Carolina & McDowell & 19.42 & 45159 & 5145 & $-\$ 31,813$ & $-0.57 \%$ & $-2.30 \%$ \\
\hline Louisiana & St. Bernard & 30.19 & 46202 & 7699 & $-\$ 29,695$ & $-0.29 \%$ & $-0.88 \%$ \\
\hline Kentucky & Marshall & 19.72 & 31382 & 3446 & $-\$ 28,904$ & $-0.85 \%$ & $-3.28 \%$ \\
\hline North Carolina & Columbus & 18.55 & 55936 & 6873 & $-\$ 28,549$ & $-0.58 \%$ & $-2.26 \%$ \\
\hline West Virginia & Mingo & 47.82 & 24127 & 2709 & $-\$ 28,475$ & $-0.63 \%$ & $-6.81 \%$ \\
\hline West Virginia & Mercer & 51.13 & 59753 & 6950 & $-\$ 27,970$ & $-0.93 \%$ & $-3.28 \%$ \\
\hline Alabama & Escambia & 27.63 & 37447 & 5137 & $-\$ 26,971$ & $-0.86 \%$ & $-3.30 \%$ \\
\hline Pennsylvania & Greene & 24.14 & 36770 & 4537 & $-\$ 26,960$ & $-0.87 \%$ & $-3.38 \%$ \\
\hline California & Plumas & 29.15 & 18742 & 1870 & $-\$ 26,748$ & $-1.17 \%$ & $-4.19 \%$ \\
\hline California & Amador & 22.87 & 38626 & 4122 & $-\$ 26,561$ & $-0.83 \%$ & $-3.13 \%$ \\
\hline Kentucky & Rowan & 27.86 & 24517 & 2903 & $-\$ 26,536$ & $-0.82 \%$ & $-3.29 \%$ \\
\hline Indiana & Starke & 32.86 & 22893 & 2619 & $-\$ 26,433$ & $-0.86 \%$ & $-5.17 \%$ \\
\hline Tennessee & DeKalb & 26.87 & 19852 & 2398 & $-\$ 25,439$ & $-1.09 \%$ & $-4.25 \%$ \\
\hline West Virginia & Greenbrier & 22.96 & 35287 & 3848 & $-\$ 25,282$ & $-0.86 \%$ & $-3.43 \%$ \\
\hline North Carolina & Jackson & 16.15 & 42973 & 5045 & $-\$ 24,917$ & $-0.26 \%$ & $-1.01 \%$ \\
\hline Virginia & Martinsville & 39.67 & 13142 & 1491 & $-\$ 23,755$ & $-0.96 \%$ & $-3.22 \%$ \\
\hline Kentucky & Clay & 33.37 & 20366 & 3121 & $-\$ 23,443$ & $-0.61 \%$ & $-4.23 \%$ \\
\hline Ohio & Trumbull & 29.40 & 200380 & 22813 & $-\$ 22,893$ & $-0.46 \%$ & $-1.64 \%$ \\
\hline Tennessee & Fentress & 24.67 & 18136 & 1824 & $-\$ 22,871$ & $-0.84 \%$ & $-3.36 \%$ \\
\hline Kentucky & Russell & 33.70 & 17775 & 1883 & $-\$ 22,515$ & $-0.85 \%$ & $-5.40 \%$ \\
\hline California & Siskiyou & 19.52 & 43853 & 4591 & $-\$ 22,119$ & $-0.57 \%$ & $-2.20 \%$ \\
\hline Michigan & Clare & 20.38 & 30653 & 3180 & $-\$ 22,026$ & $-0.57 \%$ & $-2.16 \%$ \\
\hline New York & Sullivan & 19.69 & 75485 & 8981 & $-\$ 21,516$ & $-0.57 \%$ & $-2.22 \%$ \\
\hline North Carolina & Macon & 17.62 & 34732 & 3437 & $-\$ 21,476$ & $-0.27 \%$ & $-1.02 \%$ \\
\hline Kentucky & Lawrence & 32.04 & 15719 & 1824 & $-\$ 21,431$ & $-1.15 \%$ & $-4.60 \%$ \\
\hline Oklahoma & McCurtain & 20.91 & 32808 & 3954 & $-\$ 21,246$ & $-0.58 \%$ & $-2.14 \%$ \\
\hline West Virginia & Kanawha & 39.52 & 183293 & 22353 & $-\$ 20,941$ & $-0.46 \%$ & $-1.64 \%$ \\
\hline Virginia & Wythe & 21.16 & 28882 & 3189 & $-\$ 20,671$ & $-0.86 \%$ & $-3.38 \%$ \\
\hline Oklahoma & Mayes & 18.42 & 40921 & 4847 & $-\$ 20,505$ & $-0.57 \%$ & $-2.24 \%$ \\
\hline Oklahoma & Garvin & 24.27 & 27909 & 3430 & $-\$ 19,553$ & $-0.84 \%$ & $-3.32 \%$ \\
\hline Texas & Polk & 17.92 & 49162 & 5933 & $-\$ 19,417$ & $-0.26 \%$ & $-0.99 \%$ \\
\hline California & Calaveras & 15.77 & 45670 & 4382 & $-\$ 19,239$ & $-0.28 \%$ & $-0.97 \%$ \\
\hline Kentucky & Kenton & 40.21 & 165399 & 24547 & $-\$ 18,897$ & $-0.46 \%$ & $-1.64 \%$ \\
\hline New Mexico & Lincoln & 28.91 & 19395 & 1812 & $-\$ 18,618$ & $-0.87 \%$ & $-3.30 \%$ \\
\hline Michigan & Gladwin & 21.15 & 25234 & 2328 & $-\$ 18,377$ & $-0.58 \%$ & $-2.18 \%$ \\
\hline
\end{tabular}


Appendix A - Table 6. County Results - Highest Population Change Effects

\begin{tabular}{|c|c|c|c|c|c|c|c|}
\hline State & County & Overdose Rate & $\begin{array}{l}\text { Population } \\
\text { (2017) }\end{array}$ & $\begin{array}{l}\text { Population 25-34 } \\
\text { (2017) }\end{array}$ & $\begin{array}{c}\text { Direct Income } \\
\text { Effect }(x \$ 1,000)\end{array}$ & $\begin{array}{c}\text { Forecasted Total } \\
\text { Pop Change } \\
(\%) \\
\end{array}$ & $\begin{array}{c}\text { Forecasted 25-34 } \\
\text { Pop Change } \\
(\%)\end{array}$ \\
\hline Kentucky & Bell & 56.79 & 26894 & 3354 & $-\$ 61,909$ & $-1.91 \%$ & $-6.50 \%$ \\
\hline New Mexico & Rio Arriba & 63.74 & 39159 & 4549 & $-\$ 86,789$ & $-1.86 \%$ & $-6.65 \%$ \\
\hline California & Lake & 37.61 & 64246 & 7312 & $-\$ 73,374$ & $-1.37 \%$ & $-4.67 \%$ \\
\hline Kentucky & Martin & 32.57 & 11452 & 1865 & $-\$ 17,360$ & $-1.24 \%$ & $-4.97 \%$ \\
\hline Virginia & Buchanan & 33.03 & 21514 & 2394 & $-\$ 32,175$ & $-1.23 \%$ & $-5.13 \%$ \\
\hline California & Lassen & 29.12 & 31163 & 5735 & $-\$ 46,062$ & $-1.21 \%$ & $-4.76 \%$ \\
\hline Kentucky & Harlan & 32.14 & 26713 & 3290 & $-\$ 39,178$ & $-1.21 \%$ & $-4.64 \%$ \\
\hline Virginia & Wise & 26.13 & 38586 & 5273 & $-\$ 55,399$ & $-1.19 \%$ & $-4.64 \%$ \\
\hline Virginia & Russell & 25.14 & 27048 & 2931 & $-\$ 38,525$ & $-1.18 \%$ & $-4.82 \%$ \\
\hline California & Plumas & 29.15 & 18742 & 1870 & $-\$ 26,748$ & $-1.17 \%$ & $-4.19 \%$ \\
\hline Nevada & Mineral & 28.09 & 4457 & 545 & $-\$ 6,303$ & $-1.17 \%$ & $-3.87 \%$ \\
\hline Ohio & Adams & 26.70 & 27726 & 3039 & $-\$ 38,403$ & $-1.16 \%$ & $-4.63 \%$ \\
\hline Ohio & Jackson & 25.45 & 32449 & 4035 & $-\$ 44,588$ & $-1.15 \%$ & $-4.51 \%$ \\
\hline Montana & Deer Lodge & 22.52 & 9106 & 1027 & $-\$ 12,516$ & $-1.15 \%$ & $-4.14 \%$ \\
\hline Kentucky & Lawrence & 32.04 & 15719 & 1824 & $-\$ 21,431$ & $-1.15 \%$ & $-4.60 \%$ \\
\hline Oklahoma & Johnston & 31.02 & 11060 & 1318 & $-\$ 14,746$ & $-1.13 \%$ & $-4.36 \%$ \\
\hline Colorado & Jackson & 27.96 & 1385 & 159 & $-\$ 1,852$ & $-1.13 \%$ & $-4.14 \%$ \\
\hline Tennessee & DeKalb & 26.87 & 19852 & 2398 & $-\$ 25,439$ & $-1.09 \%$ & $-4.25 \%$ \\
\hline Virginia & Martinsville & 39.67 & 13142 & 1491 & $-\$ 23,755$ & $-0.96 \%$ & $-3.22 \%$ \\
\hline West Virginia & Boone & 50.55 & 22349 & 2253 & $-\$ 10,679$ & $-0.94 \%$ & $-3.43 \%$ \\
\hline Alabama & Walker & 28.37 & 64058 & 7525 & $-\$ 68,029$ & $-0.94 \%$ & $-3.24 \%$ \\
\hline West Virginia & Brooke & 41.15 & 22443 & 2309 & $-\$ 10,578$ & $-0.93 \%$ & $-3.18 \%$ \\
\hline West Virginia & Raleigh & 49.66 & 75022 & 9265 & $-\$ 35,353$ & $-0.93 \%$ & $-3.34 \%$ \\
\hline West Virginia & Mercer & 51.13 & 59753 & 6950 & $-\$ 27,970$ & $-0.93 \%$ & $-3.28 \%$ \\
\hline Kentucky & Boyd & 39.03 & 47979 & 5775 & $-\$ 39,357$ & $-0.93 \%$ & $-3.35 \%$ \\
\hline West Virginia & Cabell & 66.97 & 94958 & 11774 & $-\$ 43,929$ & $-0.92 \%$ & $-3.35 \%$ \\
\hline Utah & Carbon & 40.46 & 20295 & 2440 & $-\$ 9,387$ & $-0.92 \%$ & $-3.41 \%$ \\
\hline Maryland & Baltimore & 18.63 & 611648 & 115219 & $\$ 0$ & $-0.92 \%$ & $-3.07 \%$ \\
\hline Pennsylvania & Montour & 42.93 & 18272 & 2526 & $-\$ 8,386$ & $-0.92 \%$ & $-3.17 \%$ \\
\hline Virginia & Fredericksburg & 39.15 & 28360 & 4393 & $-\$ 12,915$ & $-0.91 \%$ & $-3.37 \%$ \\
\hline Kentucky & Campbell & 39.27 & 92488 & 13734 & $-\$ 41,960$ & $-0.91 \%$ & $-3.22 \%$ \\
\hline Indiana & Scott & 35.76 & 23870 & 2872 & $-\$ 10,826$ & $-0.91 \%$ & $-3.20 \%$ \\
\hline Virginia & Winchester & 48.77 & 27932 & 3953 & $-\$ 12,568$ & $-0.90 \%$ & $-3.28 \%$ \\
\hline New Mexico & Colfax & 23.28 & 12174 & 1273 & $-\$ 9,366$ & $-0.90 \%$ & $-3.49 \%$ \\
\hline California & Modoc & 27.36 & 8859 & 904 & $-\$ 10,785$ & $-0.90 \%$ & $-3.32 \%$ \\
\hline West Virginia & Webster & 26.66 & 8372 & 794 & $-\$ 6,346$ & $-0.89 \%$ & $-3.59 \%$ \\
\hline Utah & Emery & 27.69 & 10077 & 1067 & $-\$ 9,844$ & $-0.89 \%$ & $-3.84 \%$ \\
\hline New Mexico & Quay & 26.14 & 8306 & 820 & $-\$ 6,244$ & $-0.88 \%$ & $-3.52 \%$ \\
\hline Florida & Bradford & 19.89 & 27038 & 4019 & $-\$ 36,275$ & $-0.88 \%$ & $-3.53 \%$ \\
\hline Nevada & White Pine & 26.55 & 9592 & 1457 & $-\$ 7,135$ & $-0.88 \%$ & $-3.41 \%$ \\
\hline West Virginia & Pocahontas & 23.73 & 8456 & 939 & $-\$ 9,986$ & $-0.88 \%$ & $-3.43 \%$ \\
\hline Virginia & Galax & 22.41 & 6625 & 726 & $-\$ 6,343$ & $-0.88 \%$ & $-3.32 \%$ \\
\hline Texas & Baylor & 22.62 & 3581 & 381 & $-\$ 4,223$ & $-0.87 \%$ & $-3.14 \%$ \\
\hline Pennsylvania & Greene & 24.14 & 36770 & 4537 & $-\$ 26,960$ & $-0.87 \%$ & $-3.38 \%$ \\
\hline New Mexico & Lincoln & 28.91 & 19395 & 1812 & $-\$ 18,618$ & $-0.87 \%$ & $-3.30 \%$ \\
\hline North Carolina & Mitchell & 25.35 & 15072 & 1601 & $-\$ 17,667$ & $-0.87 \%$ & $-3.37 \%$ \\
\hline Missouri & Crawford & 23.54 & 24102 & 2687 & $-\$ 17,513$ & $-0.87 \%$ & $-3.52 \%$ \\
\hline Indiana & Starke & 32.86 & 22893 & 2619 & $-\$ 26,433$ & $-0.86 \%$ & $-5.17 \%$ \\
\hline Tennessee & Houston & 19.63 & 8213 & 907 & $-\$ 9,454$ & $-0.86 \%$ & $-3.29 \%$ \\
\hline Alabama & Escambia & 27.63 & 37447 & 5137 & $-\$ 26,971$ & $-0.86 \%$ & $-3.30 \%$ \\
\hline Tennessee & Claiborne & 25.71 & 31609 & 3893 & $-\$ 36,365$ & $-0.86 \%$ & $-3.26 \%$ \\
\hline California & Sierra & 21.86 & 2999 & 221 & $-\$ 2,168$ & $-0.86 \%$ & $-3.46 \%$ \\
\hline Tennessee & Clay & 33.71 & 7703 & 767 & $-\$ 9,960$ & $-0.86 \%$ & $-5.20 \%$ \\
\hline Tennessee & Hancock & 34.41 & 6600 & 747 & $-\$ 4,733$ & $-0.86 \%$ & $-5.44 \%$ \\
\hline West Virginia & Greenbrier & 22.96 & 35287 & 3848 & $-\$ 25,282$ & $-0.86 \%$ & $-3.43 \%$ \\
\hline Colorado & Conejos & 25.27 & 8184 & 866 & $-\$ 5,860$ & $-0.86 \%$ & $-3.33 \%$ \\
\hline Virginia & Wythe & 21.16 & 28882 & 3189 & $-\$ 20,671$ & $-0.86 \%$ & $-3.38 \%$ \\
\hline Oklahoma & Pushmataha & 22.48 & 11173 & 1238 & $-\$ 8,014$ & $-0.86 \%$ & $-3.25 \%$ \\
\hline Missouri & Dent & 23.28 & 15480 & 1685 & $-\$ 17,638$ & $-0.85 \%$ & $-3.30 \%$ \\
\hline Mississippi & Tishomingo & 22.87 & 19542 & 2229 & $-\$ 13,882$ & $-0.85 \%$ & $-3.19 \%$ \\
\hline Kentucky & Marshall & 19.72 & 31382 & 3446 & $-\$ 28,904$ & $-0.85 \%$ & $-3.28 \%$ \\
\hline Kentucky & Russell & 33.70 & 17775 & 1883 & $-\$ 22,515$ & $-0.85 \%$ & $-5.40 \%$ \\
\hline Oklahoma & Garvin & 24.27 & 27909 & 3430 & $-\$ 19,553$ & $-0.84 \%$ & $-3.32 \%$ \\
\hline Montana & Mineral & 23.90 & 4255 & 385 & $-\$ 4,766$ & $-0.84 \%$ & $-3.14 \%$ \\
\hline Georgia & Jeff Davis & 22.36 & 15025 & 1826 & $-\$ 13,563$ & $-0.84 \%$ & $-3.39 \%$ \\
\hline
\end{tabular}


Appendix A - Table 7. County Results - Highest 25-34 Year Old Population Change Effects

\begin{tabular}{|c|c|c|c|c|c|c|c|}
\hline State & County & Overdose Rate & $\begin{array}{l}\text { Population } \\
\text { (2017) }\end{array}$ & $\begin{array}{l}\text { Population } 25-34 \\
\text { (2017) }\end{array}$ & $\begin{array}{c}\text { Direct Income } \\
\text { Effect }(x \$ 1,000)\end{array}$ & $\begin{array}{c}\text { Forecasted Total } \\
\text { Pop Change } \\
(\%)\end{array}$ & $\begin{array}{c}\text { Forecasted 25-34 } \\
\text { Pop Change } \\
(\%)\end{array}$ \\
\hline Kentucky & Floyd & 51.37 & 36271 & 4261 & $\$ 0$ & $0.00 \%$ & $-8.52 \%$ \\
\hline Kentucky & Perry & 44.36 & 26553 & 3314 & $\$ 0$ & $0.00 \%$ & $-8.15 \%$ \\
\hline West Virginia & McDowell & 66.21 & 18456 & 1953 & $-\$ 14,374$ & $-0.35 \%$ & $-7.89 \%$ \\
\hline Kentucky & Breathitt & 48.05 & 12946 & 1570 & $\$ 0$ & $0.00 \%$ & $-7.87 \%$ \\
\hline West Virginia & Logan & 51.13 & 32925 & 3660 & $-\$ 15,526$ & $-0.31 \%$ & $-7.78 \%$ \\
\hline West Virginia & Wyoming & 56.53 & 21210 & 2251 & $-\$ 15,309$ & $-0.32 \%$ & $-7.36 \%$ \\
\hline Virginia & Dickenson & 40.30 & 14782 & 1668 & $-\$ 6,723$ & $-0.30 \%$ & $-7.36 \%$ \\
\hline Virginia & Norton & 111.20 & 3936 & 572 & $\$ 0$ & $0.00 \%$ & $-7.25 \%$ \\
\hline Kentucky & Johnson & 37.61 & 22594 & 2640 & $-\$ 1,604$ & $-0.28 \%$ & $-7.15 \%$ \\
\hline Kentucky & Powell & 46.45 & 12374 & 1495 & $-\$ 8,175$ & $-0.29 \%$ & $-7.07 \%$ \\
\hline Kentucky & Pike & 41.42 & 58883 & 6686 & $-\$ 45,891$ & $-0.60 \%$ & $-6.88 \%$ \\
\hline West Virginia & Mingo & 47.82 & 24127 & 2709 & $-\$ 28,475$ & $-0.63 \%$ & $-6.81 \%$ \\
\hline New Mexico & Rio Arriba & 63.74 & 39159 & 4549 & $-\$ 86,789$ & $-1.86 \%$ & $-6.65 \%$ \\
\hline Kentucky & Knott & 33.56 & 15291 & 1624 & $-\$ 11,703$ & $-0.59 \%$ & $-6.60 \%$ \\
\hline Colorado & San Juan & 33.43 & 715 & 81 & $\$ 0$ & $0.00 \%$ & $-6.59 \%$ \\
\hline Kentucky & Bell & 56.79 & 26894 & 3354 & $-\$ 61,909$ & $-1.91 \%$ & $-6.50 \%$ \\
\hline Kentucky & Estill & 37.60 & 14277 & 1610 & $-\$ 15,667$ & $-0.58 \%$ & $-6.26 \%$ \\
\hline New Mexico & Guadalupe & 38.78 & 4429 & 652 & $-\$ 3,950$ & $-0.59 \%$ & $-6.16 \%$ \\
\hline Tennessee & Benton & 37.20 & 15986 & 1562 & $-\$ 17,523$ & $-0.58 \%$ & $-6.13 \%$ \\
\hline Kentucky & Clinton & 41.60 & 10276 & 1162 & $-\$ 10,879$ & $-0.56 \%$ & $-5.94 \%$ \\
\hline Tennessee & Hancock & 34.41 & 6600 & 747 & $-\$ 4,733$ & $-0.86 \%$ & $-5.44 \%$ \\
\hline West Virginia & Summers & 33.96 & 12993 & 1392 & $-\$ 923$ & $-0.28 \%$ & $-5.41 \%$ \\
\hline Kentucky & Russell & 33.70 & 17775 & 1883 & $-\$ 22,515$ & $-0.85 \%$ & $-5.40 \%$ \\
\hline Tennessee & Clay & 33.71 & 7703 & 767 & $-\$ 9,960$ & $-0.86 \%$ & $-5.20 \%$ \\
\hline Indiana & Starke & 32.86 & 22893 & 2619 & $-\$ 26,433$ & $-0.86 \%$ & $-5.17 \%$ \\
\hline Virginia & Buchanan & 33.03 & 21514 & 2394 & $-\$ 32,175$ & $-1.23 \%$ & $-5.13 \%$ \\
\hline Kentucky & Leslie & 38.91 & 10334 & 1322 & $-\$ 7,326$ & $-0.32 \%$ & $-4.99 \%$ \\
\hline Kentucky & Lee & 30.25 & 6570 & 757 & $-\$ 1,914$ & $-0.58 \%$ & $-4.99 \%$ \\
\hline Kentucky & Martin & 32.57 & 11452 & 1865 & $-\$ 17,360$ & $-1.24 \%$ & $-4.97 \%$ \\
\hline New Mexico & Sierra & 34.05 & 11116 & 938 & $-\$ 789$ & $-0.28 \%$ & $-4.85 \%$ \\
\hline Virginia & Russell & 25.14 & 27048 & 2931 & $-\$ 38,525$ & $-1.18 \%$ & $-4.82 \%$ \\
\hline California & Lassen & 29.12 & 31163 & 5735 & $-\$ 46,062$ & $-1.21 \%$ & $-4.76 \%$ \\
\hline California & Lake & 37.61 & 64246 & 7312 & $-\$ 73,374$ & $-1.37 \%$ & $-4.67 \%$ \\
\hline Virginia & Wise & 26.13 & 38586 & 5273 & $-\$ 55,399$ & $-1.19 \%$ & $-4.64 \%$ \\
\hline Kentucky & Harlan & 32.14 & 26713 & 3290 & $-\$ 39,178$ & $-1.21 \%$ & $-4.64 \%$ \\
\hline Ohio & Adams & 26.70 & 27726 & 3039 & $-\$ 38,403$ & $-1.16 \%$ & $-4.63 \%$ \\
\hline Kentucky & Lawrence & 32.04 & 15719 & 1824 & $-\$ 21,431$ & $-1.15 \%$ & $-4.60 \%$ \\
\hline Utah & Daggett & 51.47 & 1029 & 98 & $\$ 0$ & $0.00 \%$ & $-4.57 \%$ \\
\hline Ohio & Jackson & 25.45 & 32449 & 4035 & $-\$ 44,588$ & $-1.15 \%$ & $-4.51 \%$ \\
\hline Kentucky & Wolfe & 26.37 & 7264 & 794 & $-\$ 6,206$ & $-0.57 \%$ & $-4.38 \%$ \\
\hline Oklahoma & Johnston & 31.02 & 11060 & 1318 & $-\$ 14,746$ & $-1.13 \%$ & $-4.36 \%$ \\
\hline Kentucky & Carroll & 30.84 & 10713 & 1301 & $-\$ 6,954$ & $-0.57 \%$ & $-4.33 \%$ \\
\hline Tennessee & DeKalb & 26.87 & 19852 & 2398 & $-\$ 25,439$ & $-1.09 \%$ & $-4.25 \%$ \\
\hline Kentucky & Clay & 33.37 & 20366 & 3121 & $-\$ 23,443$ & $-0.61 \%$ & $-4.23 \%$ \\
\hline Colorado & Dolores & 26.45 & 2067 & 175 & $\$ 0$ & $0.00 \%$ & $-4.21 \%$ \\
\hline California & Plumas & 29.15 & 18742 & 1870 & $-\$ 26,748$ & $-1.17 \%$ & $-4.19 \%$ \\
\hline Colorado & Jackson & 27.96 & 1385 & 159 & $-\$ 1,852$ & $-1.13 \%$ & $-4.14 \%$ \\
\hline Montana & Deer Lodge & 22.52 & 9106 & 1027 & $-\$ 12,516$ & $-1.15 \%$ & $-4.14 \%$ \\
\hline Kentucky & Knox & 32.11 & 31227 & 3944 & $-\$ 15,797$ & $-0.57 \%$ & $-4.00 \%$ \\
\hline Nevada & Mineral & 28.09 & 4457 & 545 & $-\$ 6,303$ & $-1.17 \%$ & $-3.87 \%$ \\
\hline Utah & Emery & 27.69 & 10077 & 1067 & $-\$ 9,844$ & $-0.89 \%$ & $-3.84 \%$ \\
\hline Utah & Kane & 28.54 & 7567 & 859 & $-\$ 4,916$ & $-0.54 \%$ & $-3.84 \%$ \\
\hline New Mexico & Mora & 23.96 & 4551 & 440 & $\$ 0$ & $0.00 \%$ & $-3.83 \%$ \\
\hline West Virginia & Webster & 26.66 & 8372 & 794 & $-\$ 6,346$ & $-0.89 \%$ & $-3.59 \%$ \\
\hline Florida & Bradford & 19.89 & 27038 & 4019 & $-\$ 36,275$ & $-0.88 \%$ & $-3.53 \%$ \\
\hline Missouri & Crawford & 23.54 & 24102 & 2687 & $-\$ 17,513$ & $-0.87 \%$ & $-3.52 \%$ \\
\hline New Mexico & Quay & 26.14 & 8306 & 820 & $-\$ 6,244$ & $-0.88 \%$ & $-3.52 \%$ \\
\hline New Mexico & Colfax & 23.28 & 12174 & 1273 & $-\$ 9,366$ & $-0.90 \%$ & $-3.49 \%$ \\
\hline Kentucky & Letcher & 31.81 & 22339 & 2551 & $-\$ 10,387$ & $-0.31 \%$ & $-3.46 \%$ \\
\hline California & Sierra & 21.86 & 2999 & 221 & $-\$ 2,168$ & $-0.86 \%$ & $-3.46 \%$ \\
\hline West Virginia & Pocahontas & 23.73 & 8456 & 939 & $-\$ 9,986$ & $-0.88 \%$ & $-3.43 \%$ \\
\hline West Virginia & Greenbrier & 22.96 & 35287 & 3848 & $-\$ 25,282$ & $-0.86 \%$ & $-3.43 \%$ \\
\hline West Virginia & Boone & 50.55 & 22349 & 2253 & $-\$ 10,679$ & $-0.94 \%$ & $-3.43 \%$ \\
\hline Utah & Carbon & 40.46 & 20295 & 2440 & $-\$ 9,387$ & $-0.92 \%$ & $-3.41 \%$ \\
\hline Nevada & White Pine & 26.55 & 9592 & 1457 & $-\$ 7,135$ & $-0.88 \%$ & $-3.41 \%$ \\
\hline
\end{tabular}




\section{Appendix B - Topic 2 - Water Contamination and Population Change: A Tipping Point} in Distressed Communities?

Appendix B - Table 1. DID rank, joint score, and CDF analysis for each county.

\begin{tabular}{|c|c|c|c|c|c|c|c|}
\hline & Base Case & $\begin{array}{c}\text { DID Rank } \\
\text { Including Coal } \\
\text { Placebos } \\
\end{array}$ & $\begin{array}{l}\text { Only ARC } \\
\text { Counties }\end{array}$ & Base Case & $\begin{array}{c}\text { Joint Significance } \\
\text { Including Coal } \\
\text { Placebos } \\
\end{array}$ & $\begin{array}{l}\text { Only ARC } \\
\text { Counties }\end{array}$ & Predicted Population Impact \\
\hline $\begin{array}{c}\text { Kanawha County, WV } \\
\text { FIPS } 54039\end{array}$ & 1 & 2 & 1 & 0.889 & 0.952 & 0.909 & -5720 \\
\hline $\begin{array}{l}\text { Logan County, WV } \\
\text { FIPS } 54045\end{array}$ & 1 & 3 & 1 & 0.909 & 0.932 & 0.857 & -881 \\
\hline $\begin{array}{l}\text { Boone County, WV } \\
\text { FIPS } 54005\end{array}$ & 1 & 1 & 1 & 0.875 & 0.976 & 0.800 & -747 \\
\hline $\begin{array}{l}\text { Putnam County, WV } \\
\text { FIPS } 54079\end{array}$ & 2 & 6 & N/A & 0.905 & 0.889 & N/A & -1204 \\
\hline $\begin{array}{c}\text { Roane County, WV } \\
54087\end{array}$ & 2 & 6 & 3 & 0.882 & 0.880 & 0.750 & -191 \\
\hline $\begin{array}{l}\text { Cabell County, WV } \\
\text { Fips } 54011\end{array}$ & & $\Delta \mathrm{TR}<0$ & & & N/A & & N/A \\
\hline $\begin{array}{l}\text { Clay County, WV } \\
\text { FIPS } 54015\end{array}$ & & $\Delta \mathrm{TR}<0$ & & & N/A & & N/A \\
\hline $\begin{array}{l}\text { Jackson County, WV } \\
\text { Fips } 54035\end{array}$ & & $\Delta \mathrm{TR}<0$ & & & $\mathrm{~N} / \mathrm{A}$ & & N/A \\
\hline $\begin{array}{l}\text { Lincoln County, WV } \\
\text { FIPS } 54043\end{array}$ & & $\Delta \mathrm{TR}<0$ & & & N/A & & N/A \\
\hline
\end{tabular}




\section{Appendix C - Topic 3 - A Case Study on Fear: The impact of PFOA water}

\section{contamination and environmental risk on county level population change}

Appendix C - Table 1. DID rank, joint score, and CDF analysis for each county.

\begin{tabular}{|c|c|c|c|c|c|c|c|c|c|}
\hline \multirow[b]{2}{*}{ Directly Impacted Counties } & \multicolumn{3}{|c|}{ Average DID Rank (by Year) } & \multicolumn{3}{|c|}{ Joint Significance (by Year) } & \multicolumn{3}{|c|}{ Average Predicted Population Impact } \\
\hline & 2005 & 2006 & 2007 & 2005 & 2006 & 2007 & 2005 & 2006 & 2007 \\
\hline $\begin{array}{l}\text { Washington County, OH } \\
\text { Fips } 39167\end{array}$ & 2 & 2 & 1 & 0.909 & 0.900 & 0.958 & -2324 & -1300 & -1559 \\
\hline $\begin{array}{l}\text { Wood County, WV } \\
\text { Fips } 54107\end{array}$ & 1 & 1 & 1 & 0.933 & 0.933 & 0.938 & -4154 & -2892 & -2284 \\
\hline $\begin{array}{l}\text { Athens County, OH } \\
\text { Fips } 39009\end{array}$ & 1 & 2 & 1 & 0.889 & 0.833 & 0.923 & -1898 & -1919 & -2002 \\
\hline $\begin{array}{l}\text { Meigs County, OH } \\
\text { Fips } 39105\end{array}$ & 1 & 1 & 1 & 0.909 & 0.929 & 0.941 & -573 & -683 & -392 \\
\hline $\begin{array}{c}\text { Mason County, WV* } \\
\text { Fips } 54053 \\
\end{array}$ & 4 & 3 & 2 & 0.714 & 0.786 & 0.867 & -613 & -613 & 51 \\
\hline \multicolumn{10}{|l|}{$\begin{array}{c}\text { Counties without an impacted } \\
\text { Water District }\end{array}$} \\
\hline $\begin{array}{c}\text { Pleasants County, WV } \\
\text { Fips } 54073\end{array}$ & 1 & 1 & 1 & 0.923 & 0.929 & 0.929 & -637 & -469 & -448 \\
\hline $\begin{array}{l}\text { Cabell County, WV } \\
\text { Fips } 54011\end{array}$ & 1 & 2 & 1 & 0.889 & 0.778 & 0.900 & 3927 & 1109 & 3399 \\
\hline $\begin{array}{l}\text { Ritchie County, WV } \\
\text { Fips } 54085\end{array}$ & 4 & 4 & 2 & 0.636 & 0.667 & 0.846 & -539 & -502 & -464 \\
\hline $\begin{array}{l}\text { Jackson County, WV } \\
\quad \text { Fips } 54035\end{array}$ & & $\Delta T R<0$ & & & N/A & & & N/A & \\
\hline $\begin{array}{l}\text { Wirt County, WV } \\
\text { Fips 54105 }\end{array}$ & & $\Delta T R<0$ & & & N/A & & & N/A & \\
\hline \multicolumn{10}{|l|}{ *Added 2009 for Mason County } \\
\hline $\begin{array}{l}\text { Mason County, WV*, } 2009 \\
\text { Fips } 54053\end{array}$ & & 1 & & & 0.929 & & & -508 & \\
\hline
\end{tabular}

